UNIVERSIDADE DE SÃO PAULO

FACULDADE DE ECONOMIA, ADMINISTRAÇÃO E CONTABILIDADE DEPARTAMENTO DE ADMINISTRAÇÃO PROGRAMA DE PÓS-GRADUAÇÃO EM ADMINISTRAÇÃO

AVALIAÇÃO DE RESULTADOS EM EDUCAÇÃO CORPORATIVA: UM ESTUDO COM AS ORGANIZAÇÕES QUE SE DESTACAM EM GESTÃO DE PESSOAS

Carolina Aparecida de Freitas Dias

Orientador: Prof. Dr. Lindolfo Galvão de Albuquerque

SÃO PAULO 
Prof. Dr. João Grandino Rodas

Reitor da Universidade de São Paulo

Prof. Dr. Reinaldo Guerreiro

Diretor da Faculdade de Economia, Administração e Contabilidade

Prof. Dr. Adalberto Américo Fischmann

Chefe do Departamento de Administração

Prof. Dr. Lindolfo Galvão de Albuquerque

Coordenador do Programa de Pós-Graduação em Administração 


\section{AVALIAÇÃO DE RESULTADOS EM EDUCAÇÃO CORPORATIVA: UM ESTUDO COM AS ORGANIZAÇÕES QUE SE DESTACAM EM GESTÃO DE PESSOAS}

Dissertação apresentada ao Departamento de Administração da Faculdade de Economia, Administração e Contabilidade da Universidade de São Paulo para a obtenção do título de Mestre em Ciências

Orientador: Prof. Dr. Lindolfo Galvão de Albuquerque

Versão Corrigida

(versão original disponível na Faculdade de Economia, Administração e Contabilidade)

\section{SÃO PAULO}


FICHA CATALOGRÁFICA

Elaborada pela Seção de Processamento Técnico do SBD/FEA/USP

Dias, Carolina Aparecida de Freitas

Avaliação de resultados em educação corporativa: um estudo com as organizações que se destacam em gestão de pessoas / Carolina Aparecida de Freitas. -- São Paulo, 2012.

$258 \mathrm{p}$.

Dissertação (Mestrado) - Universidade de São Paulo, 2012.

Orientador: Lindolfo Galvão de Albuquerque.

1. Educação corporativa 2. Universidade corporativa 3. Avaliação de Educação corporativa I. Universidade de São Paulo. Faculdade de Economia, Administração e Contabilidade. II. Título.

CDD - 658.3124 
Aos meus pais, às minhas irmãs queridas e ao Rogério, meu amor. 


\section{AGRADECIMENTOS}

É muito gratificante chegar ao final desta etapa, olhar para trás e ver todo o caminho percorrido. Passa um filme em minha cabeça, a conclusão deste primeiro ciclo só foi possível graças a pessoas muito especiais. Primeiramente, gostaria de agradecer ao Rogério. Seu apoio para eu realizar esta mudança de trajetória profissional exigiu esforços e sacrifícios compartilhados, peço desculpas pela ausência. Minhas irmãs, Sheila e Simone, sempre pacientes em ouvir minhas queixas, apoiando-me e incentivando-me com tanta convicção, renovando minhas energias. Davi, sua vinda a este mundo me encheu de emoção e de alegria. Tão pequenino e tão grande! Quanta alegria nos traz. Pai e mãe, obrigada por me educar e me dar bons exemplos. Hoje esta conquista também é de vocês!

Agradeço ao meu orientador, Prof. Lindolfo, que com sabedoria e paciência me conduziu nesse projeto! Muito obrigada por sua dedicação! Agradeço às professoras Marisa Eboli e Liliana Vasconcellos com suas valiosas contribuições no momento de minha qualificação. Agradeço também ao Prof. André Fischer e demais professores por compartilharem seus conhecimentos.

Viver neste ambiente acadêmico é muito prazeroso, pois, além de nos desenvolvermos, damos muitas risadas. Um trio muito especial tornou este momento mais leve, compartilhamos alegrias e angústias, choramos e gargalhamos muito também, muito obrigada, Carol Shinoda, Fabíola e Talita, pelos momentos inesquecíveis! Agradeço também à Bárbara pelo carinho e disponibilidade e aos demais colegas pelo convívio e pelas trocas! Agradeço a todos os membros dos grupos de pesquisa “Gestão Estratégica de Pessoas” e “Grupo de Estudo em Gestão da Educação Corporativa” pelo aprendizado e pela parceria. Também sou grata à Marilsa, secretária do Prof. Lindolfo, e ao Samuel, por serem sempre tão atenciosos! Ao Serviço de Pós-Graduação da FEA e à Secretaria do Programa de Pós-Graduação em Administração, muito obrigada. À toda a equipe da Biblioteca da FEA, é muito bom ter a tranquilidade de poder contar com a ajuda de vocês, sempre prestativos. Agradeço à FEA por me acolherer, ao CNPq pelo apoio financeiro e ao PROGEP-FIA por disponibilizar os dados para este estudo.

Durante esta caminhada, também me desenvolvi profissionalmente e, por isso, não posso deixar de agradecer a toda a equipe do PROGEP-FIA, Prof. Joel, Vilma, Priscila, Ana Luiza, Ana Carolina, Vivian e Fernanda. Foi muito bom trabalhar com vocês. Meus sinceros agradecimentos à turma 29 do MBA RH, pelo aprendizado e pela amizade, admiro muito vocês!

Por fim, agradeço ao Itaú Unibanco, principalmente aos membros da Escola Itaú Unibanco de Negócios, por participarem desta pesquisa, contribuindo com suas experiências. Foi muito bom reencontrá-los. 


\section{RESUMO}

O ambiente organizacional, marcado, principalmente, pela competitividade acirrada, vem sofrendo constantes transformações. A resposta adequada a esse ambiente passa pelas pessoas, por isso, desenvolvê-las nas competências humanas que suportem as competências organizacionais torna-se um imperativo. Assim, surge a Educação Corporativa para alinhar a capacitação das pessoas aos objetivos da organização, desse modo, a educação adquire caráter estratégico nas organizações. Entretanto, para averiguar se ela está contribuindo para o alcance desses objetivos é preciso avaliá-la e, com esse intuito, este estudo foi desenvolvido. Desse modo, a presente pesquisa buscou investigar "como as organizações que se destacam em gestão de pessoas avaliam os resultados em educação corporativa”. Para alcançar esse objetivo geral, foram estabelecidos os seguintes objetivos específicos: descrever o sistema de educação corporativa empregado pelas Melhores Empresas para Você Trabalhar (MEPT) e suas práticas de avaliação de resultados; descrever a organização alvo do estudo de caso e seu sistema de educação corporativa; levantar as práticas e os procedimentos de avaliação de resultados em EC no caso estudado; analisar as limitações, vantagens e tendências de avaliação de resultados em EC na organização investigada. Para a condução da pesquisa, adotou-se a abordagem qualitativa, por meio da realização de estudo junto às MEPT, empregando o método de análise de conteúdo; e da condução de um estudo de caso único junto ao Itaú Unibanco, este último contou com a entrevista semiestruturada como instrumento de coleta de dados. Como principais resultados deste estudo, propôs-se um modelo teórico de avaliação de resultados em educação corporativa e identificou-se uma das principais barreiras à implantação da avaliação em educação corporativa: a criação de uma cultura de avaliação. Por isso, possivelmente, haja poucas organizações que realizam avaliação de suas ações educacionais. Este estudo atingiu o objetivo geral a que se propôs, visto que descreveu o modo de avaliação empregado nas organizações estudadas, identificando um fator contextual que pode interferir nesse processo: a maturidade do sistema de educação corporativa. Uma das principais vantagens apontadas pelos entrevistados no modelo de avaliação de educação corporativa adotado no estudo de caso foi o estabelecimento de parceria com áreas internas especializadas em algum aspecto/etapa da avaliação, o que dá mais credibilidade aos resultados. Por fim, as limitações deste estudo referem-se, principalmente, à forma de generalização de seus achados, pois, ao utilizar o estudo de caso, não é possível generalizar os resultados para outras organizações, mas sim realizar generalizações teóricas. Como estudos futuros recomendam-se a replicação deste estudo em outros casos e o aprofundamento da análise quantitativa, por meio da análise de conteúdo, utilizando técnicas estatísticas avançadas.

Palavras-chave: gestão estratégica de pessoas; educação corporativa; universidade corporativa; avaliação de educação corporativa. 


\begin{abstract}
The organizational environment, marked mainly by the fierce competitiveness, has been undergoing constant changes. The proper response to this environment is the people, so develop them in human competences that support organizational competences becomes imperative. Thus arises the Corporate Education (EC) to align the capacity of people to the goals of the organization, thus education acquires strategic character. However, to ascertain if it is contributing to the achievement of these goals we must evaluate it and, to this end, this study was designed. Thus, the present study aimed to investigate "how organizations that excel in people management evaluates the results in corporate education." To achieve this overall objective, was established the following specific objectives: to describe the system used by corporate education As Melhores Empresas para Você Trabalhar (MEPT) and their evaluation practices; describe the target organization of the case study and its education corporate system; raising practices and procedures for evaluating results in EC in the case study, analyze the limitations, advantages and trends of evaluation results in EC in the organization investigated. To conduct the research, was adopted a qualitative approach by conducting the study at MEPT, employing the method of content analysis, and conducting a single case study with Itaú Unibanco, the latter had the semi-structured interview as a tool for data collection. The main results of this study, was proposed a theoretical model for evaluating results in corporate education and identified one of the main barriers to the implementation of evaluation in corporate education: creating a culture of evaluation. So possibly there are few organizations that perform evaluation of their educational activities. This study achieved the overall objective to which it has since proposed, because described the method of valuation used in the organizations studied, identifying a contextual factor that can interfere with this process: the system maturity of corporate education. One of the main advantages cited by respondents in the evaluation model of corporate education adopted in the case study was the establishment of partnerships with internal areas specialized in some aspect/stage of the evaluation, which gives more credibility to the results. Finally, the limitations of this study relate mainly to how to generalize their findings, therefore, to use the case study, it is not possible to generalize the results to other organizations, but make theoretical generalizations. As future studies are recommended replication of this study in other cases and further quantitative analysis, through content analysis, using advanced statistical techniques.
\end{abstract}

Keywords: strategic management of HR, corporate education, corporate university; evaluation of corporate education. 


\section{SUMÁRIO}

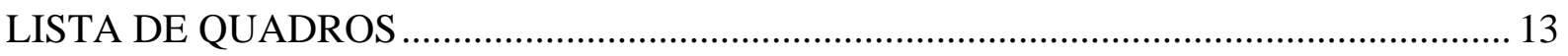

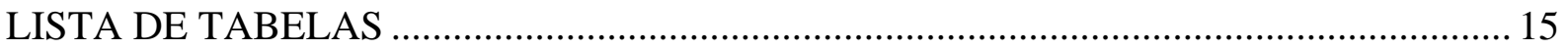

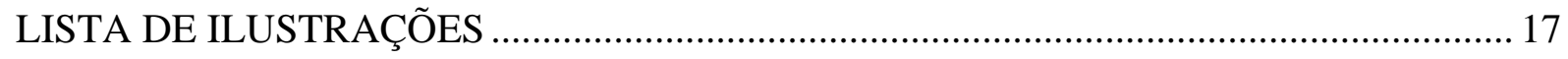

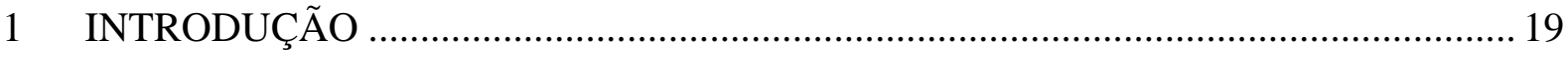

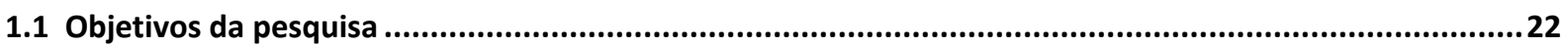

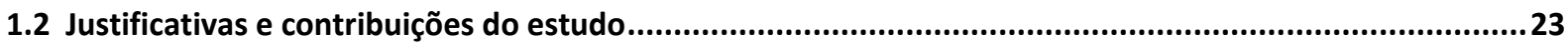

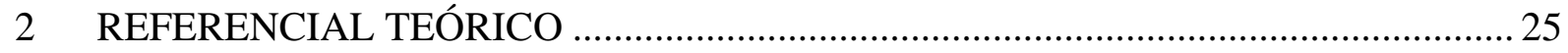

2.1 Treinamento, Desenvolvimento e Educação - TD\&E..............................................................25

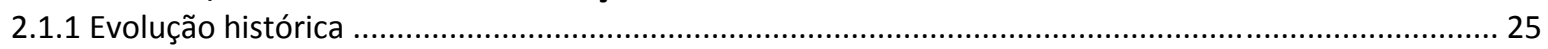

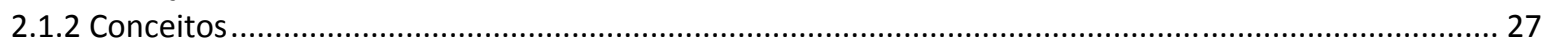

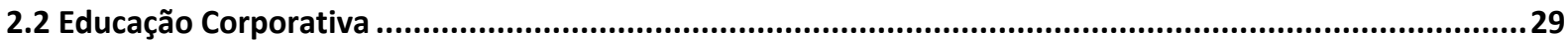

2.3 Avaliação de resultados em gestão de pessoas.........................................................................35

2.4 Avaliação de resultados em Educação Corporativa .....................................................................38

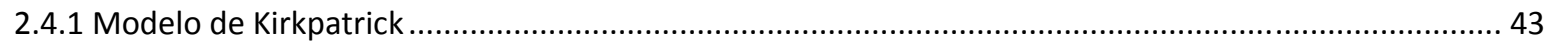

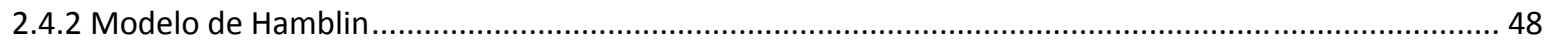

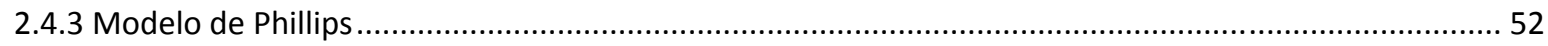

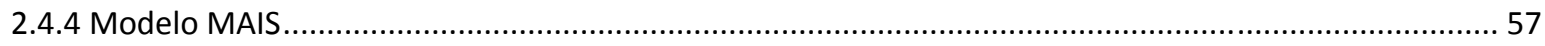

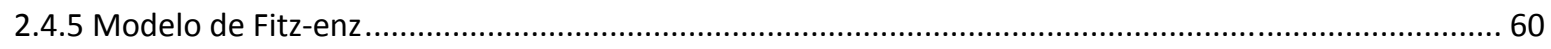

2.4.6 Revisão sobre estudos de avaliação de resultados em educação corporativa .....................................67 67

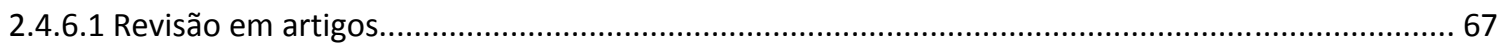

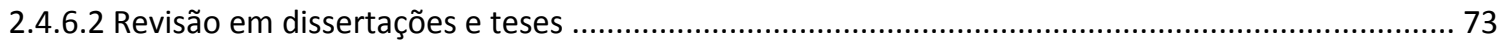

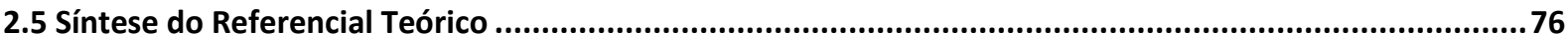

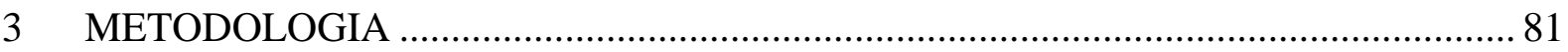

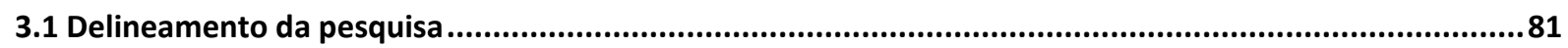

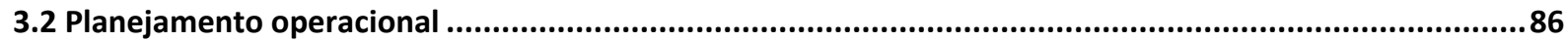

3.2.1 Estudo amplo: análise das empresas que se destacam em gestão de pessoas ............................... 86

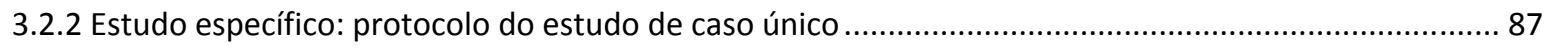

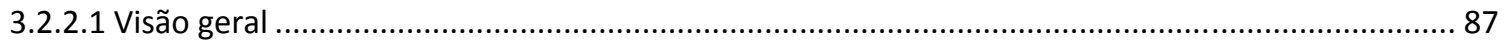

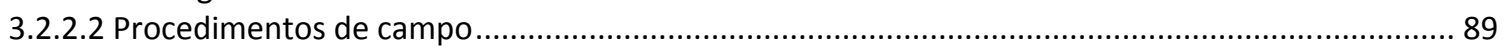

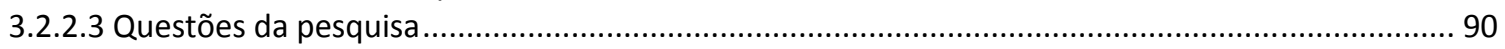

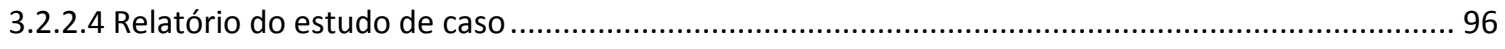

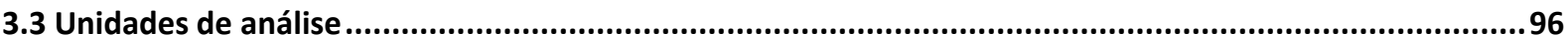

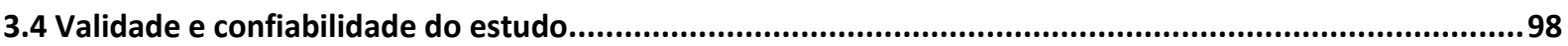




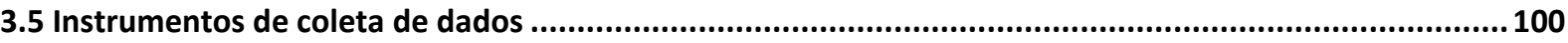

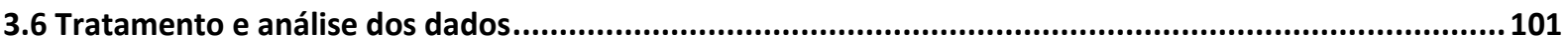

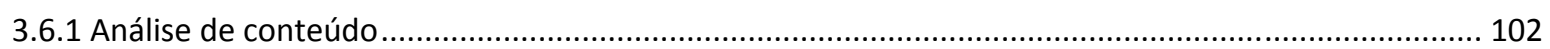

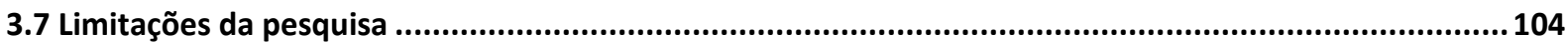

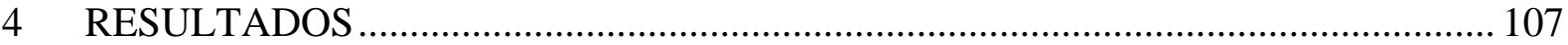

4.1 As Melhores Empresas para Você Trabalhar - MEPT ......................................................................... 107

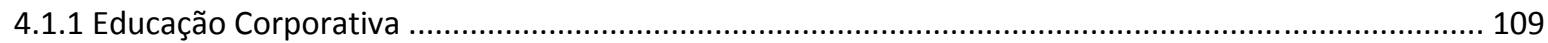

4.1.2 Avaliação de resultados em educação corporativa: as práticas realizadas pelas MEPT ...................... 114

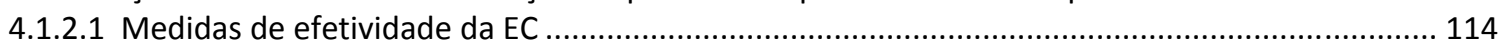

4.1.2.2 Medidas de eficiência da EC .............................................................................................. 120

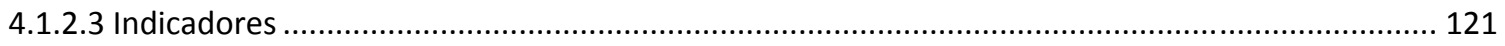

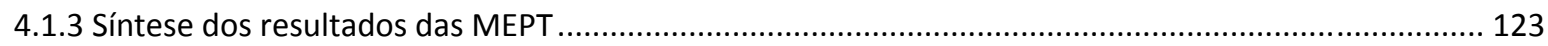

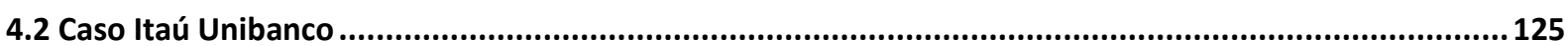

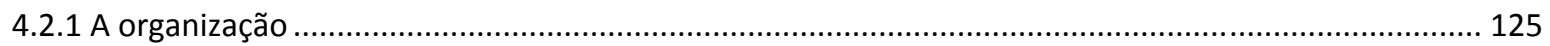

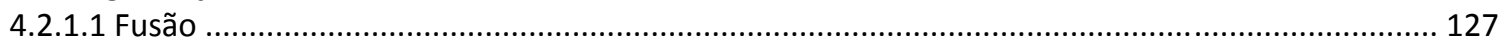

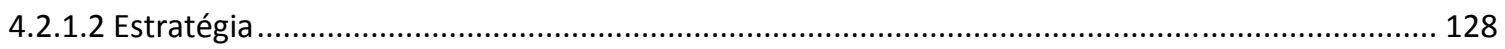

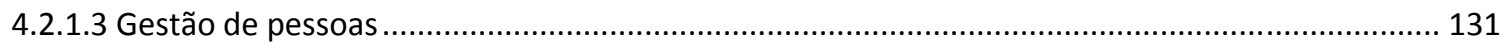

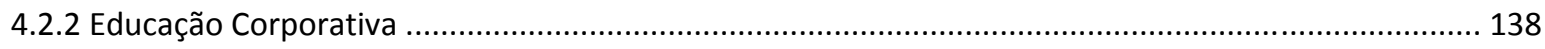

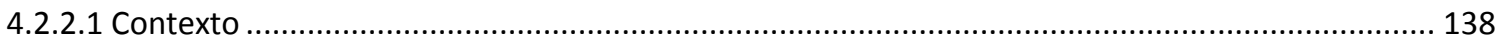

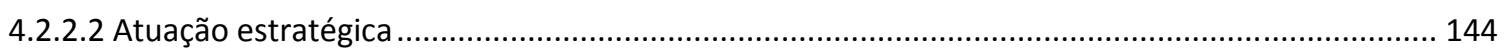

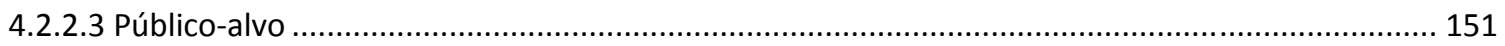

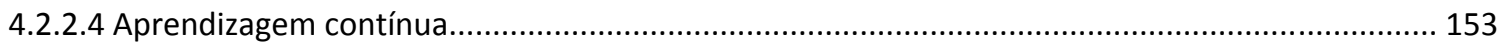

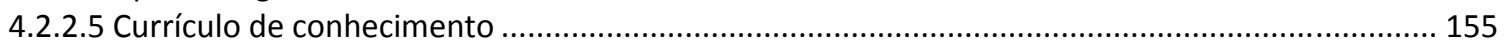

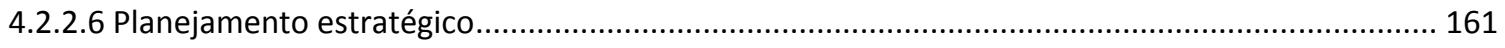

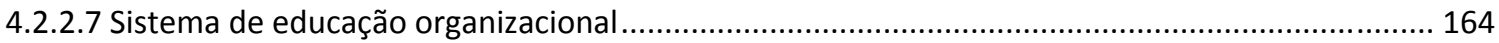

4.2.3 Avaliação de resultados em educação corporativa ...................................................................... 170

4.2.3.1 Modelo de avaliação de resultados da Escola Itaú Unibanco de Negócios................................... 174

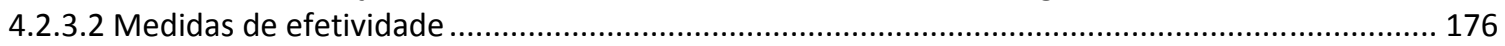

4.2.3.3 Medidas de eficiência ........................................................................................................... 196

4.2.4 Vantagens, limitações e tendências em avaliação de resultados em educação corporativa................ 203

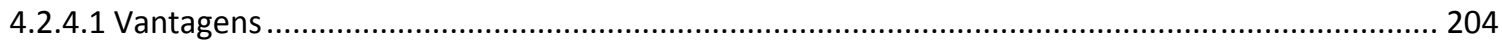

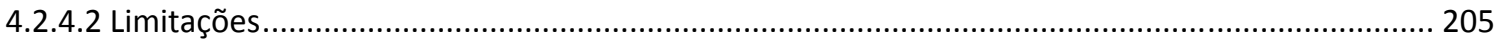

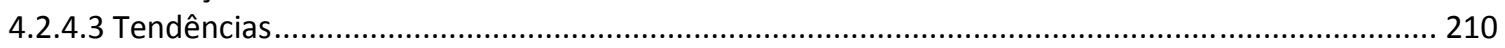

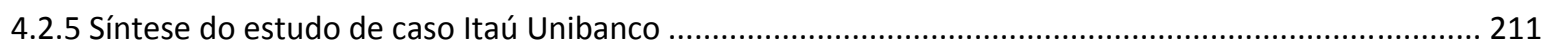

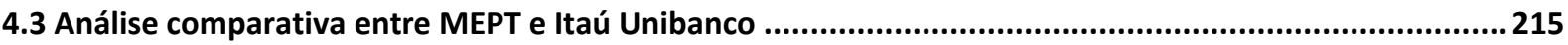

4.4 Proposição de modelo teórico: avaliação de resultados em educação corporativa ...............................220

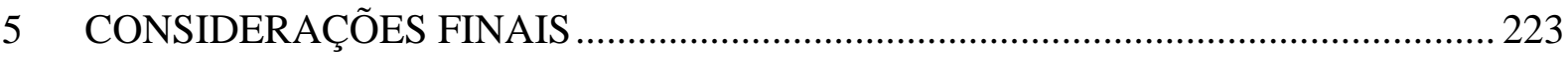

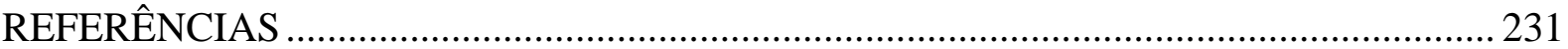

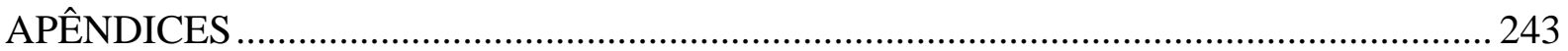

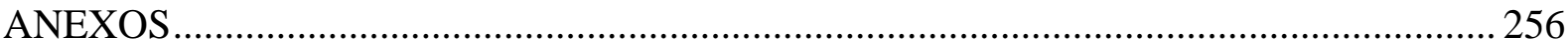




\section{LISTA DE QUADROS}

Quadro 1 - Princípios de sucesso de um sistema de educação corporativa ............................. 34

Quadro 2 - Métodos de avaliação de treinamento ................................................................. 66 Quadro 3 - Artigos localizados sobre o tema avaliação de resultados em educação corporativa

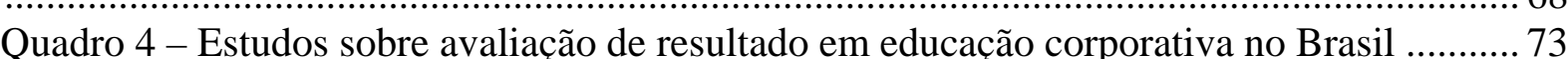

Quadro 5 - Objetivos dos estudos e principais resultados ...................................................... 74

Quadro 6 - Operacionalização da pesquisa empírica................................................................ 85

Quadro 7 - Dimensões e variáveis para avaliação de resultados em educação corporativa.... 92

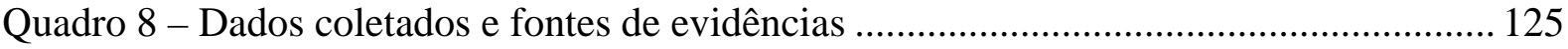

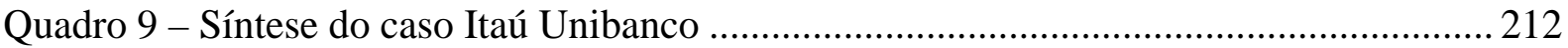

Quadro 10 - Análise comparativa entre MEPT e Itaú Unibanco: educação corporativa ...... 216

Quadro 11 - Análise comparativa entre MEPT e Itaú Unibanco: medidas de efetividade.... 218

Quadro 12 - Análise comparativa entre MEPT e Itaú Unibanco: medidas de eficiência ...... 219 


\section{LISTA DE TABELAS}

Tabela 1 - Visão geral sobre a adoção do sistema de educação corporativa e da avaliação de

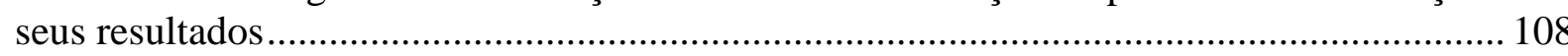

Tabela 2 - Práticas de promoção da aprendizagem contínua................................................. 109

Tabela 3 - Públicos externos atendidos pela educação corporativa...................................... 111

Tabela 4 - Alinhamento da educação corporativa ao sistema de gestão de pessoas .............. 112

Tabela 5 - Alinhamento da educação corporativa aos objetivos organizacionais: frequência de

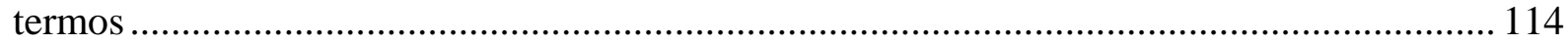

Tabela 6 - Medidas de efetividade de educação corporativa................................................ 115

Tabela 7 - Agrupamento dos níveis de avaliação por similaridade de codificação................ 117

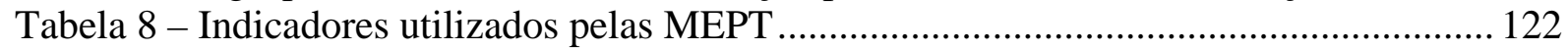




\section{LISTA DE ILUSTRAÇÕES}

Ilustração 1 - Abrangência dos conceitos informação, instrução, treinamento,

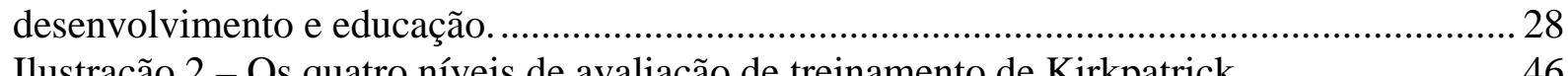

Ilustração 2 - Os quatro níveis de avaliação de treinamento de Kirkpatrick ........................... 46

Ilustração 3 - Modelo de avaliação de treinamento orientado por resultados ........................... 53

Ilustração 4 - MAIS - Modelo de Avaliação Integrado e Somativo .......................................60

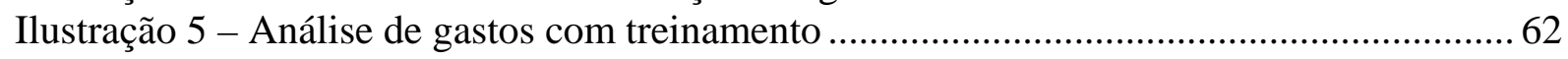

Ilustração 6 - Termos mais frequentes nos objetivos dos sistemas de educação corporativa.

Ilustração 7 - Agrupamento dos níveis de avaliação por similaridade de codificaçã..............113

Ilustração 8 - Estrutura organizacional ............................................................................. 127

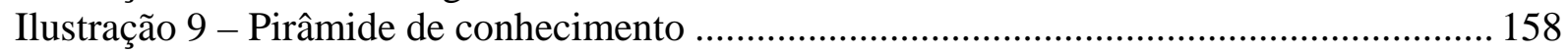

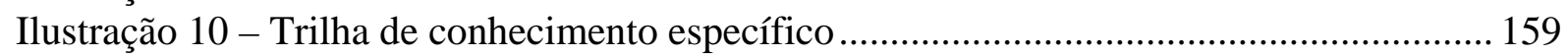

Ilustração 11 - Indicadores da Escola Itaú Unibanco de Negócios ........................................ 175

Ilustração 12 - Conceitos que embasam os níveis de avaliação das ações educacionais -

indicadores de qualidade ............................................................................................ 176

Ilustração 13 - Proposta de modelo teórico: avaliação de resultados em educação corporativa 


\section{INTRODUÇÃO}

O tema Treinamento e Desenvolvimento (T\&D) está presente nas organizações desde a criação das primeiras fábricas, com o advento do período industrial. Mesmo sendo um tema antigo, não perdeu sua importância, pois faz parte da própria constituição de uma organização. Acompanhando as mudanças sofridas pelas organizações, esse campo de conhecimento evoluiu por meio de reformulações que geralmente culminaram em ampliação de escopo de sua atuação.

Inicialmente, as ações de capacitação procuravam preparar o trabalhador para executar suas tarefas conforme fora determinado. Posteriormente, com a introdução do conceito de desenvolvimento, juntamente com o surgimento da escola das relações humanas, houve a preocupação em desenvolver o funcionário, o que se caracterizou primeiramente como preparação para cargos futuros e depois passou a abarcar o aperfeiçoamento profissional e pessoal do indivíduo. Com o surgimento das Universidades Corporativas (UC), o públicoalvo das ações educacionais passa a ser toda a cadeia de valor da organização, incluindo outros stakeholders, como clientes, fornecedores e comunidade e, em vista da competitividade enfrentada pelas organizações, a educação corporativa passa a ter como objetivo auxiliá-las no alcance dos resultados de seus negócios. Conforme apontado por Eboli (2010), houve a evolução do tradicional Treinamento e Desenvolvimento (T\&D) para Educação Corporativa (EC), fornecendo caráter estratégico à capacitação de pessoas e tornando-se um dos pilares do sucesso organizacional. O surgimento das UCs deve-se, entre outros motivos, à insatisfação com a educação fornecida por meio dos cursos de graduação e de não graduação das universidades tradicionais (ALLEN e McGEE, 2004).

A princípio, o termo universidade corporativa, no Brasil, era utilizado indistintamente, gerando confusão e a sensação de que poderia ser algo transitório, um modismo. No início dos anos 2000, autores começaram a estudar o tema e a propor definições, tais como Eboli (1999), Vergara (2000) e Alperstedt (2001). A base conceitual utilizada era a obra de Meister (1999) que traz uma visão prática e teórica, apoiando-se em sua experiência como consultora e em sua pesquisa anual sobre universidades corporativas. Desse modo, o termo surge como 
universidade corporativa e, ao ser discutido no Brasil, passa pelo processo de transformação para o termo educação corporativa.

O termo universidade corporativa foi empreendido nos Estados Unidos, pois a abordagem de universidade atendia melhor às expectativas da organização quanto às iniciativas promovidas em seus projetos de educação (MEISTER, 1999). Entretanto, ganhou a conotação de algo mais relacionado à estrutura formal, tal como entidade ou unidade educacional, conforme mencionam Vargas e Abbad (2006) e Allen e McGee (2004). Apesar de Meister (1999) apontar que o modelo de UC não é necessariamente um espaço físico, mas um processo, verificou-se neste estudo que o termo Universidade Corporativa está atrelado ao conceito de unidade de negócios, ou seja, uma estrutura formal. Ainda, segundo Bastos (1991), a educação reporta-se a um processo mais global em relação aos termos instrução ou treinamento. Portanto, ao longo deste estudo, o termo utilizado será Educação Corporativa (EC).

A EC surge com o propósito de desenvolver as competências críticas da organização e de auxiliá-la no alcance dos objetivos do negócio. Esses objetivos são traduzidos em termos de resultados, que são avaliados por meio do desempenho. Uma das ferramentas utilizadas pelas organizações para garantir o alinhamento estratégico é o Balanced Scorecard, o qual também é usado pelas áreas responsáveis pela educação dos funcionários para alinhar as ações de desenvolvimento à estratégia do negócio. Nesse sentido, a ABTD (2010) menciona em seu estudo que, dentre as prioridades do T\&D para 2011, o estabelecimento de indicadores de desempenho alinhados à estratégia da organização aparece como segundo item mais importante apontado pelas organizações pesquisadas.

Com a competição em nível global, as organizações brasileiras têm de estar preparadas para atuar em um mercado globalizado, entretanto, para se manterem competitivas, precisam arcar com os custos de educar seus funcionários em níveis educacionais primários e secundários que, a princípio, são de responsabilidade governamental. Na era do conhecimento, as organizações brasileiras ficam em desvantagem em relação aos demais competidores e cabe à EC a incumbência de educar os trabalhadores, fornecendo as bases para o desenvolvimento das competências essenciais da organização. A dificuldade de encontrar pessoas qualificadas é agravada pelo chamado apagão de talentos, fenômeno caracterizado pela falta de pessoas qualificadas para ocupar as ofertas de trabalho que surgiram com o aquecimento da economia 
(CARVALHO, 2010). Segundo dados da revista Exame (CARVALHO, 2010), essa situação será agravada com a evolução da exploração do pré-sal e dos investimentos para a Copa de 2014 e as Olimpíadas de 2016. A própria adoção de universidades corporativas no Brasil ainda é pequena, sendo realidade para apenas $22 \%$ das organizações pesquisadas pela ABTD (2010), número 25\% superior à pesquisa realizada em ano anterior, o que é reforçado pela intenção de $27 \%$ das organizações em implantar a EC nos próximos três anos.

Embora a adoção das universidades corporativas ainda seja baixa, os investimentos em treinamento vêm aumentando. Para 2010, houve previsão de aumento dos investimentos em treinamento em 74\% das organizações pesquisadas e, para 2011, a expectativa era de que houvesse também aumento dos investimentos por parte de $75 \%$ das organizações (ABTD, 2010). Nesse sentido, cresce a importância de demonstrar se as ações educacionais estão gerando resultado para a organização.

Como pode ser observado, o caráter estratégico permeia todo o sistema de educação corporativa. Dessa maneira, para iniciar a discussão sobre a avaliação de resultados em educação corporativa, primeiro faz-se necessário estudar a avaliação de resultados em gestão de pessoas (GP). Conforme apontam Oliveira e Oliveira (2011), o sistema de Gerenciamento de Recursos Humanos (GRH) como um todo, correlaciona-se mais ao desempenho organizacional do que às práticas de GRH isoladamente. Portanto, para estabelecer o sistema de avaliação de educação corporativa, é necessário alinhá-lo ao sistema de avaliação em gestão de pessoas.

Uma das ferramentas utilizadas para avaliar os resultados em gestão de pessoas é o Balanced Scorecard (BSC), ferramenta que se caracteriza pela comunicação e implementação da estratégia da organização, visto que evidencia relações de causa e efeito dos processos organizacionais (HOURNEAX JÚNIOR, 2010).

Há poucos estudos sobre avaliação em educação corporativa; já quanto à avaliação em treinamento, existem modelos desenvolvidos desde a década de 1950. Entretanto, as organizações não implantam a avaliação de suas ações educacionais devido a alguns motivos principais, que são apontados tanto por Phillips (1991) quanto por Kirkpatrick e Kirkpatrick (2010): 
a) não sabem como fazer;

b) não há pressão dos executivos da companhia para que a avaliação seja realizada;

c) há acomodação por parte dos profissionais de treinamento.

Outros motivos são apontados pelos autores e abordados nesse estudo com maior detalhe no referencial teórico. Entretanto, esse quadro está mudando, pois, conforme estudo de Fischer e Albuquerque (2011), a avaliação de resultados em gestão de pessoas tem sido preocupação dos profissionais de RH, visto que aparece como a segunda maior tendência em gestão de pessoas para 2015.

Por meio da análise dos modelos de avaliação em treinamento propostos por Kirkpatrick e Kirkpatrick (2010), Phillips (1991), Hamblin (1978), Borges-Andrade (1982) e Fitz-enz (1995), verifica-se que o campo já é bem desenvolvido, entretanto, é válida uma análise para verificar se esses modelos atendem ao novo modelo de capacitação de pessoas, a educação corporativa.

É nesse contexto que se insere o tema avaliação de resultados em educação corporativa, conceito ainda em construção e carente de pesquisas acadêmicas que o suportem.

\subsection{Objetivos da pesquisa}

A partir do contexto exposto sobre o tema avaliação de resultados em educação corporativa, este estudo tem por objetivo geral responder à seguinte questão de pesquisa:

\section{Como as organizações que se destacam em gestão de pessoas avaliam os resultados em educação corporativa?}

O alcance do objetivo geral será desdobrado nos seguintes objetivos específicos:

- descrever o sistema de educação corporativa empregado pelas Melhores Empresas para Você Trabalhar (MEPT) e suas práticas de avaliação de resultados; 
- descrever a organização alvo do estudo de caso e seu sistema de educação corporativa;

- levantar as práticas e os procedimentos de avaliação de resultados em EC no caso estudado;

- analisar as limitações, vantagens e tendências de avaliação de resultados em EC na organização investigada.

\subsection{Justificativas e contribuições do estudo}

O estudo é justificado pela escassa pesquisa realizada sobre avaliação de resultados em EC no Brasil, o próprio conceito de educação corporativa está em construção e os modelos de avaliação criados têm como objetivo analisar as ações de treinamento (KIRKPATRICK e KIRKPATRICK, 2010; PHILLIPS, 1991; HAMBLIN, 1978; BORGES-ANDRADE, 1982; FITZ-ENZ, 1995). Dessa forma, o presente estudo trouxe contribuições de natureza acadêmica e prática.

Em termos de contribuições acadêmicas, a partir da análise das práticas de avaliação de educação corporativa adotados nas empresas que se destacam em gestão de pessoas, foi possível averiguar se a forma de avaliar treinamento atende ao novo modelo de capacitação de pessoas - a educação corporativa. A análise identificou as limitações e vantagens encontradas nessas práticas, fornecendo subsídios para a geração de novos métodos.

Portanto, este estudo poderá dar subsídio ao desenvolvimento de novos modelos de avaliação de resultados em educação corporativa, contribuindo para que a área de Gestão de Pessoas consiga avaliar se as ações de capacitação dos colaboradores estão contribuindo para o alcance das estratégias do negócio.

Outro ponto a ressaltar trata das inúmeras críticas feitas aos estudos de avaliação de resultados em Gestão de Pessoas, conforme apontado por Lacombe e Albuquerque (2008), pois, conforme análise dos autores sobre estudos de revisões sistemáticas sobre o tema, são encontrados resultados de pesquisa que podem ser divergentes, dificuldades de natureza metodológica e ausência da construção de um corpo teórico cumulativo sobre o tema. Desse modo, este estudo auxiliou na compreensão da avaliação de resultados em educação 
corporativa, contribuindo para o acúmulo de seu corpo teórico e buscando minimizar as dificuldades de natureza metodológica.

Em termos de contribuições práticas, será possível aos gestores da função GP avaliar suas ações de capacitação, demonstrando a importância da educação corporativa para o alcance dos resultados do negócio. Assim será possível evitar os cortes de orçamento de educação corporativa realizados em momentos de crise econômica.

O estudo está estruturado da seguinte forma, o capítulo atual fornece uma visão geral sobre a evolução e importância do tema estudado, apresentando os objetivos do estudo e justificativas para sua realização. O capítulo 2 trata da revisão dos termos norteadores da pesquisa, que é estruturada em dois eixos: educação corporativa e modelos de avaliação de resultados em EC e treinamento, apresentando uma visão geral da evolução histórica e os principais conceitos, seguida de revisão sistemática da literatura, sendo exposta, ao final, a síntese da fundamentação teórica. No capítulo 3, é apresentada a metodologia que alicerçou a pesquisa de campo, demonstrando o detalhamento operacional do estudo. Por sua vez, no capítulo 4 são demonstrados os resultados dos dois estudos realizados nesta dissertação: pesquisa sobre as práticas de avaliação utilizadas pelas MEPT; e estudo de caso conduzido no Itaú Unibanco, ao final de cada estudo há uma síntese; e também é proposto um modelo teórico de avaliação de resultados de educação corporativa. Finalmente, o capítulo 5 apresenta as considerações finais, apurando se os objetivos desta pesquisa foram alcançados. 


\section{REFERENCIAL TEÓRICO}

Para estudar o tema avaliação de resultados em educação corporativa, faz-se necessário conhecer alguns conceitos e pesquisas anteriores. Dessa forma, a fundamentação teórica está alicerçada em dois eixos principais: Educação Corporativa (EC) e Modelos de Avaliação de Resultados em Educação Corporativa os quais nortearão todo o estudo. O segundo eixo carece de obras clássicas que o suportem, por isso, foram abordados os modelos de avaliação de resultados em treinamento e um modelo de avaliação de resultados em EC, identificado por meio da revisão sistemática de literatura.

A revisão de literatura inicia-se com a exposição sobre Treinamento, Desenvolvimento e Educação (TD\&E), para em seguida demarcar o termo Educação Corporativa. Após o entendimento desses conceitos, serão apresentadas definições sobre avaliação de resultados em Gestão de Pessoas (GP) para, em seguida, apresentar os modelos de avaliação de resultados em treinamento e educação corporativa encontrados durante a pesquisa.

\subsection{Treinamento, Desenvolvimento e Educação - TD\&E}

\subsubsection{Evolução histórica}

As ações de TD\&E são realizadas desde meados do século XIX, quando as organizações industriais foram constituídas e o objetivo era qualificar os funcionários para realizar o trabalho exatamente como o prescrito. Com o advento da administração científica, buscou-se estruturar de forma científica as ações de TD\&E, utilizando-se tecnologia nesse processo (MALVEZZI, 1994 apud PILATI, 2006). Conforme Oliveira (2006), as primeiras iniciativas de T\&D foram empreendidas nos Estados Unidos com o surgimento de grandes organizações industriais, a primeira “escola de fábrica” (grifo do autor) foi a da Hoe \& Co, criada em 1882 para formar operadores de máquinas, seguida pela Westinghouse, em 1888, General Eletric e Baldwin Locomotive Works, ambas em 1901, e International Harvester Co., em 1907. 
No Brasil, o Treinamento e Desenvolvimento (T\&D), foi introduzido com algumas décadas de atraso, em meados dos anos 1950, quando a industrialização foi impulsionada, por isso, é relativamente recente a presença de grandes empresas no país (OLIVEIRA, 2006). Na mesma linha, Pilati (2006) e Vargas e Abbad (2006) apontam que foi a partir da Segunda Guerra Mundial que o desenvolvimento dos funcionários passou a ser empreendido.

Segundo Oliveira (2006), o modelo de T\&D foi importado dos Estados Unidos com pouca alteração, sendo voltado à formação do empregado para o trabalho, além disso, a estrutura de T\&D ficava subordinada ao gerente de relações industriais. Entre as décadas de 1960 e 1990, houve a criação de incentivos fiscais para impulsionar a formação e a capacitação dos trabalhadores, tais como os “acordos de isenção” (grifo do autor) realizados pelo Serviço Nacional de Aprendizagem Industrial (Senai); o Programa Intensivo de Preparação de Mãode-Obra (PIPMO), criado pelo Ministério do Trabalho; e benefícios concedidos pela lei $\mathrm{n}^{\circ}$ 6297, que permitia a dedução de despesas com treinamento, desde que previamente aprovadas pelo Ministério do Trabalho, em até 5\% do lucro tributável. Esta última iniciativa, entretanto, na visão do autor, não foi bem-sucedida, devido a dificuldades na aprovação dos projetos de T\&D junto ao Ministério do Trabalho e à criação do Programa de Alimentação do Trabalhador (PAT), que utilizava os recursos do mesmo incentivo fiscal concedido às ações de T\&D. Esse benefício foi extinto no governo do presidente Fernando Collor.

Ainda segundo Oliveira (2006), a partir de meados da década de 1980, o modelo de T\&D começou a declinar devido aos problemas econômicos enfrentados pelo país, como a recessão mundial de 1980-82, que ocasionaram demissões, e a aplicação do downsizing nas organizações, que resultou na terceirização de muitas atividades de Recursos Humanos (RH), inclusive as de T\&D. A gestão de RH foi dividida em formulação e aplicação, sendo a primeira centralizada e a segunda descentralizada. Aos gestores, foi repassada a responsabilidade da aplicação das práticas e estratégias de RH e, para auxiliá-los, criou-se a função de consultor interno de RH.

A partir da perspectiva histórica exposta, tem- se uma visão da evolução do modelo de T\&D. Entretanto, faz-se necessário entender os conceitos que o norteiam e que serão expostos a seguir. 


\subsubsection{Conceitos}

Conforme apontam Vargas e Abbad (2006), a aprendizagem humana pode ocorrer de diferentes maneiras e expõem cinco ações para sua promoção: informação, instrução, treinamento, desenvolvimento e educação. A informação é definida como módulos ou unidades organizados de conteúdo disponibilizados em diferentes meios, principalmente o eletrônico ou digital. Por sua vez, a instrução é uma modalidade de aprendizagem planejada e ministrada de forma intencional, que envolve definição de objetivos e aplicação de procedimentos instrucionais, ademais suas ações são de curta duração e visam ao desenvolvimento de conhecimentos, habilidades e atitudes simples. Já o termo treinamento, para Bastos (1991 apud VARGAS e ABBAD, 2006), compreende o processo intencional da organização em realizar mudanças de comportamento em seus empregados, de forma a atingir os objetivos da organização, entretanto, o autor salienta que há ações de aprendizagem que ocorrem na organização e que não estão sob seu controle, tais como mudanças de valores proporcionados pela experiência de trabalho.

Quanto ao termo desenvolvimento, para Bastos (1991 apud VARGAS e ABBAD, 2006), ele engloba o termo treinamento, mas não o substitui. Segundo Vargas e Abbad (2006), o vínculo entre desenvolvimento e o contexto do trabalho é reduzido e apontam que o conceito de desenvolvimento foi aparentemente proposto pela primeira vez por Leonard Nadler, em 1969. Conforme Nadler (1984 apud VARGAS e ABBAD, 2006), desenvolvimento compreende a formação do indivíduo, mas sem relação com um trabalho específico. Entretanto, Nadler em sua obra de 1971 (apud HAMBLIN, 1978, p. 20) traz os seguintes conceitos: treinamento trata de preparação para cargos atuais e desenvolvimento trata da preparação para cargos futuros. Buscando identificar corretamente a definição proposta por Nadler (1974), buscou-se a definição de treinamento, desenvolvimento e educação. Para o autor, treinamento envolve a aplicação da aprendizagem no trabalho logo após o retorno do participante. Por outro lado, educação envolve a aprendizagem para aplicação futura, como a preparação para uma nova posição. Por fim, desenvolvimento seria mais abrangente que os conceitos anteriores, pois, está atrelado a postura de aprendizagem contínua.

Por fim o termo educação, conforme apontam Vargas e Abbad (2006), é o mais abrangente e vai além do contexto do trabalho. As autoras inclusive comentam que os eventos dessa 
natureza são realizados por instituições de ensino reconhecidas pelo Ministério da Educação, sendo possível a articulação de conteúdos entre organizações e instituições de ensino, geralmente, apenas em cursos de pós-graduação lato sensu. Desse modo, na visão dos autores, a educação compreende a formação contínua dos indivíduos por meio de programas ou conjunto de eventos de média e longa duração, tais como cursos técnicos, de graduação e de pós-graduação, tanto lato quanto stricto sensu. A articulação dos cinco conceitos, proposto pelos autores, é demonstrado na Ilustração 1. Segundo eles, as linhas tracejadas indicam a tendência de enfraquecimento das fronteiras entre os diferentes conceitos.

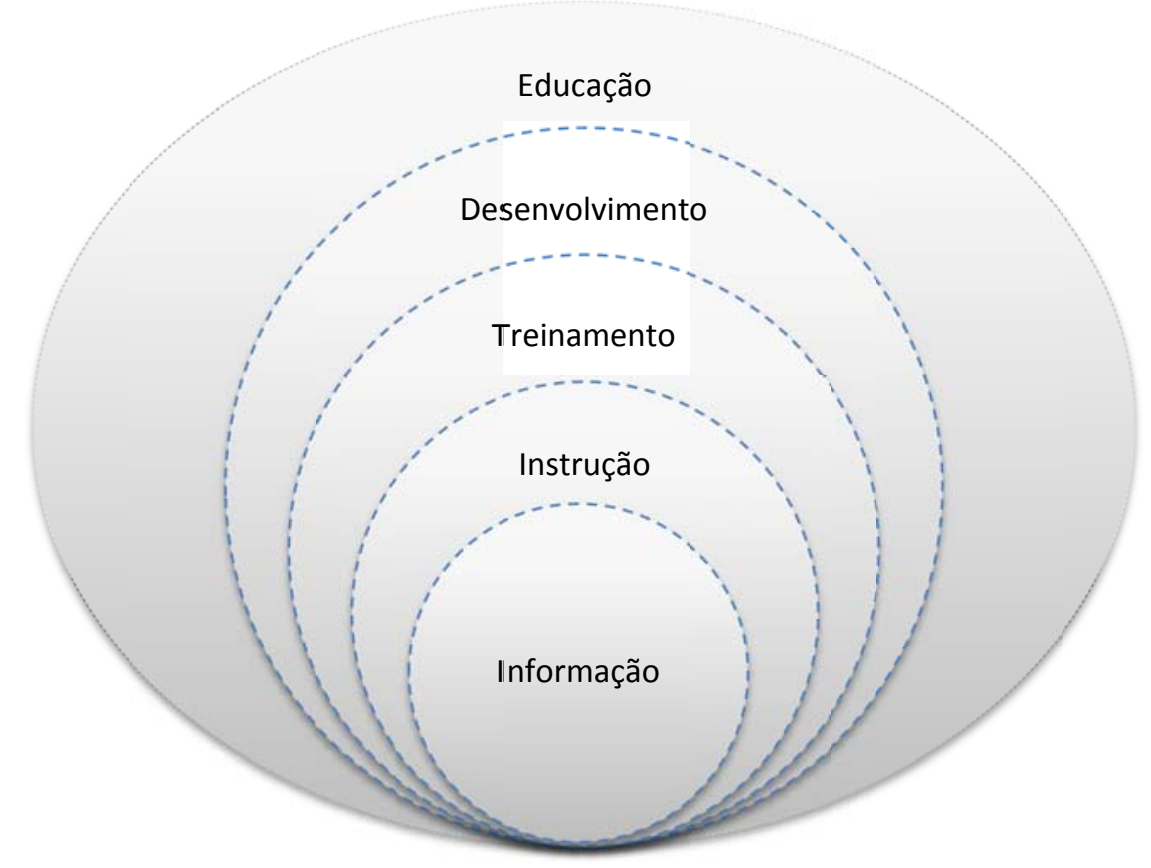

Ilustração 1 - Abrangência dos conceitos informação, instrução, treinamento, dlesenvolvimento e educação.

Fonte: Adaptado de Vargas e Abbad (2006, p. 143).

A partir dos conceitos expostos e da articulação entre eles, Vargas e Abbad (2006) esclarecem a nomenclatura utilizada em sua obra para as ações de aprendizagem: Treinamento, Desenvolvimento e Educação (TD\&E). As autoras ressaltam que a proposta inicial de Nadler (1984) era que o termo desenvolvimento de recursos humanos abarcasse os conceitos de treinamento, desenvolvimento e educação, entretanto, demonstram que houve uma evolução do termo educação nas últimas décadas e apontam que as áreas de gestão de pessoas o têm utilizado como mais abrangente que o de desenvolvimento. 
O avanço dos conceitos de TD\&E também é mencionado por Pilati (2006), que destaca a evolução do campo para a categoria de ciência. O autor relata que o TD\&E busca facilitar a aprendizagem de competências necessárias à atuação no trabalho atual ou futuro, destacando ainda seu aspecto científico, dada a intensificação do desenvolvimento e a aplicação de tecnologias nesse campo. A partir desse contexto, Pilati (2006, p. 160) conceitua treinamento:

\footnotetext{
"Treinamento pode ser definido como uma ação tecnológica controlada pela organização, composta de partes coordenadas, inseridas no sistema organizacional, calcada em conhecimentos advindos de diversas áreas, com a finalidade de (a) promover a melhoria de desempenho, (b) capacitar para o uso de novas tecnologias e (c) preparar para novas funções.”
}

Complementar ao conceito de Pilati (2006), para Leite et. al. (2009, p. 74), o treinamento tem planejamento sistemático e intencional e seu objetivo é produzir melhorias de desempenho nas atividades atuais, preparação para novas posições e retreinamento em tecnologias atualizadas. A evolução do conceito de treinamento para o de desenvolvimento de pessoas transcende a preparação do indivíduo para atividades que ele desempenhará, logo, o crescimento pessoal e o profissional passam a ser o escopo.

Verificam-se, assim, as mudanças pelas quais o modelo de T\&D vem passando que mostram a relevância do tema, ainda, uma preocupação das organizações. Entretanto, esse modelo tem dado sinais de esgotamento, nesse sentido, Oliveira (2006) aponta que a "velha" (grifo do autor) forma de se realizar T\&D entrou em declínio, pois não está sendo mais útil e comenta, inclusive, que a própria expressão T\&D envelheceu e já pede uma substituta. É nesse contexto que surge a Educação Corporativa, como uma evolução do antigo modelo de T\&D.

\subsection{Educação Corporativa}

Apesar de já existirem infraestruturas educacionais nas organizações desde a década de 1950, as quais eram conhecidas como universidades, institutos ou faculdades, é a partir do final da década de 1980 que a universidade corporativa passa a ser mais que um local físico, constituindo um processo, conforme aponta Meister (1999, p. 19). Quanto ao registro da primeira Universidade Corporativa (UC), de acordo com Vergara (2000), há quem considere a 
criada pela General Eletric, chamada Crotonville, em 1956 (BARTLETT e MCLEAN, 2006); outros que apontam a da Motorola, criada em 1983, ambas nos EUA.

As Universidades Corporativas surgem quando a área de TD\&E passa a assumir caráter estratégico nas organizações, dada a necessidade de capacitação de toda a sua cadeia de valor - empregados, clientes e fornecedores -, conforme identificado por Pilati (2006) na análise dos autores Vargas (2003) e Alperstedt (2001).

Segundo Alperstedt (2001), a Universidade Corporativa difere do modelo de T\&D em duas perspectivas principais. A primeira tem uma abordagem longitudinal e refere-se ao novo papel desempenhado pelas universidades corporativas, as quais passam a ser responsáveis pelo alinhamento do processo educacional dos funcionários à estratégia do negócio e às competências essenciais da organização; dessa forma, as universidades corporativas passam a ser entendidas como uma evolução direta do processo de treinamento e desenvolvimento. A segunda, com abordagem transversal, trata da extensão do público-alvo das ações educacionais, ofertando seus serviços além das fronteiras organizacionais; da mudança de atuação de área funcional para unidade de negócio, por meio da comercialização de seus serviços; e do estabelecimento de parcerias com instituições de ensino superior.

Contribuindo para diferenciar T\&D e UC, Allen e McGee (2004) sustentam que o escopo de atuação da UC é mais abrangente, pois desenvolve atividades mais estratégicas, enquanto o T\&D tem geralmente atuação tática. Desse modo, os autores relatam que as atividades de uma UC são relacionadas à estratégia global e à missão da organização à qual servem.

A autora que lançou as bases sobre o conceito de UC foi Jeanne Meister, por meio de sua primeira obra, intitulada Corporate Quality Universites, em 1994. Na sequência, é exposta a definição de universidade corporativa proposta pela autora em sua obra Educação corporativa, de 1999: "um guarda-chuva estratégico para desenvolver e educar funcionários, clientes, fornecedores e comunidade, a fim de cumprir as estratégias empresariais da organização” (MEISTER, 1999, p. 29). Percebe-se a ampliação do escopo de atuação do sistema educacional da organização, que passa a focar não somente os funcionários da empresa, mas toda a sua rede de valor. Uma função complementar a essa e que também caracteriza a nova modalidade de educação corporativa é o estímulo à aprendizagem contínua, visando alinhar a educação das pessoas aos objetivos estratégicos do negócio. Nesse contexto, Meister (1999, p. 
30) aponta que o principal objetivo de uma universidade corporativa é "tornar-se uma instituição em que o aprendizado seja permanente”.

Um dos primeiros trabalhos sobre EC, no Brasil, foi a publicação em 1999 do livro Universidades corporativas, uma coletânea coordenada por Marisa Eboli. Inicialmente o termo universidade corporativa, no Brasil, era utilizado indistintamente, gerando confusão e a sensação de que poderia ser algo transitório. A partir desse contexto, alguns autores iniciaram uma proposta de definição de UC, tais como Vergara (2000) e Alperstedt (2001). Suas definições são expostas a seguir:

\footnotetext{
"Universidade corporativa é um conceito inspirado no tradicional conceito de universidade, é abrigado pelo ambiente empresarial e diz respeito ao desenvolvimento de funcionários, clientes, fornecedores, franqueados e até da comunidade. Tal desenvolvimento significa absorção ou ampliação de informações, habilidades e competências exigidas ao exercício de um cargo, função ou atividade, devendo estar alinhado à missão, aos objetivos e às estratégias do negócio de uma empresa específica e ser contínuo. É uma maneira de formar, integrar e consolidar a base de conhecimentos da empresa, tornando tal base acessível a seus funcionários. Pressupõe que a comunicação torna-se mais eficaz pelo uso do código comum de referência, tornando a responsabilidade pelos resultados compartilhada" (VERGARA, 2000, p. 182).
}

Corroborando a definição dessa autora, Alperstedt (2001) também destaca o papel estratégico da UC e a ampliação do público-alvo das ações da EC e acrescenta a parceria realizada entre UC e instituições de ensino superior, conforme se observa a seguir:

\footnotetext{
“... a definição proposta para as universidades corporativas privilegia não apenas a formação estratégica de desenvolvimento de competências essenciais ao negócio da empresa, mas também, paralelamente, a detenção de duas características fundamentais destacadas: não restrição dos serviços educacionais aos funcionários, com destaque para abertura ao público externo em geral; e estabelecimento de parcerias com instituições de ensino superior, com destaque para a validação dos créditos cursados e a possibilidade de conferição de diplomas, ou a conferição de diplomas de forma independente” (ALPERSTEDT, 2001, p. 163).
}

Essa proposta de Alperstedt (2001), ao conceituar UC teve como objetivo clarificar o conceito e subsidiar pesquisas futuras. 
Cabe neste momento uma análise sobre a diferença entre os termos EC e UC. Para Eboli (2002), eles têm sido utilizados como equivalentes, pois estão intimamente relacionados.

Já para Vargas e Abbad (2006, p. 150), o termo universidade corporativa é restritivo, pois trata da criação de uma unidade educacional, conforme transcrito a seguir:

\footnotetext{
"Embora os dois conceitos - educação corporativa e universidade corporativa - tenham entrado de forma concomitante no ambiente organizacional, observa-se que universidade corporativa é um termo muito restritivo, principalmente porque nem toda organização precisa ou vai criar esse tipo de unidade educacional em sua estrutura.”
}

Todavia, os autores ressaltam que muitos dos princípios e práticas de uma UC podem ser aplicados em qualquer organização.

Também indicando a criação de uma unidade educacional, Allen (2002 apud ALLEN e McGEE, 2004) define a UC como uma entidade educacional que é uma ferramenta estratégica criada com o objetivo de auxiliar a organização a alcançar sua missão, pela condução de atividades que cultivem a aprendizagem individual e organizacional, o conhecimento e a sabedoria. Para Allen e McGee (2004) embora a definição demonstre que as universidades corporativas são educacionais por natureza, a palavra mais importante nesse conceito é estratégia, pois a UC, para servir nessa definição, deve ser verdadeiramente estratégica em suas intenções e atividades.

Já para Meister (1999), o modelo de UC não é necessariamente um espaço físico, mas um processo de aprendizagem. A autora relata que, apesar de a maioria das UCs terem surgido como um local físico, o foco saiu da sala de aula e passou para o processo de aprendizagem contínua vinculada às estratégias da organização. Entretanto, a autora destaca que algumas universidades corporativas acreditam na importância do espaço físico para a criação de um espírito de aprendizagem permanente. De acordo com Meister (1999, p. 35), a utilização do termo pelas organizações ocorreu, pois a abordagem de universidade atendia melhor a suas expectativas quanto às iniciativas promovidas em seus projetos de educação, conforme relatado a seguir: 
“O mais importante é que elas queriam usar a metáfora da universidade para criar a imagem da grande finalidade da iniciativa: prometer aos participantes e seus patrocinadores que a universidade corporativa irá prepará-los para o sucesso no trabalho atual e na carreira futura”.

Na Europa, segundo apontado por Renaud-Coulon (2002 apud ALLEN e MCGEE, 2004), as UCs estão surgindo em ritmo acelerado, porém, não utilizam o termo universidade corporativa, preferindo academia corporativa, sendo em muitos países o termo universidade reservado exclusivamente para as instituições que concedem grau de formação.

Verifica-se que não há um consenso sobre a diferença entre os conceitos de UC e EC, entretanto, percebe-se que há uma característica em comum atrelada ao termo universidade corporativa: a criação de uma estrutura formal, como mencionado por Vargas e Abbad (2006) quando citam o termo "unidade” ou, como relatado por Allen e Mcgee (2004) quando, ao definirem a UC, a caracterizam como uma “entidade”. A própria Meister (1999) tem de pontuar que a UC não é apenas um espaço físico. Desse modo, o termo universidade corporativa parece estar atrelado a criação de uma estrutura.

Nesse sentido, Eboli (2002) aponta que o surgimento das Universidades Corporativas trouxe à tona a nova modalidade de educação corporativa. Essa nova modalidade baseia-se no objetivo principal de identificar e desenvolver as competências críticas para que a empresa atinja os resultados esperados de seu negócio e na missão de "formar e desenvolver os talentos na gestão dos negócios, promovendo a gestão do conhecimento organizacional (geração, assimilação, difusão e aplicação) através de um processo de aprendizagem ativa e contínua.” (EBOLI, 2010, p. 149 e 150). Ainda, segundo a autora, o conceito de EC corresponde à implantação dos seguintes fatores:

a) objetivo principal: desenvolver competências do negócio e não habilidades individuais;

b) foco do aprendizado: a aprendizagem organizacional em detrimento do conhecimento individual;

c) escopo: atuação estratégica, focando a organização como um todo e não somente o indivíduo;

d) ênfase dos programas: desenvolver as competências críticas da organização necessárias para a implantação da estratégia corporativa: 
e) público-alvo: público interno (funcionários) e externos (familiares, clientes, fornecedores, distribuidores, parceiros comerciais e comunidade);

f) local: físico ou virtual;

g) resultado: aumentar a competitividade da organização e não somente as habilidades individuais.

Eboli (2004) define sete princípios de sucesso de um sistema de educação corporativa, alinhando a eles suas respectivas práticas, conforme se apresenta no Quadro 1:

Quadro 1 - Princípios de sucesso de um sistema de educação corporativa

\begin{tabular}{|c|c|}
\hline PRINCÍPIOS & PRÁTICAS \\
\hline Competitividade & $\begin{array}{l}\text { Obter o comprometimento e envolvimento da alta cúpula com o sistema de educação. } \\
\text { Alinhar as estratégias, diretrizes e práticas de gestão de pessoas às estratégias do negócio. } \\
\text { Implantar um modelo de gestão de pessoas por competências. } \\
\text { Conceber ações e programas educacionais alinhados às estratégias do negócio. }\end{array}$ \\
\hline Perpetuidade & $\begin{array}{l}\text { Ser veículo de disseminação da cultura empresarial. } \\
\text { Responsabilizar líderes e gestores pelo processo de aprendizagem. }\end{array}$ \\
\hline Conectividade & $\begin{array}{l}\text { Adotar e implementar a educação “inclusiva”, contemplando o público interno e o externo. } \\
\text { Implantar modelo de gestão do conhecimento que estimule o compartilhamento de } \\
\text { conhecimentos organizacionais e a troca de experiências. } \\
\text { Integrar sistemas de educação com o modelo de gestão do conhecimento. } \\
\text { Criar mecanismos de gestão que favoreçam a construção social do conhecimento. }\end{array}$ \\
\hline Disponibilidade & $\begin{array}{l}\text { Utilizar de forma intensiva tecnologia aplicada à educação. } \\
\text { Implantar projetos virtuais de educação (aprendizagem mediada por tecnologia). } \\
\text { Implantar múltiplas formas e prospectos de aprendizagem que favoreçam a “aprendizagem a } \\
\text { qualquer hora e em qualquer lugar”. }\end{array}$ \\
\hline Cidadania & $\begin{array}{l}\text { Obter sinergia entre programas educacionais e projetos sociais. } \\
\text { Comprometer-se com a cidadania empresarial, estimulando: } \\
\text { - } \quad \text { a formação de atores sociais dentro e fora da empresa; } \\
\text { - } \quad \text { a construção social do conhecimento organizacional. }\end{array}$ \\
\hline Parceria & $\begin{array}{l}\text { Parcerias internas: responsabilizar líderes e gestores pelo processo de aprendizagem de suas } \\
\text { equipes, estimulando a participação nos programas educacionais e criando um ambiente de } \\
\text { trabalho propício à aprendizagem. } \\
\text { Parcerias externas: estabelecer parcerias estratégicas com instituições de ensino superior. }\end{array}$ \\
\hline Sustentabilidade & $\begin{array}{l}\text { Tornar-se um centro de agregação de resultados para o negócio. } \\
\text { Implantar sistema métrico para avaliar os resultados obtidos, considerando-se os objetivos } \\
\text { do negócio. } \\
\text { Criar mecanismos que favoreçam a autossustentabilidade financeira do sistema. }\end{array}$ \\
\hline
\end{tabular}

Fonte: Eboli (2004, p. 60). 
São evidenciadas, por meio do princípio sustentabilidade, as práticas que poderão dar suporte para que o sistema de educação corporativa se mantenha. Nota-se que é importante haver a implantação de um sistema métrico para avaliar os resultados, isso possibilita verificar se o sistema está alinhado aos resultados do negócio. Em consonância com esse princípio, Meister (1999, p. 22) aponta algumas características da mudança de paradigma do treinamento para a aprendizagem e, dentre elas, a meta da aprendizagem passa a ser solucionar problemas empresariais reais e melhorar o desempenho no trabalho. Para verificar esse desempenho, torna-se necessário avaliar os resultados obtidos, por isso, um modelo de avaliação de resultado em educação corporativa é ferramenta fundamental no sistema de educação corporativa.

\subsection{Avaliação de resultados em gestão de pessoas}

Em muitas organizações, os líderes querem acreditar que as pessoas são seu ativo mais importante, entretanto, não conseguem visualizar como a função de gestão de pessoas pode tornar real essa visão (BECKER, HUSELID e ULRICH, 2001). Essa situação é explicada por ser difícil avaliar a influência da gestão de pessoas no desempenho da organização, conforme apontam os autores.

Segundo Becker, Huselid e Ulrich (2001), a nova realidade econômica está pressionando a gestão de pessoas a ampliar o foco de seu papel, passando da atuação administrativa, que tradicionalmente tem desempenhado, à estratégica. O impacto da gestão de pessoas na estratégia da organização é difícil de visualizar, porém, se os gestores de RH entenderem a estratégia da organização, planejarão ações para desenvolver e sustentar a vantagem da organização no mercado.

Becker, Huselid e Ulrich (2001) relatam que, geralmente, os resultados da gestão de pessoas são medidos em termos de remuneração, turnover, custos de contratação, percentual de empregados que tiveram seu desempenho avaliado nos últimos 12 meses e satisfação no trabalho, porém os atributos cruciais para a implementação da estratégia de uma organização não são avaliados, havendo, dessa maneira, desconexão entre o que é mensurado e o que é importante. Os autores expõem como atributos cruciais para a implementação da estratégia a 
capacidade e o comprometimento dos empregados, o desenvolvimento das competências essenciais dos empregados e um sistema de treinamento que auxilie os empregados a aprenderem mais rapidamente que seus competidores.

Os achados da pesquisa empreendida por Oliveira e Oliveira (2011, p. 663), que realizaram uma metanálise sobre os efeitos da gestão de recursos humanos no desempenho organizacional, corroboram o argumento anterior. Segundo os autores, treinamento e desenvolvimento são uma das práticas que mais se correlacionam ao desempenho organizacional, conforme pode ser observado no trecho transcrito a seguir:

\footnotetext{
"As práticas de GRH isoladas que mais se correlacionaram com desempenho organizacional em geral foram: as práticas de sistema de trabalhos em equipe; segurança de emprego; mudança e desenvolvimento organizacional; pagamento por desempenho e treinamento e desenvolvimento. Estes resultados mostram semelhanças e divergências com as duas metanálises realizadas anteriormente (COMBS et al., 2006; OLIVEIRA, 2006). Especificamente, as práticas de segurança de emprego e treinamento e desenvolvimento também reportaram os melhores resultados, em ambas”.
}

Entretanto, Oliveira e Oliveira (2011) alertam que o sistema de Gerenciamento de Recursos Humanos (GRH ), como um todo, se correlaciona mais ao desempenho organizacional do que as práticas de GRH isoladamente.

Em estudo realizado por Lacombe e Albuquerque (2008), verificou-se que as pesquisas que tratam o tema avaliação em gestão de pessoas dividem-se em dois tipos: estudos sobre o impacto das práticas de Recursos Humanos (RH) e estudos sobre mensuração de RH. O primeiro tipo de estudo compreende pesquisas que procuram identificar práticas ou conjuntos de práticas que sejam comprovadamente melhores para uma ou mais organizações, ou seja, o objetivo é estudar como as práticas de RH podem ser melhoradas. São destacadas pelos autores, nesse tipo de estudo, as pesquisas conduzidas por Huselid (1995) e as realizadas posteriormente por Becker e Huselid (1998) e Becker, Huselid e Ulrich (2001), que constataram que as práticas de trabalho de alto desempenho afetam os resultados da organização.

Por outro lado, o segundo tipo de estudo caracteriza-se por pesquisas de natureza aplicada que buscam identificar, de forma quantitativa, a contribuição das práticas de RH sobre os 
resultados do negócio, nesse tipo de estudo enquadram-se Becker, Huselid e Ulrich (2001), Fitz-enz (1995) e Norton e Kaplan (1997). Do ponto de vista dos autores, esse tipo de estudo é interessante, pois busca esclarecer o fluxo causal entre as ações de RH e o desempenho organizacional.

Outro ponto ressaltado por Lacombe e Albuquerque (2008) é que o processo de avaliação e mensuração em gestão de pessoas não se resume ao estabelecimento de indicadores; mais do que isso, envolve um processo amplo, no qual se estruturam procedimentos de avaliação e mensuração pela análise de todo o processo que vai da estratégia da organização às práticas de RH.

Para apurar e avaliar o desempenho das práticas organizacionais Hourneaux Junior (2010) aponta o gerenciamento por meio de sistemas como forma de avaliar a implementação das estratégias do negócio. Esses sistemas são traduzidos em indicadores que buscam representar de forma clara, precisa e estruturada a realidade e são classificados em quantitativos ou qualitativos, de curto ou longo prazo, lagging (de resultados) ou leading (de tendências), financeiros ou não financeiros. O autor ainda destaca que, há até pouco tempo, os indicadores financeiros eram o foco das atenções nas organizações, entretanto, dada as inúmeras limitações desses indicadores e com a introdução do balanced scorecard (BSC), abriu-se espaço para indicadores não financeiros.

Uma das ferramentas de gestão integrada do desempenho mais utilizada é o balanced scorecard, de Robert Kaplan e David Norton. Criada, a princípio, sob a perspectiva contábil e de controle, a ferramenta passou a ser utilizada para comunicação e implementação da estratégia, visto que evidencia relações de causa e efeito dos processos organizacionais (HOURNEAX JÚNIOR, 2010).

Becker, Huselid e Ulrich (2001) apontam que os indicadores financeiros são informações retrospectivas e os gestores tendem a concentrar-se nesses indicadores sem atentar aos processos que levam aos resultados financeiros. Assim, segundo os autores, o BSC tem como objetivo fazer com que os gestores se envolvam ativamente no processo de implementação da estratégia ao invés de se concentrarem apenas na monitoração dos resultados financeiros. 
Conforme aponta Hourneaux Júnior (2010) aparentemente falta às metodologias de avaliação de treinamento a vinculação aos aspectos estratégicos. Assim, propõe uma integração estratégica entre os níveis de avaliação de Kirkpatrick e Phillips e as perspectivas do Balanced Scorecard. Os níveis de avaliação contemplados seriam o de aprendizado, alinhado à perspectiva aprendizagem e conhecimento; o de aplicação e o de resultado estariam alinhados às perspectivas processos internos e clientes; por fim o nível de retorno financeiro (ROI) seria contemplado na perspectiva financeira.

Hourneaux Júnior (2010) ainda destaca que diferentes necessidades de avaliação remetem a diferentes níveis organizacionais, assim, um indicador de reação do participante a um programa, o qual é medido ao nível individual, não caberia no BSC corporativo. Portanto, tem de ser averiguado a qual nível organizacional estão relacionados os indicadores dos níveis tradicionais para que haja uma integração em todo o processo de avaliação.

\subsection{Avaliação de resultados em Educação Corporativa}

A avaliação de resultados em EC é um tema pouco estudado, dessa forma, na revisão de literatura foi encontrado apenas um modelo que aborda essa temática. Para embasar o presente estudo, buscaram-se então autores clássicos que abordam modelos de avaliação de treinamento para, posteriormente, avaliar se os modelos de avaliação em EC e T\&D são excludentes ou complementares.

Para Borges-Andrade (2006), a avaliação de treinamento é um processo composto por alguma forma de coleta de dados e pela análise desses dados com os objetivos de criar juízo de valor.

A avaliação começa a ganhar destaque com o surgimento da administração científica, sendo utilizada para controlar e disciplinar o trabalhador na execução de suas tarefas, conforme relatam Brandão e Guimarães (2001 apud HIPÓLITO e REIS 2002).

A área de Gestão de Pessoas, apesar de buscar ter uma atuação estratégica, tem encontrado dificuldades para alcançar esse perfil de atuação. Uma das maiores dificuldades apontadas por Giardino (2007, p. 1) é “a falta de experiência na utilização de métodos e ferramentas 
analíticas”. Além disso, a competitividade acirrada tem influenciado a postura das empresas que procuram investir seus recursos em ações que lhes garantam retorno.

Conforme apontado por Kirkpatrick e Kirkpatrick (2010), há basicamente três motivos para realizar a avaliação de resultados em treinamento. O primeiro trata de justificar os investimentos realizados em treinamento, pois, quando há redução de orçamento, busca-se eliminar custos e, muitas vezes, os treinamentos são vistos como dispensáveis, sendo um dos primeiros itens a serem cortados. Outro motivo refere-se à tomada de decisão sobre a continuidade ou não de um programa de treinamento, assim, a utilidade de um programa pode ser determinada por meio de sua avaliação. Por fim, para os programas de treinamento mantidos pela organização, torna-se necessário verificar maneiras de melhorá-los. Entretanto, o autor destaca que, apesar de necessária, a avaliação não é realizada pela maioria das empresas pelas seguintes razões:

a) não consideram importante ou urgente;

b) não sabem o que e como fazer;

c) a diretoria não pressiona para que seja realizada. Os executivos da empresa estão preocupados com outros fatores, como lucro, retorno sobre o investimento, valor das ações etc.;

d) os profissionais de treinamento acomodam-se, sentindo-se seguros no emprego e não vendo necessidade de fazer atividades além das já realizadas;

e) os profissionais de treinamento têm outras atividades que julgam mais importantes ou que preferem realizar.

Phillips (1991, passim) aborda algumas suposições errôneas sobre o "misterioso" (grifo do autor) processo de avaliação de treinamento, as quais o autor chama de mitos, que podem estar impedindo a implantação de processos de avaliação. São relatados 11 desses mitos.

Mito 1: Eu não posso mensurar os resultados de meu esforço de treinamento. Persiste o mito de que não é possível identificar e calcular os efeitos de treinamento de forma mensurável. O autor argumenta que há várias tecnologias e métodos para mensuração de qualquer tipo de treinamento. Torna-se, pois, indispensável uma mudança de atitude sobre a necessidade da avaliação. 
Mito 2: Eu não sei qual informação coletar. Se os objetivos são precisos e mensuráveis, então se tem uma ideia de qual tipo de informação coletar. Quando o treinamento foca o desempenho, a confusão sobre quais informações coletar desaparece.

Mito 3: Se eu não calcular o retorno do investimento, não há utilidade em avaliar programas. Há outros motivos que não econômicos para conduzir um programa de treinamento, alguns programas são elaborados para atender a premissas subjetivas, logo, não há como ser tão específico como o cálculo do ROI para investimentos. Em alguns casos, o custo de se realizar uma mensuração precisa e objetiva supera os custos do programa.

Mito 4: Mensuração é efetiva somente nas áreas de produção e de finanças. Toda área funcional tem sido alvo de prestação de contas, por isso a mensuração existe em todas as áreas funcionais. A área de treinamento é uma delas e também tem sido exigida, por isso a importância de produzir mensurações que tenham significado e sejam realistas.

Mito 5: Meu CEO (Chief Executive Officer) não exige avaliação, então por que eu deveria fazê-lo? Pode ocorrer repentinamente de o CEO exigir justificativas para a existência do departamento de treinamento ou um novo CEO assumir o comando da organização e exigir mensurações. Outro fato importante é que o CEO avalia os esforços de treinamento de forma explícita ou implícita, ou seja, tirando conclusões com base em dados reais ou mesmo na ausência desses dados.

Mito 6: Há muitas variáveis que afetam a mudança de comportamento, dificultando a avaliação do impacto do treinamento. Há vários estudos realizados em que se consegue avaliar o impacto do treinamento mantendo-se as demais variáveis constantes. É possível isolar as variáveis sobre as quais a área de treinamento tem controle, a saber, as que envolvem o processo de treinamento. Embora as mensurações possam não ser precisas, elas são melhores do que não realizar nenhuma mensuração.

Mito 7: Avaliação lida com a crítica. Resultados de avaliação podem ter reflexos desfavoráveis sobre quem desenhou o programa, sobre quem os conduziu e até sobre os supervisores dos participantes que falharam em dar o suporte necessário. A menos que uma organização esteja preparada para críticas, a avaliação não deveria ser empreendida, pois os comentários e feedbacks podem não ser sempre positivos. 
Mito 8: Eu não preciso justificar minha existência, eu tenho experiência comprovada. Apesar de alguns profissionais terem estabilidade e excelente reputação, os resultados da área de treinamento não são reflexo do esforço de um indivíduo. No momento de crise econômica a reputação é esquecida e os gestores precisam de dados claros para demonstrar o valor da área de treinamento.

Mito 9: A ênfase em avaliação deveria ser a mesma em todas as organizações. O interesse em avaliação depende do tamanho da organização e do escopo de atividades da área de treinamento. Organizações pequenas com processos informais de treinamento têm pouco interesse em avaliação, já as organizações maiores deveriam preocupar-se em avaliar seus programas de treinamento.

Mito 10: Medir o progresso em direção aos objetivos é uma estratégia de avaliação adequada. Os objetivos de treinamento são estritamente focados em conteúdo, atividades de aprendizagem e melhorias imediatas pós-treinamento. A avaliação nesses termos torna-se inadequada, pois não foca o impacto do treinamento no longo prazo e as medidas de mensuração não se relacionam a mudanças e resultados no nível organizacional.

Mito 11: Avaliação provavelmente tem custo elevado. A avaliação é uma pequena parte da atividade de treinamento e, consequentemente, seu custo também. Quando a avaliação está integrada aos demais processos de treinamento, o custo e o tempo relativos à avaliação podem ser pequenos.

Phillips (1991) aponta que um estudo realizado com as empresas constantes da Fortune 500 analisou suas abordagens de avaliação da gestão de treinamentos. Os resultados não foram animadores, pois apenas $15 \%$ dos respondentes mensuravam o nível de mudança de desempenho no trabalho, 8\% mensuravam mudança nos resultados da organização derivadas de treinamento e apenas 6\% conseguiam justificar os custos em treinamento por meio do cálculo do retorno sobre o investimento. A partir do estudo, alguns problemas de avaliação foram detectados: $22 \%$ dos respondentes alegaram que a falta de uma metodologia adequada foi uma restrição para os gestores de treinamento avaliarem seus esforços; 42\% disseram que a falta de regras e normas foi uma das mais significantes deficiências; e 53\% dos respondentes 
não planejaram mudanças a curto, tampouco a longo prazo, em seus sistemas de avaliação. É preciso mudar esse cenário, e Phillips (1991) destaca alguns motivos:

a) senso econômico apurado - dada a pressão por redução de custos, recursos escassos e aumento da competição, tem ocorrido o aumento da pressão sobre a área de treinamento para que sua contribuição seja efetiva;

b) tendência de mensuração em nossa sociedade - a maioria das funções e departamentos tem sido exigida a quantificar o impacto de suas atividades, o que recai também sobre a área de treinamento;

c) aprovação de orçamentos em treinamento - a mensuração de programas passados pode auxiliar a garantir a aprovação de recursos futuros;

d) pressão da cúpula por contribuições - tem sido cada vez mais comum os presidentes exigirem o alcance de resultados pela área de treinamento;

e) pares pressionam os profissionais de treinamento - a realização de avaliação de treinamento por uma organização e seu progresso nesse campo acaba gerando pressão para que as demais também implantem a avaliação em seus treinamentos;

f) satisfação pessoal - há certa satisfação pessoal quando a pessoa vê os resultados de seus esforços;

g) aumento de informações disponíveis - apesar de ser embrionário, o campo sobre avaliação e mensuração está se multiplicando e informações têm sido compartilhadas por diversos meios;

h) profissionalismo - a proporção que a avaliação e a mensuração têm tomado, conduz à diferenciação entre amadores e profissionais. A avaliação tem sido incorporada à carreira dos novos profissionais de treinamento;

i) Sobrevivência - quem não avaliar seus esforços poderá ser deixado de fora no futuro.

A avaliação dos impactos e efeitos dos programas de T\&D no Brasil é uma preocupação de grande parte das organizações e realidade para algumas. Estudo conduzido pela ABTD (2008) com 429 organizações constatou que $40 \%$ delas realizam a avaliação dos impactos dos programas por meio de indicadores de desempenho, 30\% analisam a opinião dos participantes, $13 \%$ o fazem por meio da percepção dos clientes internos e $17 \%$ não realizam nenhuma ação para mensurar esse impacto. 
São expostos na sequência cinco modelos genéricos de avaliação de treinamento, abordando seus conceitos e suas principais características. São eles o modelo de Kirkpatrick, Hamblin, Phillips, Fitz-enz e o MAIS, de Borges-Andrade. Conforme proposto por Pilati (2004 apud BORGES-ANDRADE, 2006), os modelos de avaliação de treinamento são classificados em genéricos e específicos. Os modelos genéricos descrevem um conjunto de variáveis relacionadas aos processos de treinamento, contribuindo para a compreensão dos fenômenos a eles relacionados e agindo como organizadores do campo de conhecimento em avaliação de treinamento. Já os modelos específicos baseiam-se nos genéricos e são desenvolvidos com o objetivo de testar relações entre um conjunto de variáveis específicas realizando, para tanto, testes empíricos. Ambos os modelos complementam-se, pois os genéricos fornecem as bases para o desenvolvimento dos específicos e estes retroalimentam os modelos genéricos, aprimorando-os.

\subsubsection{Modelo de Kirkpatrick}

Apesar de a metodologia de Donald Kirkpatrick ter sido desenvolvida há mais de 50 anos, a preocupação em sua implantação é recente (EBOLI, 2004). Conforme apontam Allen e McGee (2004), como as UCs são descendentes das áreas de T\&D, não é uma surpresa que o modelo básico de avaliação usado por muitas UCs seja o Modelo de Quatro Níveis de Kirkpatrick.

Para Kirkpatrick e Kirkpatrick (2010, p. 21), “o propósito de se avaliar um programa de treinamento é determinar sua eficácia”. Segundo relata o autor, para que um treinamento seja eficaz, é necessário que haja atenção às etapas de planejamento e implementação da ação de treinamento, assim, propõe dez passos para alcançar a eficácia da ação de treinamento, os quais são descritos a seguir (KIRKPATRICK e KIRKPATRICK, 2010, passim).

Passo 1 - Determinação das necessidades: consiste em identificar as necessidades de treinamento dos participantes. Segundo o autor, podem-se identificar essas necessidades perguntando diretamente ao participante, a seus chefes, a outras pessoas que conheçam bem seu trabalho, tais como colegas, subordinados e clientes, testando os participantes ou analisando formulários de avaliação de desempenho. O autor menciona que as entrevistas 
fornecem informações detalhadas, entretanto, demandam muito tempo; uma alternativa são os questionários pelos quais se obtêm as informações necessárias de forma mais eficaz.

Passo 2 - Estabelecimento de objetivos: os objetivos devem ser elaborados considerando quais resultados se deseja alcançar, quais comportamentos são necessários para atingi-los e quais conhecimentos, habilidades e atitudes são essenciais para se obterem esses comportamentos.

Passo 3 - Determinação do conteúdo temático: os temas devem ser selecionados, de forma a atender às necessidades dos participantes e atingir os objetivos.

Passo 4 - Seleção dos participantes: para selecionar o público de um programa de treinamento, é necessário analisar quem se beneficiará com o treinamento, quais treinamentos são exigidos na legislação ou regulamentos, se o treinamento será voluntário ou obrigatório e se é possível agregar níveis diferentes em uma mesma turma.

Passo 5 - Determinação da agenda ideal: a escolha da data e do horário precisa atender às necessidades dos participantes e de seus gestores e não a conveniência dos profissionais de treinamento e dos instrutores.

Passo 6 - Seleção de local apropriado: recomenda-se que o local seja confortável e conveniente, evitando-se fatos que possam distrair ou despertar atitudes negativas no participante, tais como ruídos, frio ou calor demais, salas pequenas etc.

Passo 7 - Seleção de instrutores adequados: os instrutores precisam dominar o conteúdo, ter capacidade de fazer com que as pessoas participem, gostar de ensinar, ou seja, ter foco em atender às necessidades de seu público-alvo. A escolha de instrutores perpassa questões como a utilização de profissionais internos ou externos à organização, fator influenciado por restrições orçamentárias. É preciso ter cuidado na seleção, sendo recomendável observar a atuação do profissional em situação semelhante ou pedindo recomendações sobre o instrutor a outro profissional de treinamento que já conheça seu trabalho.

Passo 8 - Seleção e preparação de recursos audiovisuais: a finalidade dos recursos audiovisuais é manter o interesse do participante, criando um clima favorável à aprendizagem, 
assim como auxiliar o instrutor a comunicar-se. A dosagem ideal de sua utilização deve ser determinada pelo instrutor ou profissional de treinamento, tendo o cuidado de usá-los como recursos auxiliares e não como o centro de um programa de treinamento.

Passo 9 - Coordenação do programa: podem ocorrer duas situações, a coordenação do programa ser realizada pelo próprio instrutor ou por uma pessoa que não atua como instrutor. Ao coordenador, cabe tomar todas as providências relativas ao treinamento, tais como apresentação do instrutor, informar o local do café e almoço, pedir aos participantes para preencherem o formulário de avaliação etc., ficando o instrutor responsável por ministrar a aula.

Passo 10 - Avaliação do programa: processo por meio do qual se determina a eficácia de um programa de treinamento. Para garantir a eficácia do treinamento, é necessário atenção às fases de seu planejamento e execução.

Os dez passos descritos acima são importantes na fase de planejamento e execução dos programas de treinamento. O autor destaca ainda que nessa fase a sequência para planejamento das ações de treinamento deve contemplar os quatro níveis na forma inversa, começando com a definição dos resultados que se deseja alcançar, envolvendo os gestores dos diferentes níveis e estimulando sua participação, isso incentivará a criação do ambiente de trabalho favorável à mudança de comportamento. Na sequência, definem-se os comportamentos esperados para o alcance dos resultados e quais atitudes, conhecimentos e habilidades proporcionarão os comportamentos desejados. Ao desenhar os programas de treinamento, o profissional de treinamento deve ter em mente a busca por despertar reações favoráveis nos participantes. Logo, a fase de planejamento e execução será realizada de forma a proporcionar um treinamento eficaz.

Para a fase de avaliação, o autor propõe em sua metodologia quatro níveis sequenciais de avaliação, conforme demonstrado na Ilustração 2. Para se passar ao nível seguinte é necessário ter realizado o anterior. 


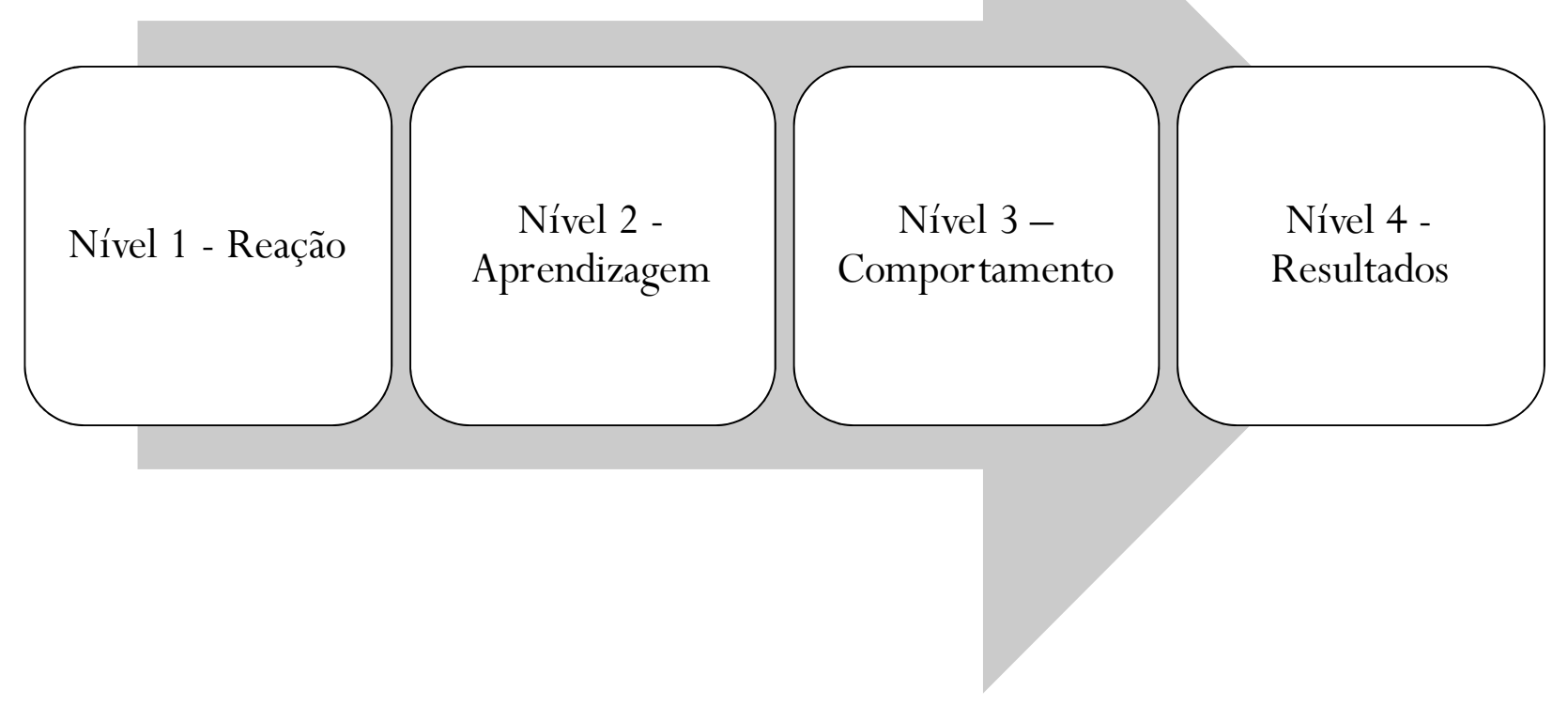

Ilustração 2 - Os quatro níveis de avaliação de treinamento de Kirkpatrick

São apresentados a seguir esses níveis (KIRKPATRICK, 1994; KIRKPATRICK e KIRKPATRICK, 2010, passim):

Nível 1 - Reação: mensura-se a reação dos participantes ao programa de treinamento, identificando sua satisfação. A reação positiva é necessária para a própria sobrevivência dos programas de treinamento, pois participantes insatisfeitos podem relatar sua insatisfação a seus superiores, chegando a informação, pois, ao conhecimento da diretoria, que tem poder de decisão sobre o futuro das ações de treinamento. Outro fator importante é a motivação do participante, influenciada pela satisfação com o treinamento. A satisfação positiva não é garantia de aprendizado, mas a insatisfação pode reduzir a possibilidade de que ele ocorra.

Nível 2 - Aprendizagem: sua avaliação ocorre por meio da verificação de mudança de atitude, aumento de conhecimento ou melhora de habilidade do participante. Para o autor, um dos fatores, ou mais, deve ocorrer para que haja aprendizagem, dependendo do tipo de programa de treinamento. Há programas que desenvolvem nos participantes mudança de atitude, há os que promovem aumento de conhecimento e outros, como desenvolvimento de lideranças, que buscam desenvolver os três fatores. Portanto, nesta etapa é averiguado se os objetivos específicos do programa foram atingidos. 
Nível 3 - Comportamento: identifica-se se houve mudança no comportamento do participante, verificando se os conhecimentos e as habilidades adquiridos estão sendo aplicados em seu trabalho. É válido destacar que a obtenção de resultados positivos nesta etapa está mais relacionada ao papel desempenhado pelo gestor, que precisa incentivar, ou pelo menos não desestimular, o uso dos conhecimentos e habilidades adquiridos. Para que o programa de treinamento seja eficaz nesse nível, quatro fatores devem ser observados: o participante precisa estar disposto a mudar; o treinando precisa saber o que fazer e como fazêlo; o ambiente de trabalho deve ser favorável à aplicação do que foi aprendido; por fim, é necessário que haja recompensas pela mudança de comportamento, sejam intrínsecas (satisfação e orgulho em aplicar o que apreendeu), sejam extrínsecas (elogio do gestor, reconhecimento dos colegas e vantagens financeiras). Caso seja constatado que não houve mudança de comportamento, as avaliações realizadas no nível 1 e 2 auxiliarão a identificar por que não ocorreu e qual ponto precisa ser melhorado.

Nível 4 - Resultados: verificam-se os resultados alcançados devido à participação do treinando no programa. Esses resultados podem ser identificados pela redução de custos, redução de acidentes, aumento das vendas, redução de turnover, melhoria da qualidade, aumento da produção, lucros mais altos e retorno do investimento. Os objetivos do programa de treinamento devem ser estabelecidos nesses termos. Pode ocorrer de alguns objetivos serem medidos em termos não monetários, para esses casos espera-se como resultado tangível a melhoria de motivação ou da qualidade de vida, por exemplo.

Em termos de avaliação, conforme apontado por Allen e McGee (2004), a maior diferença entre as universidades tradicionais e as UCs refere-se à mensuração de habilidades dos estudantes, pois muitas universidades tradicionais usam apenas os dois primeiros níveis de Kirkpatrick, finalizando a avaliação quando o curso termina. Entretanto, os autores apontam que o nível 2 do modelo de Kirkpatrick é estendido após a finalização do curso, o que para eles é o centro da avaliação em ambientes corporativos.

Allen e McGee (2004) relatam ainda que os níveis 3 e 4 são importantes para a avaliação de treinamentos, visto que é necessário avaliar se houve mudança de comportamento do funcionário treinado e se essa mudança é significativa para a organização, bem como averiguar se gerou resultados no nível organizacional. Os autores mencionam que as 
organizações que aspiram alcançar o nível 4 ficam satisfeitas em encontrar correlações entre o treinamento e resultados organizacionais positivos.

\subsubsection{Modelo de Hamblin}

Para entender a metodologia proposta pelo autor, cabe inicialmente entender alguns conceitos que norteiam seu trabalho. Hamblin (1978, p. 20) define treinamento como "qualquer atividade que procura, deliberadamente, melhorar a habilidade de uma pessoa no desempenho de um cargo", seja ele atual ou futuro. O autor conceitua treinamento e desenvolvimento como sendo atividades ligadas à preparação para o cargo; enquanto o treinamento prepara para o cargo atual, o desenvolvimento compreende treinamento para um cargo futuro.

Segundo Hamblin (1978, p. 27), a avaliação tem a finalidade de melhorar o treinamento, sendo, portanto, um auxiliar dele. Para o autor, um programa de treinamento bem avaliado é aquele em que falhas e desvios são corrigidos e os sucessos são identificados e reforçados.

Uma das dificuldades apontadas por Hamblin (1978) na avaliação do treinamento é separar os efeitos do treinamento dos efeitos de outras ações. O autor propõe que o treinamento não seja tratado como atividade separada, mas como parte integrante de um programa mais amplo. Assim, o treinamento deve compor a avaliação do desempenho global.

Outro ponto ressaltado por Hamblin (1978, p. 22) diz respeito à abrangência da avaliação. Para o autor, a avaliação precisa ser parcial e seletiva, visto que não consegue medir o "valor total” (grifo do autor) de um programa em termos sociais e financeiros. Quanto à avaliação em termos monetários, o autor faz a ressalva de que a avaliação não deve ser realizada exclusivamente visando à eficiência de lucros e custos. Há organizações que não têm objetivos exclusivamente financeiros, entretanto, mesmo as que visam ao lucro têm objetivos secundários não financeiros, podendo o treinamento ser o meio para chegar-se a esse fim, "a avaliação é, pois, a arte do possível” (HAMBLIN, 1978, p. 25). Segundo o autor, para aperfeiçoar a forma de avaliar treinamento, três premissas devem ser observadas:

a) escolher os objetivos de treinamento apropriados, que constituam os critérios usados para avaliá-lo;

b) melhorar os métodos de coleta das informações usadas na avaliação do treinamento; 
c) definir como a avaliação pode aperfeiçoar o treinamento.

Para o autor, essas premissas estão interligadas, pois os critérios de avaliação escolhidos devem possibilitar a coleta de informações sobre eles, bem como possibilitar o aperfeiçoamento do treinamento.

Um apontamento que perpassa todo o relato da metodologia é sua viabilidade ou utilidade. Segundo Hamblin (1978), os níveis de avaliação são aplicados quando há utilidade, ou seja, quando se fazem necessários. Por exemplo, há treinamentos que visam apenas à obtenção de aprendizado, visto que as pessoas estão sendo treinadas para um cargo que ainda não assumiram; ou ainda há casos em que verificar se os treinandos aplicaram o que aprenderam no cargo incorre em despesas e escala de tempo tão vastas que os tornam inviáveis.

Segundo Hamblin (1978), para avaliar um treinamento, é necessário colher informações sobre as mudanças provocadas por ele, refletindo sobre os tipos de efeitos gerados e em qual sequência ocorrem. O autor propõe sua metodologia para avaliação de treinamento baseada em cinco níveis de efeito: reações, aprendizado, comportamento no cargo, organização e valor final. Para o autor há uma corrente de causa e efeito que liga os níveis de efeito do treinamento, desse modo, o treinamento provoca reações, as quais provocam aprendizado que, por conseguinte, provocam mudanças de comportamento no cargo e assim sucessivamente até chegarmos ao último nível. Essa corrente poderá se partir em qualquer de seus elos, sendo tarefa do avaliador identificar onde e como a quebra ocorreu, sugerindo formas de melhoria. A seguir são descritos os níveis da metodologia de avaliação de treinamento proposta Hamblin (1978, passim).

Nível 1: Reações - As reações são o primeiro efeito do treinamento e consistem em uma resposta dada pelo treinando em relação ao treinador, ao tema abordado, ao método e ao cenário do treinamento. Essas reações são afetadas pelo estado de ânimo e humor do treinando e de seu conhecimento e atitude em relação aos componentes internos (treinador, treinandos e conteúdo) e externos (acontecimentos anteriores ou posteriores, tais como refeições servidas) ao treinamento. O autor ressalta ainda que as reações são complexas e mutáveis. Dado esse contexto, propõe que é necessário determinar os objetivos de reações, ou seja, quais aspectos das reações serão investigados, pois, caso os objetivos não sejam estabelecidos, corre-se o risco de obter dados irrelevantes. 
Nível 2: Aprendizado - Os programas de treinamento, geralmente, são realizados com o propósito de possibilitar às pessoas aprender, ou seja, “adquirir a capacidade de comportar-se de maneiras novas”. Entretanto, o autor aponta que em um treinamento as pessoas podem adquirir diversos tipos de conhecimento, inclusive os não previstos, por isso é importante o estabelecimento dos objetivos de aprendizagem para que seja possível direcionar a coleta de informações sobre quantidade e tipo de conhecimentos adquiridos pelos treinandos. Ele ressalta ainda que pode ser tentador passar direto do treinamento para a avaliação de aprendizado, mas lembra que o aprendizado depende das reações, pois um treinando que tenha reagido de forma negativa ao treinamento, não aprenderá de forma adequada, por conseguinte ficará difícil para o avaliador identificar se a falha do treinamento se deve à falta de aptidão ou de treinamento anterior do treinando ou a sua reação anterior. Apesar de a reação favorável ao treinamento ser condição necessária ao aprendizado, não é suficiente para que ele ocorra.

Nível 3: Comportamento no Cargo - O autor conceitua como sendo o nível em que se verifica se os treinandos aplicaram o que aprenderam no exercício do cargo, ou seja, se transferiram os conhecimentos adquiridos a seu trabalho. $\mathrm{O}$ autor ressalta que o treinando pode ter aprendido corretamente, mas não aplicar o que aprendeu. Nessa situação, é importante que os níveis anteriores tenham sido avaliados para identificar se a falha se deu nesse nível ou se decorre de incongruências em níveis anteriores.

Nível 4: Organização - Nessa etapa é identificado se os efeitos da mudança de comportamento no trabalho originaram mudanças no funcionamento da empresa, a isso o autor denomina efeitos de organização. Logo, é preciso estabelecer objetivos de organização para selecionar as informações necessárias para avaliação a esse nível.

Nível 5: Valor Final - Esta fase relaciona a avaliação aos critérios utilizados pela organização para avaliar sua eficácia e sucesso, os quais muitas vezes traduzem-se em termos financeiros, por isso, o autor aponta que, nesse caso, pode-se chamar esse nível de “eficiência de custo" (grifo do autor). Contudo, o autor destaca que há organizações em que outros critérios poderão ter maior importância, tais como hospitais, escolas, forças policiais, prisões, exércitos entre outros, nas quais há alguma medição em termos de bem humano ao invés de critérios estritamente financeiros: mesmo organizações com finalidade comercial podem realizar 
atividades que não tenham finalidade financeira e, nesses casos, a avaliação em termos de eficiência de lucro ou de custos pode ser errônea. O autor observa ainda que o treinamento pode ser, em parte, definido em termos de metas pessoais do próprio treinando, o qual pode ter objetivos próprios sobre o treinamento, como melhor recompensa financeira, aumento de autoestima, melhores oportunidades na empresa etc.

Hamblin (1978) aponta que a avaliação nos níveis 4 e 5, e em parte no nível 3, é muito difícil de realizar pela falta de informações relativas às demais atividades da organização, já que, ao estabelecer objetivos a esses níveis, estabelecem-se objetivos organizacionais e, desse modo, avalia-se a organização como um todo. Todavia, relata que é possível realizar avaliação nessas fases sem envolver-se nas esferas globais da organização, quando os objetivos a esses níveis são definidos com precisão tal que se verifica claramente a influência do treinamento no resultado, sendo justificáveis os demais fatores não relacionados ao treinamento. Quando se deseja avaliar em termos econômicos, o autor propõe que os objetivos sejam definidos em termos métricos, tais como redução de refugo em 5\%, essa medida é passível de ser transformada em termos monetários.

Relativamente à avaliação de treinamentos, Hamblin (1978) pondera que deve haver equilíbrio no estabelecimento de um modelo de avaliação, para evitar que a avaliação se torne um fim em si e seja excessiva, tolhendo a experimentação e a mudança. Para o autor,

\footnotetext{
"O problema consiste, pois, em encontrar a quantidade certa de avaliação para adaptar-se à situação: o suficiente para tirar o treinamento de seu isolamento e construir elos eficazes entre treinamento e outras atividades, mas não o bastante para colocar o treinamento numa camisa-deforça, inibindo sua liberdade de ação e, também, imaginar processos de avaliação que sejam em si flexíveis e reativos à mudança.” (HAMBLIN, 1978, p. 47).
}

O modelo fornece um esquema de como avaliar os treinamentos, entretanto, adaptações são necessárias para aplicação em cada organização, por isso, torna-se necessária a formulação de uma estratégia de avaliação, a qual definirá a maneira de avaliar, levando em conta fatores como recursos disponíveis, aceitabilidade dos tipos de avaliação pelos treinandos, treinadores e administração, capacidade de estipular objetivos de treinamento avaliáveis etc. (HAMBLIN, 1978). 


\subsubsection{Modelo de Phillips}

Para Jack Phillips, apenas por meio da adoção de um processo de mensuração e avaliação estruturado e padronizado é possível saber de que forma os treinamentos impactam os indicadores de negócio da organização (MARINO, 2009). Dessa forma, o autor propõe um modelo de mensuração que deve ser acompanhado, sobretudo, por uma postura da área de Gestão de Pessoas voltada para a avaliação e mensuração de resultados em treinamento.

O propósito de Phillips (1991, p. xi), com sua obra Handbook of Training Evaluation and Measurement Methods, é oferecer ao leitor um processo sistemático de avaliação de treinamento de um ponto de vista prático, pois, em sua opinião, os demais livros abordam muito a teoria, tendo pouco conteúdo prático, ou representam uma coleção de artigos.

O modelo proposto por Phillips (1991) passa pela mudança de atitude da organização em relação à avaliação de resultados em treinamento. A área de treinamento deve ser orientada por resultados e essa postura é parte importante da estratégia de avaliação. Sua proposta perpassa todas as fases do treinamento desde a concepção até a comunicação de seus resultados. Um dos pontos que o diferencia dos demais autores é que introduz o cálculo do retorno do investimento em treinamento em seu modelo.

A abordagem de orientação por resultados é uma filosofia de treinamento que enfatiza resultados e é caracterizada pelos seguintes pilares: a) os programas de treinamento não são comumente empreendidos sem que resultados tangíveis possam ser obtidos; b) no delineamento de um programa, é incluído um método para mensurar seus resultados como parte integrante do processo, equiparando a mensuração em nível de importância a outros fatores, como conteúdo, objetivos, instrutor etc.; c) deve ser exigida de cada um dos membros da área de treinamento a mensuração de seus esforços, e cada um deveria participar da mensuração de resultados de seus programas; d) a gestão deve ser envolvida em todas as fases do processo de treinamento, pois isso garantirá o sucesso do programa e facilitará a divulgação de seus resultados ao corpo diretivo; e) o comprometimento e suporte da gestão é crítico para alocação de recursos à área de treinamento e parte fundamental da filosofia de treinamento orientado por resultados (PHILLIPS, 1991). 
Na Ilustração 3, é apresentado o modelo de avaliação de treinamento orientado por resultados, o qual é composto por 18 etapas, 11 das quais envolvem diretamente avaliação.

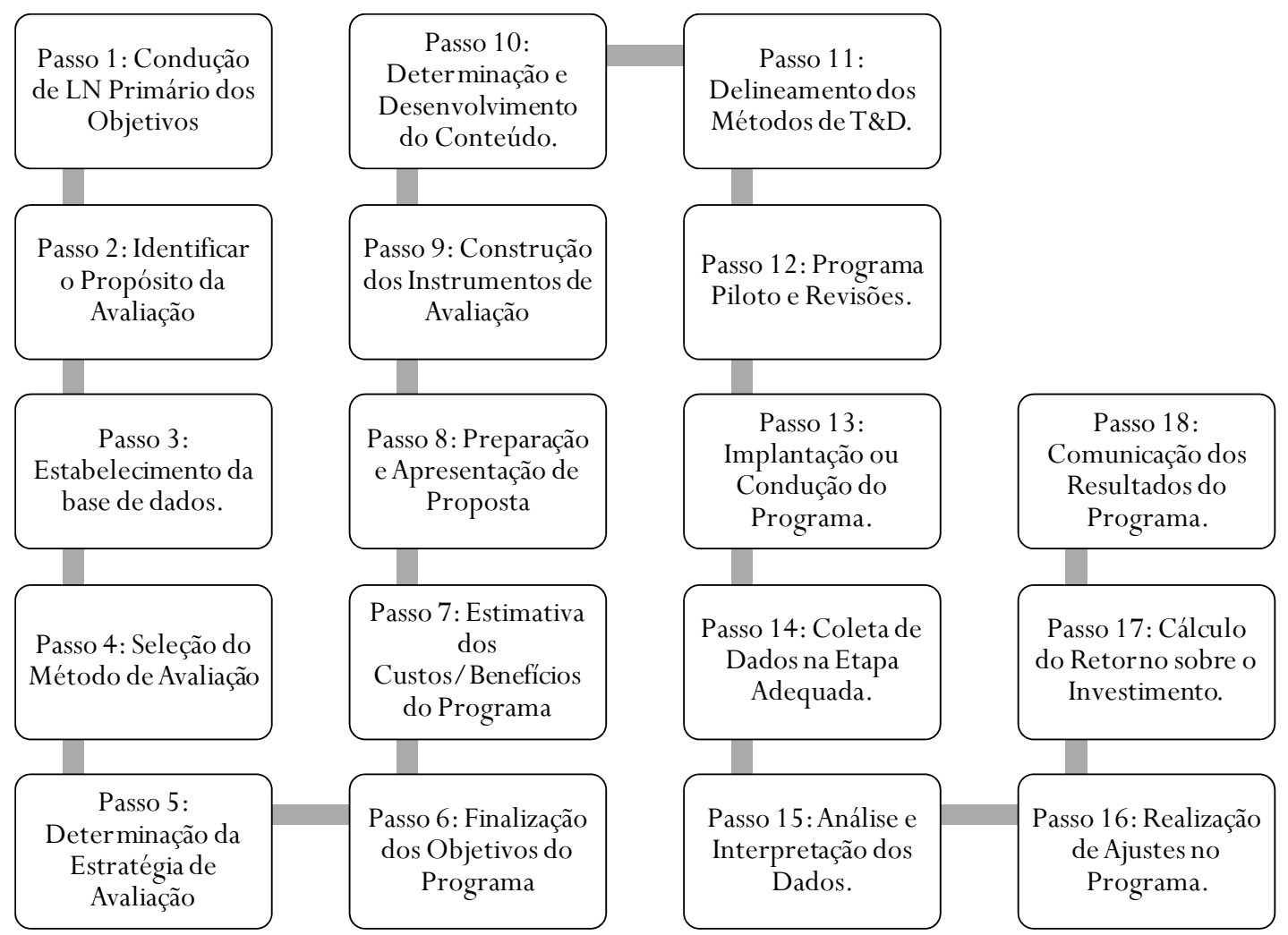

Ilustração 3 - Modelo de avaliação de treinamento orientado por resultados

O modelo apresentado, conforme apontado por Phillips (1991), é um processo sistemático com várias partes importantes, sendo as avaliações bem-sucedidas planejadas no início do processo de levantamento de necessidades. Os esforços de avaliação devem ocorrer antes, durante e após a realização do programa. A seguir é descrito cada um dos passos do modelo, conforme concebido por Phillips (1991, passim).

Passo 1: Condução de levantamento de necessidades e desenvolvimento primário dos objetivos - Nesta etapa, determina-se a necessidade de treinamento, que é disparada por deficiência de desempenho, observação de um problema, necessidade de melhoria na produtividade, necessidade de atendimento a regulação governamental etc. A análise dessa necessidade é realizada por meio da condução de entrevistas com potenciais treinandos, seus gestores ou pela aplicação de questionários. É necessário determinar se há outras variáveis afetando o desempenho para verificar se as necessidades serão solucionadas por treinamento. O resultado do levantamento é uma lista com as descrições das deficiências de desempenho. 
A segunda parte deste passo envolve a tentativa de propor objetivos para o treinamento, ou seja, o que deve ser atingido com o programa.

Passo 2: Identificação do propósito da avaliação - Podem existir diferentes motivos para realizar-se a avaliação, contudo, é preciso determinar sua finalidade, pois ela afetará a escolha do método de avaliação e a coleta de informações.

Passo 3: Estabelecimento da base de dados - Dados existem em diferentes formas e sua escolha responde à questão básica sobre o que avaliar, refletindo a informação mais importante e representando a deficiência de desempenho. O ideal é que os dados sejam coletados por um período de tempo adequado para uma comparação realística. Pode ocorrer de não haver dados disponíveis para verificar o alcance dos objetivos traçados, nesse caso, é importante constatar a real necessidade de realizar o treinamento e, em caso afirmativo, tornase necessário o desenvolvimento da base de dados, mesmo que por um período determinado.

Passo 4: Seleção do método de avaliação - Esta fase responde à questão como avaliar. Apesar de aparentemente ilógico, a escolha do método deve preceder a finalização dos objetivos do programa, pois o método de avaliação pode influenciar o estabelecimento de objetivos. A escolha do método deve considerar o tipo de dado, o ambiente de aprendizagem, os treinandos e o conteúdo do programa.

Passo 5: Determinação da estratégia de avaliação - Para planejar o processo de avaliação, é importante analisar as seguintes questões: quem, onde e quando. Quem corresponde a identificar as pessoas envolvidas no processo de avaliação e suas respectivas responsabilidades. Onde equivale ao local em que será realizada a avaliação (sala de aula ou local de trabalho). Por fim, quando determina a ocasião em que a avaliação ocorrerá (durante o curso, ao seu final, na execução das atividades de trabalho etc.).

Passo 6: Finalização dos objetivos do programa - Os objetivos do programa fornecem a direção para os desenvolvedores do treinamento, treinandos e gestores sobre como o treinamento deve ser conduzido. Eles devem ser desafiadores, precisos, mensuráveis, realizáveis e compreendidos por todos os envolvidos; para alcance deste último critério, é importante que o processo de estabelecimento de objetivos seja participativo. Como mencionado anteriormente, é recomendada a finalização dos objetivos após a definição da 
abordagem de avaliação. O ideal é que os objetivos estejam relacionados à base de dados que será coletada.

Passo 7: Estimativa dos custos/benefícios do programa - Antes de prosseguir com o desenvolvimento do programa, a apuração dos custos e a comparação com seu benefício tornam-se necessárias, principalmente quando há alguma dúvida relativa a custo para implantação do treinamento. Nesta fase, realiza-se uma previsão do retorno sobre o investimento.

Passo 8: Preparação e apresentação de proposta - Antes da implantação do programa, é recomendada a apresentação de uma proposta formal à direção.

Passo 9: Construção dos instrumentos de avaliação - No contexto de avaliação, os instrumentos são as ferramentas de coleta de dados - questionários, exames, levantamento de atitudes, entrevistas, grupos de foco, simulação de trabalho etc. É importante que o instrumento seja trabalhado após o desenvolvimento do programa para evitar que alguma informação adicional não seja contemplada.

Passo 10: Determinação e desenvolvimento do conteúdo - É a etapa que provavelmente consuma maior tempo e constitui-se pela transformação dos objetivos em princípios, fatos e habilidades que os participantes precisam aprender.

Passo 11: Delineamento ou seleção dos métodos de Treinamento e Desenvolvimento - Há diversos métodos de treinamento, tais como conferência, estudo de caso, workshop, simulação etc. A escolha dependerá de fatores como orçamento, recursos disponíveis, objetivos do programa, tempo necessário, habilidade dos participantes, habilidade dos desenvolvedores do programa, habilidade dos instrutores e local do treinamento.

Passo 12: Programa piloto e revisões - É recomendável realizar uma turma piloto quando o programa for aplicado a muitos participantes. Esta etapa dá a oportunidade ao desenvolvedor do treinamento de testar alguns métodos de avaliação e, consequentemente, a eficácia do programa, identificando suas forças e fraquezas. Contudo, a escolha do público que participará do piloto deve ser realizada com cuidado, estabelecendo regras básicas durante o piloto, desenvolvendo a coesão do grupo e observando os sinais emitidos pelo programa. 
Passo 13: Implantação ou condução do programa - Esta fase precisa de poucos comentários, exceto pelo fato de ser recomendável que os participantes sejam avisados sobre os resultados do programa. A comunicação das expectativas pode influenciar o resultado alcançado.

Passo 14: Coleta de dados na etapa adequada - A coleta de dados deve ocorrer no tempo apropriado. Sua agenda deve ser seguida nesta etapa de execução da avaliação, pois a falha na coleta nos intervalos adequados pode pôr abaixo todo o plano de avaliação. Isso é comum ocorrer, principalmente quando existem resultados positivos nos estágios iniciais da avaliação, tais como reação, aprendizagem e aplicação no trabalho, havendo a tendência de não se executarem as demais etapas. Logo, toda a avaliação estará incompleta.

Passo 15: Análise e interpretação dos dados - Nesta fase as respostas aos questionários são tabuladas e preparadas para apresentação. Na análise dos dados é utilizada a estatística, por meio de três grupos de análise estatística: 1) medidas de tendência central, que incluem média, moda e mediana, utilizadas para analisar os resultados dos participantes como um grupo; 2) medidas de dispersão, caracterizadas pelo uso de desvios padrão e análise de variância, que calculam como o desempenho dos participantes variou, comparando-os; 3) medidas de associação, que usam correlação com o propósito de verificar se há relação entre elementos do programa. Nesta etapa, ainda é calculados o valor monetário dos resultados alcançados, sendo adequado descrever os fatores considerados de forma detalhada no relatório. A análise de dados precisa ser realizada em diferentes estágios, para que ações de melhoria do treinamento sejam tomadas no tempo adequado.

Passo 16: Realização de ajustes no programa - Os resultados apurados na etapa anterior podem indicar a necessidade de mudanças no programa. Caso não tenha produzido resultados adequados, o programa pode ser ajustado ou até cancelado. Esses resultados precisam ser investigados para que as causas da falha sejam determinadas.

Passo 17: Cálculo do Retorno sobre o Investimento - Procede-se ao cálculo do Retorno sobre o Investimento (ROI) para os programas em que foi planejada a apuração de resultados econômicos. Por meio desse indicador, o resultado do programa pode ser comparado à meta, estabelecida com base nas regras da organização sobre despesas de capital ou nas expectativas da cúpula da organização em relação ao programa. A fórmula para seu cálculo é: 
ROI $=\quad$ Valor Monetário dos Resultados

Custos do Programa

Passo 18: Comunicação dos resultados do programa - A comunicação dos resultados do programa é importante, principalmente para os seguintes grupos: a) a equipe de treinamento, que precisa da informação para melhorar o programa; b) a direção, a qual precisa da informação para tomar decisões sobre o futuro do programa; c) participantes, os quais utilizam a informação para verificar seu desempenho comparado aos outros. A informação deve ser apresentada de forma imparcial.

Os passos descritos acima compõem o modelo de avaliação orientado para resultados e são necessários para que os programas de treinamento tenham foco em resultados (PHILLIPS, 1991, p. 78).

Na visão de Allen e McGee (2004), a mensuração do ROI em programas de treinamento, chamado algumas vezes de nível 5 de avaliação, envolve o exame da razão entre custos e benefícios. Para os autores, muitas empresas desejam utilizar o ROI, entretanto, o acham complicado ou dispendioso de calcular. Apesar das dificuldades, algumas organizações conseguem implantá-lo, como é o caso da Universidade Motorola, que tem como foco de avaliação o valor de seu capital humano, calculado por meio do valor gerado por sanar lacunas de desempenho, determinando o ROI do investimento em melhoria do capital humano.

\subsubsection{Modelo MAIS}

O modelo de avaliação de treinamento intitulado MAIS - Modelo de Avaliação Integrado e Somativo - foi elaborado por Borges-Andrade que o divulgou por meio de um artigo publicado em 1982. Segundo Borges-Andrade (2006, p. 344), “a avaliação somativa se refere ao processo de planejar, obter e analisar informações visando fornecer subsídios úteis para decidir sobre a adoção ou rejeição de um programa ou evento [...]” e difere da avaliação formativa, pois esta última tem como foco de avaliação o sistema instrucional. 
Conforme Borges-Andrade (2006, p. 346), “o MAIS é um modelo genérico” que se caracteriza pela descrição de conjunto de variáveis relacionadas aos processos de treinamento (PILATI, 2004 apud BORGES-ANDRADE, 2006, p. 346). Ainda segundo esse autor, o modelo genérico fornece as bases para a condução de pesquisas e a construção de modelos específicos que procuram testar relações entre um conjunto determinado de variáveis e alguns resultados de treinamento no nível individual.

O MAIS é formado por cinco componentes - insumos, procedimentos, processos, resultados e ambiente -, o último dos quais subdivide-se em quatro dimensões: necessidades, suporte, disseminação e efeitos em longo prazo. O componente ambiente é o sistema maior, que abarca os outros quatro componentes, os quais formam o centro do sistema de treinamento (BORGES-ANDRADE, 2006, passim).

Insumos: componente que trata dos aspectos precedentes à ação de treinamento e engloba os estados comportamentais e cognitivos e os fatores sociais e físicos, os quais podem afetar o treinamento ou seus resultados. Ao conhecer os insumos e seus impactos, o profissional de treinamento pode selecionar programas que contribuirão para redução das necessidades de treinamento. São exemplos de insumos nível de escolaridade, cargo ocupado e idade dos participantes, comprometimento com a carreira e com a organização, crenças individuais sobre o sistema de treinamento, domínio de competências que são pré-requisitos para o treinamento, entre outros.

Procedimentos: são as operações que viabilizarão o alcance dos resultados instrucionais ou a promoção da aprendizagem e tratam principalmente das estratégias instrucionais. A avaliação nesse nível traz informações importantes ao profissional de treinamento sobre características operacionais do programa, auxiliando-o a determinar a relevância dos procedimentos empregados. São exemplos de procedimentos a pré-apresentação dos objetivos aos participantes; a determinação de objetivos; a escolha de métodos de ensino, tais como aula expositiva, exercícios práticos e discussão de casos; a adequação dos materiais de treinamento etc.

Processos: referem-se a aspectos comportamentais do participante em relação aos procedimentos empregados. Assim, à medida que os procedimentos são aplicados, o participante começa a manifestar esses aspectos, os quais representam parte dos resultados de 
aprendizagem. São exemplos de variáveis de processos os resultados de exercícios práticos, a quantidade de tempo individual dedicada ao estudo, o número de revisões realizada pelo participante na execução de uma tarefa de aprendizagem entre outras.

Resultados: este componente é o principal foco de interesse de avaliação. Trata do desempenho imediato final e consequências do programa, reunindo variáveis relativas a desempenho dos participantes. Entretanto, o autor destaca que as variáveis de resultado diferem das de processo, pois são variáveis finais, ou seja, de consequência de todos os outros componentes do modelo. São exemplos de variáveis de resultado as aquisições de competências indicadas ou não nos objetivos, a satisfação do participante com o programa, com o desempenho do instrutor etc.

Ambiente: diz respeito a "todas as condições, atividades e eventos na sociedade, na comunidade, na organização ou na escola” (BORGES-ANDRADE, 2006, p. 350) que possam interferir ou ter relação com o treinamento, representando seu contexto. Esse componente é representado pelos seguintes fatores: avaliação de necessidades, disseminação, suporte e efeitos de longo prazo. A primeira trata da identificação das lacunas entre desempenho esperado e realizado e as alternativas para solucionar esse desvio. O suporte é um conjunto de variáveis que ocorre na comunidade, na organização, na escola ou no lar do participante e que influencia todos os componentes do treinamento, seu efeito pode ser destruidor ou contributivo ao treinamento. A disseminação refere-se à forma como as informações sobre o programa são divulgadas à organização e à comunidade, buscando facilitar sua aceitação. Por fim, os efeitos de longo prazo são as consequências do programa, determinadas em termos de medidas sobre o alcance das metas e devem incluir os efeitos esperados e os inesperados.

A partir da exposição das variáveis do modelo, o autor propõe uma forma de ilustrá-lo, demonstrando como as variáveis se relacionam (Ilustração 4). 


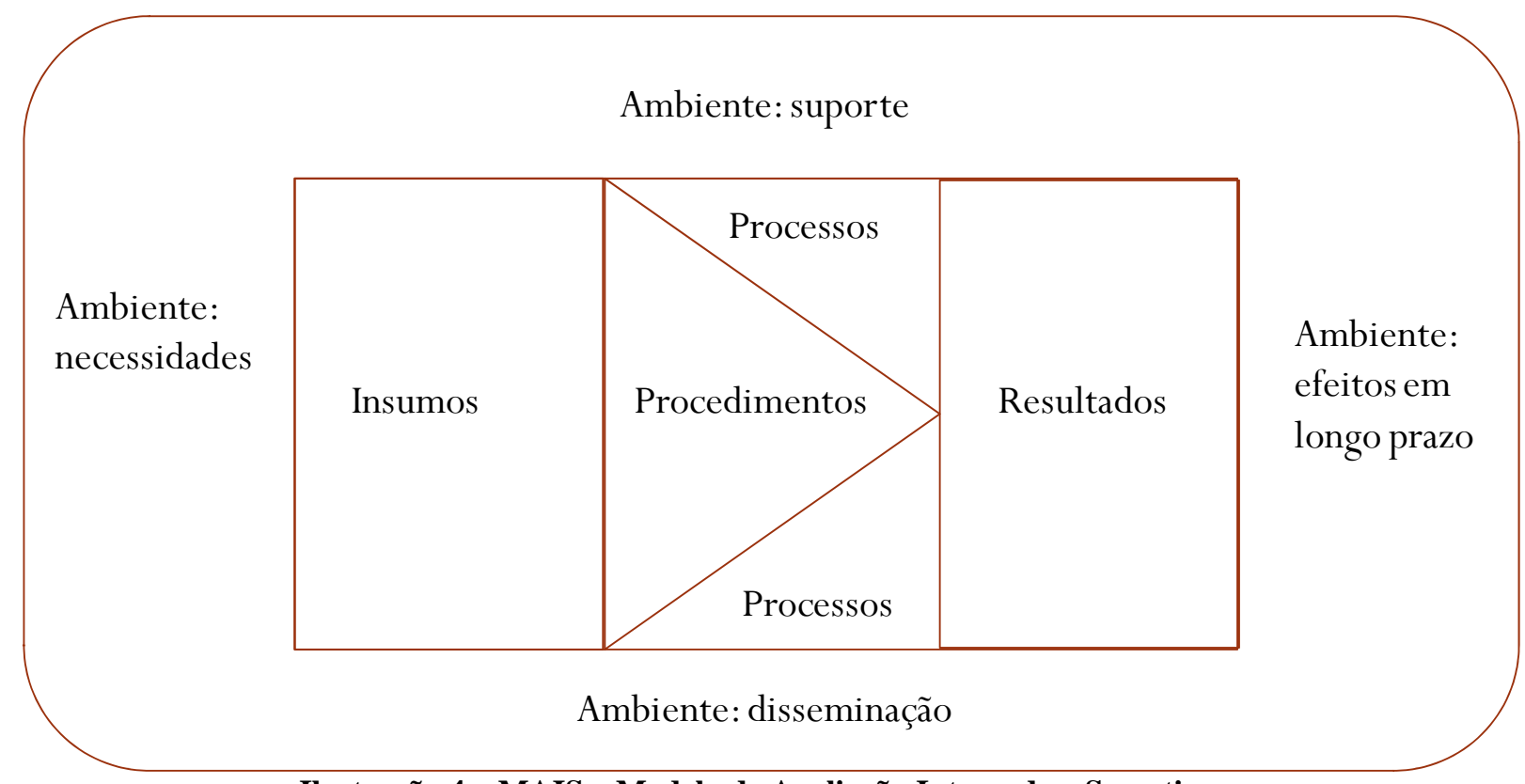

Ilustração 4 - MAIS - Modelo de Avaliação Integrado e Somativo

Fonte: Adaptado de Borges-Andrade (2006, p. 344).

\subsubsection{Modelo de Fitz-enz}

Para Fitz-enz (1995), primeiramente é necessário que o objetivo instrucional estabeleça o que se quer que o treinando seja capaz de fazer, em quais condições ele terá de fazer isso e quão bem ele deve fazê-lo. Se os programas são definidos a partir desses norteadores, será possível encontrar na organização as habilidades sendo aplicadas e o impacto por elas gerado.

Segundo o autor, há três medidas básicas em treinamento: custos, mudança e impacto. Os custos referem-se ao gasto por unidade de treinamento realizada. Já a mudança trata do ganho de habilidade ou conhecimento ou da mudança positiva de atitudes pelo treinando. Por fim o impacto mostra os resultados do uso, pelos treinandos, das novas habilidades, conhecimentos ou atitudes, os quais são medidos em termos monetários. A seguir são abordadas essas medidas (FITZ-ENZ, 1995, passim).

A variável custo é mais fácil de ser medida, principalmente se há um sistema contábil sem falhas. O cálculo consiste em somar todos os gastos realizados e dividi-lo pelo total de pessoas treinadas. Os gastos são formados por custos diretos e indiretos, sendo considerados diretos os que se referem à remuneração dos consultores, ao aluguel de sala, aos recursos, à alimentação, ao transporte e à hospedagem. Quanto aos custos indiretos, os mais comuns são 
salários e benefícios dos treinandos, salários e benefícios dos treinadores e custo fixo da área de treinamento. Dessa forma, o cálculo é demonstrado pela fórmula a seguir:

$\mathrm{C} / \mathrm{T}=\frac{\mathrm{CC}+\mathrm{AS}+\mathrm{R}+\mathrm{A}+\mathrm{T}+\mathrm{H}+\mathrm{SP}+\mathrm{ST}+\mathrm{CF}}{\mathrm{NP}}$

$\mathrm{C} / \mathrm{T}=$ custo por treinando

$\mathrm{CC}=$ remuneração dos consultores

AS = aluguel de sala

$\mathrm{R}=$ recursos (livros, papéis, canetas, apostilas etc.)

$\mathrm{A}=$ alimentação

$\mathrm{T}=$ transporte

$\mathrm{H}=$ hospedagem (para treinandos e treinadores)

$\mathrm{SP}$ = salário e benefícios dos participantes

ST = salário e benefício dos treinadores

$\mathrm{CF}=$ custos fixos da área de treinamento (local e equipamentos)

$\mathrm{NP}=$ número de pessoas treinadas

Fitz-enz aponta ainda que um relatório básico sobre gastos com treinamento inclui variáveis como total de custos do treinamento, total de horas de treinamento, total de pessoas treinadas, custo por participante e custo por participante/hora. O custo por participante/hora é mais interessante que custo por participante, pois dá um denominador comum de comparação entre programas de diferentes durações. O cálculo é demonstrado em seguida:

$\mathrm{C} / \mathrm{PH}=\frac{\mathrm{TC}}{\mathrm{TP} \times \mathrm{TH}}$

$\mathrm{C} / \mathrm{PH}=$ custo por participante/hora

$\mathrm{TC}=$ total de custos do treinamento

$\mathrm{TP}=$ total de pessoas treinadas

$\mathrm{TH}=$ total de horas do treinamento

Pela obtenção dessas medidas, conforme aponta o autor, é possível fazer comparações, tais como gastos por grupos, por departamentos, por grupos e cargos. É possível comparar custos 
de programas, dividindo-os entre fontes internas e externas, nesse sentido, o autor ressalta que, quase sempre, realizar um programa internamente é mais barato que realizá-lo externamente, entretanto, a qualidade pode não ser a mesma, pois o instrutor interno pode não dominar o tema, tal qual um instrutor externo.

Fitz-enz sugere que a apuração dos custos seja realizada por programa e dividida nos processos e fases de um treinamento, assim é possível realizar a comparação de custos quando da elaboração do conjunto final de matrizes (Ilustração 5). A partir dessa apuração, é possível identificar os programas mais eficientes, porém isso não quer dizer que sejam os mais efetivos, e realizar análises comparativas para identificar melhorias.

\begin{tabular}{|l|l|l|l|l|l|}
\hline \multirow{2}{*}{} & \multicolumn{5}{|c|}{ Gastos em valores monetários } \\
\cline { 2 - 6 } & Pessoas & Materiais & Equipamentos & Facilidades & Total \\
\hline Diagnóstico & & & & & \\
\hline Desenho & & & & & \\
\hline Desenvolvimento & & & & & \\
\hline Implantação & & & & & \\
\hline Avaliação & & & & & \\
\hline Total & & & & & \\
\hline
\end{tabular}

Ilustração 5 - Análise de gastos com treinamento

Fonte: Adaptado de Fitz-enz (1995, p. 231).

A variável mudança é outro fator a ser analisado na avaliação de treinamentos. Conforme aponta o autor, a mudança pode ser medida no nível individual em termos de melhora de conhecimentos, habilidades e atitudes, realizando-se comparações entre grupos.

A mudança de conhecimento pode ser obtida, segundo o autor, por meio da aplicação de pré e pós-teste. Este último pode ser obtido após cada aula ou após o término do programa. Essa é uma medida que não serve apenas para demonstrar se os treinandos aprenderam o que se desejava que aprendessem, mas principalmente identificar o que não foi aprendido, pois assim é possível rever os resultados em sala e reforçar o aprendizado. O cálculo se dá por meio da seguinte fórmula: 
$\mathrm{MC}=\frac{\mathrm{CP}}{\mathrm{CA}}$

$\mathrm{MC}=$ mudança de conhecimento

$\mathrm{CP}=$ conhecimento posterior ao treinamento

$\mathrm{CA}=$ conhecimento anterior ao treinamento

A mudança de habilidades pode ser obtida, como descreve o autor, por intermédio de questionários, entrevistas, demonstrações ou observações do instrutor, subordinado, pares ou superiores. Para obter um valor, é necessário ser específico na descrição das habilidades ou comportamentos que serão avaliados, não se pode colocar a descrição em exclamações vagas. A fórmula para o calculo é apresentada a seguir:

$\mathrm{MH}=\frac{\mathrm{HP}}{\mathrm{HA}}$

$\mathrm{MH}=$ mudança de habilidade

HA = nível de habilidade existente antes do treinamento (medido por meio de incidentes críticos de relacionamento interpessoal ou outro fenômeno observável).

HP = habilidade demonstrada após o treinamento (por meio dos mesmos critérios utilizados acima).

A mudança de atitude também pode ser medida utilizando-se pré e pós-teste, entretanto, é recomendado o uso de um instrumento desenhado e validado. Como as atitudes são influenciadas pelo ambiente, uma análise longitudinal deveria ser realizada no pós-teste, assim seria possível verificar se as atitudes pós-treinamento foram influenciadas quando do retorno do treinando ao ambiente de trabalho. O autor recomenda que seja aplicado um teste seis meses após o treinamento. Caso seja verificado que o ambiente não deu suporte à aplicação das novas atitudes, não faz sentido continuar treinando. O cálculo da mudança de atitude é demonstrado na sequência:

$\mathrm{MA}=\frac{\mathrm{AP}}{\mathrm{AA}}$ 
MA = mudança de atitude

$\mathrm{AP}=$ atitude pós-treinamento

$\mathrm{AA}=$ atitude antes do treinamento

Por fim, segundo Fitz-enz, há a mudança de desempenho no trabalho, medida pelo sistema de avaliação de desempenho da organização. Neste ponto, deve haver cautela para que não haja exagero na discussão da mudança no desempenho individual. A mudança de desempenho pode ser obtida por meio do seguinte cálculo:

$\mathrm{MD}=\frac{\mathrm{DP}}{\mathrm{DA}}$

$\mathrm{MD}=$ mudança de desempenho

$\mathrm{DP}=$ medidas de desempenho realizadas pelo menos 90 dias depois do treinamento

$\mathrm{DA}=$ medidas de desempenho medidas antes do treinamento

A variável impacto, na visão de Fitz-enz (1995), é decorrente da variável mudança. O impacto é obtido por meio da medição do desempenho no trabalho. Um exemplo dado pelo autor refere-se a um operador de máquina de corte que antes do treinamento cortava 80 unidades por hora, e depois passa a cortar 100; considerando que não houve mudança no número de rejeitos, o impacto foi de 25\% de redução de custos de sua produção. Ele cita ainda que a mensuração é relativamente simples, exceto quanto se utiliza um grupo de controle para comparação. Nesse caso, há necessidade de uso da estatística, todavia os fatores-chave são disciplina para certificar todos os detalhes necessários e acuracidade dos dados. A partir daí, basta fazer a apuração de todos os custos e confrontá-los com as receitas.

Após a exposição das medidas de avaliação - custo, mudança e impacto -, Fitz-enz (1995) aponta que há diferentes níveis de sofisticação da avaliação de treinamento e que há cinco níveis de avaliação. O primeiro deles é o mais aplicado pelas organizações e trata da reação do participante ao treinamento, o autor comenta que o dado autorrelatado é muito fraco, porém é o método mais comum. O segundo nível, também muito usado, é o teste de avaliação de conhecimento que mensura o quanto foi aprendido pelo treinando. Geralmente, não é realizado um pré-teste o que dificulta identificar se houve ampliação de conhecimento com a participação no programa. O terceiro nível avalia o desempenho após a participação no 
programa, mas o autor aponta também que ainda não há dados anteriores ao treinamento para realizar comparações. Já o quarto nível avalia o desempenho antes e depois do programa e inclui a verificação alguns meses depois. Segundo o autor, essa é uma medida forte pela qual se pode inferir relacionamento causal advindo da realização do treinamento. Por último, o quinto nível é o mesmo que o quarto, porém nele se estabelece o grupo de controle para compará-lo com o grupo treinado, por isso o primeiro deve ser muito similar ao segundo, diferenciando-se apenas pela realização do treinamento. Por um lado, caso haja melhora de desempenho do grupo treinado, é razoável afirmar que o treinamento foi a causa da melhora. Por outro lado, há variáveis intervenientes que podem ter influenciado a melhora de desempenho, tais como tempo, qualidade e preço do produto, ação dos competidores, economia etc.. Essas variáveis podem ser identificadas por meio de uma conversa com seu cliente interno, por isso é importante para o treinador estabelecer um relacionamento de parceria com seu cliente.

A partir dos níveis de avaliação e das medidas propostas, Fitz-enz (1995) propõe dois métodos de avaliação de treinamento, ambos compostos por sete etapas, conforme exposto no Quadro 2. 
Quadro 2 - Métodos de avaliação de treinamento

\begin{tabular}{|c|c|}
\hline $1^{\circ}$ Método & $\begin{array}{c}2^{\circ} \text { Método } \\
\text { SIIV - Situação-Intervenção-Impacto-Valor }\end{array}$ \\
\hline 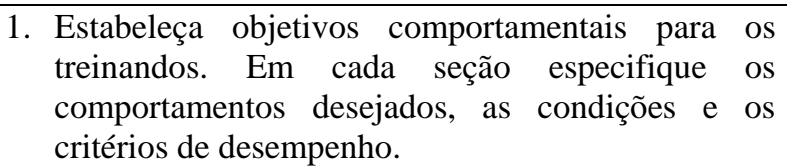 & $\begin{array}{l}\text { 1. Estude os problemas ou oportunidades do negócio, } \\
\text { identificando suas fontes, as forças e os fatores que os } \\
\text { direcionam. }\end{array}$ \\
\hline 2. Desenhe o programa ao encontro dos objetivos. & $\begin{array}{l}\text { 2. Decida se o treinamento pode ou não resolver o } \\
\text { problema ou explorar a oportunidade. }\end{array}$ \\
\hline $\begin{array}{l}\text { 3. Colete dados da base do departamento } \\
\text { treinando. As variáveis mensuradas devem } \\
\text { relacionadas ao treinamento a ser realizado. }\end{array}$ & $\begin{array}{l}\text { 3. Se o treinamento for considerado parte da solução, } \\
\text { desenhe e implante o treinamento em termos de } \\
\text { habilidades que sejam visivelmente ligadas ao } \\
\text { problema do negócio. }\end{array}$ \\
\hline $\begin{array}{l}\text { 4. Conduza o treinamento e realize pré e pós-testes de } \\
\text { habilidades, conhecimentos e atitudes (caso seja } \\
\text { apropriado) em cada evento. }\end{array}$ & $\begin{array}{l}\text { 4. Monitore o desempenho no trabalho após o } \\
\text { treinamento e identifique as variáveis exógenas que } \\
\text { também podem ter afetado os resultados. }\end{array}$ \\
\hline $\begin{array}{l}\text { 5. Aproximadamente de } 60 \text { a } 90 \text { dias após o evento, } \\
\text { colete dados comparáveis à etapa } 3 \text {. }\end{array}$ & $\begin{array}{l}\text { 5. Quando os dados de mudança de desempenho forem } \\
\text { obtidos e for estabelecido que o treinamento foi o } \\
\text { impulsionador dessa mudança, meça o impacto da } \\
\text { mudança antes e depois da intervenção de treinamento. }\end{array}$ \\
\hline $\begin{array}{l}\text { 6. Compare as etapas } 3 \text { e } 5 \text {. Essa etapa avalia o } \\
\text { impacto do treinamento, demonstrando se o } \\
\text { programa gerou diferenças. É importante } \\
\text { identificar variáveis exógenas que tenham afetado } \\
\text { o resultado. }\end{array}$ & $\begin{array}{l}\text { 6. Os efeitos ou impactos podem ser, e frequentemente } \\
\text { são, atribuídos a outros fatores além de treinamento. O } \\
\text { cliente interno é a autoridade para atestar esses efeitos. }\end{array}$ \\
\hline $\begin{array}{l}\text { 7. Aproximadamente seis meses depois do evento, } \\
\text { chame os treinandos novamente para recapitular o } \\
\text { conteúdo. Antes do início da revisão, deve ser } \\
\text { aplicado um teste de retenção que demonstrará o } \\
\text { que foi lembrado. }\end{array}$ & $\begin{array}{l}\text { 7. Calcule o valor do impacto em termos monetários e, } \\
\text { se aplicável, em termos humanos. }\end{array}$ \\
\hline
\end{tabular}

Fonte: Elaborado pela autora a partir da análise do estudo de Fitz-enz (1995).

A princípio os métodos complementam-se, pois o primeiro tem foco em identificar mudanças de comportamento, enquanto o segundo busca identificar o impacto gerado pelo treinamento em termos monetários. As etapas 1 e 2 do segundo método deveriam constar também no primeiro, pois parte de uma análise estratégica da organização e de suas necessidades. Assim, a seguir os objetivos do treinamento deveriam ser estabelecidos em termos de comportamentos esperados para solucionar os problemas do negócio para, por fim, estabelecer a periodicidade da coleta e análise dos dados, sejam eles quantitativos ou qualitativos.

Segundo Fitz-enz, para identificar se o treinamento está trazendo resultados para a organização, é necessário seguir cada etapa do método, ligando um ao outro. Reforça ainda que, na etapa de cálculo do impacto do treinamento em termos monetários, não é necessário empregar análise estatística para identificar o valor proporcionado pelo treinamento e pelas 
variáveis exógenas, pois os gestores não estão interessados e tendem a ver o esforço como desperdício e autosserviço. O cliente interno é capaz de atestar se o treinamento teve efeito positivo.

\subsubsection{Revisão sobre estudos de avaliação de resultados em educação corporativa}

Com o objetivo de trazer os conceitos mais atuais e de verificar o estado da arte sobre o tema, foi realizada pesquisa bibliográfica de artigos e estudos (dissertações e teses). A pesquisa de artigos ocorreu por meio de busca no período entre 2001 e 2010, já a pesquisa em dissertações e teses não teve limitação de período.

\subsubsection{Revisão em artigos}

A pesquisa de artigos foi empreendida a partir das bases Scielo Brasil e ISI Web of Knowledge e também nos periódicos brasileiros classificados na Web Qualis como A1, A2, B1 e B2 que contivesem o termo Administração em seu nome e que fossem eletrônicas, dessa forma, foram selecionados os periódicos: BASE - Revista de Administração e Contabilidade da Unisinos; RAC - Revista de Administração Contemporânea; RAE - Revista de Administração de Empresas; RAUSP - Revista de Administração da Universidade de São Paulo; REAd - Revista Eletrônica de Administração; RAM - Revista de Administração Mackenzie. Foram utilizados como critério de busca os seguintes termos: Avaliação em Educação Corporativa; Avaliação em Universidade Corporativa; Resultado em Educação Corporativa; Resultado em Universidade Corporativa. Esses termos foram pesquisados por meio do campo de busca título, assunto ou palavra-chave. Foram localizados cinco artigos, conforme demonstrado no Quadro 3: 
Quadro 3 - Artigos localizados sobre o tema avaliação de resultados em educação corporativa

\begin{tabular}{|l|l|l|l|}
\hline \multicolumn{1}{|c|}{ Autor } & \multicolumn{1}{|c|}{$\begin{array}{c}\text { Ano de } \\
\text { Publicação }\end{array}$} & \multicolumn{1}{|c|}{ Título } & \multicolumn{1}{c|}{ Periódico } \\
\hline Allen, Mark; Mcgee, Philip & 2004 & $\begin{array}{l}\text { Measurement and evaluation in } \\
\text { corporate universities }\end{array}$ & $\begin{array}{l}\text { New Directions for } \\
\text { Institutional Research }\end{array}$ \\
\hline $\begin{array}{l}\text { Fischer, André Luiz; } \\
\text { Albuquerque, Lindolfo } \\
\text { Galvão de }\end{array}$ & 2005 & $\begin{array}{l}\text { Trends of the human resources } \\
\text { management model in Brazilian } \\
\text { companies: a forecast according to } \\
\text { opinion leaders from the area }\end{array}$ & $\begin{array}{l}\text { International Journal } \\
\text { of Human Resource } \\
\text { Management }\end{array}$ \\
\hline $\begin{array}{l}\text { Lee, Jieun } \\
\text { Morin, Lucie; Renaud, }\end{array}$ & 2010 & $\begin{array}{l}\text { Design of blended training for transfer } \\
\text { into the workplace }\end{array}$ & $\begin{array}{l}\text { British Journal of } \\
\text { Educational } \\
\text { Technology }\end{array}$ \\
\hline $\begin{array}{l}\text { Stéphane } \\
\text { Garbini, Thaís; Abbad, }\end{array}$ & 2005 & $\begin{array}{l}\text { Participation in Corporate University } \\
\text { Training: Its Effect on Individual Job } \\
\text { Performance }\end{array}$ & $\begin{array}{l}\text { Canadian Journal of } \\
\text { Administrative } \\
\text { Sciences }\end{array}$ \\
\hline
\end{tabular}

A partir da leitura e análise dos artigos, constatou-se que o tema avaliação de resultados em gestão de pessoas não era relevante para os profissionais de gestão de pessoas do Brasil, apesar de a literatura internacional apontar como tendência a necessidade de avaliar o impacto dos modelos de gestão adotados no desempenho da organização (FISCHER e ALBUQUERQUE, 2005). Entretanto, esse panorama começa a mudar, conforme apontado por Barreto (2010), sendo a avaliação de resultados em gestão de pessoas apontada como a quarta mais importante tendência em políticas e práticas de gestão de pessoas para 2015. A partir desse contexto verifica-se a importância de estudar o tema.

Os artigos listados no Quadro 3 dividem-se em basicamente três tipos: a) tendências em gestão de pessoas (FISCHER e ALBUQUERQUE, 2005); b) modelo de avaliação de universidade corporativa (ALLEN e MCGEE, 2004); c) avaliação de impacto dos programas de treinamento (LEE, 2010; MORIN e RENAUD, 2004; ZERBINI e ABBAD, 2005).

No artigo elaborado por Allen e McGee (2004), são expostas métricas organizacionais de efetividade da UC e é proposto um modelo de avaliação de UC intitulado Modelo de Produtividade. 
A efetividade da UC, segundo os autores, é avaliada por meio da resposta a duas perguntas: “Por que vocês têm uma UC?” e “O que estamos tentando realizar?”. A primeira procura identificar o motivo pelo qual a UC foi criada, a partir dessa resposta será possível estabelecer os parâmetros que nortearão a avaliação da efetividade da UC. Já a segunda pergunta busca identificar o que medir. Nesse ponto, os autores argumentam que a proximidade de conexão entre objetivos e medidas reforça a noção de que a mensuração é parte do processo de planejamento das atividades educacionais. Alegam ainda que, apesar de as métricas de aprendizagem serem direcionadas aos indivíduos, o objetivo de mensuração para muitas UCs é a organização, por isso, as métricas organizacionais, tais como lucratividade, crescimento, retenção de funcionários, satisfação dos funcionários e produtividade, são mais apropriadas para aferição de seu sucesso.

Estabelecidos os parâmetros para avaliação da UC, parte-se para a execução, que é realizada por meio do Modelo de Produtividade. O foco do modelo é avaliar a UC de forma global, buscando fornecer informações que sirvam de insumo para melhorar a produtividade do ensino e das atividades a ela relacionadas. O modelo de Kirkpatrick e o de Phillips são criticados pelos autores por avaliarem apenas os programas individualmente. Portanto, propõem uma abordagem que intitulam como mais holística, realizando a avaliação da UC como um todo, por meio do estabelecimento de métricas organizacionais de efetividade da UC.

Allen e McGee reconhecem como valor da UC a geração de uma variedade de sistemas de ensino para alcançar os objetivos e resultados predeterminados. Para tanto, baseiam-se nos elementos de um sistema para descrever seu modelo. Para os autores, é possível descrever qualquer sistema a partir de três elementos básicos: recursos + atividades $=$ resultados. $\mathrm{A}$ dinâmica do relacionamento entre esses elementos é o que auxilia no entendimento do Modelo de Produtividade. A efetividade trata do relacionamento entre atividades e resultados, sendo um sistema efetivo quando uma atividade gera resultados predeterminados com alto grau de previsibilidade, ou seja, determina o quão bem algo funciona. Por outro lado, a eficiência trata da dinâmica de relacionamento entre recursos e atividades, respondendo à seguinte questão: “Quanto custa”. O balanceamento ótimo entre recursos e atividades e entre atividades e resultados é o que eles chamam de produtividade. 
Ainda segundo Allen e McGee (2004), para melhorar a produtividade dos sistemas de treinamento há duas dimensões a serem avaliadas. A primeira trata da qualidade do ensino ou desenvolvimento curricular, que geralmente é mensurada por meio da identificação do quão bem os participantes conseguem alcançar os objetivos do programa, para tanto, a forma comumente empregada é o teste. Já a segunda trata da quantidade do ensino ou estratégia instrucional, definida pelos autores como a escolha dos meios mais eficientes pelos quais o currículo possa ser ensinado, dessa maneira, os critérios comumente utilizados para escolha são dinheiro, tempo, apoio instrucional e equipamentos necessários.

Conforme apontado pelos autores, o Modelo de Produtividade pode ser utilizado juntamente com os quatro níveis de avaliação de Kirkpatrick e com o conceito de avaliação ROI de Phillips. Além disso, apontam que o modelo não é exaustivo, mas meramente instrutivo, podendo as organizações duplicar ou adaptar as técnicas expostas.

Allen e McGee (2004) relatam importantes pontos a serem observados em avaliação de UC. O primeiro é que não há um método que seja melhor para avaliá-la, pois cada uma existe por diferentes motivos e, portanto, deveriam ter diferentes métricas. O segundo ponto é que, ao focar os objetivos e a missão da UC, é fácil determinar o que será aferido, além disso, a avaliação não será complicada e custosa se ela tiver sua missão bem definida.

Lee (2010), Morin e Renaud (2004) e Zerbini e Abbad (2005) abordam a avaliação de programas, tendo como foco a transferência dos conhecimentos e habilidades adquiridos por meio de ações de treinamento ao trabalho do indivíduo. Dessa forma, ambos abordam a fase 3 da avaliação de Kirkpatrick, ou seja, de mudança de comportamento e aplicação do que foi aprendido ao trabalho. O estudo de Zerbini e Abbad (2005) inclui também a fase 1 - Reação da avaliação de Kirkpatrick por meio da avaliação da qualidade do desempenho do tutor e dos procedimentos instrucionais.

O estudo de Morin e Renaud (2004) verifica se a participação em programas de treinamento produziu efeito sobre o desempenho individual no trabalho. Para tanto, foram coletados dados referentes ao número de cursos concluídos pelos empregados e ofertados pela universidade corporativa entre os anos de 1996 e 1998 e às notas dadas pela supervisão em 1998 sobre o desempenho dos indivíduos. Como resultado, o estudo comprovou que a participação em programas de treinamento teve um efeito relativamente pequeno sobre o desempenho 
individual, entretanto constatou que houve relação entre número de cursos concluídos e desempenho, ou seja, quanto mais cursos completados, melhor foi o desempenho individual no trabalho, quando considerado o desempenho antes do treinamento, as características individuais e do trabalho como variáveis moderadoras. Uma explicação dada pelos autores para o pequeno efeito do treinamento no desempenho foi que os objetivos dos treinamentos da universidade corporativa geralmente abarcam mais que o aumento do desempenho individual, por isso fazer a conexão entre essas duas variáveis é uma tarefa difícil. Conforme revisão bibliográfica realizada para o estudo, a universidade corporativa tem efeito sobre a lealdade dos empregados (GALLAGHER, 2000 apud MORIN e RENAUD, 2004), é utilizada como ferramenta de desenvolvimento, reforço e compartilhamento da cultura organizacional (PANCZUK, 2001 apud MORIN e RENAUD, 2004) e atesta o aumento marginal da produtividade pela alteração do capital humano (BECKER, 1962 apud MORIN e RENAUD, 2004).

Já a investigação conduzida por Lee (2010) buscou identificar a percepção dos participantes sobre quais fatores no desenho de um treinamento misto, chamado blended learning, são importantes para a transferência do aprendizado ao trabalho. A partir da análise dos dados coletados, o autor identificou que há fatores que facilitam a transferência nos tipos por ele estudados - aprendizagem on-line e off-line. Na modalidade on-line os fatores que facilitam a aprendizagem são: usar casos de trabalho baseados em situações reais; garantir que os participantes estejam atentos ao conteúdo e aos benefícios do treinamento; ativar o conhecimento prévio; prover autoavaliação para aferição das forças, fraquezas, valores, interesses, objetivos e motivações sobre o tópico dado; prover oportunidades para demonstrar o conhecimento adquirido; elaborar aulas que engajem os participantes e interajam com eles; ensinar princípios subordinados aos conceitos; ensinar claramente sobre como o conhecimento adquirido será usado no próximo módulo; utilizar vários exemplos em vários contextos; prover quantidade adequada de informação; prover aos participantes oportunidades ricas de interação entre instrutor e aprendiz nos programas on-line; e propiciar canais abertos para sanar dúvidas sobre o tema.

Para as iniciativas de aprendizagem que o autor chama de off-line ou face a face, os fatores que facilitam a transferência são: os participantes utilizarem o próprio contexto em sua aprendizagem; prover várias e suficientes oportunidades para a prática; avaliação da transferência de forma consistente com os objetivos estabelecidos; fornecer feedback 
informativo e corretivo e instrução para a melhoria de desempenho; encorajar os participantes a fazerem um plano de ação que considere os obstáculos que enfrentarão no trabalho e os efeitos em termos de impacto organizacional; fornecer auxílio para suportar a aplicação ao trabalho; distribuir ferramentas fáceis de usar; e conter momentos suficientes de reflexão sobre a aprendizagem.

Por fim, o estudo de Zerbini e Abbad (2005) cria um modelo de avaliação de resultados em treinamentos a distância via internet, realizando para isso dois estudos. O primeiro buscou a construção e validação estatística dos instrumentos de medida; o segundo, a análise de relacionamento entre variáveis preditoras - Características da Clientela, Reações ao Treinamento e Falta de Suporte à Transferência - e a variável Impacto do Treinamento no Trabalho. Em relação ao primeiro estudo, apenas três variáveis contribuíram significativamente para a explicação do impacto no trabalho derivado dos conteúdos ministrados - Suporte, Estratégias de Aprendizagem e Elaboração do Plano de Negócio -, que, juntas, explicam perto de 23\% da variabilidade de impacto. Do mesmo modo, o segundo estudo identificou também três variáveis que contribuíram significativamente para a explicação de impacto do treinamento no trabalho - Suporte, Satisfação com os Procedimentos Instrucionais e Elaboração do Plano de Negócios -, que, juntas, explicam perto de $25 \%$ da variabilidade de impacto do treinamento no trabalho. Esse estudo, assim como o de Lee (2010), captura a percepção dos participantes em relação às variáveis avaliadas, mas não utilizam outras formas de verificar o impacto no trabalho, tais como observação direta do comportamento no trabalho e avaliação do superior e pares sobre a aplicação dos conteúdos aprendidos ao trabalho.

Os estudos de Morin e Renaud (2004), Lee (2010) e Zerbini e Abbad (2005) complementamse, pois o primeiro verifica se, de fato, a participação gerou impacto no trabalho, por meio da análise de desempenho, e o segundo e o terceiro verificam quais fatores influenciam esse impacto. Cabe destacar que os estudos de Lee (2010) e Zerbini e Abbad (2005) tratam de tipos de treinamento específicos, quais sejam, mistos e a distância via internet, respectivamente. 


\subsubsection{Revisão em dissertações e teses}

Além da pesquisa em periódicos, foi realizado um levantamento dos estudos (dissertações e teses) no Banco de Teses CAPES, que disponibiliza para consulta os resumos dos trabalhos. A pesquisa foi realizada por meio do campo assunto, buscando-se os mesmos termos utilizados na pesquisa em periódicos, quais sejam: Avaliação em Educação Corporativa; Avaliação em Universidade Corporativa; Resultado em Educação Corporativa; Resultado em Universidade Corporativa. A pesquisa resultou em 22 estudos.

No Quadro 4, é exposto um resumo sobre os estudos, que procura identificar as características metodológicas que os orientaram.

Quadro 4 - Estudos sobre avaliação de resultado em educação corporativa no Brasil

\begin{tabular}{|c|c|c|c|c|}
\hline \multicolumn{2}{|c|}{ Delineamento da Pesquisa } & \multirow{2}{*}{$\begin{array}{c}\text { Instrumento de Coleta de } \\
\text { Dados }\end{array}$} & \multirow{2}{*}{$\begin{array}{c}\text { Tratamento e Análise dos } \\
\text { Dados }\end{array}$} & \multirow{2}{*}{ Total } \\
\hline Abordagem & Método & & & \\
\hline \multirow{11}{*}{ Qualitativa } & $\begin{array}{l}\text { Informação não } \\
\text { disponível }\end{array}$ & Entrevista & Informação não disponível & 1 \\
\hline & $\begin{array}{l}\text { Informação não } \\
\text { disponível }\end{array}$ & Entrevista e questionário & Informação não disponível & 1 \\
\hline & $\begin{array}{l}\text { Estudo de caso } \\
\text { longitudinal }\end{array}$ & Informação não disponível & Informação não disponível & 1 \\
\hline & \multirow{6}{*}{ Estudo de caso } & Entrevista e questionário & Informação não disponível & 2 \\
\hline & & Entrevista e questionário & Análise de conteúdo & 1 \\
\hline & & $\begin{array}{l}\text { Entrevistas e observação } \\
\text { direta }\end{array}$ & Informação não disponível & 2 \\
\hline & & Entrevista & Informação não disponível & 2 \\
\hline & & $\begin{array}{l}\text { Entrevista, questionário e } \\
\text { observação direta }\end{array}$ & Informação não disponível & 1 \\
\hline & & $\begin{array}{l}\text { Questionário e observação } \\
\text { direta }\end{array}$ & Informação não disponível & 1 \\
\hline & $\begin{array}{l}\text { Estudo de casos } \\
\text { múltiplos }\end{array}$ & Entrevista semiestruturada & Análise de conteúdo & 1 \\
\hline & $\begin{array}{l}\text { Pesquisa } \\
\text { bibliográfica }\end{array}$ & Informação não disponível & Análise de conteúdo & 1 \\
\hline Quantitativa & Levantamento & Questionários & Análise fatorial & 2 \\
\hline $\begin{array}{l}\text { Mista (qualitativa } \\
\text { e quantitativa) }\end{array}$ & $\begin{array}{l}\text { Informação não } \\
\text { disponível }\end{array}$ & Questionário & Informação não disponível & 1 \\
\hline $\begin{array}{l}\text { Informação não } \\
\text { disponível }\end{array}$ & $\begin{array}{l}\text { Informação não } \\
\text { disponível }\end{array}$ & Informação não disponível & Informação não disponível & 5 \\
\hline \multicolumn{4}{|l|}{ TOTAL } & 22 \\
\hline
\end{tabular}

A partir da análise do Quadro 4, percebe-se que há concentração no tipo de estudo de abordagem qualitativa, com preponderância da utilização do método de estudo de caso. Percebe-se ainda o predomínio da técnica de triangulação de dados, por meio da utilização de 
diferentes instrumentos de coleta em um mesmo estudo. Desse modo, do total de 14 estudos qualitativos, oito utilizam a técnica de triangulação, com predomínio do uso de entrevistas e questionários. O emprego de questionários justifica-se quando o objetivo da investigação é avaliar os resultados de um programa ou curso, como é o caso da maioria dos estudos. Todavia, se o objetivo for investigar as práticas realizadas pelas empresas, uma investigação qualitativa, por meio da realização de entrevistas em profundidade com pessoas-chave tornase mais adequado. Essa é a proposta do presente estudo.

A partir da análise dos resumos dos estudos, foram identificados 10 trabalhos que apresentam relação direta com o tema de pesquisa deste estudo. São oito dissertações e duas teses que abordam formas de realizar a avaliação de resultados em educação corporativa ou buscam verificar o impacto da EC nos resultados organizacionais. A seguir, são expostos no Quadro 5 os objetivos dos trabalhos e os principais resultados alcançados.

Quadro 5 - Objetivos dos estudos e principais resultados

\begin{tabular}{|c|c|c|c|c|}
\hline Categoria & Referência & Tipo de Estudo & Objetivos do Estudo & Principais Resultados \\
\hline \multirow{2}{*}{$\begin{array}{l}\text { Impactos no } \\
\text { Indivíduo }\end{array}$} & Bezerra, 2009 & $\begin{array}{l}\text { Tese de } \\
\text { Doutorado }\end{array}$ & $\begin{array}{l}\text { Criação de um índice de } \\
\text { aderência entre o } \\
\text { profissional desejado e o } \\
\text { perfil do profissional } \\
\text { recém-contratado. }\end{array}$ & $\begin{array}{l}\text { A metodologia pode avaliar o } \\
\text { índice de aderência entre o } \\
\text { profissional desejado e o obtido } \\
\text { como guia de efetividade para a } \\
\text { educação corporativa. }\end{array}$ \\
\hline & Oliveira, 2007 & $\begin{array}{l}\text { Dissertação de } \\
\text { Mestrado }\end{array}$ & $\begin{array}{l}\text { Avaliar o impacto da } \\
\text { Educação Corporativa no } \\
\text { desempenho dos } \\
\text { funcionários da Perdigão } \\
\text { S/A, Unidade Carambeí. }\end{array}$ & $\begin{array}{l}\text { Os resultados apontam que o } \\
\text { impacto da EC é positivo e que } \\
\text { efetivamente contribui para a } \\
\text { melhoria do desempenho dos } \\
\text { colaboradores. }\end{array}$ \\
\hline \multirow{3}{*}{$\begin{array}{l}\text { Parâmetros } \\
\text { para } \\
\text { Avaliação }\end{array}$} & $\begin{array}{l}\text { Andrade, } \\
2008\end{array}$ & $\begin{array}{l}\text { Dissertação de } \\
\text { Mestrado } \\
\text { Profissionalizante }\end{array}$ & $\begin{array}{l}\text { Identificar o processo de } \\
\text { avaliação de retorno sobre } \\
\text { investimento em } \\
\text { treinamento. }\end{array}$ & $\begin{array}{l}\text { A organização investe em } \\
\text { treinamento constante e } \\
\text { desenvolve processo de } \\
\text { avaliação customizado para } \\
\text { atender a sua demanda de } \\
\text { mensuração. }\end{array}$ \\
\hline & Borsatto, 2007 & $\begin{array}{l}\text { Dissertação de } \\
\text { Mestrado }\end{array}$ & $\begin{array}{l}\text { Identificar os indicadores e } \\
\text { avaliação de aprendizagem } \\
\text { realizados em EC a } \\
\text { distância. }\end{array}$ & $\begin{array}{l}\text { Os participantes consideram } \\
\text { mais adequada a avaliação } \\
\text { processual e formativa, mas não } \\
\text { descartam a utilização de } \\
\text { ferramentas de avaliação } \\
\text { tradicional. }\end{array}$ \\
\hline & Ramos, 2008 & $\begin{array}{l}\text { Dissertação de } \\
\text { Mestrado } \\
\text { Profissionalizante }\end{array}$ & $\begin{array}{l}\text { Identificar indicadores em } \\
\text { EC. }\end{array}$ & $\begin{array}{l}\text { Não foram identificadas } \\
\text { organizações que possuam } \\
\text { sistema de avaliação de T\&D. }\end{array}$ \\
\hline
\end{tabular}


Continuação do Quadro 5

\begin{tabular}{|c|c|c|c|c|}
\hline Categoria & Referência & Tipo de Estudo & Objetivos do Estudo & Principais Resultados \\
\hline \multirow[b]{2}{*}{$\begin{array}{l}\text { Parâmetros } \\
\text { para } \\
\text { Avaliação }\end{array}$} & $\begin{array}{l}\text { Ruggiero, } \\
2007\end{array}$ & $\begin{array}{l}\text { Tese de } \\
\text { Doutorado }\end{array}$ & $\begin{array}{l}\text { Definir a aplicação de } \\
\text { indicadores para avaliação } \\
\text { de desempenho das } \\
\text { atividades de EC. }\end{array}$ & Informação não disponível. \\
\hline & $\begin{array}{l}\text { Schröeder, } \\
2005\end{array}$ & $\begin{array}{l}\text { Dissertação de } \\
\text { Mestrado }\end{array}$ & $\begin{array}{l}\text { Criação de indicadores de } \\
\text { mensuração de resultados } \\
\text { em treinamentos virtuais, } \\
\text { baseando-se na teoria de } \\
\text { Kaplan e Norton, } \\
\text { Kirkpatrick e outros. } \\
\end{array}$ & $\begin{array}{l}\text { Identificação de } 20 \text { indicadores } \\
\text { de resultado para treinamento } \\
\text { virtual. }\end{array}$ \\
\hline \multirow{3}{*}{$\begin{array}{l}\text { Impactos na } \\
\text { Organização }\end{array}$} & Alves, 2007 & $\begin{array}{l}\text { Dissertação de } \\
\text { Mestrado } \\
\text { Profissionalizante }\end{array}$ & $\begin{array}{l}\text { Descrever os fatores da UC } \\
\text { que contribuem para o } \\
\text { alinhamento estratégico da } \\
\text { ARH das organizações. }\end{array}$ & $\begin{array}{l}\text { As Universidades Corporativas } \\
\text { (UCs) são importantes para o } \\
\text { fortalecimento do setor de RH } \\
\text { na participação da gestão } \\
\text { estratégica da empresa, mas há } \\
\text { dificuldade de avaliar o impacto } \\
\text { nos resultados das organizações. }\end{array}$ \\
\hline & Mathias, 2009 & $\begin{array}{l}\text { Dissertação de } \\
\text { Mestrado } \\
\text { Profissionalizante }\end{array}$ & $\begin{array}{l}\text { Averiguar as relações entre } \\
\text { indicadores de treinamento } \\
\text { e melhoria de processos- } \\
\text { chave na organização } \\
\text { estudada. }\end{array}$ & Informação não disponível. \\
\hline & Silva, 2006 & $\begin{array}{l}\text { Dissertação de } \\
\text { Mestrado } \\
\text { Profissionalizante }\end{array}$ & $\begin{array}{l}\text { Avaliar a mudança } \\
\text { organizacional promovida } \\
\text { a partir da criação da UC. }\end{array}$ & $\begin{array}{l}\text { Construção de um instrumento } \\
\text { para verificar as mudanças } \\
\text { organizacionais geradas por } \\
\text { uma UC. }\end{array}$ \\
\hline
\end{tabular}

Os estudos mencionados no Quadro 5 têm como fio condutor a busca por formas de avaliar os resultados da educação corporativa. Em suma, eles podem ser classificados em três tipos, descritos a seguir:

a) Impactos no Indivíduo: procuraram verificar o impacto das ações no nível do indivíduo, identificando se houve melhora no desempenho da pessoa no trabalho ou se o profissional está aderente ao esperado (BEZERRA, 2009; OLIVEIRA, 2007).

b) Parâmetros para Avaliação: demonstraram indicadores para avaliar a educação corporativa ou formas de avaliar seus resultados financeiros (ANDRADE, 2008; BORSATTO, 2007; RAMOS, 2008; RUGGIERO, 2007; SCHRÖEDER, 2005).

c) Impactos na Organização: procuram averiguar os efeitos gerados pelas ações de EC na organização (ALVES, 2007; MATHIAS, 2009; SILVA, 2006).

Esses estudos complementam-se cada qual buscando aprofundar determinado aspecto na avaliação de educação corporativa. Entretanto, a lacuna desses estudos reside na ausência de um modelo que integre suas diferentes esferas de avaliação. 


\subsection{Síntese do Referencial Teórico}

A revisão de literatura apresenta dois pilares principais: educação corporativa e avaliação de resultados em educação corporativa.

Os conceitos inicialmente expostos são os de TD\&E, demonstrando sua evolução histórica, que passou inicialmente pela capacitação do trabalhador para realizar as tarefas prescritas; posteriormente, pela capacitação do funcionário para seu cargo atual e futuro; por fim, pela preocupação em preparar o indivíduo em aspectos pessoais e profissionais. Nota-se que a partir da década de 80, com o aumento da competição em níveis globais, ocorre a mudança da tradicional área de T\&D para a EC, que passa a desempenhar um novo papel na organização, com atuação estratégica, orientada pelo desenvolvimento das competências essenciais da organização e pelo alinhamento a seus objetivos. As diferenças fundamentais entre os conceitos de TD\&E e EC referem-se ao novo papel desempenhado pelas universidades corporativas, à extensão do público-alvo das ações educacionais, à mudança de atuação de área funcional para unidade de negócio e ao estabelecimento de parcerias com instituições de ensino superior.

Para auxiliar a organização a atingir seus objetivos, torna-se imperativa a criação de um sistema métrico para avaliar as ações de educação corporativa. Entretanto, essa não é tarefa simples e muitos são os entraves para a implantação desse sistema, vários expostos na revisão de literatura empreendida.

Ao abordar a avaliação em educação corporativa, vale destacar que se deve ter em mente seu alinhamento ao sistema de avaliação de GP como um todo, pois as práticas de GP, quando alinhadas, produzem maior impacto no desempenho organizacional que as práticas de GP tomadas isoladamente. Portanto, modelos de avaliação de GP que considerem como ponto de partida a estratégia da organização são mais adequados ao sistema de educação corporativa. Nesse sentido, a proposta de avaliação de Becker, Huselid e Ulrich (2001) torna-se mais apropriada a este estudo. 
A partir dessa contextualização, são expostos os modelos de avaliação de resultados em treinamento localizados no estudo realizado.

O pioneiro em tratar de avaliação de treinamento foi Kirkpatrick. Ele abordou o tema em sua tese de doutorado e publicou quatro artigos em 1959 intitulados Techniques for Evaluating Training Programs (KIRKPATRICK e KIRKPATRICK, 2010). O autor enfatiza a importância das fases de planejamento e execução como precedentes na determinação da eficácia do programa de treinamento. Ele propõe quatro níveis para a avaliação de programas de treinamento: avaliação de reação, de aprendizagem, de comportamento e de resultados. Os níveis devem ser realizados de forma sequencial, passando-se ao seguinte apenas após realizar o anterior. É importante a elaboração de objetivos que nortearão a avaliação e também as fases de planejamento e execução.

O modelo de avaliação de treinamento proposto por Hamblin (1978) consiste em estabelecer os objetivos que se deseja alcançar em cada um dos níveis, visto que as ações de treinamento são influenciadas por acontecimentos externos, resultando em efeitos inesperados ou irrelevantes. A partir dos objetivos, os programas são executados e as informações que atendem aos critérios de avaliação, selecionadas. Procede-se à análise, a partir da qual serão identificados pontos de melhoria e, ou, estabelecidos novos objetivos. Observa-se que o autor ressalta a importância de executar todos os níveis propostos para que seja possível identificar os pontos falhos, os motivos de sua ocorrência e as possibilidades de melhoria, entretanto, destaca que pode não ser útil ou viável realizar todas as etapas, principalmente, por, de certa forma, os níveis 3, 4 e 5 avaliarem a administração da empresa como um todo e estabelecer objetivos a esses níveis significa estabelecer objetivos em nível organizacional. Deve-se tomar cuidado para que o controle e a avaliação não sejam excessivos, entretanto, sua ausência também deve ser evitada.

Phillips (1991) destaca em seu modelo o papel importante da mudança de atitude da organização em relação à avaliação de treinamento, propondo um modelo de avaliação de treinamento orientado por resultados. Para a implantação da metodologia, a área de treinamento deve ter como filosofia a orientação a resultados. Seu modelo contempla todas as etapas de um programa de treinamento, partindo de sua concepção até a comunicação de seus resultados. O autor inova em relação aos anteriores, pois propõe em seu modelo o cálculo do retorno sobre o investimento realizado em treinamento. 
Já Fitz-enz (1995) desenvolveu um modelo de avaliação baseado em três variáveis: custos, mudança e impacto. Essas três variáveis perpassam seu modelo que parte dos problemas e oportunidades do negócio e chega ao cálculo do resultado gerado pelas ações de treinamento em termos monetários e humanos. Quanto a esse último tipo de resultado - humano -, o autor não esclarece como se pode obtê-lo. Os problemas e oportunidades do negócio podem ser destacados a partir da estratégia da organização, pois esse tipo de análise, geralmente, faz parte do planejamento estratégico da organização.

O MAIS é um modelo de avaliação que, assim como os demais, tem por objetivo analisar e fornecer informações para a tomada de decisão sobre o futuro de programas de treinamento. Esse modelo é formado por cinco componentes - insumos, processos, procedimentos, resultados e ambiente - e busca identificar a relação das variáveis de cada um dos componentes com o programa de treinamento. Esse modelo é amplo e fornece uma visão sistêmica do treinamento, pois considera o ambiente no processo de avaliação. É um modelo genérico, conforme classificação de Pilati (2004 apud BORGES-ANDRADE, 2006), e, assim como os anteriores, fornece as bases para o desenvolvimento de modelos específicos.

Por fim, o modelo de Allen e McGee (2004) é o único que aborda a avaliação de EC por meio de seu Modelo de Produtividade, que busca avaliar de forma sistêmica a efetividade da EC. Os parâmetros que norteiam a avaliação da efetividade da UC são estabelecidos a partir de métricas organizacionais, tais como lucratividade, crescimento, retenção de funcionários, satisfação dos funcionários e produtividade. Entretanto, a lacuna desse estudo reside em não considerar os objetivos do negócio como ponto de partida para a avaliação da EC. Somente estabelecer parâmetros em nível organizacional aparentemente é insuficiente, pois o sucesso de um sistema de EC está em auxiliar a organização a atingir seus resultados.

Dentre os modelos apresentados, os de Kirkpatrick (2010), Hamblim (1978) e Phillips (1991) envolvem tópicos relacionados mais aos aspectos centrais do modelo de Borges-Andrade (1982), quais sejam insumos, procedimentos, processos e resultados. Entretanto, esses modelos referenciam a estratégia da organização como sendo o ponto de partida para as demandas de programas de treinamento. O modelo de Fitz-enz (1995) e de Phillips (1991) abordam a perspectiva de custos em treinamento, critério importante principalmente para se justificarem aumentos ou manutenção do orçamento de treinamento. Já o modelo de Allen e 
McGee (2004) busca avaliar a efetividade da EC como um todo. A partir da análise dos modelos, verifica-se que há certa complementaridade entre eles, pois, cada qual fornece critérios importantes para a avaliação de resultados em EC, que nortearão a condução da pesquisa de campo, a qual é descrita no próximo capítulo, por meio das definições operacionais do estudo e sua metodologia. 


\section{METODOLOGIA}

A metodologia deste estudo foi elaborada de forma a embasar e nortear a condução da pesquisa empírica, ou seja, constitui o planejamento da pesquisa de campo. Desse modo, o capítulo está estruturado nos seguintes itens: delineamento da pesquisa, planejamento operacional, unidades de análise; validade e confiabilidade do estudo; instrumentos de coleta de dados; tratamento e análise dos dados; e limitações da pesquisa.

\subsection{Delineamento da pesquisa}

O posicionamento ontológico e epistemológico é importante para nortear a condução da pesquisa, com o intuito de manter a coerência. A ontologia trata da natureza da realidade a ser estudada (MAFFEZZOLLI e BOEHS, 2008). Segundo Grix (2002 apud MAFFEZZOLLI e BOEHS, 2008), a ontologia pode ser classificada em duas naturezas distintas: fundamentalismo e antifundamentalismo. A primeira caracteriza-se por entender que a realidade é observável e independe de seus atores sociais. Já a segunda, o antifundamentalismo, tem como princípio que a realidade é continuamente transformada por seus atores e, por isso, não pode ser observada de forma direta.

A epistemologia, por sua vez, trata sobre o modo como essa realidade será estudada, existindo, pelo menos, dois polos extremos de abordagem: o positivismo e o interpretativismo. O positivismo baseia-se em uma postura ontológica fundamentalista, pois entende a realidade como externa e independente ao observador, que procurará investigá-la de forma objetiva. Por isso, sua postura será orientada por preceitos quantitativos. Em contrapartida, o interpretativismo adota uma postura ontológica antifundamentalista, entendendo a realidade como construída pelos atores sociais e, desse modo, utiliza predominantemente estudos qualitativos (MAFFEZZOLLI e BOEHS, 2008).

A partir dessa breve explanação, justifica-se a abordagem qualitativa deste estudo, visto que a realidade a ser estudada, a avaliação de resultados em educação corporativa, é desenvolvida pelos indivíduos nas organizações estudadas e busca-se, com esta pesquisa, justamente 
conhecer como eles realizam esse processo. Assim, a abordagem deste estudo é predominantemente qualitativa, entretanto, são utilizadas ferramentas estatísticas descritivas no tratamento dos dados. Conforme apontado por Martins e Theóphilo (2009) a utilização dessa abordagem justifica-se quando se dispõe de pouca informação a respeito do assunto a ser pesquisado; quando o fenômeno a ser estudado só pode ser captado por meio da observação e, ou, interação; ou quando se deseja conhecer o funcionamento de uma estrutura social por meio do estudo de um processo. O presente estudo insere-se na primeira e última características, visto que, apesar de haver estudos sobre metodologias de avaliação de resultados em treinamento, o mesmo não se pode dizer de metodologias de avaliação de resultados em educação corporativa. Além disso, poucas organizações apresentam métodos implantados e o escopo deste estudo é analisar a forma como as organizações realizam essa avaliação.

Ainda, segundo Martins e Theóphilo (2009, p. 61), “a avaliação qualitativa é caracterizada pela descrição, compreensão e interpretação de fatos e fenômenos, em contrapartida à avaliação quantitativa, denominada pesquisa quantitativa, onde predominam mensurações”.

As características da pesquisa qualitativa, apontadas por Bogdan (1982 apud TRIVIÑOS, 2008) são:

a) a pesquisa qualitativa tem o ambiente natural como fonte direta dos dados e o pesquisador como instrumento-chave;

b) a pesquisa qualitativa é descritiva;

c) os pesquisadores qualitativos estão preocupados com o processo;

d) os pesquisadores qualitativos tendem a analisar seus dados indutivamente;

e) o significado é a preocupação essencial na abordagem qualitativa.

Este estudo caracteriza-se como descritivo, pois buscou investigar as práticas e os procedimentos de avaliação empregados pelas organizações estudadas, descrevendo-as e procurando identificar os fatores que influenciam esse processo. Este estudo descritivo está dividido em duas perspectivas: ampla e específica. A perspectiva ampla caracteriza-se pela análise de conteúdo dos Cadernos de Evidências apresentados pelas empresas na pesquisa As Melhores Empresas para Você Trabalhar (MEPT). O objetivo desta análise é identificar quais características são mais aplicadas, fornecendo um panorama da avaliação de resultados em educação corporativa no Brasil. 
A perspectiva específica do estudo descritivo será composta por pesquisa de campo para coleta de dados primários, mediante aplicação de entrevista semiestruturada junto a uma organização que realiza avaliação de resultados em educação corporativa de forma contínua e sistemática. Desse modo, será realizado estudo de caso único, de forma que haja maior aprofundamento nas práticas de avaliação empregadas pela organização estudada.

A análise de conteúdo, como método científico, caracteriza-se pela análise das comunicações. Abarca um conjunto de técnicas de análise e, como método, algumas fases para sua execução, quais sejam, a organização da análise, a codificação, a categorização e a inferência (BARDIN, 2011).

O estudo de caso é caracterizado pela análise de um caso particular, o qual deve ser significativo e representativo de um conjunto de casos análogos, permitindo, assim, a generalização para situações semelhantes (SEVERINO, 2007). Segundo Yin (2010), o estudo de caso é um método de investigação que estuda um fenômeno contemporâneo em profundidade em seu contexto de vida real. O autor destaca que o contexto é um ponto importante a ser considerado, principalmente quando os limites entre fenômeno e contexto não são claros. Portanto, como contexto é fator relevante para o método de estudo de caso, esta pesquisa buscou dados referentes às empresas estudadas e sobre o funcionamento dos sistemas de EC para averiguar a influência de fatores contextuais na utilização ou não de formas de avaliação de resultados em EC.

A importância do estudo de caso como método de pesquisa se dá quando é necessário compreender fenômenos sociais complexos, permitindo uma investigação em que se preservem as características holísticas e significativas dos acontecimentos da vida real (YIN, 2010).

No presente estudo, a utilização do método de estudo de caso justifica-se, pois, conforme apontado por Yin (2010), este método é o mais adequado quando o estudo propõe as questões “como" ou "por que”; o investigador tem pouco controle sobre os eventos; e o enfoque está em um fenômeno contemporâneo no contexto da vida real, que apresenta muito mais variáveis do que pontos de dados. Para lidar com o último fato, é recomendado pelo autor o uso de múltiplas fontes de evidência, empregando a triangulação na análise dos dados 
coletados. As fontes de evidência do caso foram as entrevistas, os documentos e os relatórios coletados junto aos entrevistados e dados retirados do site da empresa, tais como o relatório anual de sustentabilidade. Quanto à revisão de literatura, Yin (2010) destaca sua importância na orientação da coleta e da análise dos dados.

A operacionalização da pesquisa é descrita a seguir, por meio da matriz de amarração dos elementos deste estudo, baseada no modelo proposto por Mazzon (1981) e avaliada por Telles (2001), apresentada no Quadro 6. 
Quadro 6 - Operacionalização da pesquisa empírica

\begin{tabular}{|c|c|c|c|c|c|}
\hline \multicolumn{2}{|r|}{ Objetivos } & \multirow{2}{*}{$\begin{array}{c}\text { Pontos de } \\
\text { Investigação }\end{array}$} & \multirow{2}{*}{ Coleta de Dados } & \multirow{2}{*}{$\begin{array}{l}\text { Análise dos } \\
\text { Dados }\end{array}$} & \multirow{2}{*}{ Resultados Esperados } \\
\hline Objetivo Geral & Objetivos específicos & & & & \\
\hline \multirow{4}{*}{$\begin{array}{l}\text { Responder à } \\
\text { questão: } \\
\text { Como as } \\
\text { organizações que } \\
\text { se destacam em } \\
\text { gestão de pessoas } \\
\text { avaliam os } \\
\text { resultados em } \\
\text { educação } \\
\text { corporativa? }\end{array}$} & $\begin{array}{l}\text { Descrever o sistema de educação } \\
\text { corporativa empregado pelas } \\
\text { MEPT e suas práticas de } \\
\text { avaliação de resultados. }\end{array}$ & $\begin{array}{l}\text { Análise documental de } \\
\text { como as organizações } \\
\text { estudadas aplicam as } \\
\text { dimensões e variáveis } \\
\text { deste estudo. }\end{array}$ & $\begin{array}{l}\text { - Dados agregados da pesquisa } \\
\text { MEPT. } \\
\text { - Cadernos de Evidências }\end{array}$ & $\begin{array}{l}\text { Análise de } \\
\text { conteúdo }\end{array}$ & $\begin{array}{l}\text { Panorama geral sobre a } \\
\text { educação corporativa e as } \\
\text { práticas de avaliação de } \\
\text { resultados empregadas pelas } \\
\text { MEPT. }\end{array}$ \\
\hline & $\begin{array}{l}\text { Descrever a organização estudada } \\
\text { e seu sistema de educação } \\
\text { corporativa. }\end{array}$ & $\begin{array}{l}\text { Levantamento dos } \\
\text { seguintes dados do } \\
\text { sistema de EC da } \\
\text { organização estudada: } \\
\text { atuação estratégica; } \\
\text { público atendido; e } \\
\text { cultura de } \\
\text { aprendizagem } \\
\text { contínua. }\end{array}$ & $\begin{array}{l}\text { - Entrevistas semiestruturadas. } \\
\text { - Documentos e relatórios } \\
\text { fornecidos pelos entrevistados. } \\
\text { - Relatórios e informações } \\
\text { presentes no site da } \\
\text { organização. }\end{array}$ & $\begin{array}{l}\text { Análise de } \\
\text { conteúdo. }\end{array}$ & $\begin{array}{l}\text { Entendimento sobre o sistema } \\
\text { de EC da organização } \\
\text { estudada e sua influência na } \\
\text { forma de avaliar resultados } \\
\text { em EC. }\end{array}$ \\
\hline & $\begin{array}{l}\text { Levantar as práticas e os } \\
\text { procedimentos de avaliação de } \\
\text { resultados em EC no caso } \\
\text { estudado. }\end{array}$ & $\begin{array}{l}\text { Exame empírico de } \\
\text { como as organizações } \\
\text { estudadas aplicam as } \\
\text { dimensões e variáveis } \\
\text { deste estudo. }\end{array}$ & $\begin{array}{l}\text { - Entrevistas semiestruturadas. } \\
\text { - Documentos e relatórios } \\
\text { fornecidos pelos entrevistados. } \\
\text { - Relatórios e informações } \\
\text { presentes no site da } \\
\text { organização. }\end{array}$ & $\begin{array}{l}\text { Análise de } \\
\text { conteúdo. }\end{array}$ & $\begin{array}{l}\text { Avaliação da teoria que } \\
\text { fundamenta este estudo, por } \\
\text { meio da verificação de pontos } \\
\text { de convergência e divergência } \\
\text { dos achados em relação à } \\
\text { teoria. }\end{array}$ \\
\hline & $\begin{array}{l}\text { Analisar as limitações, vantagens } \\
\text { e tendências de avaliação de } \\
\text { resultados em EC na organização } \\
\text { investigada. }\end{array}$ & $\begin{array}{l}\text { Análise da percepção } \\
\text { dos entrevistados sobre } \\
\text { as limitações, } \\
\text { vantagens e tendências } \\
\text { em avaliação de } \\
\text { resultados em EC. }\end{array}$ & Entrevistas semiestruturadas. & $\begin{array}{l}\text { Análise de } \\
\text { conteúdo. }\end{array}$ & $\begin{array}{l}\text { Proposta de práticas, } \\
\text { procedimentos e processos } \\
\text { para avaliação de resultados } \\
\text { em educação corporativa. }\end{array}$ \\
\hline
\end{tabular}

Fonte: Adaptado de Telles (2001) e Nakata (2009). 


\subsection{Planejamento operacional}

\subsubsection{Estudo amplo: análise das empresas que se destacam em gestão de pessoas}

A perspectiva ampla do estudo compreende a análise dos Cadernos de Evidências das Melhores Empresas para Você Trabalhar e contemplou as organizações que disponibilizaram o documento em versão digital, o que reduziu a população estudada de 150 para 144 organizações. O Caderno de Evidências contempla as seguintes categorias: estratégia e gestão; liderança; políticas e práticas de remuneração; políticas e práticas sobre carreira; políticas e práticas sobre saúde; políticas e práticas de desenvolvimento; cidadania empresarial. Optou-se por analisar apenas o item Políticas e Práticas de Desenvolvimento, que contempla as ações educacionais promovidas pelas organizações.

Para a análise dos Cadernos de Evidências foi utilizada a análise de conteúdo. Esta análise envolveu as seguintes etapas: organização da análise, codificação, categorização e inferências (BARDIN, 2011).

A organização da análise contemplou a pré-análise dos Cadernos de Evidências, por meio da realização de leitura flutuante para ter algumas impressões sobre os materiais. A partir dessa leitura, foi possível determinar quais variáveis seriam passíveis de serem contempladas no estudo. Dessa forma, foram analisados aspectos relativos à educação corporativa e à avaliação de resultados em educação corporativa. Ainda na fase de pré-análise, a escolha dos documentos, conforme se verifica, foi realizada a priori, pois a base de dados da pesquisa As Melhores Empresas para Você Trabalhar é ampla e apresenta dados relacionados aos aspectos de Gestão de Pessoas sendo utilizada em diversas pesquisas acadêmicas (HASHIMOTO et al., 2010; NAKATA et al., 2009; TUMELERO et al., 2011). A referenciação dos índices foi realizada por meio da menção dos temas (variáveis) desta pesquisa nos materiais analisados e o indicador adotado foi a frequência em que aparecem. A preparação do material contemplou adequá-los, quando necessário, para importação para o software de análise.

A codificação envolveu a escolha das unidades, as regras de contagem e a escolha das categorias. A escolha das unidades, conforme relata Bardin (2011), compreende estabelecer as 
unidades de registro e de contexto. A unidade de registro, segundo a autora, corresponde ao segmento do conteúdo considerado como base para a categorização e contagem frequencial. A unidade de registro escolhida para este estudo foi o tema, ou seja, a unidade de significado que se desprende do texto de forma natural. Já a unidade de contexto é o segmento necessário para que a unidade de registro seja compreendida, deste modo, estabeleceu-se o parágrafo como unidade de contexto. Como regras de enumeração estabelece como será a contagem das unidades de registro, optou-se como medida a frequência. Por fim, a escolha das categorias ocorreu durante a pesquisa bibliográfica, por meio da análise das teorias e estudos encontrados que originou a estrutura teórica demonstrada no Quadro 7, no qual as variáveis compuseram as categorias desse estudo. Como a unidade de registro é o tema, a categorização foi semântica.

\subsubsection{Estudo específico: protocolo do estudo de caso único}

A validade dos achados em pesquisa conduzida por estudo de caso reside no rigor metodológico caracterizado pelo planejamento detalhado de toda a investigação, em que se destaca a construção do protocolo do caso, conforme apontam Martins e Theóphilo (2009).

O protocolo, assim como um questionário em uma pesquisa de levantamento, tem como objetivo viabilizar a coleta de dados. Além do instrumento de coleta, apresenta os procedimentos e as regras gerais que serão seguidas no uso do protocolo, sendo uma ferramenta importante, sobretudo, quando se adota um estudo de casos múltiplos. O protocolo aumenta a confiabilidade do estudo e destina-se a orientar o pesquisador na coleta de dados (YIN, 2010).

\subsubsection{Visão geral}

O estudo intitulado "Avaliação de resultados em educação corporativa - um estudo com as empresas que se destacam em gestão de pessoas” foi concebido para viabilizar a obtenção do título de mestre em ciências pela pesquisadora Carolina Aparecida de Freitas Dias. O estudo contou com o financiamento do Conselho Nacional de Desenvolvimento Científico e Tecnológico - CNPq, por meio da concessão de bolsa de mestrado à pesquisadora e com o apoio do Programa de Estudos em Gestão de Pessoas - PROGEP, por meio da 
disponibilização de dados agregados sobre as empresas participantes da pesquisa de clima organizacional conduzida pelo programa e acesso aos seus Cadernos de Evidências.

A investigação tem por objetivo geral identificar como as empresas que se destacam em gestão de pessoas realizam a avaliação de resultados em educação corporativa. Para viabilizar o alcance desse objetivo, foi realizada uma pesquisa ampla que procurou descrever as práticas de avaliação de resultados em educação corporativa empregadas pelas MEPT e uma pesquisa específica que teve o intuito de aprofundar o tema, por meio de estudo de caso único realizado na organização Itaú Unibanco. Para identificar o contexto em que se insere o caso, será descritos o sistema de educação corporativa da organização estudada; para contribuir com avanços na teoria sobre avaliação de resultados em educação corporativa, serão levantados e descritos os procedimentos de avaliação de resultados em EC empregados no caso estudado; por fim, para contribuir com novos achados, serão analisadas as limitações, vantagens e tendências de avaliação de resultados em EC no caso pesquisado.

Esta pesquisa justifica-se pela dificuldade das organizações em avaliar os resultados em educação corporativa, apesar de haver proposições teóricas para avaliar treinamentos que datam desde 1950. Investigar empresas bem-sucedidas na avaliação de resultados em educação corporativa pode indicar ajustes na teoria e proporcionar ampliação de sua aplicação empírica.

A fundamentação teórica deste estudo envolveu como eixos principais a educação corporativa e a avaliação de resultados em educação corporativa. Autores clássicos em educação corporativa são Meister (1999) e Eboli (2004; 2010). Já quanto à avaliação de resultados em educação corporativa, são indispensáveis as leituras de Kirkpatrick e Kirkpatrick (2010), Hamblin (1978), Phillips (1991); Borges-Andrade (1982; 2006) e Allen e McGee (2004), todos abordam modelos genéricos em avaliação de resultados em treinamento, exceto o estudo de Allen e McGee (2004) que é voltado especificamente para educação corporativa.

A seleção do caso para este estudo baseou-se na experiência anterior da pesquisadora, por ter conhecimento sobre a prática de avaliação de resultados em educação corporativa realizada pelo Itaú Unibanco, e na comparação deste caso com os resultados da pesquisa ampla, demonstrando que, de fato, o caso fornece as bases para a generalização teórica dos achados. Conforme aponta Yin (2010), algumas vezes a seleção é simples, pois o pesquisador pode já 
conhecer, desde o início da investigação, um caso singular. Entretanto, apesar de a seleção ser simples, é necessário certificar-se de que a escolha do caso foi apropriada. A escolha do caso único justifica-se neste estudo, pois ele representa um caso crítico no teste da teoria, ou seja, ele confirma algumas das teorias expostas neste estudo e as ampliam, visto que traz evidências sobre a ligação entre a avaliação de resultados em educação corporativa e o planejamento estratégico da organização.

Para realizar o convite formal à empresa objeto desta investigação, foi elaborada carta de apresentação da pesquisa (Apêndice A) e, posteriormente, foi solicitada autorização para a utilização dos dados coletados por meio de declaração (Apêndice B) que se baseou no modelo disponível no Código de Ética de Pesquisa. É válido destacar que este estudo observou os critérios éticos estabelecidos pela Faculdade de Economia, Administração e Contabilidade (FEA) da Universidade de São Paulo (USP) em seu Código de Ética de Pesquisa, divulgado por meio da Portaria FEA - 38/2009, de 7 de julho de 2009 e publicada no D.O.E de 14.7.2009.

Na coleta e análise de dados, buscou-se preservar as pessoas que forneceram dados para o estudo, por meio do anonimato no relato da pesquisa.

\subsubsection{Procedimentos de campo}

Para operacionalizar a pesquisa de campo, foram seguidas as etapas que seguem:

- Apresentação do projeto de pesquisa e pedido de autorização: Após a obtenção dos contatos, foi enviado e-mail de apresentação da pesquisa e convite para participação, disponibilizando-se a realizar uma apresentação presencial do projeto de pesquisa para dirimir dúvidas e esclarecer a contribuição da organização para o estudo, informando as condições da pesquisa (pessoas que serão entrevistadas, destaque do aspecto da participação voluntária, apresentação do roteiro de perguntas, acompanhamento de avaliações realizadas em EC, solicitação para gravação das entrevistas etc.).

- Conhecimento da organização estudada e de seu sistema de EC: apresentação pelo responsável pela área de Gestão de Pessoas e, ou, Educação Corporativa da organização, destacando aspectos de sua evolução e acontecimentos relevantes; e da 
EC também destacando sua evolução e acontecimentos relevantes. Identificação das seguintes informações: objetivos e missão (empresa e EC), estrutura organizacional (empresa e EC); número de funcionários (empresa e EC) e macro atividades (EC). Para preparar para esse encontro, procurar essas informações no site da empresa, no guia As Melhores Empresas para Você Trabalhar e no Caderno de Evidências a fim de tornar o encontro proveitoso para esclarecimento de dúvidas, caso haja necessidade.

- Conhecimento da forma como a organização avalia resultados em EC: apresentação, pela pessoa responsável pela avaliação em EC, da metodologia, processos e procedimentos adotados. Solicitaram-se cópias de documentos ou formulários utilizados; identificaram-se as atividades e etapas de avaliação; conheceram-se os sistemas/ferramentas utilizados; verificaram-se os relatórios elaborados; averiguou-se se há reuniões para compartilhamento dos resultados e planejamento das ações de melhoria; etc.

- Realização das entrevistas: aplicação das entrevistas aos gestores da área Gestão de Pessoas e Educação Corporativa; aos responsáveis pela avaliação de resultados em EC; ao responsável pelo planejamento estratégico da área GP; ao responsável pelo Sistema de Informações Gerenciais (SIG).

- Validação do rascunho do relatório: transcrição das entrevistas e elaboração do rascunho do relatório do caso para envio para validação pelo responsável pela EC, visando garantir o correto entendimento dos dados coletados.

- Proteção dos participantes: para garantir a privacidade e a confidencialidade dos participantes da pesquisa, foi realizada sua identificação no estudo por meio de codificação composta pela letra inicial do cargo do participante na organização (D para Diretor, S para superintendente, G para Gerente) e sua ordem na realização das entrevistas. O consentimento informado do participante foi realizado por meio de termo (Apêndice C) por ele assinado em que tomou ciência da natureza do estudo e em que foi solicitada sua participação voluntária. Esse termo foi elaborado a partir da adaptação do documento utilizado por Kerber (2007).

\subsubsection{Questões da pesquisa}

A partir da revisão bibliográfica, foi identificado um conjunto de variáveis a ser investigado na pesquisa de campo sobre o tema avaliação de resultados em educação corporativa. Essas 
variáveis resultaram da constatação de lacunas existentes nos modelos estudados e de pontos de convergência. Portanto, as variáveis de análise foram propostas visando ampliar o escopo de avaliação dos modelos existentes, buscando seu alinhamento ao sistema de avaliação em GP como um todo.

Para organizar as variáveis e fornecer o fluxo de encadeamento sobre a elaboração das perguntas, as primeiras foram agrupadas em dimensões que, por sua vez, foram definidas por meio da análise do referencial teórico, conforme demonstrado no Quadro 7. 
Quadro 7 - Dimensões e variáveis para avaliação de resultados em educação corporativa

\begin{tabular}{|c|c|c|c|c|c|c|c|}
\hline $\begin{array}{c}\text { ASPECTOS } \\
\text { PESOUISADOS }\end{array}$ & DEFINIÇÃO TEÓRICA & DIMENSÕES & DEFINIÇÃO TEÓRICA & VARIÁVEIS & AUTORES & FONTES DE EVIDÊNCIA & PERGUNTAS DA ENTREVISTA \\
\hline \multirow{6}{*}{$\begin{array}{l}\text { Educação } \\
\text { Corporativa }\end{array}$} & \multirow{6}{*}{$\begin{array}{l}\text { Processo educacional } \\
\text { estratégico que tem o } \\
\text { propósito de formar e } \\
\text { desenvolver os } \\
\text { stakeholders, alinhados } \\
\text { aos objetivos } \\
\text { organizacionais, de forma a } \\
\text { proporcionar e estimular a } \\
\text { aprendizagem contínua } \\
\text { (MEISTER, 1999; } \\
\text { VERGARA, 2000; } \\
\text { ALPERSTEDT, 2001; } \\
\text { ALLEN e MCGEE, 2004; } \\
\text { EBOLI, 2004; PILATI, } \\
\text { 2006). }\end{array}$} & \multirow{6}{*}{$\begin{array}{l}\text { Atuação } \\
\text { Estratégica }\end{array}$} & \multirow{6}{*}{\begin{tabular}{|l|} 
Auxiliar a organização no \\
alcance de seus objetivos e \\
resultados esperados \\
(MEISTER, 1999; VERGARA, \\
2000; ALPERSTEDT, 2001; \\
ALLEN e MCGEE, 2004; \\
EBOLI, 2004).
\end{tabular}} & $\begin{array}{l}\text { Entendimento sobre os } \\
\text { sistemas de educação } \\
\text { organizacional }\end{array}$ & \begin{tabular}{|l|} 
Meister (1999); Vergara \\
(2000); Alperstedt \\
(2001); Eboli (2004); \\
Pilati (2006); Vargas e \\
Abbad (2006)
\end{tabular} & $\begin{array}{l}\text { Entrevista com gestor da área EC; entrevista } \\
\text { com gestores da EC. }\end{array}$ & $\begin{array}{l}\text { Há diferença entre T\&DE, Educação } \\
\text { Corporativa e Universidade Corporativa? } \\
\text { Por quê? }\end{array}$ \\
\hline & & & & $\begin{array}{l}\text { Objetivos e missão da } \\
\text { EC }\end{array}$ & $\begin{array}{l}\text { Meister (1999); Eboli } \\
\text { (2010); }\end{array}$ & $\begin{array}{l}\text { Entrevista com gestor da área EC; entrevista } \\
\text { com gestores da EC; entrevista com } \\
\text { responsável pela avaliação em EC; } \\
\text { entrevista com gestor BSC; Cadernos de } \\
\text { Evidências. }\end{array}$ & $\begin{array}{l}\text { Quais são os objetivos da EC de sua } \\
\text { organização? }\end{array}$ \\
\hline & & & & \multirow{2}{*}{ Estrutura da EC } & \multirow[t]{2}{*}{$\begin{array}{l}\text { Meister (1999); Eboli } \\
\text { (2010); }\end{array}$} & $\begin{array}{l}\text { Entrevista com gestor da área EC; entrevista } \\
\text { com gestores da EC; entrevista com } \\
\text { responsável pela avaliação em EC; } \\
\text { relatórios; sistemas/ferramentas. }\end{array}$ & $\begin{array}{l}\text { De que forma está estruturado o sistema } \\
\text { de EC de sua organização (organograma } \\
\text { da área; parceria com } \\
\text { fornecedores/consultorias externas; } \\
\text { parcerias com insituições de ensino; } \\
\text { utilizam-se currículos de aprendizagem; } \\
\text { utilizam-se ferramentas tecnológicas)? }\end{array}$ \\
\hline & & & & & & $\begin{array}{l}\text { Entrevista com gestor da área EC; entrevista } \\
\text { com gestores de EC; entrevista com } \\
\text { responsável pela avaliação em EC; } \\
\text { Cadernos de Evidências. }\end{array}$ & $\begin{array}{l}\text { Quais são os macros processos do } \\
\text { sistema de EC de sua organização? } \\
\text { Descreva-os. }\end{array}$ \\
\hline & & & & $\begin{array}{l}\text { Alinhamento da EC a } \\
\text { GP }\end{array}$ & $\begin{array}{l}\text { Oliveira e Oliveira } \\
\text { (2011) }\end{array}$ & $\begin{array}{l}\text { Entrevista com gestor da área EC; entrevista } \\
\text { com gestor da área de GP; entrevista com } \\
\text { gestores de EC; entrevista com responsável } \\
\text { pela avaliação em EC; entrevista com gestor } \\
\text { do BSC; sistemas/ferramentas; Cadernos de } \\
\text { Evidências. }\end{array}$ & $\begin{array}{l}\text { Como ocorre o alinhamento entre a EC e } \\
\text { a GP na organização? É utilizada alguma } \\
\text { ferramenta para apoiar esse processo? }\end{array}$ \\
\hline & & & & $\begin{array}{l}\text { Alinhamento da EC aos } \\
\text { objetivos organizacionais }\end{array}$ & \begin{tabular}{|l|} 
\\
Meister (1999); Vergara \\
(2000); Alperstedt \\
(2001); Eboli (2004); \\
Pilati (2006).
\end{tabular} & $\begin{array}{l}\text { Entrevista com gestor da área de GP; } \\
\text { entrevista com gestor da área EC; entrevista } \\
\text { com gestores de EC; entrevista com } \\
\text { responsável pela avaliação em EC; } \\
\text { entrevista com gestor do BSC; Cadernos de } \\
\text { Evidências. }\end{array}$ & $\begin{array}{l}\text { Como ocorre o alinhamento entre as } \\
\text { ações educacionais e os objetivos } \\
\text { organizacionais? }\end{array}$ \\
\hline
\end{tabular}


Continuação do Quadro 7

\begin{tabular}{|c|c|c|c|c|c|c|c|}
\hline $\begin{array}{l}\text { ASPECTOS } \\
\text { PESQUISADOS }\end{array}$ & DEFINIÇÃO TEÓRICA & DIMENSÕES & DEFINIÇÃO TEÓRICA & VARIÁVEIS & AUTORES & FONTES DE EVIDÊNCIA & PERGUNTAS DA ENTREVISTA \\
\hline \multirow[t]{2}{*}{$\begin{array}{l}\text { Educação } \\
\text { Corporativa }\end{array}$} & \multirow{2}{*}{\begin{tabular}{|l|} 
Processo educacional \\
estratégico que tem o \\
propósito de formar e \\
desenvolver os \\
stakeholders, alinhados \\
aos objetivos \\
organizacionais, de forma a \\
proporcionar e estimular a \\
aprendizagem contínua \\
(MEISTER, 1999; \\
VERGARA, 2000; \\
ALPERSTEDT, 2001; \\
ALLEN e MCGEE, 2004; \\
EBOLI, 2004; PILATI, \\
2006).
\end{tabular}} & Público-alvo & \begin{tabular}{|l|} 
O público-alvo da EC \\
ultrapassa as fronteiras da \\
organização e engloba, além \\
dos funcionários, os clientes, \\
fornecedores, franqueados, \\
comunidade e outros públicos \\
que tenham relação com a \\
organização (MEISTER, \\
1999; VERGARA, 2000; \\
ALPERSTEDT, 2001; EBOLI, \\
2004; PILATI, 2006).
\end{tabular} & Públicos atendidos pela & $\begin{array}{l}\text { Meister (1999); Vergara } \\
\text { (2000); Alperstedt } \\
\text { (2001); Eboli (2004); } \\
\text { Pilati (2006). }\end{array}$ & $\begin{array}{l}\text { Entrevista com gestor da área EC; entrevista } \\
\text { com gestores da EC; relatórios; Cadernos } \\
\text { de Evidências. }\end{array}$ & $\begin{array}{l}\text { Quais são os públicos atendidos pelos } \\
\text { programas de EC? }\end{array}$ \\
\hline & & \begin{tabular}{|l|} 
Cultura de \\
aprendizagem \\
contínua
\end{tabular} & \begin{tabular}{|l|} 
Estimular e proporcionar \\
meios para que a \\
aprendizagem seja ativa e \\
contínua na organização \\
(MEISTER, 1999; VERGARA, \\
2000; EBOLI, 2010).
\end{tabular} & $\begin{array}{l}\text { Promoção da } \\
\text { aprendizagem contínua }\end{array}$ & \begin{tabular}{|l|} 
Meister (1999); Vergara \\
(2000); Eboli (2010);
\end{tabular} & $\begin{array}{l}\text { Entrevista com gestor da área EC; entrevista } \\
\text { com gestores da EC; entrevista } \\
\text { sistemas/ferramentas de aprendizagem } \\
\text { colaborativa; Cadernos de Evidências. }\end{array}$ & $\begin{array}{l}\text { Há uma cultura de aprendizagem } \\
\text { contínua na organização? Quais são as } \\
\text { práticas empregadas pela EC para a } \\
\text { promoção dessa cultura? }\end{array}$ \\
\hline \multirow{5}{*}{ Resultados } & \multirow{5}{*}{\begin{tabular}{|l|} 
Efeitos gerados pelos \\
programas no nivel \\
individual e da organização, \\
sendo esta última refletida \\
em seu funcionamento ou \\
em seus critérios de \\
sucesso (BORGES- \\
ANDRADE, 1982. 2006; \\
PHILLIPS, 1991; \\
KIRKPATRICK e \\
KIRKPATRICK, 2010; \\
HAMBLIM, 1978)
\end{tabular}} & \multirow{5}{*}{$\begin{array}{l}\text { Medidas de } \\
\text { efetividade da EC }\end{array}$} & \multirow{5}{*}{\begin{tabular}{|l|} 
A efetividade trata do efeito \\
das atividades nos \\
resultados, sendo um \\
sistema efetivo quando uma \\
atividade gera resultados \\
predeterminados com alto \\
grau de previsibilidade. O \\
critério efetividade é avaliado \\
pela dimensão qualidade do \\
ensino mensurada por meio \\
da identificação do quão bem \\
os participantes conseguem \\
alcançar os objetivos do \\
programa (ALLEN e MCGEE, \\
2004).
\end{tabular}} & $\begin{array}{l}\text { Reação dos } \\
\text { pariticipantes ao } \\
\text { programa }\end{array}$ & \begin{tabular}{|l|} 
Borges-Andrade (1982); \\
Kirkpatrick e \\
Kirkpatrick (2010); \\
Hamblim (1978); Fitz- \\
enz (1995)
\end{tabular} & $\begin{array}{l}\text { Entrevista com gestor da área EC; entrevista } \\
\text { com gestores da EC; entrevista com } \\
\text { responsável pela avaliação em EC; } \\
\text { formulários utilizados; sistemas/ } \\
\text { ferramentas; Cadernos de Evidências. }\end{array}$ & $\begin{array}{l}\text { De que forma são avaliadas as reações } \\
\text { dos participantes? Quais fatores são } \\
\text { avaliados? }\end{array}$ \\
\hline & & & & \multirow{2}{*}{\begin{tabular}{|l} 
Mudanças de \\
comportamento em nível \\
individual medidos como \\
melhora de \\
conhecimentos, \\
habilidades e atitudes
\end{tabular}} & \multirow{2}{*}{$\begin{array}{l}\text { Borges-Andrade (1982); } \\
\text { Phillips (1991); } \\
\text { Kirkpatrick e } \\
\text { Kirkpatrick (2010); } \\
\text { Hamblim (1978) }\end{array}$} & $\begin{array}{l}\text { Entrevista com gestores da EC; entrevista } \\
\text { com responsável pela avaliação em EC; } \\
\text { Cadernos de Evidências. }\end{array}$ & $\begin{array}{l}\text { A aferição da aprendizagem é realizada } \\
\text { de que forma? }\end{array}$ \\
\hline & & & & & & $\begin{array}{l}\text { Entrevista com gestores da EC; entrevista } \\
\text { com responsável pela avaliação em EC; } \\
\text { Cadernos de Evidências. }\end{array}$ & $\begin{array}{l}\text { Como é avaliado se os programas } \\
\text { promoveram as mudanças de } \\
\text { comportamentos (atitudes e habilidades) } \\
\text { a que se propuseram? }\end{array}$ \\
\hline & & & & \begin{tabular}{|l|} 
Mudança de \\
comportamento no cargo \\
o nível em que se verifica \\
se os treinandos \\
aplicaram o que \\
aprenderam no exercício \\
de suas atividades
\end{tabular} & $\begin{array}{l}\text { Kirkpatrick e } \\
\text { Kirkpatrick (2010); } \\
\text { Hamblim (1978), Fitz- } \\
\text { enz (1995), Borges- } \\
\text { Andrade (2006) }\end{array}$ & $\begin{array}{l}\text { Entrevista com gestores da EC; entrevista } \\
\text { com responsável pela avaliação em EC; } \\
\text { formulários utilizados; Cadernos de } \\
\text { Evidências. }\end{array}$ & $\begin{array}{l}\text { Como é avaliado se o que foi aprendido } \\
\text { no programa está sendo aplicado ao } \\
\text { trabalho? }\end{array}$ \\
\hline & & & & $\begin{array}{l}\text { Efeitos da mudança de } \\
\text { comportamento no } \\
\text { trabalho em mudanças } \\
\text { sobre o funcionamento } \\
\text { da empresa }\end{array}$ & Hamblin (1978) & $\begin{array}{l}\text { Entrevista com gestores da EC; entrevista } \\
\text { com responsável pela avaliação em EC; } \\
\text { Cadernos de Evidências. }\end{array}$ & $\begin{array}{l}\text { De que forma é avaliado se a mudança de } \\
\text { comportamento no trabalho está } \\
\text { provocando mudanças no funcionamento } \\
\text { da empresa? }\end{array}$ \\
\hline
\end{tabular}

Continua... 
Continuação do Quadro 7

\begin{tabular}{|c|c|c|c|c|c|c|c|}
\hline $\begin{array}{l}\text { ASPECTOS } \\
\text { PESQUISADOS }\end{array}$ & DEFINIÇÃO TEÓRICA & DIMENSÕES & DEFINIÇÃO TEÓRICA & VARIÁVEIS & AUTORES & FONTES DE EVIDÊNCIA & PERGUNTAS DA ENTREVISTA \\
\hline \multirow{3}{*}{ Resultados } & \multirow{3}{*}{$\begin{array}{l}\text { Efeitos gerados pelos } \\
\text { programas no nível } \\
\text { individual e da organização, } \\
\text { sendo esta última refletida } \\
\text { em seu funcionamento ou } \\
\text { em seus critérios de } \\
\text { sucesso (BORGES- } \\
\text { ANDRADE, 1982. 2006; } \\
\text { PHILLIPS, 1991; } \\
\text { KIRKPATRICK, e } \\
\text { KIRKPATRICK 2010; } \\
\text { HAMBLIM, 1978) }\end{array}$} & \multirow{3}{*}{$\begin{array}{l}\text { Medidas de } \\
\text { efetividade da EC }\end{array}$} & \multirow{3}{*}{$\begin{array}{l}\text { A efetividade trata do efeito } \\
\text { das atividades nos } \\
\text { resultados, sendo um } \\
\text { sistema efetivo quando uma } \\
\text { atividade gera resultados } \\
\text { predeterminados com alto } \\
\text { grau de previsibilidade. O } \\
\text { critério efetividade é avaliado } \\
\text { pela dimensão qualidade do } \\
\text { ensino mensurada por meio } \\
\text { da identificação do quão bem } \\
\text { os participantes conseguem } \\
\text { alcançar os objetivos do } \\
\text { programa (ALLEN e MCGEE, } \\
\text { 2004). }\end{array}$} & \multirow[b]{2}{*}{$\begin{array}{l}\text { Alcance dos objetivos } \\
\text { organizacionais }\end{array}$} & $\begin{array}{l}\text { Kirkpatrick e } \\
\text { Kirkpatrick (2010); } \\
\text { Hamblim (1978), } \\
\text { Phillips (1991); Allen e } \\
\text { McGee (2004) }\end{array}$ & $\begin{array}{l}\text { Entrevista com gestores da EC; entrevista } \\
\text { com responsável pela avaliação em EC; } \\
\text { entrevista com gestor do BSC; entrevista } \\
\text { com gestor do SIG; sistemas/ferramenta; } \\
\text { Cadernos de Evidências. }\end{array}$ & $\begin{array}{l}\text { Como é avaliado se a EC está auxiliando } \\
\text { a organização a atingir seus objetivos? } \\
\text { Quaas ferramentas ou sistemas são } \\
\text { utilizados para isso? }\end{array}$ \\
\hline & & & & & $\begin{array}{l}\text { Becker, Huselid e } \\
\text { Ulrich (2001) }\end{array}$ & $\begin{array}{l}\text { Entrevista com gestores da EC; entrevista } \\
\text { com responsável pela avaliação em EC; } \\
\text { entrevista com gestor do BSC; formulários } \\
\text { utilizados; Cadernos de Evidências. }\end{array}$ & $\begin{array}{l}\text { Como ocorre a avaliação em GP em sua } \\
\text { organização? } \\
\text { De que forma a avaliação em GP e a } \\
\text { avaliação em educação corporativa se } \\
\text { relacionam? }\end{array}$ \\
\hline & & & & \begin{tabular}{|l} 
Disseminação da cultura \\
organizacional
\end{tabular} & $\begin{array}{l}\text { Meister (1999); Éboli } \\
\text { (2004); Panczuk, } \\
\text { (2001, apud MORIN e } \\
\text { RENAUD, 2004) }\end{array}$ & $\begin{array}{l}\text { Entrevista com gestores da EC; entrevista } \\
\text { com responsável pela avaliação em EC; } \\
\text { Cadernos de Evidências. }\end{array}$ & $\begin{array}{l}\text { De que maneira é avaliado se a } \\
\text { disseminação da cultura da organização } \\
\text { está sendo promovida pela educação } \\
\text { corporativa? }\end{array}$ \\
\hline \multirow{4}{*}{ Resultados } & \multirow{4}{*}{$\begin{array}{l}\text { Efeitos gerados pelos } \\
\text { programas no nivel } \\
\text { individual e da organização, } \\
\text { sendo esta última refletida } \\
\text { em seu funcionamento ou } \\
\text { em seus critérios de } \\
\text { sucesso (BORGES- } \\
\text { ANDRADE, 1982. 2006; } \\
\text { PHILLIPS, 1991; } \\
\text { KIRKPATRICK e } \\
\text { KIRKPATRICK, 2010; } \\
\text { HAMBLIM, 1978) }\end{array}$} & \multirow{4}{*}{$\begin{array}{l}\text { Medidas de } \\
\text { eficiência da EC }\end{array}$} & \multirow{4}{*}{$\begin{array}{l}\text { A eficiência trata da dinâmica } \\
\text { de relacionamento entre } \\
\text { recursos e atividades, } \\
\text { respondendo a seguinte } \\
\text { questão: "Quanto custa". } \\
\text { Esse critério é avaliado por } \\
\text { meio da estratégia } \\
\text { instrucional, definida pelos } \\
\text { autores como a escolha dos } \\
\text { meios mais eficientes pelos } \\
\text { quais o currículo possa ser } \\
\text { ensinado (ALLEN e MCGEE, } \\
\text { 2004). }\end{array}$} & \multirow[b]{2}{*}{$\begin{array}{l}\text { Controle dos custos com } \\
\text { treinamento (diretos e } \\
\text { indiretos) }\end{array}$} & \multirow{2}{*}{ Fitz-enz (1995) } & $\begin{array}{l}\text { Entrevista com gestores da EC; entrevista } \\
\text { com responsável pela avaliação em EC; } \\
\text { entrevista com gestor do SIG; sistemas/ } \\
\text { ferramenta; relatórios; Cadernos de } \\
\text { Evidências. }\end{array}$ & $\begin{array}{l}\text { É realizado controle dos custos } \\
\text { envolvidos diretamente com os } \\
\text { programas, tais como remuneração dos } \\
\text { consultores, o aluguel de sala, os } \\
\text { recursos, a alimentação, o transporte e a } \\
\text { hospedagem? Como é realizado o } \\
\text { controle? }\end{array}$ \\
\hline & & & & & & $\begin{array}{l}\text { Entrevista com gestores da EC; entrevista } \\
\text { com responsável pela avaliação em EC; } \\
\text { entrevista com gestor do SIG; sistemas/ } \\
\text { ferramenta; relatórios; Cadernos de } \\
\text { Evidências. }\end{array}$ & $\begin{array}{l}\text { É realizado controle dos custos indiretos } \\
\text { relacionados aos programas, tais como } \\
\text { salários e benefícios dos treinandos, } \\
\text { salários e benefícios dos treinadores, } \\
\text { custo fixo da área de treinamento? Como } \\
\text { é realizado o controle? }\end{array}$ \\
\hline & & & & $\begin{array}{l}\text { Eficiência na utilização } \\
\text { dos recursos }\end{array}$ & $\begin{array}{l}\text { Fitz-enz (1995); Phillips } \\
\text { (1991) }\end{array}$ & $\begin{array}{l}\text { Entrevista com gestores da EC; entrevista } \\
\text { com responsável pela avaliação em EC; } \\
\text { entrevista com gestor do SIG; } \\
\text { sistemas/ferramenta; Cadernos de } \\
\text { Evidências. }\end{array}$ & $\begin{array}{l}\text { Como é realizada a avaliação dos } \\
\text { programas em relação ao uso eficiente do } \\
\text { orçamento? }\end{array}$ \\
\hline & & & & $\begin{array}{l}\text { Avaliação dos } \\
\text { procedimentos: engloba } \\
\text { o planejamento e } \\
\text { execução dos } \\
\text { programas de } \\
\text { treinamento, envolvendo } \\
\text { as formas pelas quais a } \\
\text { aprendizagem será } \\
\text { promovida. }\end{array}$ & $\begin{array}{l}\text { Borges-Andrade (1982; } \\
\text { 2006); Phillips (1991); } \\
\text { Kirkpatrick e } \\
\text { Kirkpatrick (2010) }\end{array}$ & $\begin{array}{l}\text { Entrevista com gestores da EC; entrevista } \\
\text { com responsável pela avaliação em EC; } \\
\text { formulários utilizados; Cadernos de } \\
\text { Evidências. }\end{array}$ & $\begin{array}{l}\text { Como é avaliado se a estratégia } \\
\text { instrucional adotada para os programas } \\
\text { está auxiliando no ensino dos currículos? }\end{array}$ \\
\hline
\end{tabular}

Continua... 
Continuação do Quadro 7

\begin{tabular}{|c|c|c|c|c|c|c|c|}
\hline $\begin{array}{l}\text { ASPECTOS } \\
\text { PESQUISADOS }\end{array}$ & DEFINIÇÃO TEÓRICA & DIMENSÕES & DEFINIÇÃO TEÓRICA & VARIÁVEIS & AUTORES & FONTES DE EVIDÊNCIA & PERGUNTAS DA ENTREVISTA \\
\hline \multirow{3}{*}{ Resultados } & \multirow{3}{*}{$\begin{array}{l}\text { Efeitos gerados pelos } \\
\text { programas no nivel } \\
\text { individual e da organização, } \\
\text { sendo esta última refletida } \\
\text { em seu funcionamento ou } \\
\text { em seus critérios de } \\
\text { sucesso (BORGES- } \\
\text { ANDRADE, 1982. 2006; } \\
\text { PHLLIIPS, 1991; } \\
\text { KIRKPATRICK e } \\
\text { KIRKPATRICK, 2010; } \\
\text { HAMBLIM, 1978) }\end{array}$} & \multirow{3}{*}{$\begin{array}{l}\text { Limitações, } \\
\text { vantagens e } \\
\text { tendências sobre } \\
\text { avaliação em EC. }\end{array}$} & \multirow{3}{*}{ Não se aplica. } & $\begin{array}{l}\text { Limitações do método } \\
\text { de avaliação de } \\
\text { resultados em EC. }\end{array}$ & \multirow{3}{*}{ Não se aplica. } & $\begin{array}{l}\text { Entrevista com gestor de GP; entrevista } \\
\text { com gestor da área EC; entrevista com } \\
\text { gestores da EC; entrevista com responsável } \\
\text { pela avaliação em EC; entrevista com gestor } \\
\text { de BSC. }\end{array}$ & $\begin{array}{l}\text { Quais são as limitações da metodologia } \\
\text { empregada? O que é feito para superar } \\
\text { essas limitações? }\end{array}$ \\
\hline & & & & $\begin{array}{l}\text { Vantagens do método de } \\
\text { avaliação de resultados } \\
\text { em EC. }\end{array}$ & & $\begin{array}{l}\text { Entrevista com gestor de GP; entrevista } \\
\text { com gestor da área EC; entrevista com } \\
\text { gestores da EC; entrevista com responsável } \\
\text { pela avaliação em EC; entrevista com gestor } \\
\text { de BSC. }\end{array}$ & $\begin{array}{l}\text { Explique as vantagens da metodologia de } \\
\text { avaliação em EC empregada em sua } \\
\text { organização. }\end{array}$ \\
\hline & & & & \begin{tabular}{|} 
Tendências em avaliação \\
de resultados em EC.
\end{tabular} & & $\begin{array}{l}\text { Entrevista com gestor de GP; entrevista } \\
\text { com gestor da área EC; entrevista com } \\
\text { gestores da EC; entrevista com responsável } \\
\text { pela avaliação em EC; entrevista com gestor } \\
\text { de BSC. }\end{array}$ & $\begin{array}{l}\text { Em sua opinião quais são as tendências } \\
\text { em avaliação de EC? (pedir ao } \\
\text { entrevistado para pensar em termos } \\
\text { gerais e não apenas na organização em } \\
\text { que trabalha). }\end{array}$ \\
\hline
\end{tabular}




\subsubsection{Relatório do estudo de caso}

Foi realizado um relatório individual para o estudo de caso e, posteriormente, seus dados foram analisados em conjunto com os resultados da pesquisa ampla com as MEPT, promovendo-se comparações entre os achados com a finalidade de verificar se há convergência ou não de resultados.

O relatório do estudo de caso foi composto por três partes principais. A primeira tratou do contexto em que se insere a avaliação de resultados em EC, apoiando-se em dois aspectos principais: a organização estudada, por meio de análise de fatores históricos importantes, sua evolução e posição atual; e o sistema de EC pelo estudo de sua atuação estratégica, público atendido e cultura de aprendizagem contínua. Portanto, a descrição da organização e do sistema de EC e a análise de suas principais características, destacando elementos que podem afetar a avaliação de resultados em EC, compuseram esta fase inicial do relatório.

A segunda parte foi composta pela discussão e análise das práticas e procedimentos que compõem a avaliação de resultados em EC no caso estudado à luz das variáveis levantadas neste estudo. Complementarmente, abordou-se as limitações e vantagens das formas de avaliação de resultado em EC utilizadas pelas organizações estudadas, bem como as tendências apontadas pelos entrevistados.

Por fim, a terceira parte foi composta pela síntese dos resultados, conclusões sobre o caso estudado, sugestões para futuras pesquisas e dificuldades encontradas na realização do estudo.

\subsection{Unidades de análise}

A unidade de análise neste estudo é o processo de avaliação de resultados em educação corporativa. O estudo foi composto por duas pesquisas: ampla e específica. A primeira considerou, para efeito de análise, as empresas que constam na classificação da pesquisa As Melhores Empresas para Você Trabalhar, da revista Você S.A, edição 2011. Nesta pesquisa foram analisados os Cadernos de Evidências disponibilizados em meio digital, sendo assim, foram consideradas 144 organizações. Analisou-se também algumas variáveis do questionário on line respondido pelas organizações, considerando os dados de forma agregada. 
Já a pesquisa específica, realizada por meio de estudo de caso, foi conduzida no Itaú Unibanco, onde foram realizadas nove entrevistas, cada uma com duração de aproximadamente uma hora e meia. Foram entrevistados o diretor responsável pelas áreas de cultura, recrutamento e seleção, talentos, relações sindicais e educação corporativa; a superintendente responsável pela área de educação corporativa; a superintendente responsável pelo planejamento estratégico da área de gestão de pessoas; e cinco gerentes que atuam na área de educação corporativa, sendo que um deles também é responsável pelo Sistema de Informações Gerenciais (SIG) da diretoria e, desse modo, foi conduzida uma entrevista específica sobre essas atividades.

Conforme a Política de Uso do Banco Dados da Pesquisa As Melhores Empresas para Você Trabalhar: Dados edição 2010 (2011, pag. 2), o Caderno de Evidências compõe o Índice de Qualidade da Gestão de Pessoas (IQGP), o qual tem a seguinte composição:

“IQGP - Índice de Qualidade da Gestão de Pessoas: composto por dados relativos às políticas e práticas que a empresa adota para os seus empregados. É obtido por meio de informações fornecidas pela empresa em um formulário eletrônico sobre seus processos de gestão de pessoas (10\% da nota total ou 50\% do IQGP), além do Caderno de Evidências (10\% da nota total ou 50\% do IQGP). Este índice equivale a 20\% do total de pontos na apuração do IFT.”

A pesquisa As Melhores Empresas para Você Trabalhar tem como objetivo identificar as melhores empresas para se trabalhar no Brasil, realizando pesquisa de clima organizacional em que se identificam as melhores práticas de recursos humanos na opinião dos empregados e segundo informações prestadas pelas empresas. A classificação é realizada a partir da apuração do Índice de Felicidade no Trabalho (IFT), que é composto pelos índices IQGP (equivalente a 20\%), IQAT - Índice de Qualidade do Ambiente de Trabalho (equivalente a $70 \%$ ) e avaliação realizada por jornalistas às empresas pré-classificadas (equivalente a 10\%) (POLÍTICA DE USO DO BANCO DADOS PESQUISA AS MELHORES EMPRESAS PARA VOCÊ TRABALHAR: DADOS EDIÇÃO 2010, 2011).

Para compor o índice IQGP, as empresas participantes preenchem em torno de 60 questões on-line e enviam material institucional complementar, o Caderno de Evidências. Já o índice 
IQAT é obtido a partir das respostas de cerca de 120 mil questionários válidos, compostos por 80 questões com preenchimento on-line e em papel. Os temas abrangidos pela pesquisa são clima organizacional, liderança, estratégias, carreiras, remuneração e benefícios, gestão do treinamento, desenvolvimento e educação corporativa, cidadania empresarial e qualidade de vida no trabalho (POLÍTICA DE USO DO BANCO DADOS PESQUISA AS MELHORES EMPRESAS PARA VOCÊ TRABALHAR: DADOS EDIÇÃO 2010, 2011).

A pesquisa As Melhores Empresas para Você Trabalhar do Brasil é fruto de uma parceria entre a Fundação Instituto de Administração (FIA), por meio do Programa de Estudos em Gestão de Pessoas (PROGEP) e a revista Você S/A. A pesquisa é coordenada por professores da FEA-USP, a qual mantém os dados para a elaboração do guia em bases que servem como material de pesquisa para projetos acadêmicos de seus cursos de graduação e pós-graduação, dos programas de especialização da FIA e para professores e alunos de outras instituições. No ano de 2010, a pesquisa obteve respostas de mais de 120 mil profissionais de cerca de 490 empresas (POLÍTICA DE USO DO BANCO DADOS PESQUISA AS MELHORES EMPRESAS PARA VOCÊ TRABALHAR: DADOS EDIÇÃO 2010, 2011).

\subsection{Validade e confiabilidade do estudo}

Em ciências sociais, há quatro testes geralmente usados para estabelecer a qualidade de pesquisas sociais empíricas, são eles: validade do constructo, validade interna, validade externa e confiabilidade (YIN, 2010). Esses testes também são aplicáveis para proporcionar qualidade ao estudo de caso, sendo traduzidos em táticas recomendadas, conforme se descreve a seguir (YIN, 2010, passim).

A validade do constructo é alcançada por meio da identificação de medidas operacionais corretas para os conceitos estudados, o que perpassa pela definição dos termos da pesquisa e seu alinhamento aos objetivos do estudo e identificação de medidas que combinam conceitos. As táticas de estudo que proporcionam a validade do constructo são o uso de múltiplas fontes de evidência, o estabelecimento de uma cadeia de evidências e a revisão do rascunho do relatório de estudo de caso pelos informantes-chave, todas realizadas nesse estudo. 
A validade interna é aplicada a estudos de caso que buscam estudar relações de causa e efeito, não sendo aplicado a estudos de caso descritivos e exploratórios. Esse tipo de teste busca minimizar o problema da inferência realizada pelo pesquisador, por meio da utilização das táticas de combinação de padrão, construção de explanações, tratamento de explanações rivais e uso de modelos lógicos.

O terceiro teste, validade externa, trata da generalização do estudo de caso. Muitos pesquisadores apontam que um estudo de caso único é fraco para realizar generalizações, entretanto, estão comparando o estudo de caso aos levantamentos que possuem generalização estatística. O estudo de caso possui generalização analítica, que se caracteriza pela busca da generalização dos resultados a alguma teoria mais ampla. Todavia, a generalização se dá por meio da replicação dos achados da pesquisa para um segundo ou terceiro local, onde se supõe que ocorreriam os mesmos resultados. Nesse sentido, Martins e Theóphilo (2009) mencionam que, enquanto as pesquisas quantitativas são mais aplicáveis ao processo de testar teorias, as avaliações qualitativas são mais aplicáveis quando se deseja construir teorias, enfoque da pesquisa de estudo de caso.

O teste de confiabilidade tem como objetivo garantir que, se um segundo pesquisador realizar o mesmo procedimento descrito pelo primeiro e conduzir o estudo de caso na mesma unidade de análise, ele deverá ter os mesmos resultados. Esse teste tem o intuito de minimizar os erros e as parcialidades no estudo. Desse modo, torna-se fundamental a documentação dos procedimentos seguidos no caso, por meio do uso do protocolo de estudo de caso e do desenvolvimento de uma base de dados do estudo de caso, recomendações estas que foram observadas na condução dessa pesquisa.

A opção pelo método de estudo de caso único ou múltiplo perpassa mais o campo empírico do que teórico do estudo. O estudo de casos múltiplos é preferível ao estudo de caso único, pois dá mais robustez aos resultados encontrados, visto que segue a lógica da replicação. Entretanto, o caso único é justificável quando haja um caso raro, único ou exclusivo sobre o tema de sua pesquisa (YIN, 2010). Portanto, a definição sobre a adoção ou não do caso único ou múltiplo apoia-se mais no que o pesquisador encontrará em campo. Ainda, sobre a escolha do método de estudo de caso único ou múltiplo, o autor aborda como variável influenciadora a maturidade do pesquisador. Segundo Yin (2010, p. 192): 
“Não surpreendentemente, a análise é o estágio mais difícil na realização do estudo de caso, e os pesquisadores iniciantes provavelmente terão uma experiência perturbadora. Novamente, uma recomendação é a de iniciar com um estudo de caso simples e direto [...].”

Um aspecto importante no estudo de caso é a flexibilidade. A partir da coleta de dados, situações novas e diferentes das esperadas podem surgir e exigir revisão parcial ou total do projeto inicial de pesquisa, mudando inclusive questões e proposições de pesquisa, conforme aponta Yin (2010). Todavia, essa flexibilidade deve vir acompanhada de rigor metodológico, assim, Yin (2010, p. 97) destaca “a necessidade de equilibrar a adaptabilidade com o rigor mas não com a rigidez”.

A flexibilidade também é uma característica que perpassa a técnica de análise de dados deste estudo: a análise de conteúdo (BARDIN, 2009). Há também critérios para que se busquem a confiabilidade e a validade nesta técnica de análise de dados, são eles a descrição e a execução de cada uma das fases da análise; e a organização dos dados (MOZZATO e GRZYBOVSKI, 2011). Ainda em relação à validade, é necessário que haja qualidade na elaboração conceitual realizada a priori pelo pesquisador, exatidão em sua tradução em variáveis, esquema de análise ou das categorias e que estas tenham concordância com a realidade analisada (FREITAS, CUNHA e MOSCAROLA, 1997, p. 108 apud MOZZATO e GRZYBOVSKI, 2011).

\subsection{Instrumentos de coleta de dados}

Nesta pesquisa foi utilizada a técnica de entrevista semiestruturada na condução do estudo de caso. Segundo Selltiz (1987), a principal vantagem da entrevista sobre o questionário é que ela quase sempre produz uma melhor amostra da população em estudo, já que, após diversos acompanhamentos, a taxa de retorno de questionários enviados por correio é de 10 a 15\%. Já o índice de resposta para a entrevista face a face ou por telefone fica em aproximadamente 70 a $80 \%$. Outra vantagem apontada pela autora é que a entrevista permite evitar a inabilidade de muitas pessoas em responder de forma adequada por escrito; isso ocorre, pois o questionário é apropriado apenas a sujeitos com um considerável nível educacional. Por fim, a entrevista permite que se corrijam enganos dos informantes, ou seja, interpretação errada de determinada questão. Entretanto, quanto a essa última vantagem, a autora ressalta que é 
limitada, pois em um levantamento padrão o entrevistador é comumente instruído a apenas repetir as questões em vez de explicá-las.

\subsection{Tratamento e análise dos dados}

O método de estudo de caso ainda é carente no que tange à análise das evidências, conforme aponta Yin (2010). Para o autor, a análise das evidências é especialmente difícil, pois as técnicas ainda não foram suficientemente definidas, por isso, elaborar uma estratégia analítica geral toma grande importância, visto que orienta a estabelecer prioridades sobre o que e por que analisar. Assim, esta pesquisa adotará como estratégia geral:

a) desenvolver a descrição do caso;

b) verificar os fatores contextuais que podem influenciar a adoção da avaliação de resultados em educação corporativa. Os fatores contextuais referem-se às características da organização, de sua educação corporativa e das práticas e ferramentas utilizadas na avaliação em educação corporativa.

Já como técnica de análise dos estudos de caso, primeiramente os dados oriundos de entrevistas e de documentos serão categorizados e analisados por meio da técnica de análise de conteúdo, a qual se caracteriza pelo tratamento sistemático dos dados com o objetivo de identificar o que está sendo dito a respeito de determinado tema (VERGARA, 2008). O cruzamento dos dados obtidos na análise documental e nas entrevistas possibilitará o entendimento das práticas de avaliação em educação corporativa utilizadas pelas empresas que se destacam em gestão de pessoas, analisando-as à luz das variáveis levantadas neste estudo.

Neste trabalho foi utilizada a técnica de triangulação de dados no estudo de caso, por meio do emprego de diferentes fontes de evidência: documentos da organização; seus sistemas e, ou, ferramentas utilizados para suportar o processo de avaliação de resultados em EC; e as entrevistas semiestruturadas com gestores de GP, gestores de EC, gestor do planejamento estratégico da Área Pessoas e responsáveis pela avaliação de resultados em EC. Segundo Martins e Theóphilo (2009), há quatro tipos de triangulação: a de fontes de dados; a de 
avaliação de pesquisadores; a de teorias; e a metodológica. Este estudo utilizou o primeiro tipo de triangulação, a que emprega diferentes fontes de dados.

\subsubsection{Análise de conteúdo}

Cabe neste momento do estudo uma explanação sobre a análise de conteúdo. Foi utilizada como referência central a obra de Bardin (2009) e como apoio o artigo de Mozzato e Grzybovski (2011) e o livro de Vergara (2008).

A análise de conteúdo justifica-se neste estudo, pois é uma técnica de análise que apresenta técnicas refinadas que buscam ultrapassar as incertezas e já se consolidou como uma abordagem clássica para análise de material textual (MOZZATO e GRZYBOVSKI, 2011). Ainda segundo os autores, sendo o investigador o instrumento principal, o interesse de análise está no processo e não nos resultados e produtos. Este estudo caracteriza-se pelo estudo do processo de avaliação de resultados em educação corporativa, estando, assim, alinhado ao uso dessa abordagem. Outro ponto importante a destacar é que o contexto é um fator importante para a análise de conteúdo, apresentando compatibilidade estreita ao método de estudo de caso, que também o considera como aspecto extremamente relevante na análise.

Cabe ainda salientar que a análise de conteúdo tem se mostrado, como técnica de análise, de grande potencial para o avanço das pesquisas em administração, conforme apontado por Mozzato e Grzybovski (2011) e seu uso tem se legitimado neste campo.

A análise de conteúdo é uma abordagem de análise muito rica, pois, compõe-se por diferentes técnicas e métodos (MOZZATO e GRZYBOVSKI, 2011). Segundo Bardin (2009), é uma técnica muito empírica que depende do tipo de fala a ser analisada e do tipo de interpretação que se busca. Ainda, segundo a autora, a análise de conteúdo apresenta dois objetivos principais:

a) a superação da incerteza - rigor: a interpretação que o pesquisador realiza da mensagem pode ser partilhada por outros? Ou seja, a leitura que ele realiza é válida e generalizável?; 
b) o enriquecimento da leitura - necessidade de descobrir: além da leitura imediata, busca também significados e descrição de mecanismos que não são compreendidos $a$ priori, mas a partir de uma leitura atenta.

Para conceituar a análise de conteúdo, Bardin (2009) vai, aos poucos, esclarecendo cada frase que compõe o conceito, por meio de tópicos que mostram a complexidade dessa abordagem de análise. A seguir é transcrito o conceito e, em seguida, há uma breve compreensão sobre ele:

\footnotetext{
"Um conjunto de técnicas de análise das comunicações visando obter por procedimentos sistemáticos e objetivos de descrição do conteúdo das mensagens indicadores (quantitativos ou não) que permitam a inferência de conhecimentos relativos às condições de produção/recepção (variáveis inferidas) destas mensagens.” (BARDIN, 2009, p. 44)
}

Como observado anteriormente, a análise de conteúdo não é uma técnica, mas um conjunto de técnicas e métodos. Os procedimentos sistemáticos utilizados buscam organizar os dados coletados para que possam então ser analisados. As condições de produção/recepção da mensagem tratam do contexto em que elas foram geradas, mostrando sua importância para a produção de conhecimento acerca do objeto de estudo, como também destacam Mozzato e Grzybovski (2011).

A análise categorial é um primeiro passo para ordenar os dados coletados, auxiliando no processo descritivo. Para a criação de categorias de fragmentação da mensagem são estabelecidas regras, entretanto, para que a análise seja válida, essas regras devem ser, segundo Bardin (2009):

a) homogêneas: os conteúdos devem ser coerentes;

b) exaustivas: esgotar todo o texto;

c) exclusivas: um mesmo elemento não pode ser classificado em duas categorias diferentes;

d) objetivas: codificadores diferentes devem chegar aos mesmos resultados;

e) adequadas: adaptadas ao objetivo e ao conteúdo. 
A categorização pode seguir dois procedimentos de partição, conforme aponta Bardin (2009). O primeiro, em que se parte do geral para o particular, ou seja, determinam-se primeiramente as rubricas de classificação para depois organizar o todo. Já o segundo parte de elementos particulares, fazendo reagrupamentos progressivos através de elementos próximos para, ao final, dar título à categoria. No presente estudo, buscou-se determinar previamente as rubricas de classificação, por meio da identificação de variáveis levantadas a partir do referencial teórico (vide Quadro 7). Entretanto, também se utilizou o segundo procedimento, visto que alguns pontos foram deixados em aberto para captar as percepções dos participantes para reagrupamento posterior. São exemplos de questões dessa natureza as que procuraram identificar os fatores que influenciaram a gestão de pessoas e educação corporativa; as limitações, vantagens e tendências em avaliação de resultados em educação corporativa.

Para realizar a análise de conteúdo, todas as entrevistas foram transcritas utilizando-se o software Express Scribe Pro v.5.51, e, para auxiliar na categorização e análise dos dados, foi utilizado o software NVIVO, versão 9. Neste último, foram organizados os materiais coletados, tanto os Cadernos de Evidências das Melhores Empresas para Você Trabalhar, quanto as entrevistas, relatórios e documentos coletados para o caso Itaú Unibanco.

\subsection{Limitações da pesquisa}

Este estudo, por caracterizar-se como estudo de caso, não poderá ter seus resultados extrapolados para outras organizações, entretanto, o aprofundamento proporcionado pela metodologia de estudo de caso fornece uma visão ampla e profunda sobre as variáveis estudadas, assim, Yin (2010, p. 24) aborda a necessidade e a aplicação do estudo de caso como método de pesquisa:

“[...] a necessidade diferenciada dos estudos de caso surge do desejo de entender fenômenos sociais complexos. Em resumo, o método de estudo de caso permite que os investigadores retenham as características holísticas e significativas dos eventos da vida real - como os ciclos individuais da vida, o comportamento dos pequenos grupos, os processos organizacionais e administrativos [...].” 
Yin (2010) sustenta também que, assim como os experimentos, os resultados dos estudos de caso são generalizáveis às proposições teóricas e não às populações e aos universos, pois os estudos de caso e os experimentos não representam uma amostragem, seu objetivo é expandir e generalizar teorias. Para isso, o procedimento sistemático é peça fundamental para possibilitar a replicação do estudo, assim como ocorre com os experimentos.

Corroborando o argumento de Yin (2010), Mozzato e Grzybovski (2011) apontam que a generalização não pode ser considerada como limitação, pois essa dificuldade é inerente à pesquisa qualitativa.

A falta de rigor na utilização do método de estudo de caso é um fator que contribui para que essa estratégia de investigação seja desprezada em detrimento do uso de experimentos ou levantamentos (YIN, 2010). Conforme o autor, a falta de rigor se dá pela negligência do pesquisador no uso de procedimentos sistemáticos, aceitação de evidências equivocadas ou visões parciais que acabam por influenciar os resultados do estudo. Outro problema apontado por Yin (2010) é a confusão gerada entre os métodos de caso de ensino e estudo de caso: enquanto o primeiro permite que haja alteração dos materiais para destacar determinado ponto, no estudo de caso isso é enfaticamente proibido. Por isso, a utilização de procedimentos sistemáticos, a isenção do pesquisador na coleta e análise dos dados e o conhecimento aprofundado do método de estudo de caso são pontos que foram buscados para garantir o caráter científico deste estudo.

Há também limitações neste estudo derivadas do uso da análise de conteúdo como método e técnica de análise de dados. Segundo Mozzato e Grzybovski (2011), as principais limitações referem-se à falta de neutralidade do investigador e à falta de ou fraca análise contextual. A postura neutra do pesquisador fica prejudicada no uso desta técnica, pois toda a categorização e interpretação sofre sua influência subjetiva, entretanto, esta limitação é minimizada pelo detalhamento dos procedimentos adotados na abordagem, buscando-se, deste modo, a validade da análise. Já a análise contextual foi também foco desta pesquisa, buscando-se entender e descrever a organização e o sistema de educação corporativa para atender aos requisitos do método estudo de caso e à técnica de análise de conteúdo. 


\section{RESULTADOS}

Os resultados desta pesquisa estão divididos em duas perspectivas de análise: ampla e específica. Na perspectiva ampla, buscou-se identificar as práticas de avaliação de resultados realizadas pelas Melhores Empresas para Você Trabalhar, edição 2011, visando fornecer um panorama de como este tema está desenvolvido dentro das organizações. Já na perspectiva específica, o intuito foi descrever de forma aprofundada um caso em que é empregado um modelo de avaliação de resultados em educação corporativa. Deste modo, este capítulo iniciase com a análise dos resultados das Melhores Empresas para Você Trabalhar e, na sequência, relata-se o caso da organização Itaú Unibanco.

\subsection{As Melhores Empresas para Você Trabalhar - MEPT}

As empresas que compuseram este estudo são as classificadas entre as 150 Melhores Empresas para Você Trabalhar, edição 2011, divulgadas por meio de edição especial da revista Você S/A e da Exame. A relação das organizações que compuseram essa classificação consta nos Anexos deste estudo.

A partir das respostas das empresas ao questionário, foi possível traçar um perfil geral sobre a adoção do sistema de educação corporativa e da avaliação de seus resultados, conforme demonstrado na Tabela 1. 
Tabela 1 - Visão geral sobre a adoção do sistema de educação corporativa e da avaliação de seus resultados

\begin{tabular}{|c|c|c|c|c|c|}
\hline Variável & Categoria & Descrição & Abrangência & $\mathrm{N}^{0}$ Empresas & $\%$ \\
\hline V935 & $\begin{array}{c}\text { A Empresa adota um Modelo de } \\
\text { Educação Corporativa para apoiar o } \\
\text { desenvolvimento pessoal e profissional } \\
\text { de seus empregados? }\end{array}$ & & & 150 & $100 \%$ \\
\hline V990 & \multirow{9}{*}{$\begin{array}{l}\text { É realizada avaliação dos resultados dos } \\
\text { investimentos em educação }\end{array}$} & \multirow{6}{*}{$\begin{array}{l}\text { Gerentes e } \\
\text { Supervisores }\end{array}$} & Todos & 29 & $19 \%$ \\
\hline V991 & & & Parte & 102 & $68 \%$ \\
\hline V992 & & & Não & 19 & $13 \%$ \\
\hline V993 & & & Todos & 24 & $16 \%$ \\
\hline V994 & & & Parte & 105 & $70 \%$ \\
\hline V995 & & & Não & 21 & $14 \%$ \\
\hline V996 & & \multirow{3}{*}{$\begin{array}{l}\text { Demais } \\
\text { Empregados }\end{array}$} & Todos & 27 & $18 \%$ \\
\hline V997 & & & Parte & 97 & $65 \%$ \\
\hline V998 & & & Não & 26 & $17 \%$ \\
\hline & TOTAL EMPRESAS & & & 150 & \\
\hline
\end{tabular}

As 150 organizações eleitas como As Melhores Empresas para Você Trabalhar afirmam possuir um modelo de educação corporativa para o desenvolvimento pessoal e profissional de seus funcionários, conforme respostas concedidas pelas organizações em formulário eletrônico e, a partir das quais, foram compilados os resultados expostos na Tabela 1. Entretanto, confrontando esse resultado ao encontrado nos Cadernos de Evidências isso não se confirma, pois há quatro organizações que afirmam não possuir o modelo de educação corporativa ou universidade corporativa.

Quando questionadas sobre a avaliação de resultados dos investimentos realizados em educação corporativa, a maioria das organizações afirma realizá-la para todos ou parte de seus funcionários: 87\% para o nível de direção; 86\% para os níveis de gerência e supervisão; para os demais empregados, 83\% fazem alguma forma de avaliação. No mínimo 19 organizações, ou seja, 13\%, não realizam avaliação de resultados dos investimentos aportados em educação corporativa. A partir das análises seguintes, foram investigados os sistemas de educação corporativa e as práticas empregadas para avaliar os resultados de suas ações educacionais, por meio da análise dos Cadernos de Evidências. 


\subsubsection{Educação Corporativa}

O sistema de educação corporativa neste estudo será analisado por meio de três categorias macros: aprendizagem contínua, atuação estratégica e público-alvo. Assim, serão analisadas as práticas de promoção da aprendizagem contínua, o público atendido e quais as características preponderantes em uma atuação estratégica.

A aprendizagem contínua é promovida pelas organizações por meio de práticas, as quais, a partir da análise empreendida, foram classificadas em eventos, ferramentas colaborativas, leitura, atuação docente, recursos financeiros, reuniões e visitas técnicas (Tabela 2). Eventos são as ações que englobam concursos internos para eleição de projetos, seminários e palestras. As ferramentas colaborativas compreendem a criação de comunidades virtuais, chats, fóruns de discussão e ambiente para troca de materiais. A leitura foi citada por duas organizações como práticas de aprendizagem, por meio da disponibilização de livros e uma delas ainda realiza fóruns de leitura e discussão. A atuação dos funcionários em sala de aula, como professores de outros funcionários, também foi identificada como prática de aprendizagem, esta, inclusive foi a prática mais identificada entre as organizações estudadas, seis empresas atuam com essa modalidade de aprendizagem. Fornecer incentivos financeiros atrelados ao desenvolvimento é uma prática que se manifestou em duas organizações. Uma fornece um valor fixo anual para o funcionário investir como quiser em seu desenvolvimento e outra atrela aumento salarial à obtenção de título. As reuniões de trabalho também foram citadas como práticas de desenvolvimento dos funcionários, pois por meio delas são disseminados conhecimentos e informações. Finalmente as visitas técnicas, também conhecidas como benchmarking, são oportunidades de aprendizado, pois os funcionários são estimulados a conhecer outras técnicas, métodos e ferramentas.

Tabela 2 - Práticas de promoção da aprendizagem contínua

\begin{tabular}{lccc}
\hline \multicolumn{1}{c}{ Prática } & Número de Fontes & $\%$ & Número de Referências \\
\hline \hline Eventos & 1 & $7 \%$ & 2 \\
Ferramentas colaborativas & 2 & $13 \%$ & 2 \\
Leitura & 2 & $13 \%$ & 2 \\
Atuação docente & 6 & $40 \%$ & 7 \\
Incentivos financeiros & 2 & $13 \%$ & 2 \\
Reuniões & 1 & $7 \%$ & 1 \\
Visitas Técnicas & 1 & $7 \%$ & 1 \\
\hline Total & 15 & $100 \%$ & 17 \\
\hline \hline
\end{tabular}


Uma das características da educação corporativa é a ampliação do público atendido, não se limitando aos funcionários, mas contemplando em suas ações o público externo, tais como familiares, clientes, fornecedores, distribuidores, parceiros comerciais e comunidade, desde que estejam atrelados ao alcance dos objetivos do negócio (MEISTER, 1999; EBOLI, 2004). Deste modo, foram compilados na Tabela 3 os públicos externos atendidos pelas organizações classificadas na MEPT. O público externo mais citado pelas fontes estudadas, correspondendo a 22\% do total, foi a comunidade. É interessante notar que as ações desenvolvidas têm relação com as ações realizadas para os próprios funcionários, muitas vezes estendendo-as à comunidade, como as ações para formação técnica em parceria com instituições de ensino e palestras com renomados conferencistas. O desenvolvimento de jovens foi apontado por duas organizações como ações voltadas à comunidade, uma delas inclusive busca formar os jovens do entorno de uma de suas fábricas. Essa é uma estratégia que beneficia a própria organização, pois ela pode empregar futuramente esses jovens como profissionais para seu negócio.

O segundo público mais citado foi clientes, correspondendo a $17 \%$ do total de fontes. As ações promovidas envolvem a capacitação de clientes pessoa jurídica em conteúdos técnicos e estratégicos para utilização ou promoção dos produtos; ações de promoção da qualidade de vida; eventos científicos; e disponibilização de cursos a distância.

Os familiares correspondem ao terceiro público mais citado pelas fontes, $15 \%$ ou seis organizações. Destas organizações, três apontaram oferecer subsídio ou desconto obtido por meio de parcerias com instituições de ensino superior para formação, em nível de graduação e pós-graduação, aos familiares dos funcionários. Outra ação citada foi o programa de estágio de férias ofertado aos filhos, sobrinhos irmãos, enteados ou primos de funcionários ou terceiros. Foram mencionados também o programa de educação financeira e palestras como ações estendidas também aos familiares.

Foram relatados também como públicos externos atendidos os distribuidores, os fornecedores, os parceiros e os terceiros, cada um citado por 10\% das fontes estudadas. As ações envolvem capacitação técnica voltada aos distribuidores, aos revendedores e às assistências técnicas, envolvendo produtos e inovações, e também foi evidenciada por uma das fontes a realização de programas comportamentais direcionados a distribuidores. Já quanto aos fornecedores apenas uma organização apontou as ações realizadas para este público, as quais envolvem 
encontros com fornecedores e programa de qualidade de vida. Os parceiros são compostos, em geral, por lojas que vendem os produtos das organizações estudadas, assim, são fornecidas ações como workshops, palestras, oficinas entre outros. Os terceiros são desenvolvidos em conteúdos técnicos e também em conteúdos que abordem princípios da organização, buscando, dessa forma, desenvolver a cultura organizacional também neste público.

Foram citados ainda como públicos atendidos: as universidades, as organizações que as citaram possuem pesquisas e inovações em seu segmento de atuação e compartilham-nas com instituições de ensino; e concorrentes, neste caso, a organização possui um simulador para formação em uma função especializada, por meio do qual são capacitados seus funcionários e os de outras empresas também.

Tabela 3 - Públicos externos atendidos pela educação corporativa

\begin{tabular}{lccc}
\hline \multicolumn{1}{c}{ Públicos } & Número de Fontes & $\%$ & Número de Referências \\
\hline \hline Clientes & 7 & $17 \%$ & 7 \\
Comunidade & 9 & $22 \%$ & 10 \\
Concorrentes & 1 & $2 \%$ & 1 \\
Distribuidores & 4 & $10 \%$ & 4 \\
Familiares & 6 & $15 \%$ & 8 \\
Fornecedores & 4 & $10 \%$ & 4 \\
Parceiros & 4 & $10 \%$ & 4 \\
Terceiros & 4 & $10 \%$ & 4 \\
Universidades & 2 & $5 \%$ & 2 \\
\hline Total & 41 & $100 \%$ & 44 \\
\hline \hline
\end{tabular}

Para que a EC tenha atuação estratégica há três aspectos relevantes, os quais foram identificados na revisão de literatura: o alinhamento da EC aos objetivos organizacionais; o alinhamento da EC ao sistema de gestão de pessoas; e a elaboração de objetivos para a EC.

O alinhamento da educação corporativa ao sistema de gestão de pessoas ocorre, em geral, por meio da utilização de práticas de gestão de pessoas como insumos no diagnóstico das ações educacionais. Sendo assim, verifica-se na Tabela 4 que a avaliação de desempenho é a prática mais utilizada pelas organizações, mencionada por $54 \%$ das fontes categorizadas, como insumo para identificação de lacunas de desenvolvimento dos funcionários. A gestão de carreira aparece como segunda prática mais citada pelas fontes estudadas, 21\%, para garantir o alinhamento da educação corporativa ao sistema de gestão de pessoas. As ferramentas de gestão de carreiras utilizadas nesse alinhamento foram o plano de desenvolvimento 
individual, o planejamento estratégico de pessoas, o plano de sucessão, resultados das reuniões de mentoria e o sistema de gestão de talentos ou potenciais. A terceira prática mais relatada pelas fontes classificadas, com $17 \%$ do total, foi a gestão por competências. O sistema de gestão por competências, como mencionado por uma organização, funciona como elo entre os diversos processos fundamentais de gestão de pessoas, tendo todos o mesmo referencial como base: as competências. Outra organização aponta a gestão por competências como sistema integrador de gestão de pessoas e duas organizações realizam, inclusive, a avaliação de competências, utilizando-a como insumo no desenvolvimento de programas. Por fim, a pesquisa de clima organizacional também foi citada como prática que fornece insumos para a identificação de lacunas de desenvolvimento.

Tabela 4 - Alinhamento da educação corporativa ao sistema de gestão de pessoas

\begin{tabular}{lccc}
\hline \multicolumn{1}{c}{ Prática } & Número de Fontes & $\%$ & Número de Referências \\
\hline \hline Avaliação de Desempenho & 28 & $54 \%$ & 29 \\
Gestão da Carreira & 11 & $21 \%$ & 11 \\
Gestão por Competências & 9 & $17 \%$ & 10 \\
Pesquisa de Clima Organizacional & 4 & $8 \%$ & 4 \\
Total & 52 & $100 \%$ & 54 \\
\hline \hline
\end{tabular}

Objetivos da educação corporativa. Das organizações estudadas, 49 demonstraram, em seus Cadernos de Evidências, quais são os objetivos de seus sistemas de educação corporativa. Ao investigar a frequência de palavras nesses objetivos, verificou-se a predominância de alguns termos, conforme pode ser visualizado na Ilustração 6. Considerando os dez termos mais referenciados pelas fontes, há dois grupos de palavras. No primeiro bloco, predomina o termo “desenvolvimento”, o qual foi referenciado 50 vezes, ou seja, apareceu 50 vezes nos objetivos de EC. Na sequência, vem o termo “educação” com 30 referências; "pessoas” aparece referenciado por 29 vezes; “corporativa” tem 25 indicações; o termo "treinamento”, 22 referências e o “conhecimento” aparece com 17 indicações. É interessante notar que o termo “corporativa” aparece 22 vezes precedido pelo termo educação ou universidade e, em apenas três citações, este termo aparece acompanhado pelas palavras governança, atividades e estratégia. Este primeiro bloco de termos está diretamente ligado com a atuação principal de um sistema de educação corporativa, que é promover a aprendizagem individual e organizacional, conforme aponta Eboli (2010). 
No segundo bloco, aparecem quatro termos que mantêm relação estreita: objetivo, negócio, empresa e competências, citados 28, 20, 19 e 17 vezes, respectivamente. Esses termos também estão em consonância com outro importante aspecto do objetivo da EC que é o de auxiliar a organização a atingir seus objetivos, por meio do desenvolvimento de suas competências críticas (MEISTER, 1999; VERGARA, 2000; ALPERSTEDT, 2001; EBOLI, 2010).

ações aprendizado aprendizagem assim atividades através capacitação carreira rnlahnradnres companhia competências conhecimento corporativa desafios desenvolver

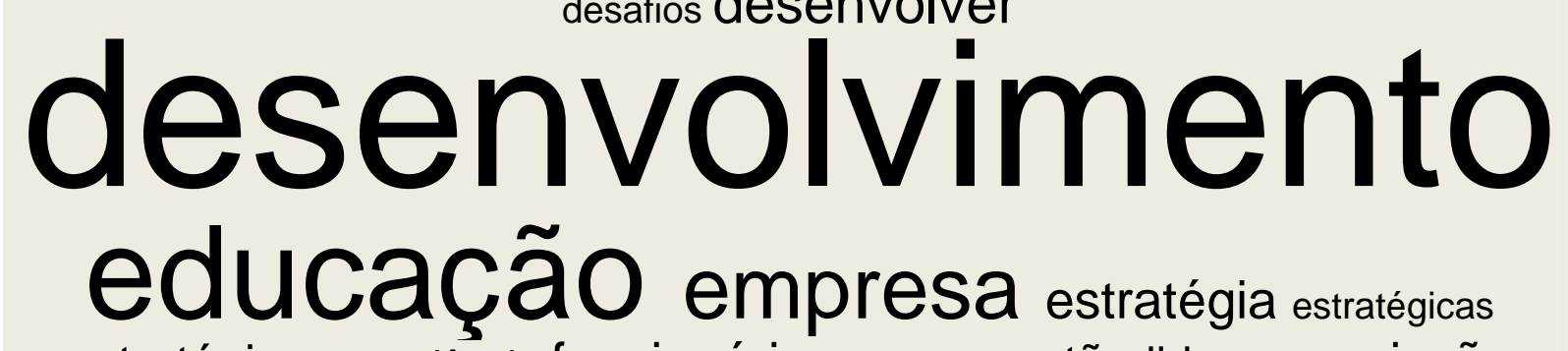
estratégicos excelência funcionários geração gestão liderança missão modelo negócio nosso ObjetivO opoturiadades organização pessaal PESSOAS politica prática processo profissional programas promover qualidade resultados técnicas todos treinamento universidade valores

Ilustração 6 - Termos mais frequentes nos objetivos dos sistemas de educação corporativa.

Alinhamento da educação corporativa aos objetivos organizacionais. A educação corporativa alinha-se aos objetivos organizacionais, como visto na Tabela 5, pois a palavra com maior frequência é empresa, com 64 registros. Se forem somadas as palavras “estratégico”, “estratégia” e “estratégicas” teremos o total de 89 referências. Assim, há indícios de que há alinhamento entre da educação corporativa aos objetivos organizacionais, visto a frequência de termos que fazem referência a objetivos organizacionais. 
Tabela 5 - Alinhamento da educação corporativa aos objetivos organizacionais: frequência de termos

\begin{tabular}{lcccl}
\hline \multicolumn{1}{c}{ Palavra } & Extensão & Contagem & Percentual ponderado (\%)* & \multicolumn{1}{c}{ Palavras similares } \\
\hline \hline empresa & 7 & 64 & 1,15 & empresa, empresas \\
desenvolvimento & 15 & 58 & 1,05 & desenvolvimento \\
programas & 9 & 47 & 0,85 & programa, programas \\
colaboradores & 13 & 46 & 0,83 & colaborador, colaboradores \\
treinamento & 11 & 46 & 0,83 & treinamento, treinamentos \\
competências & 12 & 41 & 0,74 & competência, competências \\
educação & 8 & 38 & 0,68 & educação \\
corporativa & 11 & 37 & 0,67 & corporativa, corporativas \\
estratégico & 11 & 37 & 0,67 & estratégico, estratégicos \\
estratégia & 10 & 31 & 0,56 & estratégia, estratégias \\
objetivos & 9 & 30 & 0,54 & objetivo, objetivos \\
necessidades & 12 & 25 & 0,45 & necessidade, necessidades \\
negócio & 7 & 25 & 0,45 & negócio, negócios \\
planejamento & 12 & 25 & 0,45 & planejamento \\
ações & 5 & 23 & 0,41 & ações \\
pessoas & 7 & 22 & 0,4 & pessoas \\
plano & 5 & 22 & 0,4 & plano, planos \\
estratégicas & 12 & 21 & 0,38 & estratégica, estratégicas \\
resultados & 10 & 20 & 0,36 & resultado, resultados \\
diretrizes & 10 & 19 & 0,34 & diretrizes \\
\hline \hline
\end{tabular}

*Percentual ponderado: a frequência da palavra relativa ao total de palavras contadas.

Após essa contextualização sobre o sistema de educação corporativa empregado pelas MEPT, serão relatadas a seguir as práticas de avaliação de resultados em educação corporativa utilizadas por elas.

\subsubsection{Avaliação de resultados em educação corporativa: as práticas realizadas pelas}

\section{MEPT}

\subsubsection{Medidas de efetividade da EC}

A efetividade de um sistema é averiguada, conforme apontam Allen e McGee (2004), por meio dos resultados por ele gerados, dessa forma, um sistema efetivo será aquele que gera resultados predeterminados com alto grau de previsibilidade. Traduzindo isso em dimensão de avaliação do sistema de educação corporativa, seria avaliar a qualidade do ensino ou desenvolvimento curricular, a qual geralmente é mensurada por meio da identificação do quão bem os participantes conseguem alcançar os objetivos do programa. Desse modo, os níveis de 
avaliação propostos por Kirkpatrick e Kirkpatrick (2010) e Hamblin (1978) apresentam relação com este conceito. Por isso, foram investigados os seguintes níveis de avaliação: reação, aprendizado, aplicação, processos, cultura e objetivos; verificando como eles são aplicados pelas MEPT, edição 2011.

Após a categorização dos dados presentes nos Cadernos de Evidência das MEPT, verificou-se a distribuição de citações pelas fontes em cada nível de avaliação, conforme demonstrado na Tabela 6. A avaliação de reação foi o nível mais citado pelas fontes investigadas, cerca de 36\% do total daquelas classificadas. Em seguida, o nível mais citado pelas fontes foi processo, sendo referenciado por $23 \%$ das organizações categorizadas. A avaliação de aplicação do aprendizado no trabalho, que inicia a transferência dos efeitos gerados pela ação de desenvolvimento do indivíduo para a organização, aparece como o terceiro nível mais evidenciado pelas organizações, apontada por 21\%. Já o nível aprendizagem foi relatado por $12 \%$ das fontes como prática de avaliação realizada. Por fim, avaliações que procuram identificar a contribuição das ações educacionais para o alcance dos objetivos do negócio aparecem como último nível mencionado pelas fontes pesquisadas, $12 \%$ do total. Nenhuma organização apontou, em seus Cadernos de Evidências, se avaliam a contribuição da educação corporativa na disseminação da cultura organizacional.

Tabela 6 - Medidas de efetividade de educação corporativa

\begin{tabular}{lccc}
\hline \multicolumn{1}{c}{ Nível de Avaliação } & $\mathrm{N}^{\circ}$ de Fontes & $\%$ & $\mathrm{~N}^{\circ}$ de Referências \\
\hline \hline Reação & 26 & $36 \%$ & 29 \\
Aprendizagem & 9 & $12 \%$ & 11 \\
Aplicação & 15 & $21 \%$ & 17 \\
Processos & 17 & $23 \%$ & 23 \\
Cultura & 0 & $0 \%$ & 0 \\
Objetivos & 6 & $8 \%$ & 8 \\
\hline Total & 73 & $100 \%$ & 88 \\
\hline \hline
\end{tabular}

A partir da elaboração da tabela anterior, foi empreendida uma análise de grupo para investigar se havia fontes que apareciam em mais de um nível de avaliação. O resultado foi muito interessante, pois constatou-se que há 99 fontes que não realizam nenhum destes níveis de avaliação, 31 que realizam apenas um nível, sete organizações que realizam dois níveis de avaliação; três que fazem três níveis de avaliação; três que elaboram quatro níveis de avaliação; e apenas uma que realiza os cinco níveis (reação, aprendizagem, aplicação, processos e objetivos). Desse modo, verifica-se que mesmo entre as organizações que se 
destacam em gestão de pessoas, poucas realizam a avaliação de resultados em educação corporativa.

Outra análise relevante foi o agrupamento de nós, ou seja, categorias de classificação por similaridade de codificação (Ilustração 7). Verifica-se que há dois grupos distintos de organizações que realizam avaliação de resultado. O primeiro, envolve os níveis de avaliação de reação, aprendizagem e aplicação; e o segundo agrupou os níveis de avaliação objetivos, processos e cultura. Uma possível explicação para essa distinção é a mudança de foco da avaliação: enquanto no primeiro grupo as avaliações são realizadas tomando por base o indivíduo, no segundo grupo as avaliações têm a intenção de verificar as mudanças promovidas pelas ações educacionais na organização.

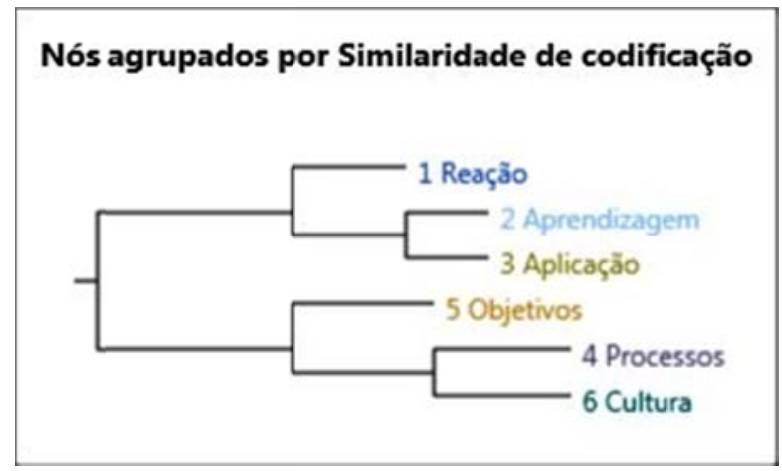

Ilustração 7 - Agrupamento dos níveis de avaliação por similaridade de codificação

A ilustração anterior é derivada da obtenção da correlação de Pearson entre os níveis de avaliação, conforme demonstrado na Tabela 7: 
Tabela 7 - Agrupamento dos níveis de avaliação por similaridade de codificação

\begin{tabular}{llc}
\hline \multicolumn{1}{c}{ Nó A } & \multicolumn{1}{c}{ Nó B } & Coeficiente de correlação de Pearson \\
\hline \hline Aplicação & Aprendizagem & 0,475218 \\
Aplicação & Reação & 0,329448 \\
Aprendizagem & Reação & 0,211475 \\
Processos & Aprendizagem & 0,19004 \\
Objetivos & Aprendizagem & 0,134418 \\
Objetivos & Aplicação & 0,005987 \\
Cultura & Reação & 0 \\
Cultura & Aprendizagem & 0 \\
Cultura & Aplicação & 0 \\
Cultura & Processos & 0 \\
Cultura & Objetivos & 0 \\
Objetivos & Processos & $-0,029072$ \\
Processos & Aplicação & $-0,052214$ \\
Objetivos & Reação & $-0,181164$ \\
Processos & Reação & $-0,509559$ \\
\hline \hline
\end{tabular}

Cada um dos níveis de avaliação mencionados há pouco serão descritos a seguir, com o objetivo de ilustrar as práticas empregadas pelas MEPT para avaliar os resultados de seu sistema de educação corporativa.

Reação. A avaliação de reação busca identificar a satisfação do participante em relação ao programa. As reações são o primeiro efeito do treinamento e consistem em uma resposta dada pelo treinando em relação ao treinador, ao tema abordado, ao método e ao cenário do treinamento (HAMBLIN, 1978). Esse é o nível mais aplicado pelas MEPT, conforme visto anteriormente. Neste estudo foram identificados os aspectos avaliados nesse nível, os quais foram agrupados nas seguintes categorias: metodologia, conteúdo, instrutor e infraestrutura. Em metodologia são avaliados adequação dos exercícios aos programas em termos de quantidade e qualidade; duração da ação educacional; e entendimento dos objetivos do programa pelos participantes. Conteúdo envolve a avaliação da aplicabilidade dos conteúdos aprendidos ao trabalho, adequação do conteúdo aos objetivos do programa, consistência e profundidade dos conteúdos; contribuição do conteúdo para a melhora de desempenho do participante; e a pertinência do tema relacionado às estratégias do negócio. Sobre o instrutor, são avaliados a didática e o domínio do conteúdo. Em infraestrutura, os aspectos avaliados são recursos audiovisuais, materiais didáticos, coordenação administrativa e operacional (logística) do programa. Enfim, também são avaliados os benefícios proporcionados pelo 
programa ao participante e, neste quesito, são avaliadas a ampliação de conhecimento e a possibilidade de networking.

É válido destacar que uma organização estabelece critério de elegibilidade para realizar a avaliação de reação. O critério utilizado é carga horária mínima que, no caso desta organização, é de duas horas. Outro ponto importante é que cinco organizações informaram o índice de avaliação de reação de seus programas que variou entre 89\% e 98\%, com média de 93\%.

Aprendizagem. A avaliação de aprendizagem ocorre por meio da verificação de mudança de atitude, aumento de conhecimento ou melhora de habilidade do participante (KIRKPATRICK, 1994; KIRKPATRICK e KIRKPATRICK, 2010). Nas organizações estudadas, as avaliações de aprendizagem são aplicadas quando há necessidade de certificação, apontado por duas organizações; e em cursos técnicos. Uma fonte apontou que realiza a avaliação de aprendizagem após três meses para verificar o que foi retido pelo participante e outra fonte apontou ainda realizar medições antes e após a realização do programa. Observa-se que a avaliação de aprendizagem tem sido aplicada nos moldes tradicionais, ou seja, para aferir conhecimentos e prover certificados.

Aplicação. Este é o nível de avaliação em que se verifica se os treinandos aplicaram o que aprenderam no exercício do cargo, ou seja, se transferiram os conhecimentos adquiridos a seu trabalho (HAMBLIN, 1978). Foram identificados, nas fontes estudadas, alguns critérios que são avaliados neste nível: a aplicação dos conhecimentos no trabalho; em quanto tempo o colaborador começou a utilizar os conhecimentos adquiridos; e exemplo de situações resolvidas utilizando a aprendizagem decorrente da ação educacional. Seis fontes indicaram que nessa avaliação são colhidas as percepções da liderança e apenas uma organização mencionou que o participante também responde a essa avaliação. Foi relatado ainda por uma fonte que a aplicação dessa avaliação é realizada por amostragem. Duas organizações classificadas nesta categoria mencionaram que realizam a avaliação de impacto por meio da análise de indicadores de produtividade, tais como redução de erros; desempenho da área de trabalho do participante; e resultado da avaliação de desempenho do participante. É interessante observar que seis fontes discorreram sobre o período para aplicação da avaliação, o qual variou entre 30 dias e seis meses. Entretanto, três organizações apontaram que aplicam essa avaliação 90 dias após a finalização do evento. 
Processos. Nesta etapa é identificado se os efeitos da mudança de comportamento no trabalho originaram mudanças no funcionamento da empresa, a isso Hamblin (1978) denomina efeitos na organização. Esses efeitos podem ser verificados pela redução de custos, redução de acidentes, aumento das vendas, redução de turnover, melhoria da qualidade, aumento da produção, lucros mais altos e retorno do investimento (KIRKPATRICK, 1994; KIRKPATRICK e KIRKPATRICK, 2010). Na análise das MEPT foram identificados os indicadores apontados pelas organizações como medidas de impacto em seu funcionamento:

a) indicadores operacionais: percentual de equipamentos com problemas recorrentes; tempo médio entre chamadas; índice de acidentes (mencionado por três fontes); redução de custos gerada por melhorias em processos; e indicador de produção;

b) indicadores de qualidade: conquista de premiações e certificações como a ISO 9001 e ISO 14001; número de reclamações; e índice de satisfação do cliente;

c) indicadores de gestão de pessoas: percentual de execução do plano sucessório; número de vagas preenchidas com candidatos internos; aumento do envolvimento dos participantes com o negócio; avaliação de fornecedores de programas educacionais; índice de satisfação, seja do cliente interno em relação à educação corporativa, seja dos funcionários em relação à organização, esta última medida pela pesquisa de clima.

É importante ressaltar que esses indicadores são exemplos mencionados pelas organizações estudadas. A escolha de indicadores para compor a avaliação de determinado programa deve ser norteada pelo que a ação educacional deseja alcançar, quais são seus objetivos.

Cultura. Não foi localizada, neste estudo, nenhuma referência a esse nível de avaliação. A contribuição da EC na disseminação da cultura organizacional ainda não é foco de avaliação das organizações.

Objetivos. Esta fase relaciona a avaliação aos critérios utilizados pela organização para avaliar sua eficácia e sucesso, os quais muitas vezes se traduzem em termos financeiros (HAMBLIN, 1978). As organizações estudadas apresentam indícios de apuração de resultados neste nível por meio da identificação da contribuição dos programas para o alcance dos objetivos traçados no planejamento estratégico. Para isto, algumas fontes apontaram como realizam essa apuração, seus relatos são expostos na sequência. O desdobramento da 
estratégia para os programas foi apontado por uma fonte como ocorrendo da seguinte forma: busca-se traduzir os objetivos estratégicos em metas, identificando a competência organizacional necessária para atingi-la e as competências humanas atreladas à competência organizacional. Outra organização relata que colhe a percepção do gestor sobre o impacto dos eventos educacionais nos indicadores do planejamento estratégico ou do plano anual de metas. Uma organização inclusive relata que a universidade corporativa tem seu próprio planejamento estratégico. Percebe-se que, neste nível, a avaliação da contribuição da educação corporativa para os objetivos do negócio tem alinhamento estreito com o planejamento estratégico, por meio do monitoramento dos indicadores a ele atrelados.

\subsubsection{Medidas de eficiência da EC}

A eficiência, conforme relatado por Allen e McGee (2004), trata da avaliação da estratégia instrucional, definida pelos autores como a escolha dos meios mais eficientes pelos quais o currículo possa ser ensinado, dessa maneira, os critérios comumente utilizados para escolha são dinheiro, tempo, apoio instrucional e equipamentos necessários. Foram analisados neste estudo se as MEPT apresentam esses critérios, por isso, foi investigado se há controle dos custos diretos, dos custos indiretos, se há indicadores de eficiência na utilização de recursos e se há indícios de avaliação dos procedimentos instrucionais.

Custos diretos. Os gastos são formados por custos diretos e indiretos, sendo considerados diretos os que se referem à remuneração dos consultores, ao aluguel de sala, aos recursos, à alimentação, ao transporte e à hospedagem (FITZ-ENZ,1995). Capturar essa informação junto às MEPT foi mais fácil, pois o orçamento de educação corporativa é uma informação solicitada pela pesquisa das MEPT. Dessa forma, os custos diretos apontados nos Cadernos de Evidências foram recursos investidos nos programas, tais como diárias de palestrante; e despesas com logística, como, por exemplo, hospedagem; subsídios para idiomas, graduação, pós-graduação e eventos. Há organizações que fazem a divisão de custos por projeto.

Custos indiretos. Quanto aos custos indiretos, os mais comuns são salários e benefícios dos treinandos, salários e benefícios dos treinadores, custo fixo da área de treinamento (FITZENZ,1995). As organizações investigadas apontaram como custos indiretos a remuneração da equipe dedicada à educação corporativa (32 fontes) e as despesas com estrutura (6 fontes). 
Eficiência na utilização de recursos. Foram investigadas evidências sobre as formas utilizadas pelas MEPT para avaliar a eficiência na utilização dos recursos destinados às ações de educação corporativa. O retorno financeiro gerado pelas ações de educação corporativa foi citado por cinco organizações, nesse sentido, compreendeu-se que a eficiência na utilização de recursos é medida desta maneira. Os benefícios gerados pela ação de educação corporativa são calculados por meio de indicadores de desempenho dos funcionários, como relatado por uma das organizações classificadas nesta categoria.

Avaliação dos procedimentos instrucionais. Verificar se os procedimentos instrucionais adotados para o programa estão auxiliando o ensino dos currículos também é um critério a ser avaliado. Uma organização menciona que realiza reuniões com um grupo multidisciplinar que realiza análise crítica do sistema gerencial, do qual fazem parte os métodos de Treinamento e Educação. A avaliação e melhoria desses métodos ocorrem por meio da análise de dados, de comentários e de sugestões fornecidas pelos funcionários e gestores e pelos estudos comparativos, realizados pelo RH, sobre formas de execução de treinamento e educação.

\subsubsection{Indicadores}

Além de averiguar as medidas de efetividade e eficiência utilizadas pelas MEPT, foram investigados também os indicadores monitorados por elas. Neste estudo, foram identificados 21 indicadores, dos quais alguns apresentam relação direta com as ações educacionais e outros têm relação indireta. Os indicadores que apresentam relação direta, em sua maioria, são utilizados frequentemente como medidas em treinamento e são apresentados na Tabela 8, destacados por meio de sombreamento. 
Tabela 8 - Indicadores utilizados pelas MEPT

\begin{tabular}{lrrr}
\hline \multicolumn{1}{c}{ Indicadores } & Fontes & \% Fontes & Referências \\
\hline \hline Absenteísmo & 1 & $0,4 \%$ & 1 \\
Desempenho & 1 & $0,4 \%$ & 1 \\
Dias de treinamento por funcionário & 1 & $0,4 \%$ & 1 \\
Execução do plano de treinamento & 3 & $1,3 \%$ & 3 \\
Investimento em treinamento sobre receita & 1 & $0,4 \%$ & 1 \\
Número de contratações internas & 1 & $0,4 \%$ & 1 \\
Número de eventos de treinamento & 6 & $2,6 \%$ & 6 \\
Número de funcionários treinados & 26 & $11,1 \%$ & 31 \\
Número de horas de treinamento & 55 & $23,4 \%$ & 68 \\
Número de horas de treinamento por colaborador & 49 & $20,9 \%$ & 54 \\
Número de líderes formados pela EC & 1 & $0,4 \%$ & 1 \\
Número de participações & 22 & $9,4 \%$ & 26 \\
Número de programas realizados & 23 & $9,8 \%$ & 24 \\
Número de temas de treinamento & 2 & $0,9 \%$ & 2 \\
Prêmios & 1 & $0,4 \%$ & 1 \\
Promoções & 11 & $4,7 \%$ & 11 \\
Retenção & 7 & $3,0 \%$ & 7 \\
Rotatividade & 1 & $0,4 \%$ & 1 \\
Satisfação dos funcionários com as ações de EC & 14 & $6,0 \%$ & 18 \\
Taxa de acesso & 1 & $0,4 \%$ & 1 \\
Valor de investimento em treinamento por colaborador & 8 & $3,4 \%$ & 8 \\
\hline Total & 235 & $100,0 \%$ & 267 \\
\hline \hline
\end{tabular}

Fitz-enz (1995) menciona que um relatório básico sobre gastos com treinamento inclui variáveis como total de custos do treinamento, total de horas de treinamento, total de pessoas treinadas, custo por participante e custo por participante/hora. O custo por participante/hora é mais interessante que custo por participante, pois dá um denominador comum de comparação entre programas de diferentes durações. Essas variáveis foram identificadas neste estudo (Tabela 8), com exceção do custo por participante/hora, porém, esta última variável é facilmente obtida por meio de cálculo que utiliza as variáveis anteriores.

Por meio da Tabela 8 verifica-se que os indicadores mais utilizados pelas MEPT são número de horas de treinamento (23,4\%); número de horas de treinamento por colaborador (20,9\%); e número de funcionários treinados (11,1\%). Vale realizar uma breve explicação sobre alguns indicadores que não são facilmente entendidos por meio de sua nomenclatura. O indicador “Desempenho” é medido pela alteração no resultado da avaliação de desempenho das equipes. A "Execução do plano de treinamento" consiste em monitorar os treinamentos previstos e confrontá-los aos treinamentos realizados. Por conseguinte, o "Investimento em treinamento 
sobre receita” procura dar uma dimensão de proporção dos investimentos aportados em treinamento em relação à receita líquida da organização. Já o "Número de eventos de treinamento” está relacionado ao número de turmas, ou seja, o número de vezes que um programa é realizado. Por sua vez, o “Número de participações” foi citado com esta nomenclatura pelas organizações estudadas, indicando que é uma terminologia comum e, segundo a descrição de uma das fontes, a participação compreende a contagem de todas as participações dos funcionários em eventos de treinamento, assim o número de participações será igual ao número de eventos que eles realizarem. O "Número de programas realizados" compreende o número de cursos executados. Enquanto o "Número de temas de treinamento" corresponde ao número de módulos, ou seja, blocos de conteúdos agrupados por similaridade. As fontes classificadas na categoria "Satisfação dos funcionários com as ações da EC" monitoram o grau de satisfação do funcionário com as ações promovidas pela EC por meio da pesquisa de clima, seja ela realizada interna ou externamente. Por fim, o indicador "Taxa de acesso" monitora a proporção de funcionários treinados em relação ao quadro total de funcionários da organização.

\subsubsection{Síntese dos resultados das MEPT}

A partir da pesquisa ampla realizada junto às MEPT, observou-se o quão incipiente ainda é a avaliação de resultados em educação corporativa, visto que poucas organizações realizam uma avaliação sistemática. Há indícios de avaliações em diferentes níveis, mas, como se percebeu, em geral, não há um sequenciamento, visto que a avaliação de aprendizagem foi menos citada pelas fontes que a avaliação de processos, que é posterior à de aprendizagem. Segundo Hamblin (1978), a avaliação necessita ser realizada de forma sequencial para identificar-se, caso haja resultados insatisfatórios, em qual nível eles ocorreram.

É importante destacar que, das medidas de efetividade, apenas uma organização apresenta cinco níveis de avaliação e, quando confrontada às características de EC investigadas neste estudo, ela é uma das três organizações que mais apresentam essas características.

Outro ponto a ressaltar é que não há avaliação sobre a influência da EC na disseminação da cultura organizacional. Esse é um aspecto relatado como importante por Meister (1999) e 
Eboli (2004), entretanto, ainda não há avaliações que verifiquem o desempenho da EC neste quesito.

Quanto aos indicadores monitorados pelas MEPT, observou-se a predominância de medidas relacionadas a treinamento. É preciso avaliar se esses indicadores fornecem informações relevantes e, principalmente, o que é feito a partir da apuração dos resultados. É grande o esforço para avaliar as ações de EC, por isso, planejar o quê e como avaliar torna-se fundamental, assim como estabelecer ações de melhoria a partir dos resultados apurados. 


\subsection{Caso Itaú Unibanco}

O estudo de caso conduzido neste estudo investigou o Itaú Unibanco, organização do segmento financeiro. O convite para participação na pesquisa foi enviado em 29 de fevereiro de 2012 e, no mesmo dia, houve retorno com solicitação de uma apresentação presencial sobre a pesquisa, a qual foi agendada para 23 de março. Após essa apresentação, a condução da pesquisa foi autorizada. A coleta de dados ocorreu entre os períodos de 2 de abril e 13 de julho e envolveu a realização de entrevistas, busca de relatórios e visualização de sistemas, ferramentas e formulários. A seguir são expostos os tipos de dados coletados e suas respectivas fontes de evidência (Quadro 8).

Quadro 8 - Dados coletados e fontes de evidências

\begin{tabular}{|l|l|}
\hline Tipo de Dados Coletados & \multicolumn{1}{|c|}{ Fontes de Evidências } \\
\hline Entrevistas & $\begin{array}{l}\text { S01, G02 (responsável pela avaliação de resultados), G03, D04, G05, G06 } \\
\text { (responsável pelo Sistema de Informações Gerenciais - SIG), G07, S08 } \\
\text { (responsável pelo Balanced Scorecard da Área Pessoas). }\end{array}$ \\
\hline Sistemas & Fábrica de Gente e Share Point. \\
\hline Formulários & $\begin{array}{l}\text { Avaliação de reação de programas presenciais - padrão; } \\
\text { Avaliação de reação de programas presenciais - múltipla; } \\
\text { Avaliação de reação - coleta de dados do mapa; } \\
\text { Avaliação de reação de programas a distância; } \\
\text { Validação da turma piloto; } \\
\text { Pesquisa de aplicação do aprendizado. }\end{array}$ \\
\hline Documentos & $\begin{array}{l}\text { Currículo de Conhecimento (pirâmide e trilha); } \\
\text { Escola Itaú Unibanco de Negócios - Modelo de Atuação. Out. 2011. }\end{array}$ \\
\hline Relatórios & $\begin{array}{l}\text { Relatório anual de sustentabilidade 2011. } \\
\text { Análise gerencial da operação, desempenho das ações e dos ADRs e } \\
\text { demonstrações contábeis. }\end{array}$ \\
\hline
\end{tabular}

\subsubsection{A organização}

O Itaú Unibanco é fruto da fusão entre Itaú e Unibanco, a partir da qual a nova organização passou a constar entre as 20 maiores instituições financeiras do mundo em valor de mercado (ITAÚ UNIBANCO, 2012a). Em 2011, segundo ranking mundial da Bloomberg sobre valor de mercado de bancos, o Itaú Unibanco ocupa a oitava posição (ITAÚ UNIBANCO, 2011a). O Itaú Unibanco Holding S.A. é composto pelas empresas Itaú Unibanco S.A., Banco Itaú BBA S.A., Banco Itaucred Financiamentos S.A. e Itaú Seguros S.A. (ITAÚ UNIBANCO, 2011b). 
Os serviços e, ou, produtos oferecidos pela empresa são: banco de varejo, microfinanças, pequenas e médias empresas, cartões de crédito, crédito imobiliários, wealth managment and services, financiamento de veículos, banco de atacado, banco de investimento, tesouraria, seguros, previdência e capitalização (ITAÚ UNIBANCO, 2011a). Os serviços bancários são oferecidos por meio dos segmentos banco comercial, Itaú BBA e crédito ao consumidor. O banco comercial oferece serviços para pessoas físicas e jurídicas, os quais abrangem cartões de crédito, seguro, previdência e capitalização, gestão de ativos, produtos de crédito e soluções personalizadas. Já o Itaú BBA atende a grandes empresas, clientes pertencentes ao segmento corporate, e é responsável pelo banco de investimento que trata de ofertar recursos de financiamento a esse segmento por meio de instrumentos de renda fixa, variável e outros. Por fim, a unidade de negócios crédito ao consumidor tem como público atendido as pessoas de renda inferior, correntistas ou não, por meio da oferta de serviços tais como financiamento de veículos, empréstimos e cartões de crédito (ITAÚ UNIBANCO, 2011a).

Com atuação no Brasil e no exterior, o Itaú Unibanco está presente em 20 países e dois territórios, sendo estes últimos Cayman e Hong Kong. A organização possui escritórios e representações em países da Europa, da Ásia, do Oriente Médio e das Américas (ITAÚ UNIBANCO, 2012a).

A organização apresentou, em 2011, R\$ 851,3 bilhões em ativos totais e lucro líquido de R\$ 14,5 bilhões. O conglomerado apresentava nesse mesmo ano o total de 104.542 funcionários, cerca de 6.000 dos quais atuavam em unidades no exterior (ITAÚ UNIBANCO, 2011b) e entre 94.000 a 96.000 no banco (S01).

A estrutura organizacional do Itaú Unibanco S.A. apresenta conselho de administração, presidente executivo e dez vice-presidências, divididas em negócios e suporte, conforme apontado a seguir pelos entrevistados.

Nós temos são dez vice-presidências, elas tão divididas em negócios e suporte. Então você tem várias unidades de negócio, como banco PF, a Itaucred, a ACC que é cartão de crédito e outras, e você tem as áreas de suporte como é o RH, como é tecnologia, como é a área de finanças, como é a controles internos, então o banco é divido dessa maneira (D04).

Então a gente tá organizado, a gente tem embaixo do presidente executivo hoje, acho que o pessoal já deve ter te explicado, a gente tem dez vice-presidências. E cada um cuida de uma área. Então 
você tem, destes 10, você tem pessoas que cuidam só de um negócio, pessoas que cuidam de suporte e ainda tem gente que está misturada. Então, por exemplo, tem um VP que ele cuida de... hoje ele cuida de uma área que é operacional, que é a área de compliance tal, que é suporte, vamos assim dizer, mas ele também tem o chapéu de seguros, tá? Então ele tem uma área de negócio e uma área de suporte que a gente chama aqui (S08).

São dez áreas executivas, dez vice-presidências hoje dentro do banco, tá? E cada vice-presidência, ela tem um... ela, como que ela tá dividida? A gente tem áreas de suporte e áreas de negócio, então a vice-presidência de Marketing, RH e Relações Institucionais e Eficiência. Aí tem toda a TI até...; é o Jurídico, o Jurídico não é uma vice-presidência, mas ele é uma diretoria executiva. A Auditoria que não é uma vice-presidência, ela tá reportando direto pro conselho, né? (S01)

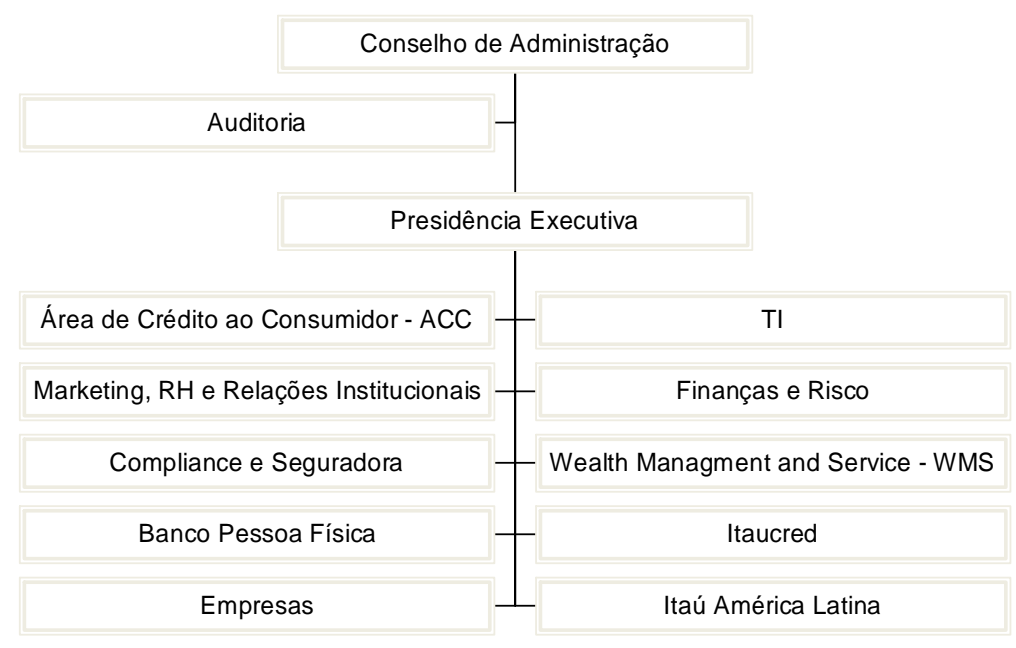

Ilustração 8 - Estrutura organizacional

\subsubsection{Fusão}

O Itaú Unibanco Holding S.A. é uma instituição financeira criada a partir da fusão entre Itaú e Unibanco. Essa associação ocorreu em 3 de novembro de 2008, visando à unificação das operações financeiras (ITAÚ UNIBANCO, 2012a).

A consolidação do mercado financeiro perpassou a história dos dois bancos. Integrar para crescer, esta foi a estratégia utilizada pelo Itaú e Unibanco para ampliar seus negócios. Ambas as organizações têm histórico de aquisições de outras empresas. O Itaú adquiriu o Banco Fiat e Banco AGF em 2003 e BankBoston em 2006. Já o Unibanco adquiriu parte dos ativos do Banco Nacional S.A. em 1995, e o controle total em 2000 do banco Fininvest, Credibanco e Banco Bandeirantes (ITAÚ UNIBANCO, 2012a). 
Após a fusão entre Itaú e Unibanco, a nova organização passou por um processo de integração de três anos. Para a condução desse processo, foi criado um Comitê Superior de Integração, que buscou estudar os processos das organizações, identificar melhores práticas e garantir a continuidade do funcionamento dos negócios (ITAÚ UNIBANCO, 2012a).

Em 2009, a organização estava em fase de acomodação, sem muitas alterações ou mudanças. Entretanto, 2010 foi um ano de muitas transformações, pois foram definidas as ferramentas de gestão e também a cultura do banco. Já 2011 foi o ano de continuidade do processo de mudança, mas com intensidade menor que em 2010. Seguem abaixo alguns pontos trazidos pelo informante:

\footnotetext{
A gente tem, eu já vi no primeiro ano talvez, foi um ano em que a gente estava tentando fazer com que essas duas organizações se acomodassem. O segundo ano foi um ano de muita aceleração por conta dessa definição da cultura. E aí muitas coisas foram organizadas, desde suas ferramentas de gestão até as grandes diretrizes, metas de negócios, estruturas, porque foi um ano de, né? de muita mudança [...] Em 2011 eu vejo que a gente continuou fazendo esse processo de mudança, de acerto de estruturas, de escolhas de pessoas, mas num ritmo talvez menor do que foi em 2011, desculpa, 2010, porque a gente já tinha o grosso, o grosso já tinha acontecido, né? [...] Então assim, eu sinto que 2012 é um ano muito favorável para consolidação de uma série de aspectos, né?, desses que eu já comentei e o banco começa a ter apetite para outros, né? Então eu não tenho dúvida que todos os nossos instrumentais de gestão estão muito mais robustos hoje (S01).
}

A integração dos dois bancos foi concluída em dezembro de 2011 com o encerramento do sistema legado do Unibanco, passando a organização a operar em uma plataforma sistêmica unificada (ITAÚ UNIBANCO, 2011a).

\subsubsection{Estratégia}

O planejamento estratégico da organização ocorre de forma descentralizada, ou seja, as diretrizes e os principais objetivos são definidos pelo presidente executivo e cada área de negócio elabora o seu planejamento para atingi-los. Sendo assim, não há um planejamento estratégico formalizado do banco, as metas e objetivos da organização são elaborados e monitorados em comitês executivos semanais e há, no segundo semestre do ano, uma discussão a respeito da elaboração do orçamento para o ano seguinte. Entretanto, em cada 
área de negócio, em geral, há uma área de planejamento que auxilia o executivo da área na elaboração e monitoramento da estratégia, utilizando, por vezes, ferramentas de planejamento, tal como o Balanced Scorecard - BSC.

[...] o BSC, quando você olha para uma empresa do tamanho do Itaú, ele muda um pouco a configuração, né? Não existe um BSC do Itaú. Um BSC do Itaú seria tão longe de tudo, porque você tem negócios tão diferentes que ele seria super, como é que eu posso te dizer, é... superetéreo, né?, porque ele seria muito macro, né? Então a gente tem essa visão de BSC em cada um dos negócios. [...] As áreas têm com o presidente executivo quais são os goals, né?, o que ele quer para cada negócio. [...] E os executivos montam todo o planejamento das áreas em cima desses goals que eles combinam com o presidente, que o presidente tá vendo pro banco para daqui há cinco anos, dez anos. [...] Você tem áreas que efetivamente desenham um BSC e vão fazer em cima de um modelo de BSC e áreas que não, áreas que elas fazem o orçamento, fazem toda a parte de estratégia, né, da estratégia decorre o orçamento, e aí elas vão fazer lá, olha, macro-objetivos e não necessariamente está num formato de BSC. (S08)

O desdobramento da estratégia da organização ocorre nos diferentes níveis por meio do estabelecimento dos contratos de metas. Assim, a estratégia é desdobrada para o nível de diretoria, de superintendência, de gerência e equipes, por meio do estabelecimento de metas. Essas metas, nos níveis de diretoria, superintendência e gerências são definidas tomando-se as perspectivas do BSC, quais sejam, aprendizado, processos, clientes e financeira, entretanto, a organização não chama esse contrato de BSC. Ao estabelecer as metas nestas diferentes perspectivas, responsabilizam-se os executivos pelo alcance dos resultados organizacionais.

[...] a gente tem hoje na organização é meta e avaliação de desempenho para 100\% da organização. Então hoje não tem nenhum indivíduo na organização que não tenha meta, que não tenha um contrato previsto para entregar no final do ano, que ele não seja avaliado por isso. Aí depende do que você chama um BSC. Como que a gente tem isso? A gente tem isso nos diversos níveis desdobrando. Então eu parto da estratégia, coloco pro diretor, o diretor passa pro superintende que passa pro gerente e assim sucessivamente. Quando você olha hoje pro contrato de metas de um diretor... eu tenho inclusive as categorias de um BSC, mas a gente não chama isso de um BSC, tá? Porque que tenho as categorias de um BSC? Porque a gente entende que um diretor no nível que ele tá hoje na organização, ele tem que ser cobrado pelo financeiro, ele tem que ser cobrado por satisfação de pessoas, de clientes, de pessoas e ele tem que ser cobrado por processos. Então a gente cobra ele de todos os quesitos que tem num BSC e, conforme a gente vai descendo o nível, a gente vai tirando um pouco essa trava [...] (S08). 
As principais diretrizes e os objetivos estratégicos do Itaú Unibanco podem ser traduzidos por meio de sua missão e visão. No que tange à missão, as instituições financeiras têm um papel importante no desenvolvimento econômico do país, pois proporcionam investimentos em empresas, atuando como elo entre o investidor e o tomador. Deste modo, a missão de uma organização financeira é relatada pelo entrevistado, conforme verificado a seguir:

Então missão de uma instituição financeira está muito ligada ao desenvolvimento econômico do país, a você dar ferramentas, uma instituição financeira ela fomenta o crescimento do país na medida em que ela financia empresas né?, o investimento dessas empresas, e isso impulsiona o crescimento econômico. Pensando no aspecto da missão. (D04)

A visão do Itaú Unibanco reflete sua estratégia de atuação, norteando suas ações e esforços: “Ser o banco líder em performance sustentável e em satisfação dos clientes” (ITAÚ UNIBANCO, 2012a). Performance sustentável é a busca de resultados que gerem valor não só para acionistas, mas também para clientes, funcionários e sociedade. Já a satisfação dos clientes se traduz em atender a suas necessidades de forma que isso seja, de fato, algo maior que os próprios resultados que a organização deseja alcançar, pois, ao ter clientes satisfeitos, os resultados tornam-se consequência.

A visão da empresa que é um negócio mais tangível para todo mundo, que foi estabelecido junto com o desenho da nossa cultura, né?, que é de buscar liderança. Nós queremos ser líderes em performance sustentável e satisfação de clientes. Então por performance sustentável, né?, é a visão de você ter resultado de longo prazo, é você buscar o melhor produto pro seu cliente, não necessariamente é aquele produto que você vai ganhar mais, mas é aquele produto que, né?, ele é rentável para você, mas ele é o melhor para o cliente. (D04)

[...] a gente tem dois objetivos, o primeiro é satisfação do cliente e o segundo aspecto é performance sustentável. Então, assim, não é gerar resultado de, a qualquer forma, e é por isso que o banco tá numa agenda forte de transparência tão grande, ele tá numa postura muito forte com todos os clientes em relação a como que a gente pode atender às necessidades do cliente e isso ser de fato algo maior do que os próprios resultados que o banco quer, o resultado que o banco vai conquistar, ele é uma consequência desse posicionamento frente aos clientes [...]. (S01)

Para alcançar essa visão, a organização definiu algumas metas e estratégias. Uma das metas para 2012 é reduzir o número de reclamações nos órgãos de defesa do consumidor (ITAÚ UNIBANCO, 2011a). Para alcançar essa meta, uma das principais estratégias tem sido a forte atuação sobre a consolidação da cultura organizacional. Esta cultura, chamada pela instituição 
de Nosso Jeito de Fazer, apresenta dez atitudes que direcionam o comportamento dos funcionários.

Outra meta é o alcance do índice de eficiência de 41\% até o final de 2013. Esse índice de eficiência significa que, para cada $\mathrm{R}$ \$ 1,00 de receita, é necessário investir até $\mathrm{R}$ \$ 0,41. Como estratégia para atingir essa meta, foi implantado o Projeto Eficiência, uma abordagem sistêmica de gestão de custos que dissemina a cultura sobre o tema dentro do banco (ITAÚ UNIBANCO, 2011a). É válido salientar que, na fala dos dirigentes, a busca pela eficiência não deve impactar a qualidade dos serviços prestados, pois se busca também a melhoria em processos para gerar aumento de receita, tal como a redefinição do modelo de atendimento das agências (ITAÚ UNIBANCO, 2011a).

A internacionalização também aparece como uma das estratégias de crescimento da organização. A ampliação de sua atuação na América Latina e, talvez, nos Estados Unidos se dará, principalmente, pelas oportunidades de aquisições (ITAÚ UNIBANCO, 2011a).

Por fim, outro objetivo estratégico é a meritocracia. No Encontro entre Líderes 2011, o presidente executivo e o presidente do conselho de administração compartilharam essa diretriz com 12.000 gestores da organização. A meritocracia para o Itaú Unibanco consiste em diferenciar os diferentes, por meio do reconhecimento e da diferenciação das pessoas de acordo com seu desempenho, com base em critérios transparentes e objetivos de avaliação (ITAÚ UNIBANCO, 2011a). Essa é uma das dez atitudes da cultura corporativa da organização.

\subsubsection{Gestão de pessoas}

A gestão de pessoas é praticada na organização pelos líderes. Portanto, ela é vista como sendo de responsabilidade da liderança. A área funcional de gestão de pessoas, intitulada internamente de Área Pessoas (AP) tem o papel de disseminar o modelo de gestão de pessoas que a organização deseja, apoiando a liderança na gestão das equipes e fornecendo os recursos e instrumentos necessários. Por várias vezes, durante a condução das entrevistas, ao falar sobre gestão de pessoas, alguns informantes perguntavam-me o que eu queria dizer por gestão de pessoas: 
E como que ocorre então o alinhamento entre a educação corporativa e a gestão de pessoas na organização? (Pesquisadora).

O que que você tá chamando de gestão de pessoas? (G02)

Quando você fala gestão de pessoas é o que? São os gestores? (G03)

Então, é, na verdade, eu não acho que tem um alinhamento da gestão de pessoas com a escola. É a escola que dissemina, é uma das disseminadoras do modelo de gestão que a gente quer pro banco, tá? Mas eu não sei se eu entendi bem a sua pergunta. Você tá me perguntando como que os líderes da organização interagem com a escola ou como que o tema gestão de pessoas interage com a educação corporativa e vice-versa? (S01)

Ao abordar a evolução da organização, foi pedido que os participantes destacassem aspectos que impactaram a gestão de pessoas. Deste modo, eles trouxeram alguns fatores importantes que influenciaram esse modelo de gestão. O fator mais apontado pelos entrevistados, citado por quatro fontes, foi a cultura. A cultura corporativa direciona os comportamentos dos funcionários e, consequentemente, todas as ferramentas e práticas de gestão de pessoas. Assim, a organização declara o que ela valoriza, o que ela espera. Alguns impactos da cultura, mencionados pelos entrevistados foram: ela define as pessoas que a organização quer ter; muda a forma de gerir e lidar com pessoas; afeta a avaliação das pessoas; ela é seletiva. Para ilustrar, a seguir foram transcritos alguns trechos das entrevistas:

Ao longo de 2009 o desenho e a discussão do que que seria a nova cultura deste banco, que nós batizamos como o Nosso Jeito de Fazer, que foi lançado é, aí ao longo de 2009, 2010, no começo de 2010 foi lançado. E isto influencia todos os, as ferramentas e os modelos de gestão de pessoas no banco, porque a partir da construção né?, do que é essa nossa, do que é a nossa cultura, Nosso Jeito de Fazer, que você define as pessoas que você quer trazer pro banco, as pessoas que você quer ter no banco é, e direcionar também o que que o banco quer ser e, portanto, os programas de desenvolvimento, de formação e capacitação eles acabam acompanhando isso. (D04)

Então o que que eu acho, o Itaú tem um histórico muito forte de incorporação de empresas [...]. E aí Carol que acontece? A gente vê uma mudança na cultura e, quando a gente muda a cultura, muda também o jeito de fazer gestão, né?, o jeito de lidar com as pessoas e também um processo normal de, de evolução. (G03)

Então o Unibanco tinha lá o que era chamado de Jeito Unibanco e o Itaú tinha o Modo Itaú de Fazer, né? O que que é isso, na verdade? É uma declaração para dentro da organização num 
primeiro estágio para dizer, olha o que valorizamos, o que queremos, o que não queremos, né?, e aí todo o processo de, de ferramentas de gestão de pessoas, de incentivos, de, é, de, de, outras ferramentas quaisquer, elas são alinhadas à questão da cultura corporativa. [...] E todo o processo de educação é orientado e baseado no Nosso Jeito de Fazer, né? [...] Então, assim, não existe nenhuma ferramenta de recursos humanos nessa organização que não converse com Nosso Jeito de Fazer. (G07)

Então quando essas duas empresas elas se uniram, teve uma necessidade muito grande de se pensar assim, que cultura então nós queremos. Porque não vai ser nem a cultura do que o Unibanco era, não é nem a cultura que o Itaú era, e essa nova cultura precisava ser construída. Então, a partir dessa nova cultura, acho que o banco, de fato, se posicionou e conseguiu dar clareza para cada uma das pessoas do que que de fato deveria se esperar dela, né?, e aí eu tô falando claro num primeiro momento fortemente da liderança. Então a liderança passou a ser cobrada de uma forma muito clara assim: olha é isso que nós queremos, como que você está aderente ou não em relação a esse rol de atitudes que nós queremos valorizar, que acaba sendo o nosso, nossos valores. [...] A partir dele, qualquer pessoa poderia olhar para aquilo e falar bom tô aderente ou não tô, quero ou não quero fazer parte dessa empresa, né?, é uma escolha, acima de tudo, cultura é seletivo, né? (S01).

O segundo fator mais relevante em termos de impacto em gestão de pessoas, apontado por três entrevistados, foi a fusão. Este fato gerou mudança em toda a organização, afetando os empregados, o funcionamento da empresa e, como visto anteriormente, a própria cultura da organização. Esta, inclusive, só foi impactada de forma tão profunda devido à fusão dos dois bancos, pois anteriormente ambas tinham sua própria cultura e, após a fusão, estabeleceu-se uma nova, ou seja, não prevaleceu uma cultura anterior. Um entrevistado relatou que a fusão provocou sentimentos positivos e negativos nas pessoas, devido ao impacto da mudança. As ferramentas e práticas de gestão de pessoas tiveram de ser revistas e reformuladas atendendo às diretrizes e objetivos da nova organização. A fusão foi um fato tão importante que um dos entrevistados se lembra da data exata em que ela ocorreu. A seguir alguns relatos sobre os impactos gerados pela fusão:

[...] acho que o que tem de mais relevante nos últimos anos na empresa foi a própria fusão que aconteceu em final de 2008 e ao longo de 2009, foi todo o processo de integração [...].Os anos de 2009 e 2010 foram bastante importantes porque eles tiveram toda a integração de sistemas, das novas, das agências é, a construção da identidade do banco, da marca, né?, isso passou por uma discussão muito importante. (D04) 
É da fusão para cá é, eu acho que eu citaria a fusão, porque é um impacto muito grande na gestão de pessoas, principalmente quando você tá falando de gestão de mudanças, de como essas pessoas é, estão se sentindo, né?, porque vem à tona uma série de sentimentos, de medo, de preocupação, de ansiedade, seja ela positiva ou não e, eu acho que também o movimento da nossa internacionalização que se fortaleceu depois dessa fusão também e acho que tanto essa questão da mudança, de novas diretrizes estratégicas, de construção de um novo banco, isso impacta muito em gestão de pessoas. (G05)

Então o banco, ele teve a fusão em 2008, em novembro de 2008, 3 de novembro de 2008, para ser bem exata (risos) e, quando essas duas organizações se juntaram, a gente ouvia é que eram organizações muito parecidas, mas, de fato, eram organizações muito diferentes, né? É, só que tinha uma coisa que era muito interessante, o presidente executivo com o Itaú, né?, tinha uma sede muito grande de mudança. Ele queria trazer uma coisa de modernidade, do novo, de fazer com que o Itaú fosse uma empresa moderna e que ela conseguisse acompanhar as, o, o, o novo, ou seja, o futuro. Ele tinha uma percepção que ele precisava é se reposicionar enquanto empresa e aí quando a gente fala empresa, empresa é feita de gente, né?, então eu tava falando especificamente das pessoas, elas precisavam adotar uma nova postura, né?, e o Unibanco ele vinha é, construindo isso a um caminho um pouco maior. (S01)

Outros dois fatores que afetaram a gestão de pessoas, apontado por um entrevistado, foram a definição do papel do gestor e o fortalecimento da atuação da consultoria interna de recursos humanos. A gestão de pessoas passou a ser responsabilidade do gestor e a área funcional de gestão de pessoas passou a atuar como apoio, instrumentalizando-o para conduzir a gestão de suas equipes. Esse processo de definição do papel do gestor inicia-se em 2003 em ambas as organizações, Itaú e Unibanco.

Ah, eu acho que isso com a questão, assim, da solidificação do papel da área de consultoria interna de recursos humanos. Porque eu acho que, assim, uma área de educação melhor preparada e a área de consultoria pessoas mais é dentro dos negócios e mais atuante, eu acho que trouxe para gente um cenário promissor para que a gente pudesse melhorar o processo de desenvolvimento das pessoas e que seja em gestão ou que seja em outros aspectos relacionados à educação. (G07)

É, desde 2003 a organização investe muito na questão de gestão de pessoas [...] Então na época o Unibanco começou por volta de 2003, o Itaú já tinha essa prática também nessa, nesse, nesse ano também aproximadamente. Então veio o processo de maturação, então um esforço, um trabalho muito grande, que acho a primeira coisa que esses dois bancos fizeram no passado foi definir o que que era esperado de um gestor e aí ao definir o que era esperado de um gestor, tem toda uma bagagem de programas de treinamento que vão trabalhar o embasamento deles para atuarem naquilo que é esperado deles no dia a dia. (G07) 
A gestão de pessoas é, então, realizada pelo gestor e a área funcional, chamada internamente de Área Pessoas, fornece o suporte ao líder na gestão das pessoas e realiza a gestão do modelo de gestão de pessoas na organização, conforme vemos nos relatos a seguir:

[...] é, hoje boa parte do que, do processo de educação, ele provê produtos para gestão de pessoas. A gente entende que a gente é meio, a gente viabiliza ferramenta, eu não sou responsável por garantir que a gestão de pessoas, ela de fato aconteça de forma estruturada na organização. A gente entende que essa é uma responsabilidade do gestor de cada estrutura. (G02)

Em termos de estrutura, a Área Pessoas (AP) reporta-se à vice-presidência de Marketing, RH e Relações Institucionais. A AP está dividida em três grandes blocos: produtos, serviços e consultoria. Na esfera produtos, são contemplados a remuneração, os benefícios, a previdência, o desempenho, a liderança, os talentos, a seleção, as relações sindicais e a educação corporativa, ou seja, são as áreas que desenvolvem conceitos e processos relacionados à gestão de pessoas. Já na esfera serviços, são contempladas as áreas que realizam entregas operacionais, tais como folha de pagamento, que abarca o processamento de férias, licenças, admissões, demissões etc. Finalmente, a esfera consultoria abrange o relacionamento entre a Área Pessoas e as áreas de negócio, fornecendo auxílio aos gestores na gestão de seus funcionários, utilizando-se dos recursos providos pelas áreas de produtos e serviços.

Em grandes linhas a, a Área Pessoas tá dividida em três grandes blocos, né? Uma área de produtos, uma área de serviços e a consultoria pessoas, né? Então a área de produtos é... efetivamente cuida da parte, vamos dizer assim, do, do, da gestão do, do produto em si, por exemplo, nós aqui de educação, o nosso produto é treinamento, né? Então, nós somos responsáveis por cuidar e desenvolver esse produto, se eu for para uma área de remuneração é uma outra [...] E aí você vai ter a área de serviços, que aí entra mais a parte de operação que aí vai processar, por exemplo, folha de pagamento, né?, todos os processos de recursos humanos, de férias, é licença, então essa é a parte de serviços. E a parte de consultoria pessoas que cuida da, que tá mais no front com a área de negócios, que tem mais a estratégia, né? (G06)

Ainda na Área Pessoas há uma estrutura responsável por receber e tratar as reclamações, sugestões e denúncias dos funcionários, chamada de Ombudsman (S01). 
A Área Pessoas tem entre 700 e 800 funcionários e, dentro desta área, a diretoria de Cultura e Gente, na qual se encontra a Escola Itaú Unibanco de Negócios, tem aproximadamente 200 funcionários (D04).

A Diretoria de Cultura e Gente compreende quatro superintendências: uma responsável pela cultura, clima e talentos; outra que abrange recrutamento e seleção; uma terceira que trata das relações sindicais e, por fim, a quarta é responsável pela educação corporativa, intitulada de Escola Itaú Unibanco de Negócios, conforme relatos de S01.

Quanto ao objetivo da área gestão de pessoas, os entrevistados relatam que é colocar a pessoa certa, no lugar certo, capacitando-a e reconhecendo-a segundo seu desempenho. Deste modo, está alinhada ao objetivo da organização de valorizar a meritocracia e buscar a eficiência em custos, pois, ao colocar a pessoa certa no lugar certo ao menor tempo e custo possíveis, tem-se como objetivo subjacente a eficiência do processo e, ao reconhecer as pessoas por seu desempenho relativo, busca-se um processo meritocrático. A seguir são expostos trechos das entrevistas:

O de gestão de pessoas é sempre você colocar a pessoa certa no lugar certo e capacitar a pessoa para o melhor exercício daquela função dela e reconhecer ela segundo o seu mérito, né? Então um dos valores mais trabalhado e pregado pela empresa, pelo RH, é o da meritocracia que significa que é você diferenciar as pessoas de acordo com a sua performance relativa. Então a grande missão de gestão de pessoas aqui é você atrair a pessoa certa, colocá-la no lugar certo, né?, na função que é a função que lhe cabe, é capacitá-la pro melhor exercício de sua função e reconhecêla, né?, reconhecer o seu mérito, é praticar meritocracia em todos os níveis e há todo o custo, né? (D04).

Então o conceito de educação corporativa tá muito atrelado à questão da performance da organização, né?, então como é que eu faço para garantir que as pessoas tão performando bem. Então quando eu extrapolo isso para seleção e junto essas duas coisas, então a gente costuma dizer que essas duas áreas juntas têm o papel de garantir a pessoa certa, no lugar certo, né?, num tempo adequado e no menor custo possível. Então eu junto uma coisa com outra, né? É, é o conceito da cadeira vazia, a cadeira ficou vazia, alguém deixou, foi promovido ou saiu da organização, eventualmente, né?, como é que eu reponho essa cadeira, o mais rápido possível, no custo adequado e... e a pessoa capacitada inteira nesse processo. Então a gente batizou esse fluxo, a gente chama de Fábrica de Gente. (G07) 
Em termos de planejamento estratégico, a Área Pessoas utiliza o Balanced Scorecard (BSC) como ferramenta de gestão estratégica. O BSC abrange todas as subáreas da AP, contemplando as metas prioritárias para a área auxiliar a organização a alcançar seus objetivos. A título de exemplo, a AP tem como uma de suas metas para este ano a implantação de seus produtos e serviços nas unidades externas, isto em consonância com a estratégia de internacionalização da organização. Para tanto, essa meta é desdobrada em projetos em cada subárea da AP e são elencados indicadores para acompanhamento, conforme mencionado na sequência.

[...] a gente tem um BSC, que é o BSC da Área Pessoas. Quando você olha pro BSC da Área Pessoas, ele contempla todos os principais pontos da Área Pessoas. [...] Então o que que a gente precisa ajudar é... o banco, como que a gente tem que prover os nossos produtos e serviços para ajudar o banco a chegar onde tem que chegar.[...] Então tem lá o que a gente precisa na parte financeira [...] o que a gente precisa em satisfação, o que a gente precisa em processos, obviamente, como é uma área de suporte toda essa parte de processos ela é muito grossa, vai, é a maior parte porque é onde a gente tem efetivamente uma atuação. E a parte, a última parte lá de pessoas e tecnologia. Mas o grosso mesmo do que a gente tem que trabalhar é... tá em processo. E aí em processo vai aparecer diversas coisas, por exemplo, vai aparecer toda uma parte que a gente tem que dar foco agora, que é foco esse ano, que é a parte de internacionalização. O que é internacionalização? A gente já tem uma série de unidades externas, então a gente tem América Latina, a gente tem Estados Unidos, a gente tem Europa, só que essas unidades hoje é... e aí é... que obviamente a gente tá olhando a parte de RH, é... na parte de RH não necessariamente elas estão com todas as diretrizes da que a gente funciona aqui [...] então a gente tem dentro desse chapéu de internacionalização um projeto que deve durar esse ano e o ano que vem, grande de arrumar todos os produtos de RH nas unidades externas, né? [...] Então e aí a gente tem esse único, disso desdobra projetos, que aí, aí tem projetos para cada uma dessas áreas, qual vai ser o foco, tal, e indicadores que a gente acompanha. (S08)

Percebe-se no relato acima que, por ser uma área de suporte, no BSC a perspectiva de processos é a que mais possui objetivos a serem alcançados. Quanto à periodicidade de revisão do BSC, como o processo é recente, pois está sendo desenvolvido desde a fusão, não houve tempo suficiente para estabelecer uma periodicidade na revisão, entretanto, o intuito é que a revisão ocorra anualmente, conforme relato de S08.

É valido destacar que o planejamento estratégico ocorre por meio do estabelecimento do contrato de metas. Outro ponto de atenção é que há projetos que podem constar no contrato de metas de um supervisor ou coordenador e que não necessariamente está atrelado a algum 
objetivo do contrato da superintendência ou diretoria. Isto ocorre, pois há projetos que são demandados pelas áreas de negócio e, provavelmente, estão no BSC dessa área (S08).

\subsubsection{Educação Corporativa}

\subsubsection{Contexto}

A educação corporativa no Itaú Unibanco, chamada de Escola Itaú Unibanco de Negócios, surge a partir da consolidação das áreas de educação do Itaú e do Unibanco. Anteriormente à fusão, o Itaú já atuava no modelo de educação corporativa, o qual foi estruturado por volta de 2003, por meio da criação das academias que visavam à formação das pessoas para o negócio (G03). Até o momento da fusão, havia áreas de treinamento descentralizadas no Itaú que atuavam dentro das áreas de consultoria interna de recursos humanos (S01; G02). Já no Unibanco, as ações eram centralizadas:

[...] eu acho que no Unibanco ele era centralizado, mas no Itaú onde a gente tem a nossa maior volumetria hoje ele era descentralizado. (G02)

Na evolução do sistema de educação corporativa do Itaú Unibanco, alguns fatos tiveram relevante impacto. O mais citado pelos entrevistados foi a fusão, comentada por três pessoas pesquisadas. Novamente, a fusão aparece como fator relevante, apresentando-se nas falas dos entrevistados como "um marco" e "um divisor de águas” (G02). Com a fusão, a educação corporativa passa a ser vista de forma diferente: as ações de educação, antes descentralizadas no Itaú, passaram a ser realizadas de forma centralizada pela Escola Itaú Unibanco de Negócios. A educação corporativa tem importante papel na disseminação da nova cultura organizacional e há mudanças na capacitação.

Outro dado que impulsiona também ahn... estratégia e capacitação é fusão e aquisições. Quando você junta empresas ou você funde com empresas você tá lidando com, você sai do seu ambiente de conforto, da sua zona de conforto e lida com pessoas, é, de diferentes culturas, né? (G06)

Eu acho que assim, a gente vem nesses dois últimos, nesses três últimos anos, Carol, passando por uma transformação muito grande, principalmente em relação ao processo de, de fusão. E desde então eu acho que a gente tem passado a olhar para o processo de educação de uma forma um 
pouquinho diferente. Porque antes todo o processo de educação corporativa ele era feito, talvez você se lembre, pelos RHs dedicados, onde você tinha a estrutura de educação corporativa explicitada no atendimento da consultoria de pessoas e, momentos antes da fusão, quer dizer, meses antes da fusão, tomou-se a decisão de centralizar todo esse processo [...] Isso, mas que tem a ver com todo o processo de educação do, do banco. Que eu acho que, que olhar pro Itaú, a gente tem um divisor de águas, né? Antes da fusão e pós-fusão. (G02)

Claro, eu acho que, assim, você tem uma série de ações quando você tá falando de um processo de mudança. Eu considero todas as ações de sensibilização para mudança, tá? Assim como toda a adequação, a gente construiu um conjunto de valores, né?, com a fusão dos dois bancos, toda a adequação da nossa educação corporativa, esses valores, o alinhamento com consultorias externas, com os colaboradores internos, para mim eles constituem fortemente, assim, sem educação corporativa isso ficaria muito mais difícil com certeza, né? (G05)

\begin{abstract}
Além da fusão, outros fatores afetaram a educação corporativa na organização. Foram citadas pelos entrevistados: as demandas da área de negócio; a evolução das tecnologias em educação; e a competitividade do mercado.
\end{abstract}

As demandas da área de negócio podem afetar o modelo de atuação da educação corporativa. Por exemplo, nesta organização foi realizado um pedido de uma área interna para que todo novo colaborador seja capacitado antes que inicie suas atividades Assim, para suprir essa demanda foi criado um projeto chamado Fábrica de Gente, que busca alinhar todos os subprocessos de gestão de pessoas, tais como atração e seleção e educação, para que atuem de forma integrada:

Uma mudança talvez, é, para ser mais específico, é uma mudança maior que está acontecendo, é um compromisso que o banco de varejo, o banco PF, tá fazendo com todos os seus empregados, seus funcionários e nós temos o compromisso de honrar esse acordo, esse compromisso, que é não permitir que nenhum funcionário novo ocupe uma posição e trabalhe naquela posição sem antes ter sido capacitado para isso. Então o vice-presidente responsável pelo banco PF colocou: eu não terei mais um, um atendente na agência, né?, um caixa que ele vai, ele começa trabalhando sem ter sido antes treinado. Porque isso era uma prática, pela demanda de contratação, pela urgência, as áreas contratavam, botavam o funcionário para trabalhar e ele aprendia fazendo e depois de alguns meses ele era submetido a treinamento. Quando ele ia ser submetido a treinamento, em geral, talvez aquele treinamento fosse inócuo para ele. (D04) 
A evolução tecnológica é outro ponto relevante que tem impacto na educação corporativa. Novas modalidades de educação têm gerado redução de custos, conforme apontado pelo entrevistado:

Se a gente for pensar em evolução em educação, há uns dez anos atrás, você só tinha praticamente treinamento presencial, em sala de aula. Hoje não, hoje a gente trabalha muito mais com metodologia híbrida de educação e não necessariamente só e-learning, a gente tenta fazer um mix mesmo. Então hoje a gente trabalha com telepresencial, com vídeo, foca sala de aula para treinamento mais comportamental, né?, para otimizar o tempo, né?, evitar o que gente fala de custo de oportunidade, de estar tirando a pessoa do local de trabalho, tudo isso. (G03)

Finalmente, a competitividade do mercado pressiona a organização a atingir melhores resultados e, para isso, é necessário capacitar os funcionários para obter melhoria de desempenho:

Acho que fatos relevantes que impulsionam tanto a estratégia de negócio como a, a, a, a parte de educação corporativa, acho que a gente pode falar em dois grandes pilares, primeiro os fatores externos e depois os internos. Externos, a própria agressividade de mercado, é, aumento de competitividade que isso já é uma coisa natural em qualquer segmento de empresa, isso força as pessoas a melhorar performance, tendo de melhorar a performance necessariamente precisa melhorar a capacitação, né? (G06)

Atualmente, a área de educação corporativa está em processo de transformação. Há indícios, apontados pelos entrevistados, de que a área está estudando a definição de seu papel, sua forma de governança e seus objetivos.

Teve um movimento de, de estruturação, de criar mesmo uma área de educação corporativa, isso mais ou menos em 2003, foi quando eu vim para cá e que começou a trabalhar com o conceito de educação corporativa, mas também já pensando numa evolução para universidade corporativa. Porque naquela época, há nove anos atrás, foi criada uma estrutura de academias, para quê? Para conseguir focar os vários negócios do banco e formar realmente a pessoa pro negócio. (G02)

Eu acho que a gente é uma área de educação em processo de transformação, aonde a gente tá tentando definir claramente qual é o nosso papel perante a estratégia da organização, ou seja, quais são as contribuições que a gente pode trazer. (G02)

Eu acho que, assim, a escola, ela vem se transformando profundamente desde que ela surgiu. Ela começou como uma área que não tinha a configuração de uma educação corporativa, ela estava 
espalhada dentro das consultorias. Teve um determinado momento, na fusão, que essa determinada área de educação se juntou e o foco dela foi oferecer, foi apoiar os negócios em desenvolvimento de programa de treinamento. (S01)

Neste processo de transformação, a Escola Itaú Unibanco de Negócios está buscando ter uma atuação mais estratégica que possibilite seu reconhecimento interno como área importante para a organização. Para isto, tem ampliado suas ações, contemplando uma atuação mais proativa, com customização das ações às necessidades dos negócios e desenvolvendo projetos internos que buscam a inovação em educação, a gestão do conhecimento e a avaliação de seus resultados. O desenvolvimento dessa postura estratégica perpassa os relatos de diversos entrevistados quando abordam a evolução da educação corporativa na organização:

[...] quando eu migrava para universidade, que a gente estava chamando de escola, quais os benefícios que a gente tinha, isso que a gente estava trabalhando com centros de conhecimento, porque trabalhar com centros de conhecimento, eu teria alguns conhecimentos transversais igual eu dei o exemplo de mercado financeiro, né? Enfim, e a gente conseguir vender para a organização os benefícios da gente estar mudando nossa estrutura, nossa forma de atendimento aqui dentro. (G03)

[...] eu sinto um movimento de evolução na escola, Carolina. É, quando a gente fala de educação hoje, né?, o que eu sinto particularmente, e aí é a minha opinião e conversas que a gente vem tendo e nas quais eu sinto uma reciprocidade muito grande da S01 para trazer inovação para dentro da área de educação, né? [...] Então eu entendo, assim, que é a gente tem estado muito aberto e tem buscado muito trazer essas coisas novas para organização, então, por exemplo, na parte que eu cuido, a gente tá revisitando toda a nossa grade de liderança, conhecendo outras empresas, é, conhecendo práticas de construção coletiva, metodologias de resolução de problemas. (G05)

[...] que eu percebo nessa evolução é de um processo que a gente tinha de educação mais tecnicista, ou seja, você preparava as pessoas para, é, exercer uma determinada função, né? E hoje ele tá muito, é, é, ele está muito mais abrangente [...] Você tem que pensar na tecnicidade daquela função, você tem que pensar no comportamento que você vai ter que desenvolver naquela pessoa, você vai ter que desenvolver uma visão estratégica de negócio, então quer dizer o espectro foi ampliado, né? [...] Então eu vejo essa evolução, saindo de um eixo e indo para vários eixos de conhecimento. (G06)

E eu acho que foi nesse ritmo que a gente chegou em 2011, como uma grande fábrica, como uma área de treinamento que faz muitas ações, né? E qual momento que a gente está hoje? A gente está no momento de avaliar será que tudo o que eu faço de fato eu tô gerando resultado? [...] Eu tô identificando os temas e, e identificando assim, puxa, o que que de fato esse banco precisa para 
gerar os resultados que ele quer e não só sendo demandada, mas eu de uma forma proativa? Então eu vejo essa curva de uma grande fábrica para uma área mais estratégica, tá? Eu acho que é esse o movimento. E fábrica de treinamento a gente nunca vai deixar de ser porque o banco é muito grande, eu tenho um ato contínuo de formação das pessoas [...] Eu acho que a gente ainda é uma área que faz um diagnóstico aqui dentro do banco, chama parceiro, diz o que a gente quer, recebe, ajusta e entrega. O movimento vai ter que inverter. A gente tem que ser uma área que identifica fortemente diagnóstico, soma isso à questão de todo o movimento e estratégia do banco, chama parceiros que vão entregar aquilo que nós desenhamos, é bem diferente essa abordagem, né? Eu não estou comprando um programa de treinamento pronto, eu desenvolvo esse programa [...]. (S01)

A partir do último relato, percebe-se que, para a mudança e a consolidação de um papel mais estratégico para a área de educação corporativa, torna-se necessário que sejam avaliados os resultados por ela gerados. Assim, um sistema de avaliação de resultados de educação corporativa é ferramenta-chave para uma atuação estratégica.

Este papel estratégico está muito atrelado à geração de resultados para o negócio, identificando o impacto da EC no alcance dos objetivos organizacionais. Nesse sentido, um entrevistado aponta alguns benefícios da EC. Ele menciona que a EC gera resultados para o negócio, principalmente, por meio da promoção de melhorias no atendimento aos clientes e geração de satisfação dos funcionários, conforme descrito a seguir:

A gente quer melhorar a qualidade de atendimento, você ter menos reclamações de clientes, menos erros, menos retrabalho, então o treinamento ajuda. Tudo se reverte em custo. Quando você tem menos erro e menos retrabalho você reduziu teu custo e aumentou o resultado. (D04)

Quando treina, capacita para vender melhor, você vende mais, você gera mais receita, né? Quando você atende melhor, o cliente volta, você tem mais resultado também. (D04)

[...] a satisfação dos funcionários, este é um, o nível de conhecimento que os funcionários têm em relação aos objetivos do banco, aos valores do banco, você tem as pessoas para isto, tá? É um pouco mais intangível, né? Mas se reflete muito pelo nível de satisfação dos funcionários. Você tem funcionários mais engajados, motivados, treinamento ajuda. (D04)

Para conquistar uma atuação estratégica, entretanto, a EC tem alguns desafios a ultrapassar. Um entrevistado aponta como desafios o ambiente político da organização; o volume de 
programas que pode gerar desalinhamento entre as ações; e o envolvimento da liderança, questão que perpassa a fala do entrevistado por duas vezes, conforme trechos destacados:

\begin{abstract}
É, nenhum programa de liderança hoje ele é implementado sem aprovação de um comitê, ou seja, o quanto a gente está ou não está aderente daquilo que a organização, ela, ela quer pregar. Mas tem uma mobilização que a gente precisa fazer, que ela é muito forte. O banco, ele é muito político, então até você desenvolver uma solução isso demora um tempo, até você mostrar o quanto ela é importante, demora mais outro tempo e assim vai (risos). (G02)
\end{abstract}

Então, talvez eu acho que o grande desafio da nossa área é entender se a quantidade de soluções que a gente tem à disposição é... a gente não tenha uma overdose de informação para o cliente, ou uma overdose de produtos distribuídos nas nossas prateleiras, ou seja, talvez o nosso grande desafio é como a gente faz o alinhamento de tempos em tempos, porque as soluções vão sendo construídas em tempos diferentes. (G02)

Talvez hoje o nosso grande desafio seja como que eu mobilizo os diretores da organização. A gente até tem soluções para esse nível de cargo, mas eu, assim, são soluções que eu não tenho clareza se estão $100 \%$ aderentes porque é muito difícil você mobilizar um diretor para entrar em sala de aula ou para, para deixar de cumprir uma atividade para discutir o tema de educação, para discutir o tema aprendizado para ele. Porque são pessoas que já têm uma capacidade intelectual, passaram por uma série de programas para chegar onde chegaram então eu acho que o nosso desafio é como eu mobilizo e como que eu articulo para que este público passe a fazer discussões nesse sentido. (G02)

A partir desta contextualização da educação corporativa na organização estudada, visualiza-se a importância de uma atuação estratégica da área para que ela consiga demonstrar sua importância para o alcance dos resultados do negócio, o que é potencializado pelo segmento de atuação da organização, que tem como um dos principais objetivos a geração de resultados; e pelo ambiente de mercado caracterizado pela elevada competitividade, conforme se visualiza no trecho a seguir:

[...] porque eu estou dentro de uma instituição financeira, né? Nós, como escola, a gente está dentro de uma instituição financeira, a gente está aqui para gerar resultado, a gente está aqui para alavancar resultado acima de tudo. (S01) 


\subsubsection{Atuação estratégica}

Para a educação corporativa alcançar uma atuação estratégica, há alguns aspectos relevantes que, conforme apontado na literatura, caracterizam essa atuação, são eles o estabelecimento de objetivo para a EC (MEISTER,1999; EBOLI, 2010); o alinhamento da EC à Gestão de Pessoas (OLIVEIRA e OLIVEIRA, 2011); o alinhamento da EC aos objetivos organizacionais (MEISTER, 1999; VERGARA, 2000; ALPERSTEDT, 2001; EBOLI, 2004; PILATI, 2006; ALLEN e MCGEE, 2004); e a estrutura da EC, por meio do estabelecimento de parceria com instituições de ensino (MEISTER,1999; EBOLI, 2010).

Sobre o objetivo da EC, não há formalmente objetivos estabelecidos para a educação corporativa do Itaú Unibanco. Inclusive, a superintendente da área relatou, no momento da entrevista, que estava com programação já agendada para realizar essa discussão. Entretanto, colhendo as percepções dos entrevistados sobre esse quesito, cinco pessoas pesquisadas relataram que o objetivo da Escola Itaú Unibanco de Negócios é desenvolver as pessoas de forma a atender aos objetivos do negócio. Esse é, de fato, o objetivo da educação corporativa apontado por Meister (1999); Eboli (2010); Vergara (2000); Alperstedt (2001); Allen e Mcgee (2004). A seguir alguns trechos das entrevistas:

É eu não quero apenas ter pessoas mais capazes e mais cultas dentro da empresa, mas eu quero mudar o patamar de performance dentro do banco. Então, né?, para algumas áreas comerciais um desafio que eu coloco para o meu pessoal de treinamento é aquela área que ela tinha um conjunto de indicadores de produtividade ou de resultado. Depois que nós treinamos isso, melhorou? E aí o meu cliente interno, ele vai reconhecer a área como uma área que é, que ajudou a gerar valor para a instituição. Aquele treinamento que vocês proporcionaram melhorou os resultados do meu negócio. É para isso que a gente serve. Se a gente não for capaz de impulsionar a performance do banco, de melhorar a qualidade de atendimento, pensando nas duas metas principais do banco: líderes em performance sustentável e satisfação de clientes, se os meus treinamentos não atender esses dois propósitos, eu não tenho a razão de existir. (D04)

Ah, com certeza, é apoiar o negócio, né?, apoiar a estratégia, para que a gente alcance a nossa visão alinhada aos nossos valores, né? A gente tem como uma ambição muito grande de estar próximo ao negócio, o negócio construir com a gente, não ser aquela imagem de, de você ser uma área de pessoas, que a gente chama de $\mathrm{RH}$ apartado do negócio. A estratégia tem que estar presente naquilo que a gente respira e ela tem que estar construída junto com a área de negócio. (G05) 
Os objetivos da educação corporativa é conseguir, é apoiar o cumprimento da estratégia da organização. Como é que a gente faz isso? É, para cada área de negócio que a gente tem, por exemplo, dentro do banco, nós, a ideia é entender qual é a estratégia, necessidades desse negócio e procurar capacitar as pessoas nessa direção, né? Então eu acho que o grande objetivo é a gente conseguir apoiar mesmo, né?, por meio da capacitação das pessoas a estratégia do negócio. (G06)

Então o objetivo da educação corporativa, na minha visão, no Itaú Unibanco tem a ver com o processo de como é que eu garanto, né?, o desenvolvimento das pessoas de uma forma efetiva para que elas possam contribuir pro resultado do, pro atingimento dos resultados do banco. Então educação corporativa tem a ver, assim, de garantir a capacitação e o desenvolvimento adequado das pessoas para que elas possam trazer uma performance, é, e superar as expectativas do banco em relação às suas entregas. (G07)

E a educação corporativa, o quê que eu entendo? A gente tem que saber é, é, a organização não tem que falar: vem, educação corporativa, entre. A educação corporativa tem que entrar na hora em que ela percebe todo esse movimento. Então assim, estou falando de todos pelo cliente, estou falando de sustentabilidade, estou falando é de liderança ética e responsável. Como que eu, como escola, vou ajudar a organização a... a... a passar por esse processo da melhor forma possível. Seja fortalecendo os gestores, seja fortalecendo as equipes, seja passando todo esse direcionamento, esse norte estratégico, que a organização está querendo dizer, eu preciso deixar assim, eu preciso aproveitar a minha sala de aula, o meu e-learning, todas as minhas ações que eu tenho aqui de educação, uma leitura de um livro, um artigo que a gente publica, para mostrar que é esse o caminho. Então eu, como escola, como educação corporativa, eu tenho que pegar esse bonde e potencializar ele, esse é o meu papel. (S01)

Em relação ao alinhamento da EC à gestão de pessoas na organização, os entrevistados relataram que ela ocorre de duas formas. Uma primeira forma, chamada por um dos entrevistados de vertical, é realizada por meio do repasse pelo comitê executivo dos direcionadores sobre gestão de pessoas, e aqui entendido tanto como direcionadores do modelo de gestão de pessoas, quanto o que se espera da liderança. O repasse destes direcionadores ocorre por meio de comitês da Área Pessoas, em que estas diretrizes são desdobradas em suas subáreas. Uma segunda forma de alinhamento, conhecida como horizontal, ocorre por meio do que as áreas de negócio esperam em termos de gestão de pessoas e, nesse sentido, a consultoria de recursos humanos é quem realiza esse alinhamento da educação corporativa às necessidades do negócio.

E aí assim, ela, a gestão de pessoas acontece de duas formas aí. Uma forma mais é, vertical, né?, que o grupo, o comitê executivo da empresa decide em termos de estratégia de pessoas, isso desce 
de forma vertical para organização e nós executamos isso dentro de produtos, serviços e consultoria. Mas existem algumas decisões que podem ser tomadas dentro da área de negócio e aí a gente tem uma decisão horizontal, né? O próprio negócio decide isso e alinha entre a gente. (G06)

Então na verdade a gente recebe inputs sempre de um, principalmente quando eu falo de gestão de pessoas, de um comitê executivo, isso vai se desdobrando, ou seja, ele vai virando um efeito cascata e aí, a partir daí, que a gente promove soluções. Então hoje a área de liderança, ela tem uma parceria muito forte com a área de clima do banco, com a área de cultura, com a área de talentos onde discute fortemente o que que é o papel de um líder, junto com os inputs que vêm de um comitê executivo, onde a gente tem todos os membros do CE, discutindo o que a gente espera de uma liderança, discutindo quais são os nossos objetivos pros próximos anos e é a partir disso que a gente tem que prover as nossas soluções [...] Então a gente percebe que o patrocínio da liderança é fundamental para que a gente tenha a direção correta, que a gente desenhe a melhor solução e para que a gente consiga implementar a melhor solução. Eu acho que isso ainda falta um pouco. (G02)

A gente recebe essa informação através de uma série de comitês que a gente participa. Quando tem necessidade através de reuniões específicas, a gente trabalha muito com grupo focal para atender uma série de soluções dentro do banco, seja ligada à cultura, seja ligada à liderança, a gente tem o hábito de fazer encontro com as pessoas da organização, entender, ouvir da base, a gente ouve da liderança, ouve o comitê, a gente vai na base, a gente entende como essas coisas tão acontecendo. (G02)

Porque assim, quando a gente desenvolve uma solução de treinamento antes de estar implementando tem que fazer um alinhamento com a consultoria pessoas, de certa forma acaba representando o negócio porque ela tá junto do negócio, tá? (G03)

Então ele é feito pelas consultorias pessoas, tá? Então exatamente essa conexão que eu estou te falando que a consultora fez aqui na Área Pessoas, ela faz em cada uma das áreas, tá? [...] Então ela vai trazer a necessidade específica, tá? (S08)

Entretanto, há uma terceira forma de alinhamento da EC à gestão de pessoas, citada por dois entrevistados, que se refere à integração da educação corporativa ao modelo de gestão de pessoas, avaliando seu impacto nos demais subsistemas deste modelo. Esse alinhamento ocorre por meio de comitês da Área Pessoas e é monitorado por meio de um modelo de planejamento estratégico, o Balanced Scorecard (D04). 
Outro fator relevante para uma atuação estratégica é o alinhamento da EC e, consequentemente, de suas ações educacionais, aos objetivos do negócio. Analisando as entrevistas, é possível observar que há duas fontes principais que trazem os objetivos do negócio para a EC: o comitê executivo e as áreas de negócio. A visão do comitê executivo é trazida pelo vice-presidente da Área Pessoas e a visão do negócio é trazida pelos executivos das áreas de negócio e pela consultoria interna de RH.

Você tem uma entrada maior que vem do nosso vice-presidente, tá? Que aí é assim, o que que o nosso vice-presidente traz para gente, né? [...] a entrada do nosso vice-presidente é a visão dos executivos, a visão do comitê executivo, então o que que os pares dele tão pedindo, o que que os pares dele tão reclamando, [...] o que que o presidente quer, onde é que o presidente quer que a gente chegue[...], mas a gente nunca faz uma construção só com essa fonte, tá? Sempre que a gente vai montar o que a gente quer para AP para o próximo ano, ou rever o BSC etc., o que que a gente faz? A gente sempre monta grupos com a liderança da Área de Pessoas, né?, e aí a gente faz uma troca, porque além dessas entradas eu tenho uma outra entrada importante, que é a consultora de pessoas que tá muito próxima do negócio, tá? (S08)

Eu bebo da estratégia da organização, é a minha maior fonte de diagnóstico, a estratégia da organização, né? E o meu segundo diagnóstico são as demandas do negócio, é o desafio que essas áreas de negócio têm para o futuro. (S01)

Para capturar estes objetivos e garantir o alinhamento, são utilizadas algumas práticas e ferramentas. A ferramenta mais citada foi o currículo de conhecimento, apontado por três pessoas. Através do currículo, são identificados os objetivos do negócio e os conhecimentos necessários para atingi-los.

[...] um dos princípios básicos a, o, a, o desenho, a definição de um currículo de conhecimento básico que cada área de negócio deve ter para direcionar as ações de treinamento. Todo o programa de formação e de desenvolvimento, ele tem que ter por referência, tem que ter como referência quais gaps de competência que você tem em cada área para você poder direcionar as tuas ações de treinamento [...]. (D04)

Eu acho que assim, o currículo, ele provê para gente a possibilidade da gente desenhar hoje parte das nossas soluções, ligadas à estratégia daquela vice-presidência. Então eu acredito que a melhor ferramenta, quando eu falo do funcional para a equipe, é o currículo de conhecimento. Porque lá a gente consegue entender o momento que a área está, que tipo de transformação a área vai estar passando, que tipo de solução é mais interessante, fazer a provocação se a gente está investindo no momento certo, nas pessoas certas, com os temas corretos. [...] Como ferramenta, o currículo de 
conhecimento, ele tem esse propósito de ter um olhar muito mais estratégico e muito mais ligado ao momento daquela estrutura, daquela vice-presidência e as ações que a gente tá fazendo de liderança também. (G02)

Os objetivos organizacionais são dados pelo nosso comitê executivo, então são nosso presidente e nossos vice-presidentes estão lá e vão definir a estratégia do banco, onde a gente quer chegar, o como a gente quer chegar, que é tão importante do que aonde a gente quer chegar, o como a gente quer fazer esse negócio. Muito bem. As áreas de negócio, elas depuram este objetivo macro do banco em suas estratégias de negócio, aí entra o currículo que a gente falou agora há pouco. Como o currículo é construído em cima da estratégia da área, ele respeita todo esse ciclo. Então, como a estratégia da área foi construída em cima dos objetivos e anseios do banco, a gente pode afirmar hoje que as ações de treinamento que estão atreladas ao currículo estão necessariamente atreladas ao objetivo maior da organização. (G07)

Uma prática utilizada também para promover o alinhamento entre EC e objetivos organizacionais é a instituição de comitês. A consultoria interna de RH participa dos comitês das áreas de negócio e funciona como a ponte entre as demandas do negócio e os subsistemas de gestão de pessoas. Conforme apontado por um entrevistado, os comitês são importantes para acompanhar se os programas realizados atendem aos objetivos do negócio:

[...] você já tem uma grade curricular preestabelecida, né?, e você nos comitês acompanha se o que está sendo feito está atendendo os objetivos do negócio. Comitê, ele é importante para você ter uma discussão aberta, né?, do tipo, tá nós estamos investindo tempo na coisa certa? [...] Ele tem é, também, a gente colocou, né?, os dois objetivos da organização são liderança em performance sustentável e satisfação de clientes. Então todo treinamento tem que dar suporte para essas duas coisas e o alinhamento se dá nos comitês das áreas de negócio [...]. (D04)

Por meio de comitês. [...] Sempre é a consultoria pessoas, sempre está nos comitês de negócios, das decisões que são tomadas nesses comitês de negócio, a área de produtos pode estar junto ou não. Se nós não estivermos juntos, a consultoria pessoas, depois de recebida essa demanda, essa orientação, eles chamam a gente para uma reunião e passam essas informações. (G06)

Finalmente, a estrutura também é fator importante para uma atuação estratégica da EC. Sobre estrutura, a literatura aponta a parceria com instituições de ensino como relevante (EBOLI, 2004; ALPERSTEDT, 2001). Além deste quesito, também serão descritos outros fatores para auxiliar na compreensão do sistema de educação corporativa da organização estudada. 
A Escola Itaú Unibanco de Negócios conta com 84 funcionários e 54 terceiros que atuam na logística dos programas. Ela está estruturada em cinco centros, que se dividem na condução dos programas e atendimento às áreas de negócio. Três centros atendem às áreas de negócio, são os chamados centros de negócio, e os outros dois são responsáveis pelos temas transversais, ou seja, que perpassam todas as estruturas da organização. Um centro é responsável pelos programas a distância, pelos temas corporativos e pela logística de treinamento; o outro trata dos programas de liderança e valores (ITAÚ UNIBANCO, 2011c; S01).

Para entender um pouco o funcionamento da educação corporativa na organização estudada, foi pedido aos participantes que descrevessem os macroprocessos realizados. De forma geral, os entrevistados descreveram quatro etapas: diagnóstico, desenvolvimento, implantação e avaliação. A seguir é exposto um trecho de uma entrevista a título de ilustração:

Então a primeira etapa que a gente tem num processo de educação é um processo de diagnóstico. E o diagnóstico, ele acontece independentemente de um currículo de conhecimento, né? Porque, uma vez que um conhecimento x é dado como prioritário, eu preciso entender o que exatamente eu quero com aquele conhecimento, aonde eu quero chegar, qual é a minha necessidade, qual é o meu problema, se existe ou não existe gap e se aquele gap é tratável ou não tratável por treinamento. Então tem uma grande função aqui que é diagnóstico. O próximo step do processo de educação é o step de desenvolvimento, que é aonde eu vou me preocupar com o processo de construção da minha solução. Então, dado o diagnóstico que eu fiz, qual é a melhor solução, qual é o melhor modelo para atender àquela necessidade. Aí é que eu vou entender se eu vou buscar externo, se eu vou trabalhar com parceiro interno, se eu vou trabalhar em sala de aula, se eu vou trabalhar a distância; se for a distância, se eu vou trabalhar com apostila, se eu vou trabalhar com e-learning, ou seja, se eu vou fazer um mix de metodologias ou não. Essa é a solução. Eu tenho a aplicação, que é o terceiro step desse processo. E aí entra toda a minha estruturação da entrega efetiva, né? Então tem todo o processo logístico de entrega, de organização, de calendarização disso tudo, tal. E aí tem uma etapa final, que é a etapa de mensuração, que é assim: tá bom, eu diagnostiquei, desenhei, apliquei, agora eu preciso mensurar para saber o quanto desse investimento teve retorno pro banco, o quanto ele foi efetivo daquilo que era previsto. E aí uma vez mensurado, isso retroalimenta meu diagnóstico e aí esse ciclo ele passa a girar, né? (G07)

Para apoiar a operação desses macroprocessos e auxiliar no processo de gestão da escola, são utilizados alguns sistemas. O sistema aparentemente mais utilizado e de maior importância, citado por quatro entrevistados, é o SABA, que é o Learning Managment Sistem (LMS), plataforma utilizada para fazer a gestão do processo de educação do banco. Assim, são 
disponibilizados nesse sistema os treinamentos e-learning e ferramentas colaborativas, tais como o chat; além disso, suporta o gerenciamento da operação logística, envolvendo a convocação dos funcionários para participação nos programas; verificação da situação do funcionário, tal como férias ou licença; a gestão de indicadores etc. É utilizado também o Share Point para elaboração e compartilhamento de indicadores dentro da área; entretanto, esta ferramenta está sendo descontinuada, pois estão implantando uma nova ferramenta web, chamada de site da Fábrica de Gente (S01; G02; G06; G07).

O modelo de atuação da Escola Itaú Unibanco de Negócios é marcado pela parceria que estabelece com fornecedores externos, instrutores internos e instituições de ensino. Os fornecedores externos são consultorias contratadas para entrar em sala de aula, a principal vantagem dessa parceria é ter profissionais especialistas e com experiência na condução de sala de aula, conforme apontado pelo entrevistado abaixo:

O consultor externo é aquele cara que normalmente a gente vai buscar o quê? É expertise, conhecimento de mercado sobre determinado tema, né?, e até a forma com que ele conduz o programa de treinamento e as discussões com que ele promove dentro do banco, tomando o cuidado de integrá-lo à cultura, eu acho que isso funciona muito bem. (G07)

Os instrutores internos atuam na condução de temas relacionados aos produtos do banco, dos quais eles são gestores. Porém, há consultores externos que também ministram temas relativos a produtos. A vantagem de realizar parceria com funcionários é que eles já conhecem a realidade e cultura da organização e dominam determinado tema dentro do contexto organizacional.

O parceiro interno é diferente, o parceiro interno eu trago aquele cara, assim, que conhece muito bem o nosso negócio, conhece muito bem aquela metodologia, aquela técnica ou aquele assunto, né?, que já está totalmente inserido na nossa realidade, então já traz exemplos, termos que são mais de fácil assimilação das pessoas internas porque é, fala a língua já do pessoal de dentro do banco, tal, e conhece muito bem. É claro que tem perfil e tem uma dinâmica toda para condução de um grupo. (G07)

Conforme apontado por dois entrevistados, a parceria com funcionários para a condução de programas se dá mais em temas técnicos, já em programas e temas comportamentais são utilizadas consultorias externas, conforme trechos transcritos a seguir: 
É, nós temos um modelo, um modelo, um modelo híbrido mesmo, né? A gente usa instrutores internos, né? Esses instrutores internos eles são, eles são os próprios gestores de produtos de uma área, né? Então eu desenvolvo um produto, mas eu também é, entro em sala de aula para explicar sobre esse produto. Mas a gente também, como a gente não trabalha só a parte técnica do produto, mas também a parte comportamental, aí a gente tem parceria com consultorias externas que nos apoiam também nesse, nesse modelo, tá? (G06)

Hoje a gente trabalha muito com gestores de produtos e serviços que entram em sala de aula, então hoje a gente explora o conhecimento desses gestores; e muito com consultorias externas. Então eu não tenho analistas aqui na escola que entram em sala de aula para dar aula, então, por exemplo, vou pegar o gerente comercial, eu vou falar sobre capitalização, consórcio, vem, entra o gestor do produto em sala de aula, tá? Ah, eu vou falar sobre técnicas de atendimento, técnicas de visita, entra consultoria externa para dar esse conteúdo. (G03)

\subsubsection{Público-alvo}

Um dos aspectos que caracterizam a educação corporativa é a ampliação do público atendido, ou seja, o público-alvo da EC ultrapassa as fronteiras da organização e engloba, além dos funcionários, os clientes, fornecedores, franqueados, comunidade e outros públicos que tenham relação com a organização (MEISTER, 1999; VERGARA, 2000; ALPERSTEDT, 2001; EBOLI, 2004; PILATI, 2006). Desse modo, foram investigados quais os públicos atendidos pela Escola Itaú Unibanco de Negócios. Constatou-se que o foco principal das ações educacionais são os funcionários, sendo todos os públicos internos atendidos pela escola, conforme apontado por três entrevistados (G05; G06; S01). Entretanto, há algumas iniciativas voltadas a outros públicos. A ampliação do público atendido é uma preocupação dos gestores da área e, inclusive, há o desejo de se tornarem uma unidade de negócios, ofertando suas ações educacionais para a sociedade e ampliando a fonte de receitas.

O segundo público mais citado pelos entrevistados, cinco fontes, foi fornecedores. Há ações estruturadas para a formação desse público para que consigam compreender a cultura e a estratégia da organização para repassá-las nos programas educacionais. Estas ações compreendem a realização de workshop com esses fornecedores sobre a cultura do banco, palestra e distribuição do código de ética e participação no evento Encontro entre Líderes, promovido anualmente pelo presidente executivo e o presidente do conselho de administração 
em que são repassadas as diretrizes estratégicas da organização. Além da formação dos fornecedores, há a intenção de certificá-los, segundo relatos do entrevistado G05.

Hoje com fornecedores eu acho que a gente prepara bastante, ou tenta preparar nosso fornecedor no sentido como ele pode entender melhor essa organização, para, no momento em que ele estiver em contato com o..., o nosso funcionário, ele poder falar a linguagem. A gente ainda não é um, uma empresa que fornece conteúdo para todos os fornecedores. (G02)

Então o que que a gente prevê nessa frente, trazer esses fornecedores para os eventos que são mais voltados para estratégia, ter reuniões periódicas no ano para que eles tenham atualizações do momento que a organização está vivendo e para que eles possam nos ajudar a compartilhar isso em sala de aula, né? [...] Mas eu te diria que até a questão de fornecedores, a gente já tem esse processo de inserir na estratégia, de preparar, a gente tem um, uma grande aspiração aí, até de certificar esses fornecedores. (G05)

Então, normalmente tem um banho de loja que a gente faz com esse parceiro externo para ele entender quem é o Itaú Unibanco, o que que a gente valoriza aqui, o que a gente quer, o que a gente não quer, né?, e é uma pessoa que precisa respirar um pouquinho do ar do Itaú Unibanco até para quando estiver com nosso público em sala ou a distância que seja, ele seja uma pessoa que tenha essa empatia realizada, entenda um pouco das dificuldades das pessoas, das coisas que a gente se propõe a fazer, tal. Então tem um cuidado especial na introdução desse parceiro na nossa cultura e isso desde o processo, o cara de compras se envolve no processo de homologação desse parceiro, né? A gente tem um workshop que a gente faz de cultura com os parceiros externos, a gente junta ahn... todos os recém-chegados num auditório e fala sobre a cultura, fala sobre o Itaú, ou seja, procura integrá-los à nossa cultura. (G07)

Quando eles estão em sala de aula, eles estão representando a instituição. Então é como se a gente tivesse que falar com esse grupo dizendo quais são as atitudes, o que que é a visão do banco, para onde nós estamos querendo ir, o que que significa todos pelo cliente, o que que significa performance sustentável, brabrabra... Então eu dou assim um, eu dou um, um banho de banco mesmo, uma imersão deles no que que significa tá aqui dentro do Itaú Unibanco. (S01)

Por fim, a comunidade e terceiros são atendidos pontualmente pela EC. Em ações para a comunidade, foi apontado por um entrevistado (G02) que são desenvolvidas cartilhas de educação financeira para auxiliar a área de microcrédito do banco na capacitação de seus clientes. Já em ações para os terceiros, são desenvolvidos programas a distância para capacitar esse público, como as centrais de atendimento (G03). 
[...] você pega uma área como microcrédito que é uma estrutura que precisa lidar com pessoas de baixa renda e prover crédito para essas pessoas progredirem, essa estrutura hoje ela treina o seu cliente. [...] Mas hoje ele tem isso através de cartilhas. [...] Quando a gente precisa ajudar a desenvolver as cartilhas, na verdade, a área de educação financeira, ela é nossa cliente, a gente ajuda a prover as soluções pro banco para esse cliente em relação a esse tema. (G02)

Então o que eu tenho hoje para público externo são algumas ações a distância onde, onde eles acessam um ambiente apartado do banco. [...] Então a gente acaba facilitando esse processo, né?, então a gente disponibiliza os recursos tecnológico para isso, a gente customiza os conteúdos para os terceiros, a gente gera os conteúdos, mas é muito pouco. (G03)

\subsubsection{Aprendizagem contínua}

A promoção da aprendizagem contínua pela EC é um tema controverso. Alguns entrevistados disseram que a escola promove a aprendizagem contínua, dado que há o mapeamento dos conhecimentos para as diferentes posições dentro de determinada carreira e a realização de programas educacionais em cada estágio de carreira, porém, a aprendizagem contínua para alguns entrevistados vai além do aprendizado formal realizado pela EC, a disseminação de conhecimento entre os funcionários e a busca pelo autodesenvolvimento também foram apontados como características da aprendizagem contínua. A seguir trechos dos relatos dos entrevistados:

Eu acho que, é isso tá mais forte dentro da área de educação corporativa do que no negócio em si. É, mas eu não sei se a gente já tem isso instalado, eu diria que não. Eu acho que a gente fala bastante sobre isso, mas eu acho que a gente não sabe fazer isso bem. (G02)

Porque assim, quando a gente pensa nas ofertas da escola, é, nós, nós temos as trilhas, as grades, como eu falei para você, tem o foco de formação, temos é, as ações de aperfeiçoamento também e temos as ações pontuais. [...] Agora, se eu falar, por isso que eu questionei, porque quando eu penso um pouco no colaborador e em um processo de aprendizagem contínua, que aí envolve a busca pelo conhecimento, envolve o autodesenvolvimento, eu acho que não. Eu acho que isso não é só no Itaú, eu acho que isso é uma mudança de mentalidade do processo de aprendizagem no Brasil, onde as pessoas vêm ainda daquela cultura de sala de aula, onde eu sento numa mesa, eu recebo informação, conhecimento, eu não vou atrás da busca pelo conhecimento, né?, então eu acho que ainda tem muito disso. Aquele discurso assim o que a organização vai fazer para me desenvolver e não o que eu vou fazer para me desenvolver. Então ainda tem pessoas que ainda têm esse tipo de mentalidade. (G03) 
[...] a gente tem campanhas de autodesenvolvimento onde a gente lança novos cursos, reforça os cursos atuais, quais são os temas e aí a gente faz sorteios de livros pras pessoas que concluírem o treinamento dentro de determinado prazo. É uma forma de tá estimulando as pessoas no seu processo de aprendizagem. É, em 2008, também, né?, a gente teve um movimento muito bacana que a gente chamava de Semana do Desenvolvimento, teve 2007, teve 2008, e esse movimento acabou cessando devido a $\mathrm{n}$ mudanças que a gente teve. O que que era essa Semana do Desenvolvimento? A gente trazia um palestrante de mercado, então na época a gente trouxe aquele cara que fala sobre emprego no Fantástico [...]e no outro ano foi a família Schürmann, né?, então vinham e falavam sobre questões de educação, de motivação, tá? Haviam vários quiosques, cada quiosque falava um tema, uma questão de desenvolvimento, né?, enfim... (G03)

Acho que formal, formal, não, né? Porque acho que, quando você fala de uma cultura de educação, parece que pressupõe uma metodologia ou alguma ferramenta, né? A gente faz meio que empiricamente, a gente vai aprendendo e trocando ideias e percepções entre pares e vai melhorando, mas um processo formal na organização eu não, não vejo. Não tem. (G06)

Olha, eu acho que cada vez mais, eu ainda não me sinto confortável de te, te trazer isso como uma afirmativa. Eu acho que a gente vem evoluindo bastante nesse sentido. Eu acho que existe, assim, um fomento muito grande da nossa parte em relação ao autodesenvolvimento, né? E os programas que são construídos na escola, de certa forma, eles respeitam os estágios de carreira das pessoas. Então o que traz essa visão de educação continuada, né? Que eu, eu não estou focado em somente um estágio de carreira dele, eu estou focado no processo de crescimento daquele profissional, então desde a entrada dele num cargo de base, por exemplo, como um caixa, como um assessor de uma rede de agências até ele se tornar um gerente dessa agência, por exemplo. Então eu tenho programas que endereçam cada estágio de carreira que traz um pouco essa visão de educação continuada, de uma cultura de aprendizagem. Agora, a cultura da aprendizagem mesmo, assim, literal, eu acho que a gente tá caminhando para isso, mas ainda não é algo que a gente possa dizer: olha isso aqui é uma característica forte do Itaú Unibanco, por exemplo. [...] Eu não me sinto confortável de, de, de dizer isso. Mas eu acho que a gente caminha, sim, fortemente para isso, né? E porque eu acho que uma cultura de aprendizagem tem uma questão, assim, que ambiente é esse que a gente faz parte, o quanto que esse ambiente propicia esse processo, mas também o quanto as pessoas se responsabilizam pelo seu processo de desenvolvimento e de aprendizagem. Então a gente tem trabalhado nas duas frentes, na criação do ambiente, na ferramenta, na disponibilização de informações e no fomento, né?, da importância disso, mas também trabalhado fortemente na questão da atitude do indivíduo para que ele, ele se responsabilize por isso ainda. (G07)

Cultura, eu acho que ainda é muito distante assim, a gente tem iniciativas, não posso dizer que a gente não tem uma cultura de aprendizagem. A gente tem porque a organização a todo momento, só de a gente falar de iniciativas das áreas, tem uma série de iniciativas de educação que não passam por mim, pela escola, e que são iniciativas de aprendizagem, né? A escola talvez seja o 
canal mais formal, mais institucional de todo esse processo de disseminação. Mas as áreas têm iniciativas de palestras até treinamentos individuais. Então é um banco que tem um foco muito grande no aprendizado, no, no aprender. Mas a gente ainda não tem isso de uma forma assim, por exemplo, uma ferramenta de gestão de conhecimento que seja nosso grande arcabouço de informações, isso a gente ainda não tem. (S01)

A partir desses relatos, verifica-se que a aprendizagem contínua envolve, para a organização estudada, ações formais e não formais de aprendizagem. A EC aparece como agente fomentador do ambiente para a aprendizagem, fornecendo os recursos e ferramentas necessários, entretanto, a atitude ativa do funcionário na busca de seu desenvolvimento é apontada por dois entrevistados como fator-chave para que a aprendizagem contínua ocorra.

\subsubsection{Currículo de conhecimento}

O currículo de conhecimento é uma metodologia desenvolvida pela Escola Itaú Unibanco de Negócios para mapeamento dos conhecimentos necessários para alcançar os objetivos organizacionais. Esse mapeamento ocorre por meio de diagnóstico realizado com os executivos das áreas de negócio e suas equipes, partindo da estratégia da área, verificando a situação em que ela se encontra em relação a esta estratégia e mapeando os conhecimentos necessários para que esta última seja alcançada. A metodologia aborda os conhecimentos estratégicos, táticos e operacionais.

O que que é o currículo? O currículo na verdade é um grande mapeamento que a gente faz de quais são os conhecimentos necessários para que aquela área, naquela função, naquele cargo, exerça sua atividade. Então o processo do currículo começa com uma conversa com o executivo responsável pela área para entender: olha, me conte um pouquinho da estratégia da sua área. Tá bom, ele vai te contar aonde ele quer chegar, aí a próxima pergunta é aonde nós estamos, então muito bem, com o executivo eu vou entender assim, aonde nós estamos e aonde ele quer chegar com essa área dele. Porque aí eu vou descendo na estrutura dele, vou conversando com seus reportes, seus diretos, os diretos de seus diretos, tal, para ir depurando um pouco essa visão até chegar nas próprias equipes, porque a gente se reúne com as equipes para entender também na visão deles como é que isso acontece. À medida que eu vou descendo na estrutura, né?, até chegar às equipes, eu deixo de falar somente de estratégia e passo a falar do tático também. Então, quando eu chego no nível gerencial, por exemplo, até no nível de superintendentes, eu já estou conversando com ele assim: oh, onde você quer chegar com essa área? mas me conta um pouquinho como é que ela tá estruturada hoje, quais são as macrofunções que você tem na sua área, né?, qual é a responsabilidade dessas macrofunções e quais são os conhecimentos que essas macro funções precisam ter para exercer sua 
atividade no dia a dia. E quando eu chego na equipe, eu tô falando do dia a dia deles, então o que você faz, sobre o que que você é responsável e o que que você precisa conhecer. Então, assim, percebe, eu saí da estratégia da área e cheguei no tático operacional totalmente daquela estrutura [...]. Todas as ações de treinamento são construídas em cima deste rol de conhecimentos, como os conhecimentos são atrelados à função, que tão atrelados a uma área, que tão atrelados a uma estratégia e o treinamento é construído em cima deste conhecimento, automaticamente eu estou dizendo: oh, o seu treinamento está totalmente atrelado com a estratégia da sua área. (G07)

Currículo de conhecimento, que é como a gente chama, ele passa exatamente por essas etapas que eu comentei com você. São entrevistas, né?, que a gente faz desde o mais alto nível da estrutura até grupos focais com as equipes. A gente faz conversas individuais com VP, com os diretores e com os superintendentes. Gerentes, analistas e coordenadores, a gente faz grupo focal para gente ter represent, amostras representativas para a gente colher. O que que a gente faz nessas entrevistas? A gente entende onde a área tá, para onde ela vai, como que eles tão se enxergando e quais são os conhecimentos, como é que a pessoa constrói a sua carreira, enfim, a gente faz pergunta às vezes para ter um mapa de conhecimento. (S01)

O currículo de conhecimento é definido pela EC como: “o currículo de conhecimento tem por objetivo desenhar a estrutura curricular de 'conhecimentos' necessários para o desempenho das funções de cada área, por extratos de carreira, a fim de desenvolver os profissionais para termos uma equipe de alta performance” (ITAÚ UNIBANCO, 2011c).

Os conhecimentos mapeados pelo diagnóstico são estruturados em duas vertentes: os conhecimentos genéricos e os específicos. Os conhecimentos genéricos são os comuns a todos os funcionários das áreas de negócio, já os conhecimentos específicos são aqueles necessários a determinado cargo ou função. Deste modo, os conhecimentos genéricos são demonstrados em uma pirâmide, na qual constam as funções de equipes, coordenador, gerente e superintendente; e os conhecimentos específicos são demonstrados nas trilhas de conhecimento, os quais também são agrupados por cargo ou função.

O Currículo é composto por duas dimensões: conhecimentos comuns e específicos. "Pirâmide" apresenta a visão consolidada dos eixos de conhecimento - Negócios, Funcionais, Pessoas e de Excelência Pessoal. Conterá os conhecimentos comuns da área/negócio. “Trilhas” conterão de forma detalhada os conhecimentos, considerando a natureza da atividade, carreira e as especificidades do negócio, os quais não são comuns a área/negócio (ITAÚ UNIBANCO, 2011c).

Nasce daí um rol de conhecimentos, então, que cada macrofunção daquela área executiva precisa ter para exercer o seu papel no dia a dia, ah, e aí eu tenho as trilhas que a gente fala, trilhas de 
conhecimento. Porque, assim, se eu, dependendo da área executiva que eu estou, por exemplo, se eu sou um analista de uma área executiva, independentemente da área, daquela área executiva que eu faça parte, por eu ser um analista daquela área executiva, eu preciso ter um rol de conhecimentos que eu preciso ter no meu dia a dia. Só que, como eu faço parte de uma área específica, eu preciso ter aqueles conhecimentos que são comums, mais alguns que são específicos da minha função. Então, juntando essas duas coisas, eu tenho o que que o analista dessa área precisa conhecer. Vou dar um exemplo: na área de recursos humanos, eu faço parte da área de recursos humanos, eu faço parte da área de educação corporativa. Então, por ser um gerente de uma área de recursos humanos, eu preciso ter um rol de conhecimentos $\mathrm{x}$, independente da área que eu esteja dentro da área de recursos humanos; agora, como eu sou gerente de uma área de educação corporativa, além desses que eu mencionei, eu preciso de outros específicos da minha área, e aí nasce esse currículo de conhecimentos. (G07)

O modelo currículo de conhecimento é estruturado em quatro eixos, os quais são chamados negócios, funcionais, gestão de pessoas e excelência pessoal, conforme descrito a seguir:

Negócios: conteúdos voltados para as questões relacionadas à gestão estratégica, compreendendo cenários, mercados, clientes e perenidade dos negócios. Funcional: conteúdos voltados para a excelência operacional, máxima produtividade, qualidade e mitigação de riscos com foco em conteúdos técnicos ou funcionais. Pessoas: conteúdos voltados para a gestão de pessoas, compreendendo coordenação do trabalho, avaliação e feedback, desenvolvimento etc. Excelência Pessoal: conteúdos voltados para as habilidades do indivíduo (ITAÚ UNIBANCO, 2011c). 


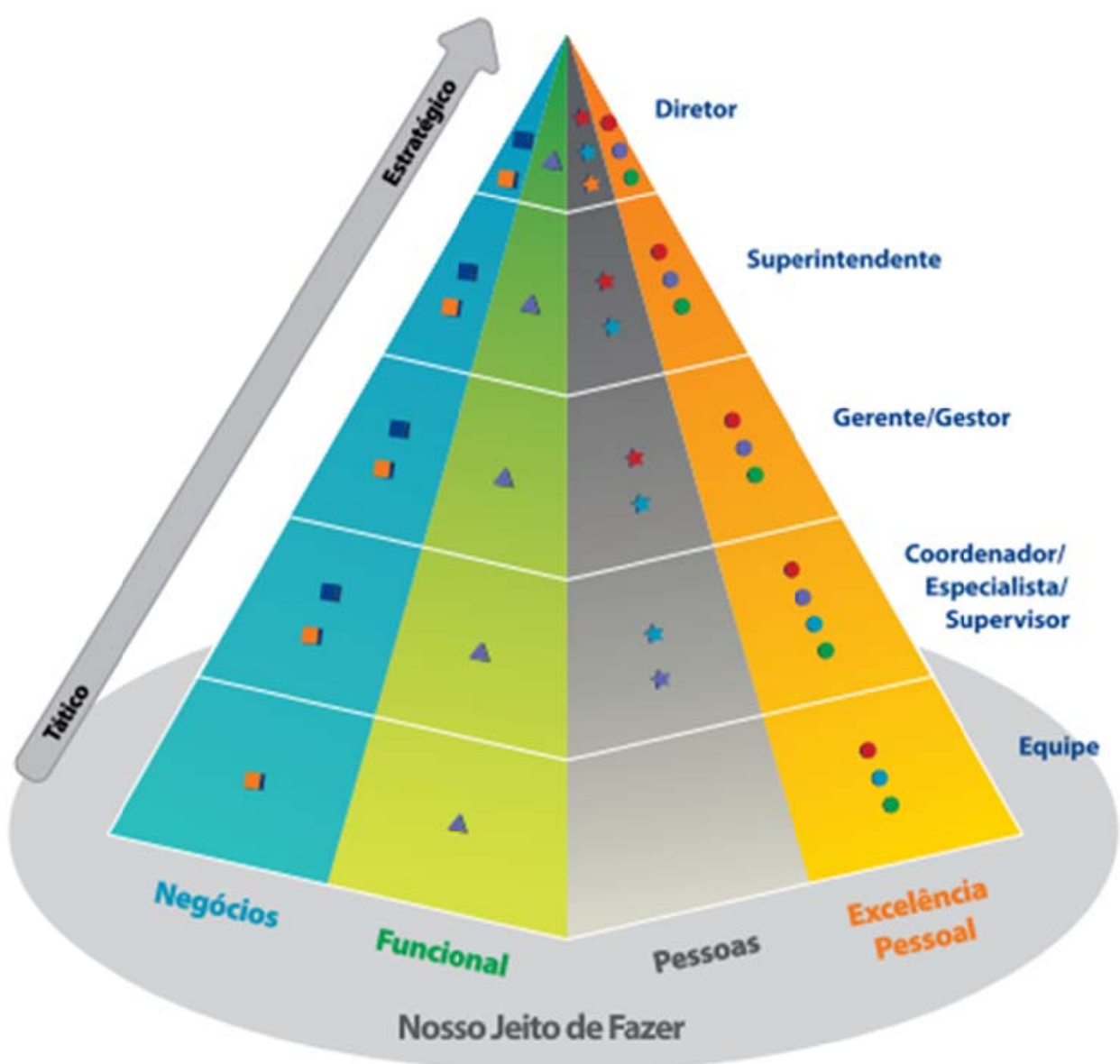

Conhecimentos Comuns - ASPC

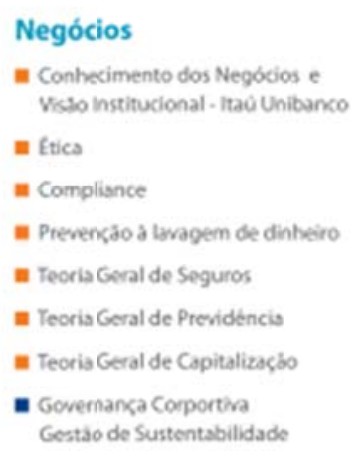

\section{Funcional}

A Gestio de riscos.

Os demais conhecimentos funcionsis estiso contemplados nas trithas das ateas?

\section{Pessoas}

* Gestao de Pessaas ide acordo com e programa de Desernolvimento de Lideranças e exclusivamente para quem tem Gestao de Pessoas?

- Relacoes Trabalhistas

* Processos internos de PH
Excelência Pessoal

- comunicasao verbal e escrita

- Técnicas de Apresentacso

- Técnicas de foedback

- Trabaho em equipe

\section{Ilustração 9 - Pirâmide de conhecimento}

Fonte: Itaú Unibanco (2012b). 


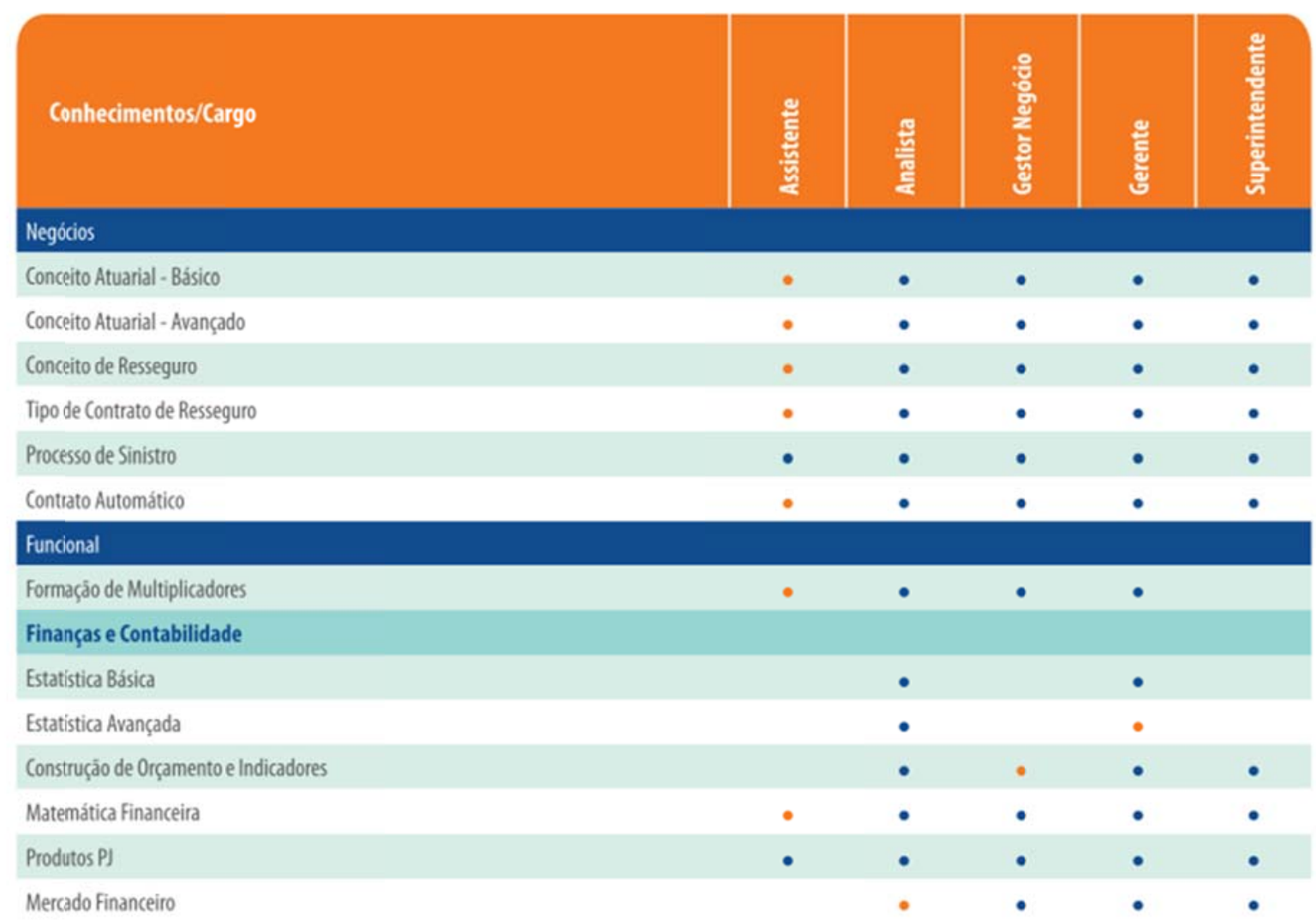

Ilustração 10 - Trilha de conhecimento específico

Fonte: Itaú Unibanco (2012c)

O currículo de conhecimento contém os conhecimentos necessários a determinada área de negócio, mas estes não são estruturados em programas educacionais. Essa estruturação ocorrerá após a priorização e o planejamento de quais conhecimentos serão desenvolvidos. Na sequência, uma breve descrição desta etapa:

O Modelo envolve quatro eixos de conhecimento: Negócios, Funcional, Pessoas e Excelência Pessoal. A partir da identificação dos conhecimentos, definimos um plano de capacitação para a Área, onde alguns conhecimentos tornam-se treinamentos, mediante a priorização. Estes treinamentos serão customizados para a realidade da área e alinhados ao Nosso Jeito de Fazer (ITAÚ UNIBANCO, 2011c).

Hoje a gente tem uma metodologia que a gente chama de currículo de conhecimento, na verdade a gente chama de conhecimento, não de treinamento, porque a gente entende que o nosso papel é mapear todos os conhecimentos necessários para aquela função, ahn... e a gente vai prover treinamento do que for gap, daquilo que a gente entender que é a melhor forma de trabalhar aquele desenvolvimento seja através de um treinamento. (G02) 
Um aspecto relevante é que o currículo de conhecimento serve a dois propósitos. Primeiro, refere-se a estruturar os conhecimentos de forma que estes estejam atrelados aos resultados que a área deseja atingir. O segundo trata da orientação de carreira que ele fornece aos funcionários, visto que apresenta os conhecimentos por função e, ou, cargo, possibilitando a autogestão de carreira e a orientação estruturada pelo gestor.

Nele, você encontrará a relação de conhecimentos necessários para o desempenho das funções na sua área, especificados por nível de cargo/função, de maneira transparente e objetiva. O Currículo de Conhecimento é uma importante ferramenta que o orientará no planejamento de seu desenvolvimento e de seus colaboradores, ajudando-o a obter uma alta performance (ITAÚ UNIBANCO, 2012b).

Então é a grande ferramenta que extrai para gente uma visão e ela traz alguns benefícios que não só mostrar que a ação de treinamento está atrelada ao negócio, mas também te dá uma visão clara do que a gente espera das pessoas, no estágio que ele está de carreira atual e o estágio futuro. Então se hoje, se amanhã, eu olho pro próximo estágio da minha carreira que é, que é ser um superintendente e, se esse for o meu desejo, dentro de uma estrutura de educação dentro do banco eu posso olhar lá, porque está disponível para mim, e entender quais são os conhecimentos que são necessários e eu consigo orientar minha carreira para isso. Então eu consigo fazer investimento mais direcionado no meu autodesenvolvimento, eu posso pleitear isso junto ao banco, eu posso buscar programas dentro do banco que me, me norteia a questão. Então a gente costuma dizer que o currículo beneficia não só a questão de alta performance aliada à estratégia, mas a um processo legal de autogestão de carreira. (G07)

E aí esse plano de, esse currículo de conhecimento não é necessariamente o treinamento em si, mas é um plano ou um norte de como a pessoa precisa ou pode buscar o seu desenvolvimento, né? [...] Como é que a gente identifica se você precisa ou não desse conhecimento? Pode ser por meio de uma avaliação de conhecimento, pode ser até por meio de uma entrevista com o próprio gestor, né?, e aí você identifica dentro daquela, daquele currículo, daquela grade de conhecimentos o que que exatamente o funcionário A ou B precisa. (G06)

A metodologia do currículo de conhecimento está documentada e é utilizada como ferramenta estratégica da área, principalmente para vincular as ações educacionais aos resultados do negócio:

[...] a gente tem não só arquivo, como a gente desenvolveu um guia de como se constrói o currículo de conhecimento, né?, temos exemplos de currículo de conhecimento de várias áreas do banco que já detém. Não é 100\% das áreas do banco que têm currículo pronto, a gente tá em fase 
de evolução, mas tem toda uma documentação de como é o currículo, de como que se constrói, como é que se publica isso, como é que se comunica o currículo, então tem toda uma documentação pronta para isso. (G07)

Em termos de utilização, o currículo de conhecimento é voltado para mapeamento dos conhecimentos das áreas de negócio, assim, o centro de liderança e valores, por exemplo, não utiliza essa metodologia, pois para o mapeamento dos conhecimentos necessários para a liderança, por exemplo, são utilizados os conceitos de autores específicos, como descrito no relato do entrevistado:

[...] eu acho que é até interessante você se aprofundar um pouco mais com os meus pares de negócios porque o curriculum de aprendizagem ele tá mais voltado para as áreas de negócio. Em liderança, por exemplo, eu trabalho muito com o modelo do pipeline do Ram Charam, então eu tenho uma dinâmica um pouco diferente. (G05)

\subsubsection{Planejamento estratégico}

No Balanced Scorecard da Área Pessoas, há projetos que são de responsabilidade da Escola Itaú Unibanco de Negócios ou de que ela participa, juntamente com outras subáreas da AP. Dessa forma, buscou-se, durante as entrevistas, investigar alguns projetos para identificar como é realizado o monitoramento e quais são os indicadores atrelados. Neste momento serão apenas descritos os projetos. Posteriormente, no item Avaliação de Resultados de Educação Corporativa, serão descritos os indicadores atrelados a cada projeto.

O projeto mais citado pelos entrevistados, três fontes, foi o Fábrica de Gente. Esse projeto consiste em monitorar as etapas de gestão de pessoas pelas quais passa um funcionário dentro do banco, desde sua seleção até seu desligamento.

A ideia do ciclo aqui é dizer que a gente monitora a vida do colaborador, desde o início do ciclo até o fim do ciclo, inclusive desligamento, né? (G06)

Então você tem a estratégia do negócio, né?, que é definida pelo Nosso Jeito, pela cultura do banco, você tem os nossos produtos, né?, e você tem processos. Então desde... a gente monitora a vida da pessoa desde que ela é selecionada e entra no banco até o processo de gestão de consequências, depois que ela está treinada e atuando na empresa. (G06) 
Assim, são monitorados os processos de atração e seleção, integração, formação, gestão da performance e gestão da consequência, visando integrá-los para minimizar tempo e custos. Atração e seleção é a etapa responsável por trazer a pessoa para o banco. Integração consiste em realizar ações educacionais, tais como cultura e ética para integrar o novo funcionário ao banco. A formação compreende as ações educacionais realizadas pela Escola Itaú Unibanco de Negócios, ou seja, trata da capacitação e do desenvolvimento. Gestão de performance é composto pela avaliação de desempenho. Por fim, a gestão da consequência compreende ações relativas à área de Talentos.

O projeto, na verdade, assim, é a Área de Pessoas tem produtos, né? Então ela tem o produto de atração e seleção, que é a pessoa, o processo de seleção da pessoa, a integração dela, a formação, aqui a gente tá falando da escola, a gestão de performance e a gestão de consequências. Então a gente, a Área de Pessoas, a diretoria do D04 vê a pessoa como um todo. (G06)

A seguir são expostos mais alguns relatos sobre o projeto, que dão uma dimensão de seu objetivo:

[...] a Fábrica de Gente, ele está atendendo o banco inteiro, na verdade, a gente está trazendo um conceito de supply chain para recursos humanos. Quem trouxe esse conceito de supply chain foi uma consultoria externa que mexe com, inclusive, com processos de logística, né? E a gente estava se perguntando: poxa a gente trabalha numa área de grande volume, a gente precisa ter a pessoa contratada no tempo certo, é no menor tempo possível, com o menor custo. [...] Só que, quando a gente transporta esse conceito para cá, a gente lida com uma, com um problema que é como é que a gente vai estocar gente? Produto você estoca, mas gente você não estoca, né? E aí é que entra o que a gente chama de planejamento da demanda, né? Como é que eu posso fazer para cada área de negócio do banco um planejamento de demanda de quantas pessoas ela vai precisar no ano e em que período ela vai precisar, né? (G06)

Sem ser pejorativo, mas assim, a Fábrica de Gente porque, assim, é um conceito de supply chain, cadeira vazia, cadeira cheia, só que cadeira cheia para o banco não é só trazer a pessoa pro banco, contratar, admitir e botar na cadeira, não, é capacitá-la e desenvolvê-la para que ela possa, ahn, performar de forma adequada. (G07)

É válido destacar o motivo de inclusão deste projeto no BSC da Área Pessoas. Apesar de ser um projeto que trata da operação de gestão de pessoas, ele abrange modificações no modelo de atuação das áreas, integrando-as e estabelecendo a gestão do processo como um todo. 
O projeto Fábrica de Gente, ele é um projeto que faz parte do BSC, tá?, é... por que que ele faz parte do BSC? Porque a gente estava com alguns problemas nisso é, em conectar tudo isso, né?, admissão, formação, colocar na porta, no time que precisava, às vezes era 500 , às vezes 800 , às vezes era 1000 pessoas, né?, e aí é complicado. Então, é, a gente tinha um problema e aí foi montado todo esse projeto é... eles fizeram lá um war room para conduzir o projeto, para acompanhar de perto os indicadores para eles conseguirem montar uma linha certinha, porque ela estava com alguns problemas. Então ele faz parte hoje é do BSC exatamente por isso, pela importância que tem isso para suprir os negócios e isso bate em resultado na veia, né?, porque, se eu não tenho o cara lá na agência, é, eu não posso abrir, eu posso impactar resultado, eu não estou vendendo, então isso impacta em resultado direto e era algo que a gente precisava arrumar [...]. (S08)

Uma meta da organização é o alcance do índice de eficiência de $41 \%$, conforme descrito anteriormente. Para viabilizar alcançar esse índice, foi desenvolvido o Projeto Eficiência, uma abordagem que busca disseminar práticas de gestão de custos. O índice de eficiência também foi desdobrado para a Área Pessoas e, consequentemente, para a Escola Itaú Unibanco de Negócios. Esse índice foi traduzido para a EC em dois indicadores que impactam diretamente em custos, são eles a taxa de ocupação e adesão:

Então, por exemplo, eles têm metas, a gente chama isso de meta de operação, por exemplo, dentro do projeto que a gente tem da Área de Pessoas, a gente tem... uma meta que é [...] é o quando não falta. Que a gente tinha baixa, então dentro lá do projeto eles têm. Por quê? Porque a gente já pagou, a pessoa falou que vai, eu já aloquei o cara, eu vou pagar de qualquer jeito: se o cara não for, é um custo perdido. Então, por exemplo, esse é um dos indicadores que tem dentro do projeto da AP de é... lá de treinamento da AP específico, e essa é uma meta maior que eles têm lá dentro. Por quê? Porque isso vai impactar diretamente em despesa, que impacta diretamente no custo de eficiência que a gente tem lá a meta do presidente dos $41 \%$, tá? É assim que as coisas vão se conectando. (S08)

Foram citados ainda outros dois projetos, Internacionalização e Liderança. Entretanto, até o momento de realização das entrevistas, esses projetos ainda não tinham sido desenvolvidos a ponto de definirem indicadores:

[...] o que que tem de estratégia dela em termos de internacionalização? (Pesquisadora)

Então não tem. É isso que ela tem que montar. (S08)

[...] eu estou olhando o PMO da internacionalização, porque é um projeto muito grande e... a gente tá estruturando. [...] Tem muita coisa indefinida ainda. (S08) 
Só número de participações e horas. (G06)

Fora esses indicadores a gente não tem nada. O que eu estou pedindo é, assim, a gente tá desenhando alguns programas de liderança e valores que eu já estou pedindo para G02 para que a gente coloque dentro daquela metodologia de mensuração dela. (G05)

\subsubsection{Sistema de educação organizacional}

Com o intuito de captar a percepção dos entrevistados sobre a definição dos sistemas educacionais, foi perguntado a eles o que entendiam por Treinamento, Desenvolvimento e Educação - TD\&E; Educação Corporativa - EC; e Universidade Corporativa - UC.

Por Treinamento, Desenvolvimento e Educação os entrevistados enxergam como conceitos diferentes o treinamento e o desenvolvimento. Treinamento é entendido pela maioria, três pessoas, como capacitação técnica ou funcional, voltada para preparar o individuo para melhor exercer sua função. Para um dos entrevistados, G06, treinamento é adestramento, assim como apontado por G05, que faz a relação de treinamento com a teoria da psicologia que estuda o comportamento e seus condicionantes, o Behaviorismo. Assim, percebe-se que o treinamento adquire significados negativos, apontado inclusive como tendo atuação reativa, conforme citado por S01: “Ela age sob demanda, ela tira pedido”. Desenvolvimento foi mencionado apenas por um entrevistado, G05, que o considera como um conceito que abrange treinamento e que está ligado à preparação da pessoa para posição futura, o que pode ser confirmado pela seguinte passagem: "Você prepara para um próximo passo”. A seguir, as exposições dos entrevistados sobre o tema:

Tem, tem, tem muita diferença, né? Porque, quando eu penso em treinamento, eu vou capacitar simplesmente, como é que fala, eu vou capacitar a pessoa para aquela função específica, eu dou aquele conhecimento, então, por exemplo, você chega aqui e tem um gap em Excel, eu te dou o Excel (G03).

Então, assim eu enxergo o treinamento como desenvolvimento de capacitação técnica. Então, por exemplo, se eu trouxer um, um colaborador novo para a rede, para uma área de negócio, que demande um conhecimento específico daquele negócio, eu entendo que essa pessoa precisa ser treinada e assim, sinceramente, eu acho que a palavra treinamento ela é muito, né? (risos), assim, tá ligada muito ao Behaviorismo, aos Pavlovs da vida, então, acho que, assim, você precisa conhecer tecnicamente, então você treina quando você tá capacitando e tudo o mais. O desenvolvimento para mim é hoje uma das funções elementares, né?, e eu te diria que a própria 
capacitação em treinamento para mim tá dentro de um guarda-chuva de desenvolvimento. Porque cada vez mais você vê que o ser humano é integral, então você precisa ajudar que ele se autoconheça para que ele tenha um bom resultado na gestão, para que ele tenha uma boa performance. Então, ao mesmo tempo que você dá a parte técnica, você dá a parte comportamental, você prepara para um próximo passo, aqui a gente usa muito o conceito de Ram Charam do pipeline de liderança. Então, eu enxergo mais o desenvolvimento como uma questão constante, orgânica, viva, né?, que precisa tá em constante atualização com o que tá acontecendo no mundo, né? (G05)

[...] treinamento é um processo, vai, clássico de adestramento, né? Você conseguir com que aquela pessoa faça é, repita um processo, mas a gente incorpora treinamento com processo de desenvolvimento, né? Acho que na essência o treinamento é isso, mas a gente pode entender como um processo de capacitação, né? (G06)

[...] a questão do treinamento mesmo que tem a ver com atividades do dia a dia, com a função das pessoas. (G07)

Assim, quando eu falo da primeira que são ações de treinamento, para mim, é assim uma área de educação que ela age sob demanda, ela tira pedido, ela, de uma forma com muita qualidade, ela pode lá identificar junto às áreas quais são as ações de treinamento, identificar parceiro e entregar, tá? (S01)

Já por Educação Corporativa, os entrevistados apontam algumas características desse modelo de atuação. O aspecto mais destacado foi o de disseminador da cultura, apontado por duas fontes (G07; S01). Assim, a educação corporativa está relacionada à educação do funcionário, ampliando o espectro de formação. Outros dois pontos destacados também foram a continuidade, ou seja, a educação corporativa abrange ações contínuas e não apenas pontuais (G03); e a atuação estratégica, direcionando as ações educacionais para atingir os resultados esperados pelo negócio (S01). É válido destacar que, para os entrevistados, o público das ações de educação corporativa é composto somente pelos funcionários da organização, conforme narrativa do G02, que já prenuncia a visão de outros entrevistados que atribuem à universidade corporativa uma atuação além dos muros da organização.

Então, eu, eu acho que tem a, a, a diferença conceitual. Eu acho que, quando você olha a educação corporativa, você tá falando aquilo que você provê de, de conhecimento pro seu colaborador. Eu acho que $100 \%$ pro teu colaborador. (G02) 
Já quando eu penso em educação corporativa, é um conceito mais amplo, eu penso em formar aquela pessoa pro negócio, né?, e eu tô falando de forma bem simplificada.

Então, quando a gente pensa em treinar, em educação corporativa, a gente pensa muito mais no processo de formação do colaborador, não é tão pontual como treinamento. (G03)

E aí com relação à educação corporativa, eu enxergo o conjunto de qualquer atividade de aprendizado, que aconteça dentro ou fora de uma estrutura formal, que aí seria uma universidade corporativa, né? (G05)

Educação corporativa, ela tá muito focada no desenvolvimento e capacitação de colaboradores, ela prepara as pessoas dentro da é, prepara as pessoas para dentro da própria organização. (G06)

Quando a gente fala dentro do banco, ah, eu acho que sim, a gente consegue enxergar que hoje nós somos uma área de educação corporativa, porque o que a gente quer promover extrapola um pouco a questão só do funcional, do específico para área, a gente quer trazer aspectos culturais que tão mais atrelados à questão da educação [...]

$[\ldots]$

Então, assim, eu acho que sim, a gente tá num momento de educação corporativa onde eu trabalho outras questões além do, do trivial do dia a dia dos colaboradores [...]. (G07)

[...] uma educação corporativa eu acho que a gente já começa a trazer a estratégia da organização para dentro da área, né? Eu não vou só fazer lá um diagnóstico e entender o que a área quer. Eu também vou fazer um movimento inverso, eu vou entender quais são o, o, eu vou entender assim, um pouco do que eu comentei na, na pergunta anterior: qual é todo o direcionamento que essa organização tá querendo e como que eu trago esse assunto para dentro do tema. Eu começo a dizer o seguinte: eu sou uma área de educação que apoio o resultado. Todas as minhas ações de desenvolvimento e ações de educação elas vêm aqui em favor de alavancar performance. Então, para mim, isso é a questão do conceito da educação corporativa, né? [...]

Eu acho que essa questão de área de educação como disseminadora de cultura para mim esse também é um posicionamento imprescindível. Enfim, independente de, não tem como você ser uma educação corporativa, uma universidade corporativa se você não tá disseminando a cultura e os valores do que o banco quer. Esse é um movimento muito forte, tá? (S01)

Por fim, a Universidade Corporativa é vista como um conceito mais abrangente que Educação Corporativa, pois, na visão de quatro entrevistados, as ações educacionais são estendidas a outros públicos, além dos funcionários. Para eles, a UC passa a atender fornecedores, familiares dos funcionários, terceiros, parceiros, clientes e comunidade. A segunda característica mais apontada pelos entrevistados, três pessoas (G02, G07, S01), relaciona-se a tornar-se uma unidade de negócios, ou seja, uma área geradora de receitas, por meio da venda 
de suas ações educacionais externamente, principalmente as relativas à educação financeira, atividade core da organização. Outras três características apontadas pelos entrevistados foram a de ser uma estrutura formal (G05), a de possuir um modelo de governança (G03) e a de ter uma preocupação e atuação sobre a carreira dos funcionários.

Quando você fala de universidade corporativa, se não me falha a memória, a gente tá falando de três pilares, né? Aquilo que eu promovo para dentro de casa, pros colaboradores, aquilo que eu promovo também para, não, eu estendo aos familiares dos colaboradores e aquilo que eu promovo para a comunidade, ou seja, o que que eu posso promover pro ambiente externo que não necessariamente tá ligado, que é um prestador de serviços nosso, nosso, ou seja, eu olho tanto na esfera para dentro quanto para fora, estendendo para funcionário, familiares de funcionários, mas para prestadores de serviços, para a comunidade em si, ou seja, eu acho que a gente tem hoje, inclusive, essas três frentes, mas capturadas de formas distintas.

$[\ldots]$

Porque hoje a gente olha muito para esfera do colaborador, eu acho que a gente não se enxerga como um fornecedor externo pro mercado. A gente hoje não é desejado pelo mercado como especialistas nesses temas para que a gente pudesse prover, seja de forma remunerada ou não, programas para a comunidade, programas para a sociedade. Eu poderia ser um fornecedor para, para qualquer pessoa que quisesse entender sobre mercado financeiro. Por que não? A gente é uma indústria de mercado financeiro. A gente não se coloca muitas vezes nessa condição e talvez eu acho que por uma série de questões. Eu acho que o tempo de a gente poder amadurecer o nosso processo, entender que, que tipo de benefício isso traria para organização, que tipo de estrutura e de recursos eu precisaria para prover esse tipo de, de conhecimento. (G02)

Não somos uma universidade até porque, quando a gente pensa em universidade, a gente pensa em tá, pensa na capacitação da cadeia de valores, dos vários stakeholders.

[...] E aí tem também a questão de ter um modelo de governança, né?, aonde eu consigo envolver os executivos, enfim, é muito mais amplo o conceito de universidade, tá. (G03)

[...] uma estrutura formal que aí seria uma universidade corporativa, né? Então, sei lá, eu vou pegar um exemplo, Crotonville, da General Eletric, é uma universidade corporativa, é um espaço onde as pessoas se desenvolvem, né? Mas hoje a gente tá vendo tanto movimento de rede social, de assim, as pessoas tão se juntando para compartilhar conhecimento, tá se construindo um novo cenário na organização, né? Então eu acho que as empresas vão passar a ser universidades corporativas [...]. (G05)

Quando a gente fala de universidade corporativa, é, entende que tem um conceito mais ampliado, ou seja, além de abranger os colaboradores ele, ele extrapola isso pros stakeholders, né? Então você entra é na abrangência de fornecedores, parceiros, você entra na comunidade, você, é, atinge 
os familiares desses colaboradores, então eu vejo como, como uma ampliação da ação de educação. (G06)

Agora quando a gente fala de universidade corporativa, sim, eu vejo uma diferença, há um sonho grande que a gente tem, mas é uma conversa que a gente vai começar a ter com o banco daqui a pouco, eu não sei se é um sonho do banco. Não dá para ser um sonho só da área de educação e não ser do banco, não faria o menor sentido. Por quê? Porque tem alguns aspectos que, quando a gente olha pro conceito de universidade que a gente hoje não atua, exemplo, eu não atuo com públicos fora da, da, da, das divisões do banco, então, assim, eu fico preso na parede do banco. Então eu não trabalho hoje com fornecedores, eu não trabalho com a minha, o meu supply chain, eu não trabalho. Então eu não pego fornecedor, eu não pego cliente, eu não olho a minha cadeia produtiva e trabalho com toda ela, então eu só olho pro público interno do banco. O que eu acho interessante é que a gente já tem demandas de algumas áreas específicas do banco para expandir essa relação, então eu tenho áreas hoje que têm relação com parceiros muito fortes e que hoje questionam por que a gente não deveria entrar, né?, para ajudar a educar esse parceiro dado que ele atua representando o banco em muitas esferas. Percebe? Então já tem solicitações pontuais, ainda não é uma visão do banco, mas já existe sim essa questão focada, né? Hoje nós não somos um centro de lucro, né?, que é um conceito que perpassa por educação corporati..., universidade corporativa, eu não atinjo a sociedade, eu não ofereço ainda de forma explícita nada para a comunidade. Claro que o banco tem lá suas fundações, os seus institutos que aí, sim, esses braços eles alcançam a sociedade, mas em educação, no papel da Escola Itaú Unibanco de Negócios, eu não tenho esse tipo de atuação.

[...] ainda não vejo a gente ainda no conceito de universidade [...]. (G07)

E talvez eu não sei se universidade corporativa traz esse conceito, eu acho que você pode começar até a avaliar é, se transformar em uma unidade de negócio de fato para empresa, né? Porque hoje é uma área de despesa, né? Nós somos overhead aqui, porque eu só, eu gasto o dinheiro de treinamento, eu não gero receita.

$[\ldots]$

Então acho que universidade corporativa a gente pode em algum momento pensar assim, bom, eu sou uma educação finance.., uma área de educação corporativa num banco, numa instituição financeira, eu tenho know how de instituição financeira, será que eu posso vender? Começar a colocar isso para fora e fazer com que outras empresas possam beber aqui dentro dessa fonte? E aí eu precifico, como eu precifico internamente e vendo esse meu produto? Talvez a universidade corporativa possa fazer isso. (S01)

Esses achados corroboram e confrontam alguns conceitos. Quanto à definição de treinamento, a percepção dos entrevistados está de acordo com o conceito exposto por Bastos (1991 apud VARGAS e ABBAD, 2006), o qual aponta que treinamento compreende o processo 
intencional da organização em realizar mudanças de comportamento em seus empregados. Assim, a visão de que o treinamento está voltado à atuação sobre o comportamento das pessoas é também compartilhada pelas fontes estudadas.

Quanto ao termo Educação Corporativa, as características apontadas pelos entrevistados, quais sejam, ser disseminador da cultura, ter atuação estratégica e promover a aprendizagem contínua, também corroboram as características do modelo de educação corporativa defendidos por Eboli (2004), porém não as esgotam.

Por fim, as características da Universidade Corporativa apontadas pelos entrevistados, quais sejam, ampliação do público-alvo e criação de governança, também corroboram as características apontadas por Meister (1999), Eboli (2004) e Eboli et al. (2010). Já a característica de atuar como unidade de negócios, como fonte geradora de receita corrobora o princípio de sustentabilidade defendido por Eboli (2004). Por fim, a característica de criação de estrutura formal não corrobora o conceito proposto por Meister (1999), Eboli (2004) e Eboli et. al. (2010), pois não necessariamente é preciso criar uma estrutura, um espaço físico, para a promoção da aprendizagem; esses autores ressaltam ainda a importância do uso da tecnologia para que a aprendizagem ocorra em qualquer lugar. Entretanto, esta característica confirma a visão de Vargas e Abbad (2006), quando citam o termo “unidade educacional” ou, como relatado por Allen e Mcgee (2004), quando definem a UC e a caracterizam como uma “entidade”. A própria Meister (1999) tem de pontuar que a UC não é apenas um espaço físico. Assim, confirma-se que há o entendimento, atrelado ao conceito de universidade corporativa, de criação de uma unidade, ou seja, de uma estrutura física.

Cabe ressaltar que, para a maioria dos entrevistados (G02, G03, G06 e G07), a UC é um conceito mais abrangente que o de EC, pois o público-alvo é maior e a atuação passa a ser de uma unidade de negócios, sendo fonte de receita para a organização. Esta visão confronta o conceito exposto por Vargas e Abbad (2006) que, justamente por a UC abarcar a criação de uma unidade educacional, torna, na visão das autoras, o termo mais restritivo que a EC. Cabem, portanto, investigações futuras para averiguar como esses conceitos estão evoluindo e como as organizações os têm operacionalizado. 


\subsubsection{Avaliação de resultados em educação corporativa}

A motivação para avaliar resultados de educação corporativa pode dar indícios sobre quais mudanças estão ocorrendo no ambiente que têm impulsionado a educação corporativa a preocupar-se com esse tema. Por isso, foi perguntado aos entrevistados por que realizam avaliação em educação corporativa. Em sua maioria, seis pessoas (D04, G03, G05, G06, G07, S01), citaram como principal motivo mostrar o retorno gerado pelas ações educacionais. A Escola Itaú Unibanco de Negócios tem como objetivo mostrar que é uma área que contribui para o alcance dos resultados da organização, que é uma área estratégica, como aponta G02. Há uma cobrança interna da área por demonstrar seus resultados e uma demanda também das áreas de negócio (D04). Assim, essa preocupação em demonstrar os resultados gerados pela EC está muito relacionada à organização estudada, pois a busca por desempenho está na própria visão da organização “ser líder em performance sustentável” (ITAÚ UNIBANCO, 2011a). Apesar disso, há pessoas na estrutura da escola que não sabem o motivo pelo qual estão realizando avaliação e o fazem apenas porque já é realizado e faz parte da rotina (G02). Por fim, foi apontado também que a avaliação de resultados em educação corporativa permite realizar a gestão da área (S01), pois possibilita realizar análises e embasar a tomada de decisões.

Para avaliar se o investimento que está sendo feito, teve resultado. (D04)

[...] Não, a gente tem é, você tem questionamento do tipo como o investimento que tá sendo feito em treinamento repercute, né?, então você tem, você tem esse tipo de discussão nos fóruns, nas reuniões, e também é uma iniciativa da própria área de recursos humanos em avaliar se o que nós fazemos gera resultados. Então é um, uma demanda, é uma autodemanda e também é uma demanda das áreas parceiras de saber se o dinheiro que nós estamos investindo tá surtindo efeito. (D04)

Olha, Carol, eu vou, eu vou te falar uma coisa, eu acho que tem algumas coisas que a gente faz por inércia, porque há muito tempo é feito. [...] Eu acho que parte do nosso grupo de educação, ele faz sem saber parte do que ele tá fazendo e ele faz porque em algum momento alguém fazia isso e disse que isso era importante.

[...] então acho que hoje a gente faz porque tá no automático, o primeiro nível.

$[\ldots]$

Olha, eu vou..., vou ser muito sincera para você. A gente é uma área que provê milhões de horas de treinamento dentro do banco, milhões. A gente tem um investimento de 170 milhões de reais. A gente tem muitas empresas, muitas empresas, e aí é meu lado idealista mesmo falando, que não fazem nem ideia o que é ter isso de orçamento. Então, assim, eu acho que a gente tem insumo 
suficiente para mostrar que a gente é uma área estratégica dentro de um banco tão grande como esse, tão vencedor como esse e mostrar que, mesmo não sendo uma área de negócio, nós somos essenciais para que o Itaú atinja o resultado dele e que a gente continue sendo o líder na América Latina e que seja o primeiro banco do mundo. (G02)

Por quê? Eu acho que o grande objetivo disso, Carol, é, assim, a gente conseguir demonstrar para as áreas de negócio, pro banco, que treinamento dá resultado. A gente não é uma área de custo, né? Porque muitas pessoas ainda veja, veem o treinamento como assim, ai, é um custo que eu vou ter e não um investimento. Então, assim, é para demonstrar mesmo qual é o resultado, como que a gente pode ajudar e potencializar o resultado do banco por meio da capacitação das pessoas. Tá? (G03)

Porque é, quando você tá falando de investimento, né?, eu acho que eu vou te dar uma visão muito de negócio, tá? Mas, assim, você precisa sempre mostrar qual foi o retorno daquele investimento, né? [...] Então eu, eu acho que assim, assim como qualquer outra forma de negócio que você tem dentro da organização, educação também precisa mostrar onde ela agrega valor, né? Talvez não sejam em formas tão, em fórmulas tão simples, vamos assim dizer formas mais tracionais, mas com certeza esse investimento traz algum retorno, então como é que a gente prova isso, né? (G05)

Na verdade, a gente precisa entender se aquilo que a gente tá implementando que pese ter, se a gente entender que está alinhado ao negócio, à estratégia do negócio, se efetivamente tá trazendo resultado. Eu acho que esse é o grande ponto. Esse é o nosso grande ponto de interrogação[...] Mas o quanto efetivamente é aquele conhecimento adquirido por aquele treinamento, por aquele colaborador, trouxe de resultado para organização, né? Essa acho que é a parte mais intangível do negócio, né? Se na hora que ele estiver na ponta lá vendendo um produto, qual é o efeito do treinamento sobre, é, aquele conhecimento. (G06)

[...] talvez eu pudesse dizer que são dois motivos, né? O primeiro motivo é eu preciso aferir o quanto o meu produto, que é um produto de educação, efetivamente trouxe aquele resultado desejado que fez com que a gente desenhasse este produto. [...] Porque a primeira pergunta que ele tinha era como é que você me garante que o treinamento tá atrelado ao meu negócio, currículo ajuda a responder. A próxima pergunta inevitável é como é que você me garante que aquele treinamento é a melhor solução pro problema que a gente diagnosticou? Então a gente precisa mostrar pro banco o quanto aquele investimento teve retorno, o quanto ele foi aplicável no dia a dia das pessoas e o quanto as pessoas entenderam que aquilo faz sentido pro dia a dia deles. (G07)

Porque a gente tem uma, uma necessidade muito grande em saber o quanto que a gente tá de fato agregando para essa organização em forma de resultados bem objetivos e tangíveis, né? Eu quero a resposta disso, ela nos dá cada vez mais proximidade das áreas de negócio, de mostrar o 
quanto que a gente pode ser um parceiro para gerar resultados. [...] Porque, assim, eu, eu começo a pensar assim que menos é mais, sabe? Eu não acho que eu tenho que treinar no ritmo que eu treino hoje. Eu tenho uma dúvida, é uma pergunta que eu faço pro pessoal: será que eu preciso de fato fazer 600 turmas por mês? Todas as 600 turmas que eu faço de fato geram o resultado que eu espero, né? [...] Tem tanta resposta que eu, eu quero ter respostas, né? Eu acho que quando eu começo a mensurar eu vou fazendo análises e a análise me permite fazer uma gestão melhor. Eu acho que é muito por isso. (S01)

Após o entendimento das motivações, cabe destacar os critérios utilizados para selecionar os programas que serão avaliados. Esse questionamento é pertinente, pois, visto que os recursos são limitados, torna-se necessário avaliar, inclusive, o que é relevante monitorar. Deste modo, foram investigados quais critérios são utilizados para selecionar os programas que serão alvos de avaliação. Dois entrevistados relataram suas visões sobre os critérios utilizados para selecionar os programas, tendo em vista as iniciativas de avaliação empreendidas a partir do segundo semestre de 2011. O entrevistado G02 apontou que houve a tentativa de analisar os custos do programa, a quantidade de pessoas envolvidas no programa, os executivos que valorizam ações educacionais, a recorrência do programa e a mudança no modelo estratégico. Já o entrevistado G07 apontou que, ao selecionar os programas, buscou-se a variedade em termos de tipo de programa, ou seja, buscaram-se programas técnicos, comportamentais, que abordavam ferramentas e que abordavam processos. Entretanto, fica visível que não havia ainda no momento da realização das entrevistas diretrizes claras para selecionar programas, visto que o processo de avaliação estava em desenvolvimento. A seguir partes dos relatos dos entrevistados:

A gente tentou olhar critérios que envolvesse custo, quantidade de pessoas envolvidas no projeto, quem são as pessoas que patrocinam esse tipo de ação, por exemplo, se eu começar com esse tipo de projeto, esse é um cara que faz um barulho dentro da organização se a gente emplacar um bom resultado? Ele é um cara que vai fazer barulho num comitê executivo? Quantidade de pessoas envolvidas, quantidade de investimento aportado nesse tipo de projeto, recorrência dessa ação, mudança de modelo estratégico. Então, por exemplo, um dos projetos que talvez a gente não chegue no ROI, mas a gente quer medir análise de custo-benefício, hoje a gente tem um cargo dentro de uma das nossas estruturas que a pessoa fica três meses em treinamento, desses três meses, esse é o maior investimento que a gente tem em capacitação para esse nível de cargo. A gente deveria dizer ao cliente quanto tempo esta pessoa precisa performar nessa função para esse investimento se pagar. (G02) 
Não, Carol, não tem hoje. Esse é, é um ponto, é um gap que a gente tem, que a gente tá desenvolvendo isso, justamente para chegar nesse percentual que a gente quer. Então hoje não é clara, não é claro para gente para dizer assim, oh o programa da natureza x, y, z terão avaliação de aprendizagem, a gente não tem isso tão claramente definidos, tá?

$[\ldots]$

Aplicabilidade. A gente teve um critério, mas que foi assim, é, foi por natureza do assunto trabalhado, então como era uma iniciativa piloto, a gente procurou pegar temas de diversas naturezas. Então eu tinha assim, treinamento comportamental, eu tinha treinamento técnico, eu tinha treinamento ferramental, eu tinha treinamento de processo, então a gente tentou mesclar. A gente também não tem claramente definido qual critério para dizer esse programa aqui teremos avaliação de aplicabilidade, o que a gente fez nessa iniciativa do ano passado foi selecionar programas de naturezas diferentes para ter uma massa de teste, mas não é um critério de seleção bonitinho da forma que a gente deveria ter. (G07)

A análise de uma apresentação da Escola Itaú Unibanco de Negócios, datada de outubro de 2011, permitiu identificar os seguintes critérios para selecionar os programas:

a) a avaliação de reação era realizada para todos os programas;

b) a avaliação de aprendizagem deveria ser realizada para programas técnicos/funcionais que fossem pré-requisito para a função, ou que disseminassem diretrizes e políticas da organização, ou que abordassem regulamentação interna e externa de mercado, além disso, os programas deveriam ser perenes, os funcionários elegíveis ao programa deveriam representar $50 \%$ ou mais da população total, e deveria ser analisado o investimento realizado;

c) a avaliação de aplicação no trabalho deveria ser realizada se a área cliente tivesse indicadores de negócio ou de qualidade que tivessem relação com a competência desenvolvida no programa e o investimento realizado por pessoa deveria ser equivalente ou superior a 50\% da média salarial mensal do público elegível;

d) para avaliar o ROI, seria necessário que os indicadores do negócio ou de qualidade da área cliente fossem transformados em valores monetários e era recomendado que o investimento realizado no programa fosse relevante quando comparado ao investimento de treinamento da área cliente, houvesse grande volume de treinados ou o programa contemplasse cargos de entrada, e quando envolvesse estruturação ou reestruturação do programa. 
Verifica-se pelas informações anteriores a relevância de estabelecer critérios para avaliar os programas para, inclusive, garantir a perenidade do processo de avaliação.

\subsubsection{Modelo de avaliação de resultados da Escola Itaú Unibanco de Negócios}

A Escola Itaú Unibanco de Negócios tem um modelo para avaliar os resultados de suas ações, que é composto por indicadores de qualidade e indicadores de processo (Ilustração 11), além disso, são classificados em indicadores financeiros e não financeiros. Os indicadores de processo contemplam como indicadores financeiros o controle do orçamento geral para a realização dos programas e o investimento per capita, considerando o número de participações. Já como indicadores não financeiros são monitorados o número de participações, o número de treinados, o número total de horas de treinamento, a taxa de ocupação e a taxa de adesão. Os dois últimos indicadores são chamados de indicadores de eficiência, enquanto os demais indicadores, de volumetria, conforme demonstrado na Ilustração 11.

Os indicadores de qualidade estão atrelados aos resultados gerados pelas ações. Os indicadores financeiros resumem-se ao ROI e os indicadores não financeiros contemplam a avaliação de reação, a avaliação de aprendizagem e a avaliação de impacto no trabalho. Os conceitos utilizados para embasar os níveis de avaliação que compõem os indicadores de qualidade são os autores Kirkpatrick e Jack Phillips, assim, há uma mescla entre os modelos de avaliação propostos pelos autores, conforme descrito na Ilustração 12. 


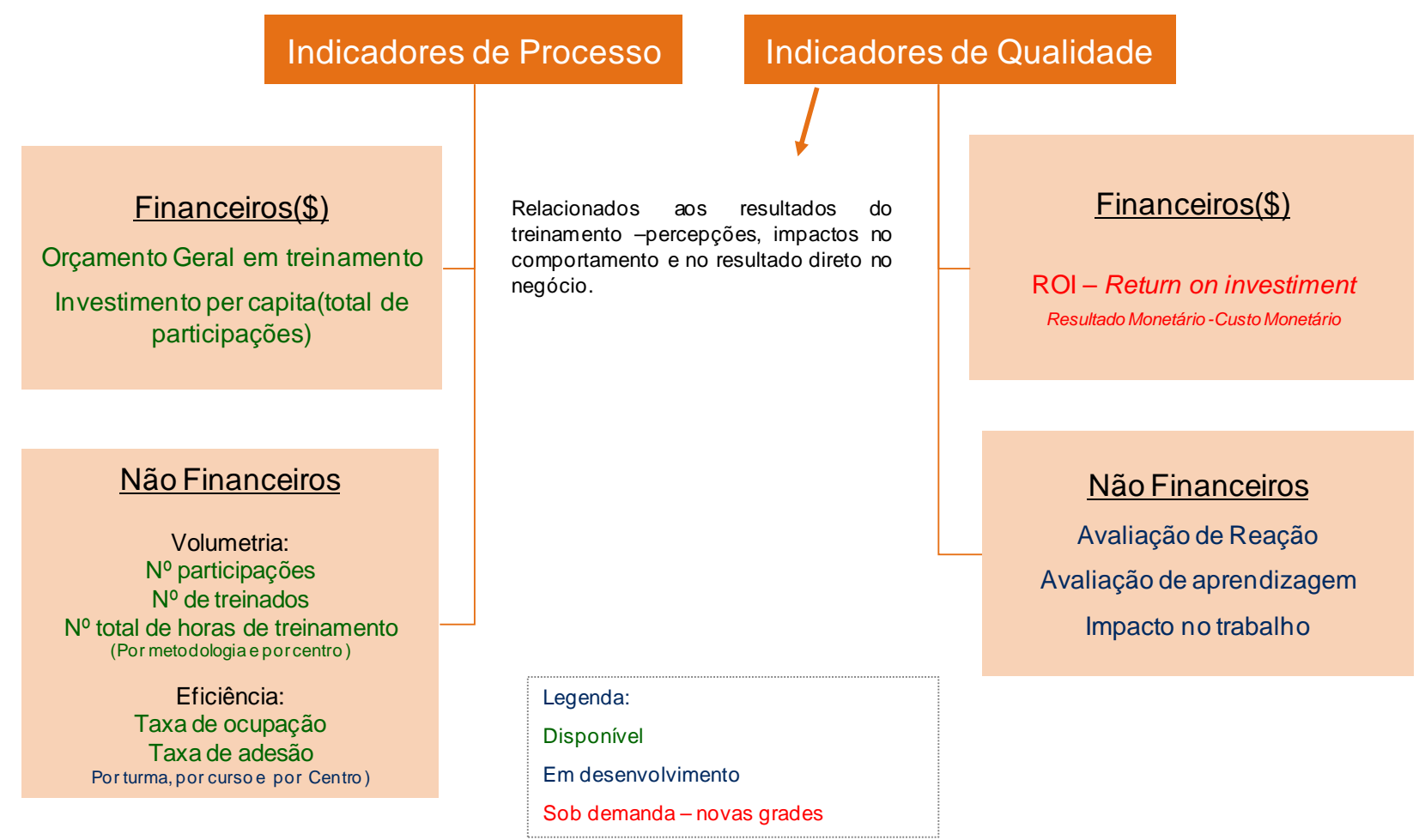

Ilustração 11 - Indicadores da Escola Itaú Unibanco de Negócios

Fonte: Itaú Unibanco (2011c).

O modelo de avaliação adotado pelo Itaú Unibanco corrobora o modelo de Allen e McGee (2004), pois os indicadores de qualidade correspondem ao conceito de efetividade proposto pelos autores, que trata dos efeitos gerados pelo programa nos resultados, em que a efetividade é um critério avaliado por meio da qualidade do ensino, mensurada por meio do quão bem os participantes conseguem atingir os resultados esperados do programa. Já os indicadores de processo estão relacionados ao critério de eficiência, que trata das medidas relativas a custos, ou seja, é avaliada a estratégia instrucional que os autores definem como os meios mais eficientes pelos quais os currículos possam ser ensinados. 


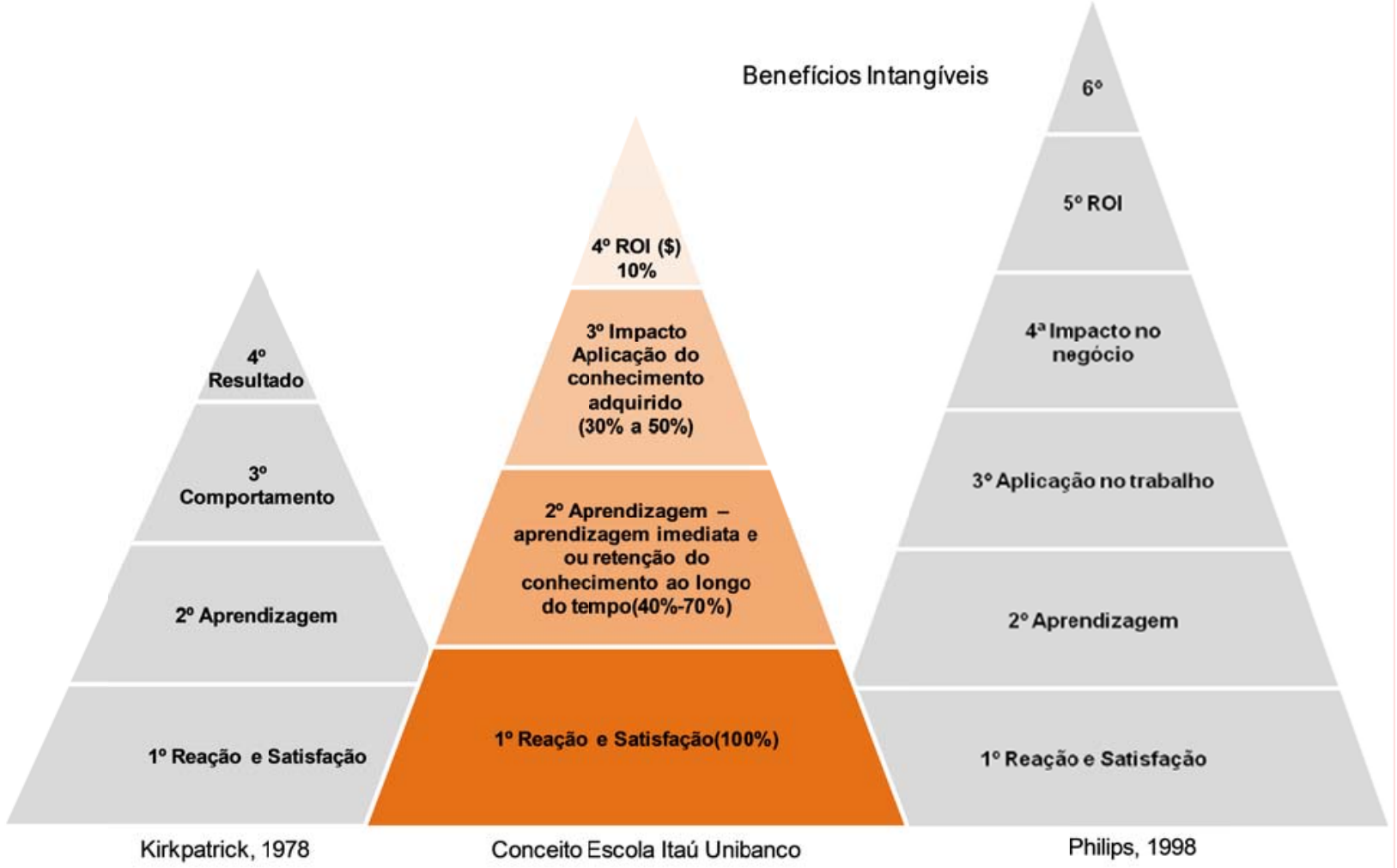

Ilustração 12 - Conceitos que embasam os níveis de avaliação das ações educacionais - indicadores de qualidade

Fonte: Itaú Unibanco (2011c).

\subsubsection{Medidas de efetividade}

As medidas de efetividade, conforme apontado por Allen e Mcgee (2004), correspondem à avaliação da qualidade dos programas, medida em termos do quão bem os participantes conseguem alcançar os resultados esperados. Por isso, essas medidas têm como foco central os efeitos gerados pelos programas nos participantes. Entretanto, como apontam os autores, o foco de avaliação de resultados é verificar os efeitos gerados na organização, por isso medidas que verifiquem essa perspectiva fazem-se necessárias. Após análise da literatura, verificou-se que a qualidade de um programa pode ser avaliada em até seis níveis: reação, aprendizado, aplicação, organização, cultura e objetivos. Desse modo, buscou-se identificar na organização estudada esses níveis de avaliação. Na sequência são expostos os achados correspondentes a cada um deles.

Reação. A avaliação de reação mede a percepção dos participantes sobre o programa, colhendo sua opinião sobre diversos aspectos. Na organização estudada, todos os programas 
são avaliados neste nível. Todas as fontes que responderam sobre esse critério apontaram como ponto avaliado a aplicabilidade do conteúdo ao dia a dia de trabalho do participante. Esse parece um critério essencial a ser questionado na avaliação de reação, pois o interesse do participante é despertado principalmente se ele enxergar que aquela ação foi relevante. Outros pontos avaliados neste nível são o instrutor - avaliando sua postura, didática, domínio do conteúdo, empatia com os participantes, item apontado por três entrevistados; o conteúdo - a carga horária; a metodologia de ensino, ou seja, se a forma como o conteúdo foi passado foi adequado; o ambiente; equipamentos e materiais. Há perguntas abertas pedindo sugestões de melhoria. Para as ações a distância, o formulário de avaliação é diferente, abordando também questões como navegação do curso no ambiente virtual e linguagem.

$1^{\circ}$ Avaliação de Reação e Satisfação: avalia a percepção da utilidade da ação de desenvolvimento para o colaborador. Buscam-se respostas para as perguntas tais como o valor prático desta ação e qual a relevância no dia a dia. Pesquisas mostram que existe correlação entre a relação da avaliação de reação e aplicação do conteúdo no trabalho (ITAÚ UNIBANCO, 2011c).

Hoje 100\% dos programas é aplicado uma pesquisa ao final do programa, imediato, no mesmo dia. Então seja numa solução presencial ao final o, o instrutor, o palestrante, o professor, enfim, ele passa uma avaliação de reação pro participante onde a gente avalia aspectos tanto em relação ao conteúdo, à carga horária, ao quanto ele, ele entendeu que aquilo é importante pro dia a dia dele, perguntando se a forma como aquele conteúdo foi passado foi a melhor forma sob a ótica do participante, assim como a gente pergunta também sobre o processo desde o período de, de convocação até o processo, se o ambiente é adequado, se a logística é adequada. (G02)

Tem, porque, quando eu falo nessas avaliações de educação a distância, a gente aborda algumas questões também para saber é..., por exemplo, se a linguagem do curso tava adequado, se ele teve algum problema de repente de navegação no curso, a navegação tava fácil, a navegação tava difícil, então os questionários são diferentes, tá? (G03)

[...] a gente tenta verificar se os objetivos de aprendizagem foram atingidos, a gente tenta verificar qual foi o desempenho do instrutor, se ele passou o conteúdo de maneira clara, né?, se ele teve uma empatia com a turma de treinamento. Que mais? Se aquele conhecimento realmente faz sentido, se aquele conhecimento foi útil, será útil pro dia a dia daquela pessoa. (G03)

É uma folha com é, pergunta de múltipla escolha, né? Se aquele conteúdo agregou ou não para função, o que que ele achou do, do instrutor, se ele domina aquele conhecimento, se aquele treinamento é tem aplicabilidade no dia a dia dele, né?, então é por meio de uma pesquisa que a gente chama de avaliação de reação, ou seja, o que que ele achou, pensou daquele treinamento e se existem pontos de melhoria. (G06) 
A gente tem duas formas de medir a reação das pessoas. Tem um formulário padrão, isso é de forma escrita que as pessoas preenchem no final do treinamento, que ele vai percorrer alguns aspectos da, a gente pergunta algumas questões para eles, né? É como é que foi a questão do conteúdo, se o conteúdo faz sentido, não faz sentido para ele no dia a dia, se ele vê aplicação daquele conteúdo no seu dia a dia ou se não vê, ahn, eu também entro nos aspectos como é que foi o consultor que atuou com você, quer seja interno ou externo, né, se teve uma abordagem didática adequada ou se não teve, se a carga horária do programa foi suficiente para trabalhar os aspectos primordiais, se sobrou carga horária, se faltou carga horária. E aí eu pergunto coisas mais práticas como foi a logística daquele evento, como era, como foram os equipamentos colocados à disposição, o ambiente, os materiais, então eu pergunto isso para eles. [...] o impresso acaba trazendo muito o quantitativo, né?, as pessoas não acabam investindo muito tempo em responder perguntas abertas nessa hora, vamos lembrar que é o final do treinamento, o cara já tá ali num processo de check out, então é mais difícil. A presença do analista favorece, ahn, relatos verbais do, de como eles reagiram, como que eles veem aquele treinamento, né? (G07)

Além da avaliação padrão, uma gerência utiliza um formulário específico para colher a percepção do participante em relação ao quanto ele se sente preparado após a realização do programa, se ele sente necessidade de apoio e o que é necessário para que ele consiga aplicar o que aprendeu no dia a dia de seu trabalho:

Olha é, nós temos questionários específicos, né?, que a gente é, é, aplica para cada um dos públicos e a gente coloca perguntas mesmo no sentido de o quanto que você sai daqui preparado, é, o quanto que você acha que esse conteúdo é aplicável, você ainda sentiria necessidade de apoio, o que você precisaria para que isso se efetivasse na sua área, para ter até um diagnóstico vivo, né? (G05)

Com o intuito de aprofundar as características da avaliação de reação, procurando identificar o que é relevante avaliar, foram analisados os formulários de avaliação de reação dos programas presenciais e a distância. Destaca-se que não foi autorizada a publicação dos formulários utilizados pela organização.

Nos programas presenciais os fatores avaliados são: cumprimento dos objetivos propostos; aplicabilidade e utilidade do aprendizado adquirido no programa para o desempenho de suas atividades; adequação dos temas ao dia a dia do trabalho; sequência dos temas abordados; qualidade do material didático; didática do instrutor; relacionamento do instrutor com o grupo; administração do tempo pelo instrutor; em logística, avalia-se o processo de 
comunicação, a equipe de apoio, infraestrutura, instalações, equipamentos; por fim, avaliamse a carga horária e sua adequabilidade ao conteúdo exposto e às atividades práticas, tais como exercícios ((ITAÚ UNIBANCO, 2012d).

Já nas ações educacionais a distância são avaliados os seguintes itens: a capacidade do programa em atingir o objetivo proposto; o tempo; a relevância do conteúdo; a importância do visual para o entendimento dos conceitos; a velocidade de navegação; e a contribuição da linguagem, exercícios e exemplos para o entendimento dos conceitos (ITAÚ UNIBANCO, 2012e).

Aprendizado. A avaliação de aprendizagem tem por objetivo mensurar se os conhecimentos, habilidades e atitudes promovidos nas ações educacionais foram desenvolvidos pelo participante. No caso estudado, este nível de avaliação não é realizado para todos os programas, mas há intenção de que seja, segundo apontado por G03 e G07. Para verificar se houve ampliação de conhecimentos, são aplicados, em geral, pré e pós-testes. Segundo os entrevistados G02 e G03, o pré-teste não é um pré-requisito para a realização do pós-teste, pois há programas que abordam temas, tais como integração, em que não há necessidade de avaliar a progressão promovida pela ação educacional. Interessante notar que essa progressão é chamada pelo entrevistado G03 como curva de aprendizagem. Um ponto importante destacado pelo entrevistado G02 é que são utilizados métodos tradicionais de avaliação de aprendizagem - testes e provas -, e não são realizadas outras formas de avaliação, apesar de serem utilizadas durante a execução dos programas, tais como o feedback fornecido pelo tutor, avaliação por meio de simuladores e role play.

$2^{\circ}$ Avaliação de Aprendizagem: avalia a retenção do conhecimento a partir da aplicação de testes tradicionais de declaração de conhecimento antes e após a ação de desenvolvimento. Esta avaliação também pode ser aplicada após algum tempo da ação de desenvolvimento (ITAÚ UNIBANCO, 2011c).

É, ela se dá, e isso é um pouco do que a gente tá tentando mudar. Acho que a maior parte do nosso grupo, ela se dá através de teste hoje, né?, provas, pré-teste e pós-teste. Então eu faço uma medição, muitas vezes para alguns casos eu faço antes para saber em que nível que ele estava e depois para ver o que ele reteve de conteúdo daquele aprendizado, ou seja, qual foi a evolução. Para alguns casos, eu só aplico a prova ao final, eu não tenho o pré para fazer a comparação, a gente usa uma métrica de que, se ele teve um aproveitamento maior que 70\%, é um nível desejado, isso porque a gente tenta se basear um pouco no que o mercado e no que o mundo tradicional de 
educação, né?, das escolas, das universidades praticam. Mas a gente tem começado a provocar um pouco a, a escola no sentido de que existem outras formas de medir aprendizagem, que você é, ter simulação é medição de aprendizagem, ou seja, uma série de programas hoje que a gente faz simulação que a gente deixa de capturar isso como uma medição de aprendizagem durante o processo de treinamento. (G02)

Eu acho que tem programas que a gente já faz isso, por exemplo, quando eu olho o call center do banco, como as pessoas passam 30 dias com, com o consultor em sala de aula, à medida que ele faz um atendimento, porque central é central, é, telefônica, ele primeiro faz uma observação e depois ele tem um tutor. Então, quando ele faz os seus primeiros atendimentos, ele recebe um feedback de como ele foi. Então ele é pontuado, ele é sinalizado, se ele foi bem, onde ele foi bem, se ele foi mal, onde ele foi mal e por quê, então eu acho que ali é uma forma de você trazer a aprendizagem pro treinando. Mas por exemplo, hoje no ciclo de gestão de pessoas, a gente faz uma série de simulações, a pessoa tem feedback em sala de aula, mas a gente deixa de capturar isso como uma oportunidade de aprendizagem. A gente até inconscientemente sabe que isso, é, é uma aferição. Mas que acho que a gente não tangibiliza, a gente vende isso pouco para, para a organização. (G02)

Então, dependendo do assunto, dependendo do custo-benefício, a gente não faz a mensuração, mas a gente tem um índice bem elevado de desejo de ter o nível de avaliação de aprendizagem e reação realizado. $\mathrm{O}$ que a gente quer dizer com isso é que são pouquíssimos casos que a gente enxerga que a avaliação de aprendizagem não é indicada. Então, mas é, de novo, é um processo de evolução que a gente tá fazendo na escola. (G07)

A observação também foi citada por duas fontes (G02 e G07) como forma de avaliação de aprendizagem. Foi apontado pela fonte G03 que não há padronização dos critérios sobre a elegibilidade de um programa à avaliação de aprendizagem, isto ainda está em estudo.

Normalmente são provas. São provas que a gente faz ao, ao final do treinamento para garantir que aquele conteúdo essencial na nossa visão, né?, que o core ali do treinamento, que é o principal, tenha sido retido ali pelo treinando. Então ele se submete a uma avaliação no final do treinamento. A gente tem algumas iniciativas de observação in loco, tal, mas ainda é bem incipiente, o mais comum são provinhas mesmo no final do treinamento que ele faz, tá? A gente tem simulados, role play que as pessoas fazem e aí o consultor observa e também pontua, uma avaliação, mas aí é uma quantidade pequena, o mais comum é a provinha mesmo. (G07)

Esse é um EAD, tá? E dos presenciais eu tenho hoje um grupo de, de treinamentos presenciais que são corporativos e dentro desse grupo, grupo tem alguns treinamentos que tem tanto pré, quanto pós e alguns outros que não, então a gente tá padronizando isso. (G03) 
A avaliação de aprendizagem em e-learnings é realizada, na maioria dos programas, por meio de um pré e um pós-teste, de acordo com o relato a seguir:

Avaliação de aprendi..., de avaliação de aprendizagem, isso, todos os treinamentos e-learnings, a

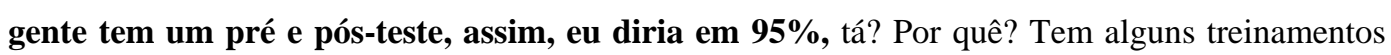
que são treinamentos ahn... de integração, que de repente tem um foco um pouco mais comportamental e aí não faz sentido fazer a curva de aprendizagem, né? Então a gente não coloca pré e pós-teste, mas a grande maioria tem pré e pós-teste, a gente consegue fazer a curva de aprendizagem, tá? (G03)

Quando questionado sobre quem elabora as avaliações de aprendizagem, o entrevistado G03 apontou que são elaboradas pelas consultorias externas ou pelos instrutores internos:

Não desculpa, de aprendizagem elas são elaboradas junto com as parcerias externas, com os consultores, tá? E nos treinamentos a distância, como tem muito treinamento de produtos e serviços que a gente faz, quem elabora também são os parceiros com base no conteúdo que a gente passou à produtora de e-learning, só que são validados pelos gestores de produto. Tá? (G03)

No decorrer das entrevistas, percebi que uma pergunta foi mal formulada. Essa pergunta procurava investigar como era realizada a avaliação de aprendizagem em programas que abordem temas comportamentais, entretanto, os entrevistados estavam respondendo sobre o nível de aplicação do que aprenderam no trabalho, assim, era necessário reformular a pergunta para obter a resposta sobre esse ponto de investigação. Veja-se o exemplo a seguir:

E como é avaliado se os programas, eles promoveram as mudanças de comportamentos (atitudes e habilidades) a que se propuseram? (Pesquisadora).

Aí entra a avaliação de aplicabilidade, né?, que não são todos os programas que são aplicados. (G06)

Este problema foi contornado, pela reformulação da pergunta. Assim, foi possível colher a percepção dos entrevistados sobre esse ponto da investigação, conforme demonstrado na sequência:

E a avaliação de resultado de aprendizagem, vocês fazem em treinamento comportamental? (Pesquisadora).

Tem, porque hoje, por exemplo, tem alguns treinamentos que possuem avaliação de aprendizagem, não 100\% tá?, e outros não, tá? Depende muito do objetivo, do público-alvo e do alinhamento que a gente faz com a área de negócio. (G03) 
Ah tá certo. E tem algum exemplo assim de treinamento comportamental que vocês tenham feito avaliação de aprendizagem? (Pesquisadora)

[...] a gente tá fazendo, verificando, na verdade a eficácia do treinamento, de treinamento que é de, é, de hora extra pros gestores, que ele tem o foco comportamental, tá? Que o grande objetivo é reduzir, claro, tem questões de procedimentos, de compensação de horas, mas ele tem uma abordagem comportamental também. (G03)

Aplicação. Para verificar se o conteúdo aprendido foi aplicado ao trabalho, a organização estudada conduz a avaliação de aplicabilidade. Essa avaliação começou a ser realizada em 2011, após a formação de um grupo de trabalho que tem como foco elaborar um sistema de avaliação e mensuração de resultados das ações de EC.

A gente começou isso, é bem recente no banco, a gente não tinha achado um modelo ainda para fazer isso até o ano passado. A gente criou um grupo de trabalho para dar uma aprofundada nessa discussão e a gente chegou num modelo onde a gente num primeiro momento, como piloto, a gente partiu para uma estratégia onde eu faço uma pesquisa onde o treinando vai me responder essa pesquisa e o gestor desse treinando vai me responder essa pesquisa, né? (G07)

Aparentemente, a diretriz utilizada para avaliar o impacto do programa no trabalho, anteriormente à formação do grupo de trabalho, era por meio do levantamento de indicadores do negócio, de acordo com o conceito exposto a seguir:

$3^{\circ}$ Aplicação no trabalho: aplicação do conhecimento obtido na ação de desenvolvimento no dia a dia do trabalho. Para esta avaliação, é necessário um indicador de resultado da área cliente que represente o objetivo da ação e o resultado no negócio. A diferença entre as duas formas de avaliações está no indicador de resultado, caso ele seja de negócio, será classificado como impacto no negócio. Caso seja um indicador qualitativo de pesquisa, será classificado como comportamental (ITAÚ UNIBANCO, 2011c).

A avaliação de aplicabilidade é conduzida após três meses da data de realização do programa e é realizada por meio de questionário, enviado por meio eletrônico, que contém entre oito e nove perguntas sobre a relevância do conteúdo para o desenvolvimento do participante; a usabilidade do conteúdo nas atividades de seu trabalho; as dificuldades na aplicação do conteúdo no dia a dia; o suporte/ambiente para aplicação do conteúdo; entre outros. São respondentes desta avaliação o próprio participante e o gestor, tendo a avaliação do participante peso de $40 \%$ e a do gestor $60 \%$ (G02). É válido ressaltar que o gestor que responde à pesquisa teve seu funcionário participando da ação educacional, mas ele não 
necessariamente responderá ao questionário, pois o intuito é avaliar o programa e não o indivíduo, segundo destaca G02. A partir das respostas, é gerado um índice sobre a aplicação do conhecimento no dia a dia. Esse índice é monitorado e mostra o percentual de aplicação do aprendizado ao trabalho. A seguir trechos das entrevistas que abordam as características da avaliação de aplicabilidade.

Onde você tem lá o treinamento que ele fez, quais são os objetivos daquele treinamento e eu pergunto, de 3 a 6 meses após o treinamento realizado, o quão ele aplicou aquele conhecimento no dia a dia dele, aonde ele aplicou, quais foram as eventuais dificuldades que ele teve para aplicar aquele conhecimento no dia a dia dele e aí ele responde isso e o gestor dele responde isso. Isso é dado um peso, a gente afere isso estatisticamente e chega num resultado que me diz percentualmente qual foi o índice de aplicação do conhecimento no dia a dia dele. Então isso é feito por meio de pesquisa, uma pesquisa eletrônica que é disponibilizada, eles respondem, a gente compila as informações aqui e transforma isso num indicador, né? Então a média do ano passado, se eu não tiver enganado, eu erro em alguns números, assim, foi que é a gente teve uma média de 95\% de aplicação. [...] eles tão dizendo para gente que apenas 5\% não conseguiu aplicar no seu dia a dia aquilo que obteve no treinamento. (G07)

[...] a gente aprendeu isso na pesquisa, Carol, eu não preciso mandar, por exemplo, se a G02 foi treinada, só pro gestor da G02, eu posso fazer isso por amostra, por um grupo, eu tenho que garantir que o gestor que está sendo avaliado tenha clareza que parte dos colaboradores tiveram aquele conteúdo porque ele tem que avaliar o treinamento e não o indivíduo. E aí a gente cruza o resultado dessas duas pesquisas. A gente toma aqui, internamente, a decisão de ponderar o peso do que, do resultado do colaborador com um peso do gestor. O peso do gestor tem um, um peso maior nessa ponderação de resultado, porque a gente entende que é muito mais fácil o indivíduo falar sim, eu fiz, do que o próprio gestor falar assim, oh fiz porque eu percebi nessa ação, nesse resultado desse projeto isso ajudou a alavancar as metas dele e aí é, é fechando a ponderação de $40 \%$ do colaborador e de $60 \%$ do gestor, a gente fecha o resultado para saber o quanto isso foi, foi efetivo. (G02)

Pelo relato a seguir, verifica-se que é investigado também se o ambiente possibilitou a aplicação do que foi aprendido. O “ambiente” é referenciado por Borges-Andrade (2006) como sendo o aspecto que contém os elementos que possam interferir ou ter relação com o treinamento, representando seu contexto. Um dos fatores que influenciam todos os componentes do treinamento é o suporte, o qual é composto por um conjunto de variáveis que ocorrem na comunidade, na organização, na escola ou no lar do participante e que influenciam todos os componentes do treinamento, seu efeito pode ser destruidor ou contributivo ao treinamento. O suporte fornecido pelo gestor é apontado por Kirkpatrick 
(1994) e Kirkpatrick e Kirkpatrick (2010) como fator determinante na promoção de um ambiente propício à aplicação da aprendizagem.

Com isso a gente montou três, duas pesquisas aonde hoje a gente envia e isso a gente fez em 2011, a gente conseguiu mandar para 11 produtos nossos, para 11 programas nossos, a gente mandou pro próprio participante para depois de três meses ele nos dar um feedback de como que ele acha que aquele conteúdo contribuiu pro desenvolvimento dele no dia a dia, tentando tangibilizar desde o momento que ele entrou em sala de aula se o conteúdo era pertinente, se ele encontrou o ambiente favorável, se de fato aquele conteúdo que foi dado ele usa no dia a dia.

Um ponto a destacar é a parceria estabelecida entre a área de educação corporativa e áreas internas do banco para auxiliar no processo de avaliação. Pedir o apoio de áreas que já têm conhecimentos consolidados em determinado aspecto da avaliação traz credibilidade para o método e divulga a iniciativa da área.

Então a gente se juntou com a área de pesquisa do banco, o que em termos percentuais era importante, e essa pesquisa ficou hospedada em um site de pesquisa que o banco tem uma licença para usar, não sei se você já ouviu falar de Survey Monkey que é um site de pesquisas e esse site também ele já tabula esse resultado para gente, depois a gente faz uma análise qualitativa dessa pesquisa. (G02)

Em 2011, a título de condução da pesquisa piloto, foram avaliados 11 programas (G02) e o intuito é ampliar o número de programas avaliados neste nível. Esta avaliação piloto não contemplou programa a distância (G03).

A avaliação de aplicabilidade é realizada por meio de um questionário padrão (G06) e tem como foco averiguar se o programa provocou mudanças de comportamento, por isso, busca identificar se houve melhora de produtividade e da qualidade do trabalho, como pode ser visualizado nos trechos a seguir:

Eu também vou perguntar pro gestor se realmente, vai, a Carol foi num treinamento, mudou comportamento? Ou aquela planilha de Excel que ela fazia de um jeito, ela tá fazendo de um jeito diferente? Melhorou a produtividade dela, a qualidade do trabalho, tá? (G03)

Então eu tenho perguntas no meu questionário de aplicabilidade que vão tentar explorar isso, quais foram os benefícios, se ele percebeu que trouxe um resultado melhor, uma coisa melhor do 
processo, a performance dele melhorou ou não melhorou, então isso eu já, já apoio na pesquisa de aplicabilidade. (G07)

Para o programa realizado para os gestores, está em estudo a inclusão dos subordinados como respondentes, conforme relato exposto na sequência:

Por aquela avaliação de aplicabilidade que eu te falei, que pode ser mandada para pessoa ou pro gestor, a gente tem alguns objetivos de começar a mandar para as equipes, por exemplo, se é um programa de gestão, né?, se o gestor tá apresentando melhoria, nesse sentido, tá? (G05)

Alguns critérios utilizados para selecionar os programas que fizeram parte do estudo piloto foram cultura e estratégia da organização. Percebe-se pelo relato a seguir que foi selecionado um programa que promovia mudança no atendimento ao cliente, tema relacionado diretamente à visão do banco de ser líder em satisfação do cliente, que é sustentado pela atitude "Todos pelo cliente" da cultura organizacional.

Porque é isso tá dentro da, do, da cultura do próprio banco que são lá um item Todos pelo Cliente, né?, e a ideia era realmente melhorar o atendimento ao cliente. [...] O programa como era estratégico uma, a ideia era mudar realmente o comportamento das pessoas em relação à forma como atendiam o cliente, então a importância de se fazer a medição, né? (G06)

Processos. Este nível de avaliação busca verificar se a aprendizagem promovida pelo programa gerou mudanças na organização, em seu funcionamento (HAMBLIN, 1978). Os cinco entrevistados afirmam que este nível ainda não é avaliado na organização estudada, entretanto, já estão se planejando para realizá-la.

Então eu acho que isso ainda é uma ambição, a gente não consegue de forma tangível comprovar isso. Eu acho que hoje é assim no cheiro, sabe? A gente sabe que a gente tem uma contribuição, mas o quanto dessa contribuição é subjetivo. O projeto de mensuração tende de forma ainda pequena tentar tornar esse resultado mais objetivo, mais tangível para organização e a gente tem uma mega-ambição. (G02)

Não, o que a gente tem é algumas iniciativas que vê muito mesmo é aplicabilidade no treinamento, no dia a dia do colaborador, né?, relacionado mais a produtividade e a mudança comportamental. Por outro, isso quando eu falo mais área de negócio, por outro lado, mas eu não tenho como tangibilizar, eu não tenho essa avaliação. (G03) 
E algo que a gente tem também já no radar como que os indicadores corporativos dessa organização nos ajudam a complementar isso. (G05)

É porque assim, na, é a pesquisa vai dar a visão do profissional, né? E o que a gente pode dizer depois disso são comentários é dos gestores ou dos executivos desse negócio que dizem: poxa o treinamento foi muito bom, gostei, é conversei com tal funcionário que participou do treinamento e ele disse que foi muito bom e que tá aplicando isso, tal. Agora em termos de processo mesmo é, por exemplo, acho que, não, acho que eu não consigo te tangibilizar isso, é, acho que não. (G06)

Não, Carol. Não vejo, hoje não. No nosso rol de avaliações eu não tenho, a gente não tá olhando isso. (G07)

A partir das conversas foi possível extrair algumas características que devem permear esse nível de avaliação. A primeira relaciona-se à utilização de indicadores do negócio, o entrevistado G05 ressalta que é necessário utilizar os indicadores já elaborados pelas áreas de negócio e pela organização.

\footnotetext{
A gente quer trabalhar assim com uma linha de menos é mais, então não vou ficar criando novos indicadores, vamos ver o que a gente já tem dentro da organização, que pode mostrar como é que a gente pode ou não ter ajudado no desenvolvimento.

[...] muito do que o resultado do negócio conseguir também pode ser indicador para gente.

[...] A gente usa mais os indicadores corporativos, a gente não quer criar novos indicadores para as áreas, né?, porque aí uma vez que a gente tá construindo os temas com as áreas de negócios, a gente tem uma responsabilidade compartilhada em ajudar, e é lógico que não vai ser só a gente, eles fazem uma série de outras ações também, mas a gente ajudar na nossa parte de educação de como a gente consegue consolidar o tema no banco, tá? (G05)
}

São citados indicadores corporativos como relevantes a serem considerados nesta etapa: avaliação de fornecedores internos e pesquisa de clima; e também instrumentos de gestão de pessoas, como a avaliação de desempenho.

A gente tá tentando linkar, é, os outros indicadores que a gente tem de gestor de pessoas, por exemplo, o Fale Francamente, que é nossa pesquisa de clima, aonde você tem lá algumas perguntas superespecíficas em relação ao comportamento do seu gestor e a gente vai tentar ver, as pessoas que participam desse treinamento elas têm um indicador melhor ou não de pessoas que não participam. Mas ainda isso ainda tá sob análise. (G02) 
Aí, Carol, eu acho que vai pela linha da pesquisa de clima, da pesquisa de satisfação do cliente interno, porque aí se esse tema tem uma conexão, com certeza você consegue é mostrar, lógico que não diretamente, ou seja, você não consegue mostrar que só treinamento foi responsável porque tem uma série de outros fatores [...]. (G05)

A pesquisa de satisfação do cliente interno é uma pesquisa corporativa, conduzida pela área de marketing, que busca identificar a satisfação das áreas de negócio em relação às áreas internas com as quais interagem. Os resultados dessa pesquisa influenciam a remuneração variável dessas áreas de apoio.

Como é que a, a empresa avalia a área institucional? Existem algumas formas. As áreas comerciais são avaliadas pelos seus resultados, então elas têm um orçamento de receita e despesa e ela é avaliada em cima disso, ou seja, trouxe o orçamento desejado, a receita desejada? Cumpriu a despesa desejada? Então ela é avaliada pela performance dela, isso impacta remuneração variável, isso impacta várias questões. As áreas de apoio, elas são avaliadas de formas diferentes, elas não são áreas de receita, são áreas originalmente, contabilmente falando, áreas de despesa. Então o banco tem uma ferramenta chamada pesquisa de fornecedores internos, então as áreas do banco avaliam as áreas adminis..., as áreas de apoio sobre os seus serviços prestados. Então existe lá uma pesquisa com perguntas elaboradas, tal, que as pessoas avaliam. E é dado uma nota para isso e isso vai computar no processo de avaliação dessa área institucional. Então as áreas de negócio têm a avaliação em cima do, do seu orçamento de negócio e as áreas de apoio são, é uma avaliação feita por uma pesquisa interna, tá? (G07)

Já como indicadores do negócio, foram citados pelas fontes pesquisadas: a melhoria gerada por um projeto de Six Sigma; a redução do número de reclamações de clientes em órgãos externos; o volume de vendas; indicadores de erro ou falhas.

Não, eu acho que a gente não. Eu acho que assim, indiretamente, quando você fala de algo técnicofuncional, por exemplo, quando você mobiliza uma equipe de projeto, ou quando você mobiliza uma equipe que vai atuar em six sigma que é melhoria de, contínua, eu acho que isso de alguma forma pode contribuir, mas hoje a gente ainda não captura. (G02)

[...] no Todos pelo Cliente, o que a gente vai ver é se a gente consegue reduzir número de reclamação, porque a gente tá priorizando as, as áreas que realmente têm maior, maior apontamento no nosso ranking de BACEN e PROCON, tá? (G05)

Mais subjetivo ainda, né? Porque a gente só consegue ir até o ponto em que a gente pergunta para ele o quanto ele tá aplicando, né? O efeito disso, a gente não consegue medir, consegue, é, é tem de forma subjetiva, vai, vamos dizer assim, é, pode ter no volume de vendas, um aumento de 
vendas, mas o quanto a gente pode efetivamente dizer que aquilo é ação de treinamento, né? Pode dizer que influenciou, mas o quanto influenciou a gente não consegue dizer, né? (G06)

Então, se eu tinha lá um indicador de erro, eu quero saber se diminuiu o erro no futuro após o treinamento, dado que treinamento é uma solução para aquele problema que foi diagnosticado lá atrás, né? Eu tinha uma performance x eu quero saber qual foi o incremento nessa performance após o treinamento, comparando isso com grupos de controle, tal, né? (G07)

Cultura. A disseminação da cultura é um dos princípios fundamentais da EC (EBOLI, 2004; MEISTER, 1999). Desse modo, cabe avaliar se a EC está contribuindo para disseminar os valores e crenças da organização para seus funcionários. No Itaú Unibanco, a cultura organizacional representa a base para o alcance de sua visão (ITAÚ UNIBANCO, 2011a, p. 39), por isso, a avaliação das ações educacionais que promovem a disseminação da cultura ganha ainda maior relevância.

Por meio da análise das falas dos entrevistados, fica claro que não há uma avaliação neste nível. A EC é reconhecida como disseminadora da cultura na organização (G02), mas não há uma avaliação que apure sua contribuição sobre isto. Entretanto, segundo apontado pelo G05, a área de cultura da organização realiza uma pesquisa para monitorar a evolução das dez atitudes, mas não há avaliações para apurar a influência dos programas educacionais no desenvolvimento desses temas. Outro fator apontado como indicador da cultura foi a pesquisa de clima interna e externa (G06). Entretanto, é importante destacar que clima e cultura são coisas distintas, apesar de apresentarem semelhanças. Segundo Nakata et al. (2009), a pesquisa de clima busca compreender como ocorre a relação entre empresa e as pessoas, enquanto a pesquisa de cultura analisa os valores e as crenças que direcionam o comportamento na organização.

Em 2010, o lançamento do Nosso Jeito de Fazer, conjunto de dez atitudes e valores que guiam todos os nossos relacionamentos, foi um marco no Itaú Unibanco. A ferramenta é uma das bases para a avaliação da meritocracia em relação ao desempenho dos colaboradores, pois indica os caminhos a serem seguidos na busca pela eficiência e pelos bons resultados (ITAÚ UNIBANCO, 2011a).

O Nosso Jeito de Fazer

Todos pelo Cliente

Paixão pela Performance

Liderança Ética e Responsável 
Craques que jogam para o Time

Foco na Inovação e Inovação com Foco

Processos servindo Pessoas

Ágil e Descomplicado

Carteirada não vale

Brilho nos Olhos

Sonho Grande (ITAÚ UNIBANCO, 2011a).

Então a área de cultura hoje ela faz algumas pesquisas em relação a isso. E a própria área de cultura ela diz que uma da, das áreas mais importantes para disseminar a estratégia é a escola. Só que eu não sei hoje, nas pesquisas que são feitas para mostrar nossa evolução, se a gente consegue mostrar qual é a nossa contribuição nesse processo. Eu acho que verbalmente isso é muito comentado, a gente tem andado muito mais próximo da área de cultura para construir todos os nossos produtos, é, mas não existe uma pesquisa que consiga mostrar isso. (G02)

Objetivos Estratégicos. A avaliação de objetivos estratégicos tem por finalidade averiguar a contribuição do programa para o alcance dos objetivos estratégicos da organização. Segundo Hamblin (1978), a avaliação neste nível relaciona-se aos critérios utilizados pela organização para avaliar sua eficácia e seu sucesso, traduzindo-se no alcance de indicadores ou metas financeiras ou não financeiras.

Como a organização estudada é uma instituição financeira, o retorno sobre o investimento é um objetivo recorrente, isto é traduzido inclusive em sua visão de ser o banco líder em performance sustentável. Desse modo, os entrevistados citaram que a Escola busca mensurar o retorno sobre o investimento, ROI, de seus projetos, conforme exposto por G02:

$4^{\circ}$ Avaliação de resultado monetário (ROI): ganhos financeiros gerados exclusivamente pela ação de desenvolvimento a partir da diferença entre a receita e os custos destas ações (ITAÚ UNIBANCO, 2011c).

E vocês fizeram o ROI ultimamente em algum programa? (Pesquisadora)

Então a gente tem hoje sete projetos selecionados. A gente já teve o ROI aplicado aqui na área em anos diferentes. Então em 2004 teve, parece que em 2006 também teve, é, a gente tem uma área dentro do banco que tá lá ligada à área de Riscos e Finanças, que é uma área para fazer a análise de retorno sobre investimento na organização, de projetos, dentre esses projetos, a gente tá tentando trazer projetos de treinamento. Eles já fazem isso, por exemplo, pros processos dos institutos que eu te comentei. Então, por exemplo, eles medem o quanto da contribuição da estratégia XPTO que o banco teve em relação a se eu vou contribuir com salário para esse profissional, se isso melhora 
ou não melhora a educação que eu estou provendo, isso eles já fazem, mas a gente não captura isso como uma oportunidade dentro da escola. [...] O que eu acho que falta, a gente tem expertise, porque a gente tem dentro de casa gente que faz, o que tá faltando na gente é disciplina para colocar isso em processo, para fazer a escolha do projeto correto e é um pouco disso que este grupo tá tentando trazer. (G02)

Além dos resultados financeiros, a organização pode buscar alcançar indicadores não financeiros. Nesse sentido, foi interessante constatar que três entrevistados apontaram a pesquisa de satisfação do cliente interno como a forma de avaliar o alcance dos objetivos do negócio, isso, aparentemente deve-se ao fato de a educação corporativa ser área meio na obtenção dos resultados da organização, de acordo com relato da fonte G02. Assim, se a área fim, ou seja, a área de negócio, aquela que está diretamente relacionada à obtenção de resultados para a organização, avalia que EC contribuiu para o alcance dos resultados de seu negócio, tem-se a avaliação de sua contribuição. Esse achado corrobora o argumento de Fitzenz (1995), o qual destaca que há várias variáveis que não só ações educacionais que influenciam o alcance dos objetivos, entretanto, se o parceiro de negócio reconhecer que o programa contribuiu, essa informação já é válida e suficiente. Vejam-se trechos das três entrevistas:

E a única coisa que tangibiliza é essa pesquisa que eu comentei com você, que é realizada no final do ano, tá? Que chama pesquisa de satisfação do cliente interno. (G03)

Aí a gente é, faz uma, uma avaliação de satisfação. A gente tem ao final do ano uma pesquisa é, com os clientes internos, isso é, quem faz é o próprio Ibope, é que entra com uma pesquisa perguntando pros executivos o quanto a gente conseguiu agregar de valor no, na, nas ações de treinamento pro, pro próprio negócio, né? E aí a gente só recebe o resultado da pesquisa depois. Mas acho que essa é a forma porque é uma pergunta, questionando quem está recebendo o nosso serviço se está satisfeito ou não e se percebe mudanças, né? (G06)

É... na verdade assim, na verdade, é vai ser por meio dos indicadores que a gente coloca. Tem duas coisas, tá? Acho que para gente é... tem uma forma que é... que é a satisfação dos clientes. Tá? Então essa a gente faz sempre. Aí você vai falar para mim assim: necessariamente a gente, eu tô conseguindo atingir os objetivos da organização? É... ele é um indicador, vamos dizer, indireto [...] por mais que esse seja um indicador indireto, ele bate exatamente nisso, eu estou conseguindo suprir os negócios com as pessoas que eles precisam, formando as pessoas da forma que eles precisam, né?, então a gente tem esse indicador, vai, que é um indicador que a gente pega a opinião do cliente na veia, né?, e aí você tem uma série de outros indicadores. (S08) 
Também foi apontado como indicador neste nível de avaliação, o Balanced Scorecard da Área Pessoas, pois ele se relaciona aos projetos estratégicos da organização. O BSC possui indicadores atrelados às metas, os quais, ao serem atrelados a programas, podem ser monitorados como indicadores de alcance dos objetivos do negócio, identificando a contribuição do programa.

Olha, ainda não, mas a gente começou esse ano na área de pessoas um Balanced Scorecard, tá? Mas ainda é um primeiro exercício, né?, e ele tá muito relacionado aos grandes projetos da organização. Então eu acho que ele vai começar a ser um bom direcionador, tá? (G05)

Outro ponto relevante foi o relato da fonte G02, que apontou que em projetos estratégicos torna-se mais fácil identificar a contribuição da ação educacional para o sucesso do projeto. Isso já não ocorre em projetos do dia a dia, em ações mais pontuais. Uma explicação possível é que o impacto de uma ação para o alcance dos objetivos organizacionais será percebido quanto mais relação o programa tiver com esse objetivo. Ações educacionais voltadas para conteúdos empregados no dia a dia da organização estão muito distantes da estratégia do negócio. As atividades rotineiras são necessárias e importantes para que a organização funcione, porém estão distantes dos objetivos estratégicos. Essa constatação corrobora ainda a afirmação de Hamblin (1978), que aponta que deve ser analisada a viabilidade ou utilidade da metodologia. Segundo o autor, os níveis de avaliação são aplicados quando há utilidade, ou seja, quando se fazem necessários, por exemplo, há treinamentos que visam apenas à obtenção de aprendizado, visto que as pessoas estão sendo treinadas para um cargo que ainda não assumiram. Desse modo, o relato da fonte G02 fornece indícios de que a avaliação nesse nível deve ter como foco somente projetos ligados diretamente à estratégia da organização, tal qual o exemplo fornecido pela fonte a seguir:

Eu acho que um pouco através dessa, dessa avaliação. Eu acho que à medida que a gente, vou dar um exemplo, eu acho que tem projetos que isso é muito mais tangível. Então, por exemplo, a gente tem que fazer uma mudança, ou implementar uma mudança de modelo estratégico num negócio. Recentemente a gente fez uma mudança superforte num modelo de negócio de uma área comercial onde a área de capacitação era essencial para que isso acontecesse. Então a gente foi lá, em menos de dois meses a gente capacitou 5.000 pessoas no que seria esse novo modelo de negócio. Então eu acho que a gente de novo é mola propulsora, a gente é uma das partes envolvidas num projeto grande desse para garantir que essas coisas aconteçam. Então nesses projetos maiores eu acho que a gente consegue é... perceber que a gente contribuiu para uma mudança, que a gente contribuiu para um resultado, que a gente contribuiu para uma implementação e que isso tá 
direcionando 100\% para estratégia. Eu acho que em ações menores, ações mais pontuais do dia, a dia a gente perde a oportunidade de capturar isso. (G02)

O Itaú Unibanco tem como um de seus objetivos estratégicos atingir o índice de eficiência de 41\% ao final de 2013. Essa meta está se traduzindo em índices de eficiência nas diversas áreas da organização, assim como na Escola Itaú Unibanco de Negócios. Os indicadores atrelados ao Índice de Eficiência são a taxa de adesão, a taxa de ocupação e a taxa de ocupação dos polos. Esses indicadores refletem o uso eficiente de recursos, item avaliado e proposto aqui neste estudo como medida de eficiência. Por isso, eles serão descritos posteriormente. Entretanto, é importante destacar que há organizações, como é o caso da estudada, que têm como objetivo estratégico a eficiência em custos, por isso, indicadores dessa natureza podem também se relacionar a objetivos estratégicos. A seguir trechos da entrevista de G06:

[...] em conversa com a superintendente do BSC da Área Pessoas, ela comentou que o banco tem a meta de atingir em 2013 o índice de eficiência de 41\% e que há indicadores monitorados na escola que estão diretamente ligados a essa estratégia, né? Quais são esses indicadores e como vocês monitoram? (Pesquisadora)

São esses indicadores aqui de adesão. [...] São as participações no treinamento, né? [...] Tem esse e tem... taxa de ocupação dos polos. Quanto mais treinamentos a gente traz pros polos, menos uso hotel, maior, é menor o nosso custo. (G06)

Um ponto identificado na revisão de literatura foi a importância de a EC estar integrada ao sistema de GP, pois este se correlaciona mais ao desempenho organizacional que suas práticas isoladamente (BECKER, HUSELID e ULRICH, 2001; OLIVEIRA e OLIVEIRA, 2011). Neste sentido, foi investigado como ocorre a avaliação em gestão de pessoas e como a avaliação em EC e em GP se relacionam.

Na organização estudada, a avaliação em gestão de pessoas pode ser classificada em dois tipos. O primeiro relaciona-se à avaliação da área funcional, ou seja, como a Área Pessoas está auxiliando a organização a atingir seus resultados que compreendem a pesquisa de satisfação de fornecedores internos, a pesquisa de clima e o Balanced Scorecard.

E você tem a pesquisa de clima que também te dá inputs em relação à gestão de pessoas e aí ele tem uma série de dimensões com relação à gestão de pessoas, é a metodologia do Great Place to Work que a gente usa. (G05) 
O segundo tipo trata das ferramentas de avaliação de pessoas, compreendendo avaliação de desempenho, avaliação de potencial e avaliação de competências. Esses dois tipos de avaliação integram-se por meio do desdobramento das estratégias do Balanced Scorecard em metas que constarão na avaliação de desempenho dos funcionários.

O modelo de apuração dos resultados busca avaliar o desempenho individual, com base em metas predefinidas. Ele se baseia em um Balanced Scorecard, no qual os diretores e os superintendentes descrevem suas metas nas seguintes dimensões: Financeira, Satisfação do Cliente, Processo e Gestão e Pessoas. A partir dessas definições, o modelo é aplicado aos demais níveis da organização (gerentes, coordenadores, especialistas e equipes) (ITAÚ UNIBANCO, 2011a).

Você tem áreas dessa forma e você tem áreas que têm menos estruturado, mas é o mesmo conceito que tá por trás. Então objetivos que você vai desdobrando em indicadores, projetos, para que você alcance o que você se colocou lá no mapa, tá? Aí o nosso link é como que as áreas tão fazendo isso e desdobrando para cada pessoa, fazendo esse alinhamento para que eu consiga depois avaliar as pessoas. Então é aí que a gente entra. Então é, quando você fala qual é o seu papel no planejamento? Eu trabalho muito é... em alinhamento com essas áreas, em parceria com essas áreas, mas eu hoje não me intrometo no planejamento deles, tá? A expertise tá lá. A expertise tá em cada negócio hoje no modelo que a gente trabalha no Itaú. A gente trabalha no sentido de que ah, beleza, dado essa estratégia que você tem, dado essa estratégia que você montou, como que a gente desdobra isso, eu ajudo a colocar isso para cada pessoa, para que eu consiga fazer a avaliação de cada pessoa, para que eu consiga é, entender é, e ter o discernimento de como cada pessoa agregou nesse planejamento, consigo ter qual que é a contribuição de cada pessoa e como que essa pessoa vai tá avaliada no fim do ciclo. (S08)

A avaliação de desempenho ocorre para todos os funcionários, pelo menos uma vez ao ano. Existem modelos de avaliação diferentes dentro da organização, dependendo da especificidade de negócio. O modelo citado pelos entrevistados compreende o que eles chamam internamente de eixo $\mathrm{x}$, que aborda o que deve ser atingido, ou seja, as metas e seus resultados:

Todos os nossos colaboradores (94.279 funcionários próprios, baseados no Brasil, dos quais 38.906 são homens e 55.373, mulheres) estão inseridos em algum modelo de avaliação de desempenho.

[...] A análise do desempenho de cada profissional é feita por meio de avaliações periódicas de performance, realizadas ao menos uma vez por ano (ITAÚ UNIBANCO, 2011a). 
O banco tenta medir o termômetro de como os gestores de pessoas estão em relação à avaliação de $360^{\circ}$, aonde o gestor, ele é avaliado por seu colaborador, por seus pares e por seu gestor. Então hoje a ferramenta de gestão de performance, ele é avaliado pelo seu resultado. (G02)

Complementarmente à avaliação de desempenho, há a avaliação de comportamento, conforme menciona G02. Essa avaliação, chamada também internamente de eixo y, compreende “como” os resultados são alcançados:

[...] a gente tem a avaliação do comportamento que tá baseado nas nossas dez atitudes culturais e essa é uma avaliação $360^{\circ}$, então desta avaliação o gestor ele acaba recebendo um feedback de como ele está em relação ao seu processo de gestão de pessoas. (G02)

[...] Tem. Hoje 100\% do, a gente tá implementando $100 \%$ da avaliação de comportamento que a gente chama aqui internamente para $100 \%$ dos colaboradores. A diferença é que o colaborador, ele tem uma visão $180^{\circ}$, ele tem a visão de pares e gestor, ele não tem a visão de, de, [...] subordinados. (G02)

Tem, tem sim. A gente tem o eixo y, que é o nosso eixo de alinhamento à nossa cultura [...] A gente tem poucas ferramentas, Carol, geralmente, assim, a gente procura ter uma ferramenta padrão, corporativa, até para conseguir ter uma análise global, entendeu? Então, assim, você tem, eu te diria que pras equipes você tem o eixo y, né?, que é esse que eu te falei e ele vai até os vicepresidentes, enfim. (G05)

Eixo x, eu vou e estabeleço as minhas metas no início do ano, faço meu contrato de metas e em cima daquele contrato eu vou ter uma nota, avaliação do eixo x, é o que eu tenho que entregar. Avaliação do eixo y é o como eu entrego, tá ok? [...] Tem a questão da avaliação do eixo y, a aderência ao Nosso Jeito de Fazer, tem hoje, que ainda tá sendo implementado, na AP já foi, mas que tá evoluindo na organização, que é a avaliação de competências. Tudo isso dá uma série de insumos pros gestores para tá realizando todo o processo de, de feedback, todo o processo de avaliação de pessoas, né?, e desse desenvolvimento é claro. (G03)

Um terceiro instrumento de avaliação é o Planejamento Estratégico de Pessoas (PEP). Esta é uma ferramenta utilizada para desenvolvimento dos funcionários. Utilizando o conceito da matriz Nine Box, são cruzados os resultados do eixo x e y das pessoas em uma matriz, identificando o posicionamento de cada indivíduo. Para elaborar a matriz, são realizadas discussões em comitê.

Então eu vou ter um x puro e um y puro, duas avaliações. E eu vou pro PEP, no PEP eu cruzo essas avaliações numa matriz, tá ok? Nessa matriz eu faço essa calibragem ou não que eu comentei 
com você e aí tem uma discussão em comitê, tá? Onde eu vou e valido para ver se faz sentido aquela pessoa tá dentro daquele quadrante, tá? (G03)

E depois o banco ele tem uma outra ferramenta que é o planejamento estratégico de pessoas, que é o PEP, ele cruza numa matriz e ele usa o conceito do nine box para ver onde esta pessoa está plotada numa matriz em termos de seu desenvolvimento para gente poder depois discutir ação de consequência para esse profissional. (G02)

Além de entender como funciona a avaliação em GP, foi investigado como ela se relaciona à avaliação em EC. A relação entre essas duas avaliações foi apontada pela S08 como ocorrendo por meio da avaliação de desempenho, ou seja, pelo contrato de metas das pessoas. Assim, como a estratégia é desdobrada até o nível individual, por meio do contrato, há indicadores ou projetos relacionados às estratégias da organização. Um exemplo é o projeto Fábrica de Gente e o Índice de Eficiência, que são monitorados pelo BSC e que estão no contrato de metas dos funcionários da Escola Itaú Unibanco de Negócios.

[...] eu só queria saber, assim, de uma forma mais direta como que essa avaliação de performance se conecta com a avaliação em educação corporativa? (Pesquisadora)

É pela avaliação das pessoas. (S08)

É pelas metas? (Pesquisadora)

É pelas metas, é pelos contratos de metas das pessoas. (S08)

Essa integração é importante para que o sistema de avaliação de EC tenha seus esforços direcionados para os programas estratégicos da organização. Entretanto, há outra forma de realizar a integração, como citado por G05, que relata a possibilidade de utilizar os resultados das ferramentas de avaliação de pessoas como indicadores das ações educacionais:

E como é que essas metodologias conversam com a avaliação de resultados em educação corporativa? (Pesquisadora)

Ainda não. Na verdade eu acho que elas são complementares, né? Eu enxergo que elas têm momentos diferentes e aí talvez até elas possam se conversar, mas a gente geralmente usa a pesquisa de clima é... e algumas informações do consolidado do eixo y para diagnóstico de programas, então ela vai para uma fase inicial. Aí a avaliação de aprendizado, de aplicabilidade, ela vai pro final do programa para ver se você tem o objetivo atingido. Aí o que que acontece? A próxima rodada dessas ferramentas podem ser indicadores do quanto você evoluiu ou não evoluiu também complementarmente, tá? (G05) 
A partir desses relatos, há indícios de que a integração entre a avaliação em Gestão de Pessoas e a avaliação de Educação Corporativa pode ocorrer de duas formas. A primeira por meio do direcionamento dado pelo planejamento estratégico da área funcional, direcionando o que deve ser avaliado. A segunda forma seria utilizando as ferramentas de avaliação de pessoas como indicadores de resultado das ações educacionais, ou seja, utilizando-as como fornecedoras de insumos do quanto a ação educacional foi efetiva.

\subsubsection{Medidas de eficiência}

A eficiência, conforme apontam Allen e McGee (2004), trata da dinâmica de relacionamento entre recursos e atividades, respondendo à seguinte questão: “Quanto custa?”. Esse critério é avaliado por meio da estratégia instrucional, definida pelos autores como a escolha dos meios mais eficientes pelos quais o currículo possa ser ensinado. A partir da análise dos diversos autores, foram identificadas algumas variáveis que possuem relação com esse conceito de eficiência, são eles: controle dos custos diretos e custos indiretos; eficiência na utilização dos recursos; e avaliação dos procedimentos instrucionais.

Custos Diretos. Os custos são os gastos efetuados com a ação educacional. São custos diretos os que se referem à remuneração dos consultores, ao aluguel de sala, aos recursos, à alimentação, ao transporte e à hospedagem (FITZ-ENZ, 1995). No caso estudado, o orçamento em 2011 foi de R\$ 114 milhões. Os custos diretos são monitorados por uma área dentro da própria Área Pessoas, que realiza a gestão de todo o orçamento da EC (G02; G03; G06; G07). Este orçamento é descentralizado, conforme indicado por três entrevistados (G03; G06; G07), a fonte G02 aponta que a gestão do orçamento é centralizada, o que também foi apontado por G07, o qual relatou que o lançamento das despesas é realizado de forma centralizada pela EC. Os custos com logística são rateados entre todos os programas, isso porque a Escola tem unidades físicas próprias para a realização dos programas, entretanto, não são suficientes (G03). O controle efetuado baseia-se no acompanhamento do orçamento realizado, confrontando-o com o orçamento previsto, esse controle é mensal (G06).

Em 2011, investimos aproximadamente R\$ 114 milhões em treinamentos para nossos colaboradores (ITAÚ UNIBANCO, 2011a). 
Mas a gente faz um controle macro de todas as ações. Então a gente tenta capturar todas essas informações e a gente gera uma informação mensal. Hoje, como a gestão do orçamento é centralizada, a gente tem menos acesso a algumas informações para poder prover esse tipo de informação com tanta exatidão, mas a gente controla. (G02)

[...] hoje orçamento é descentralizado, tá? Então a gente fecha os valores da consultoria, os valores de tudo dentro desse, dentro do nosso orçamento da verba. Para logística, é um pouco diferente, então eu tenho custo da locação da sala, eu tenho custo do coffee, eu tenho o custo de um coordenador de sala de aula, esses custos eles são rateados, tá?, independente de usar uma sala aqui ou usar uma sala em hotel, eu pego todo o custo que eu tive e rateio pelas áreas que usaram a logística naquele período, naquele mês. (G03)

Se a gente tem a gestão, fazemos a gestão. E que pese a gente tem um sistema de orçamento descen..., a gente tem um sistema de orçamento descentralizado, né? O que que isso quer dizer? É a área de educação não tem o orçamento nas mãos, mas tem é autonomia para contratar serviços, né? E aí quem controla o orçamento é a própria área de negócio, né? (G06)

[...] A gente acompanha, nós temos um sistema em que a gente tem lá do ano inteiro o que tá previsto e o que tá sendo realizado mês a mês. Esse controle do orçamento é controlado aqui pela, pela equipe de informações que gera esses números de como a gente tá indo, né? Agora, cada, cada gerente é, cada gerência controla é, os indicadores de orçamento das áreas executivas que cada um atende, né? (G06)

Sim, sim, sim é feito. O orçamento do banco é descentralizado, ou seja, ele está dentro de cada, cada área de negócio tem o seu orçamento de educação, porém o lançamento dessas despesas é feita de forma centralizada pela escola. Então a gente consegue dizer claramente onde foi gasto cada uma das, das, das verbas de treinamento. Então eu consigo dizer isso por programa quanto custou, por pessoa quanto que custou, a área quanto ela investiu em determinado período, então a gente consegue fazer isso de forma centralizada. Então a gente tem essa gestão, sim. Tem muita oportunidade de, de melhoria nesse processo, mas a gente já faz isso já de forma consistente. (G07)

Custos Indiretos. São considerados custos indiretos os relacionados a salários e benefícios dos treinandos, salários e benefícios dos treinadores, custo fixo da área de treinamento entre outros (FITZ-ENZ, 1995). Esses custos não são apurados pela organização estudada. É interessante ressaltar que, para apuração do retorno sobre o investimento nos programas, é necessário apurar inclusive os custos indiretos e, por não haver esse controle na organização estudada, o cálculo do ROI torna-se mais difícil. Um termo aparentemente disseminado é o de custo de oportunidade. Pelo relato do entrevistado G03, esse custo refere-se ao salário do participante e a quanto ele deixou de produzir por estar em sala de aula, também mencionado 
por G02. Já o entrevistado G06 aponta como custos de oportunidade os relativos à falta do participante, que compreendem transporte e hospedagem.

Hoje não, não. [...] Também é um desejo, uma das frentes, o exemplo que eu te dei dos cargos, ele mostra isso, quanto tempo a pessoa tem que ficar naquela posição e o salário dela vai ser computado, porque ela não está produzindo naquele momento, mas hoje não. (G02)

Os custos indiretos com os treinamentos? O que a gente às vezes fala é de custo de oportunidade [...] teria que ser feito todo um cálculo de custo de oportunidade, quanto custa eu tirar aquela pessoa e deixar aquela cadeira vazia porque a pessoa veio para um treinamento. A princípio, Carol, vou te falar que isso não foi feito, se foi feito, é pontualmente. (G03)

Não, ainda não. Eu acho que é uma boa, é uma boa provocação. Pelo menos que eu saiba ainda, não. (G05)

Não, não fazemos. (G06)

[...] Porque, assim, a gente 0 , o, o custo de oportunidade que é a falta que ele gerou, oportunidade, inclui passagens e hospedagens na composição de custo de treinamento e controle dos faltantes [...]. (G06)

Não. A gente hoje não computa esses, esses indica..., esses custos como sendo investimento em treinamento. Algumas empresas o faz, fazem, mas assim, nós não fazemos. [...] Eu não computo a hora que a pessoa está dedicada para treinamento, o treinando tá dedicado, a folha de pagamento da escola eu não computo, a gente não atua dessa forma hoje. (G07)

Eficiência na utilização dos recursos. A partir dos controles dos custos diretos e indiretos, mencionados anteriormente, é possível elaborar indicadores e medidas de comparação entre os programas, permitindo identificar os mais eficientes (FITZ-ENZ, 1995). O autor aponta ainda que um relatório básico sobre gastos com treinamento inclui variáveis como total de custos do treinamento, total de horas de treinamento, total de pessoas treinadas, custo por participante e custo por participante/hora. O custo por participante/hora é mais interessante que custo por participante, pois dá um denominador comum de comparação entre programas de diferentes durações.

Alguns indicadores utilizados no caso estudado são investimento per capita, taxa de adesão, taxa de ocupação do programa, taxa de ocupação das salas e índice de eficiência. A seguir a descrição do investimento per capita: 
[...] a gente tem o orçamento realizado e a gente tem as pessoas treinadas, a gente pega e vê o custo médio per capita que a gente gastou e comprara eventualmente com o mercado para saber se a gente tá muito fora, tá muito acima ou muito abaixo. (G06)

Como visto anteriormente, o alcance do índice de eficiência de 41\% ao final de 2013 é uma das principais metas estratégicas da organização. Assim, essa meta é desdobrada para as áreas que também têm de monitorar e buscar alcançá-la. Dessa forma, o índice de eficiência busca a eficiência em custos, que significa a busca por redução de custos sem prejudicar a qualidade dos programas, conforme apontado por G05:

Existe toda uma preocupação muito grande do banco em relação à eficiência de custos, então a gente tem isso default na veia, tá?

[...] O que a gente tem na verdade são metas globais de eficiência do banco, né?, a gente tem o índice aí para alcançar até 2013. Então cada economia de cada área vai se espelhar tanto nos resultados daquela área, quanto na meta de eficiência do banco. Isso impacta, por exemplo, a nossa remuneração, então, assim, mas não um reporte específico, tá?

De redução de custos e eficiência é, na verdade é, é eficência de custos, não é redução de custos, né? Então todos os programas que eu tiver como que eu consigo fazer com que o custo seja mais eficiente? O que que eu consigo tirar sem comprometer a qualidade? É nessa linha. (G05)

O índice de eficiência para a Escola Itaú Unibanco de Negócios se traduz no monitoramento das faltas, ou seja, as faltas representam a ineficiência em termos de custos, pois geraram perdas financeiras. A seguir, trecho da entrevista que relata o cálculo do índice:

Aí a gente tem o índice de eficiência dos nossos treinamentos, que aí a gente pega, na verdade, é as pessoas convocadas e as que participaram efetivamente do treinamento, mais as faltas, né? Então você vai ter o índice de eficiência, então, por exemplo, é de janeiro até junho, é... nós convocamos 40.000 pessoas para treinamento vieram 33.600, né?, isso dá um índice de eficiência aí de 16\%, ou seja, é $84 \%$ das pessoas que foram convocadas para treinamento, participaram. Só que aí a gente tem a diferença que foram mais quase 6500 pessoas que faltaram em treinamento. $E$ gerencialmente a gente sabe o quanto custa, tem o custo per capita dos treinamentos e aí a gente consegue ver o quanto a gente desperdiçou de dinheiro, o quanto foi a nossa ineficiência nesse sentido. E aí que a gente é... monitora para que a gente, apresenta isso pras áreas de negócio e a gente ganha em eficiência, ou seja, tem o menor número possível de faltas nos treinamentos. (G06)

A taxa de adesão é a relação entre número de participantes e número de pessoas convocadas, então, da quantidade convocada, quantas pessoas participaram do programa. Já a taxa de 
ocupação do programa refere-se à relação entre número de participantes comparado ao número de pessoas que aquele programa comporta:

\begin{abstract}
Taxa de adesão é da quantidade de pessoas que você convocou, quantas efetivamente vieram no treinamento. Então, se eu convoquei 25, vieram 20, ou se eu convoquei 25 e vieram 25 a minha taxa de adesão foi $100 \%$. A taxa de ocupação, ele trabalha com espaço, a capacidade que eu tenho de pessoas que comportam naquele treinamento. Então eu posso definir que um determinado treinamento é a taxa de ocupação para melhor aproveitamento daquela turma, são 15 pessoas ou eu posso chegar à conclusão que pode ser 30 pessoas. Então, se eu tiver as 15 pessoas ou as 30 pessoas, então eu tive, eu consegui otimizar a taxa de ocupação daquele treinamento, né? (G06)
\end{abstract}

Por fim, a taxa de ocupação das salas trata do uso das salas de aula que a EC tem em suas unidades físicas. Assim, ao utilizar as salas próprias, evita-se o custo de aluguel de sala:

\begin{abstract}
A taxa de ocupação em logística, eu uso no seguinte, no seguinte conceito: se eu tenho doze salas de aula, eu tenho que ter 12 salas ocupadas, tá? (G03)

Uma das coisas que a gente acompanha também é evitar o máximo possível de colocar turmas em hotéis, né? Então nós temos os nossos centros de treinamento aqui, lá no Tatuapé, na Brigadeiro, enfim, nos vários polos que a gente tem, e a ideia é que a gente consiga utilizar o máximo possível esses polos para reduzir os custos dos nossos treinamentos [...] (G06)
\end{abstract}

Avaliação dos procedimentos instrucionais. Avaliação dos procedimentos engloba o planejamento e a execução dos programas de treinamento, envolvendo as formas pelas quais a aprendizagem será promovida (ALLEN e MCGEE, 2004). No Itaú Unibanco, para realizar a avaliação instrucional, há dois processos: validação da turma piloto e avaliação de reação. A validação da turma piloto é realizada na primeira turma do programa pelo analista que o elaborou. Há um formulário utilizado por algumas gerências da EC, mas ainda não é utilizado por toda a área. Os pontos avaliados, conforme relatos dos entrevistados, são o envolvimento do treinando; conteúdo - falta ou necessidade de aprofundamento; consultor - dinâmica, didática, condução do grupo, condução das discussões em sala, promoção da participação de todos os treinandos; e o que pode ser melhorado.

Eu acho que, assim, hoje isso é feito no momento que a gente valida o piloto. É, de novo, eu acho que hoje o nosso grupo faz isso muito no automático. Eu acho que tá faltando a gente fazer algumas discussões para eles refletirem um pouco mais em relação ao como fazer essa análise. 
[...] A gente tem, assim, meu time usa um formulário para alguns projetos, mas isso não quer dizer que todo mundo usa, eu acho que tem alguns acertos que a gente precisa fazer. (G02)

Eu acho que a gente consegue é, acho que de duas formas aí. A avaliação de reação mesmo, que a gente tem a opinião do treinando e o acompanhamento do analista em sala de aula. Então, por exemplo, nos cursos, nas, nas turmas piloto, nós temos um analista que fica em sala de aula para avaliar aquela metodologia que tá sendo aplicada. Dependendo da avaliação de reação e da observação do analista, a gente pode fazer correção de rota e ajustar a metodologia. Essas são as duas ferramentas que a gente usa. (G06)

$[\ldots]$

É, se aquela, se a metodologia conse..., se, se os treinandos estão é, conseguindo é, se envolver dentro daquela metodologia, se aquela metodologia tá, que tá sendo aplicada a gente percebe se eles tão conseguindo prestar atenção ou não mais nesse treinamento, é se, ao longo do treinamento eles vão reportando isso aqui tá muito cansativo é, é mais é observação mesmo, não tem assim uma, uma ferramenta ou, as questões bá..., acho que são questões básicas do tipo é o envolvimento do treinando, o termômetro que eles vão falando durante o dia sobre o que que aconteceu, o que pode ser melhorado. É eles mesmos dizem que faltou determinado conteúdo ou, se não faltou, precisa aprofundar mais em determinado conteúdo. E aí são conversas ao final do dia em que se pergunta como foi o dia de hoje, o que que vocês sentiram falta, o que que pode ser melhorado, então é mais uma interação com eles, né? (G06)

A gente tem por prática no banco fazer o que a gente chama de turmas piloto, né? Todo programa novo ele tem uma turma piloto que é feita, avaliado, aí é feito alguns ajustes, aí a, a gente entra em processo de roll out. Em turmas piloto obrigatoriamente tem uma analista presente, né?, para fazer essa avaliação de reação, escrita e verbal, tá? (G07)

Então assim, a gente, existe, existe um formulário que a gente faz que eu não posso te assegurar que é $100 \%$ das pessoas fazem neste modelo, mas que é aonde o analista acompanha aquele treinamento e vai observar uma série de aspectos para que ele possa garantir que efetivamente aquele programa seguiu o seu plano original, né?, da forma original, que, assim sendo, a chance de sucesso foi desenhada para que ela seja elevada, elevada, né? Então, tem sim, tem um formulariozinho que ele observa o consultor, a dinâmica do consultor, a didática do consultor, como ele abordou o assunto, como ele trabalhou o grupo, é, como é que ele conduziu as discussões na sala, como é que ele garantiu a participação de todos os treinandos, então tem, sim. [...] Mas não é um padrão, não posso te dizer que seja um modelo Itaú Unibanco. (G07)

Além da turma piloto, são utilizadas as avaliações de reação, avaliação de aprendizagem e demais níveis do modelo de avaliação de resultados da escola. Entretanto, é válido ressaltar que, ao utilizar apenas os resultados dessas avaliações, corre-se o risco de já se terem realizado diversas turmas do programa. A validação da turma piloto promove correções no 
plano instrucional antes da condução das demais turmas. É válido utilizar essas metodologias de avaliação em conjunto, considerando na validação da turma piloto, inclusive, os resultados das medidas de efetividade do programa. A seguir, alguns relatos sobre a utilização das medidas de efetividade na avaliação instrucional do programa:

\begin{abstract}
Na verdade a gente vê isso de várias formas, é por meio, por exemplo, da avaliação de reação, ele vai te dar um input, né?, em relação àquela metodologia de ensino, àquele método de ensino melhor, que tá sendo dado em sala de aula, as dinâmicas e todo o planejamento instrucional que foi feito tá aderente ou não para aquele público-alvo e para aquele conteúdo. Quando a gente olha a avaliação de aprendizagem, né?, então, poxa, teve evolução na curva, não teve, isso vai dizer se a minha estratégia tá correta ou não tá correta, né?, então eu acho que é um conjunto de coisas que faz com que você tenha essa avaliação, essa percepção. (G03)

[...] aí o que a gente costuma fazer é ter as avaliações naqueles quatro níveis que eu te falei, né?, tanto de blocar módulos, então, por exemplo, eu perguntar se eu saio mais consciente do meu papel quando eu saio da sala de aula e aí isso tem muito a ver com método[...]. A gente interage muito com os fornecedores e dá feedbacks rápidos para que as melhorias já possam ser incorporadas em outras turmas, tá? (G05)
\end{abstract}

Indicadores Estratégicos. Um dos projetos de educação corporativa que constam no Balanced Scorecard da Área Pessoas é o projeto Fábrica de Gente. Como mencionado anteriormente, esse projeto possui indicadores atrelados às diversas subáreas da AP, iremos descrever apenas os indicadores relacionados à educação corporativa.

Os indicadores da Fábrica de Gente são divididos em indicadores de qualidade e de quantidade. Os indicadores de qualidade estão relacionados diretamente ao índice de eficiência, pois avaliam a eficiência na utilização do orçamento. São indicadores de qualidade o índice de eficiência, descrito anteriormente, e os indicadores relacionados à logística, quais sejam, número de ocorrências, número de solicitações logísticas (SL) realizadas fora da logística e prazo de recebimento da SL.

A solicitação de logística garante melhor qualidade na execução do programa, pois contém os principais direcionadores sobre a infraestrutura, tais como número máximo de participantes, formato das mesas e cadeiras, materiais e equipamentos necessários etc. O número de ocorrências aponta os erros ou falhas decorrentes da logística, tais como falta de coffee break, não recebimento dos materiais didáticos, convocações incorretas, problemas relacionados aos 
equipamentos em sala etc. O número de SL que não foram realizadas pela equipe logística compreende os programas que foram realizados sem o apoio da logística, esse indicador é monitorado para impedir que isso aconteça, investigando os casos e procurando evitar que eles se repitam. Finalmente o prazo de recebimento da SL é monitorado, pois a logística tem um prazo mínimo de recebimento para garantir que o programa seja realizado com qualidade, conforme relato a seguir:

E aí tem uma antecedência com que você solicita essa solicitação, faz essa solicitação de logística pro treinamento. E a gente acompanha quantas solicitações de logística estão chegando dentro e fora do prazo pra gente saber se o analista está respeitando o prazo mínimo para que o treinamento aconteça com qualidade, né? (G06)

Além dos indicadores de qualidade, são monitorados indicadores de quantidade. Esses indicadores fornecem informações quantitativas, mas que não traduzem a eficiência da área (G06). Os indicadores de quantidade monitorados são número de horas de treinamento, número de horas de treinamento por metodologia (presencial, a distância etc.), número de horas por participante, número de participações, número de participações por metodologia, número de acordos de nível de serviço atendidos no prazo e fora do prazo. Esses indicadores são tradicionais em treinamento, com exceção do último.

É importante destacar que há uma documentação dos indicadores, na qual são descritos o significado do indicador; quais critérios são utilizados para apurá-lo; qual é a meta que esse indicador tem de atingir; e a fonte desse indicador, ou seja, onde o levantamento de dados é realizado, em qual sistema esses dados são coletados.

\subsubsection{Vantagens, limitações e tendências em avaliação de resultados em educação}

\section{corporativa}

Esta parte do estudo procurou identificar a percepção dos entrevistados em relação às vantagens e limitações do modelo de avaliação de resultados em educação corporativa empregado na Escola Itaú Unibanco de Negócios, bem como as tendências que eles visualizam em avaliação de resultados de EC de forma geral. 


\title{
4.2.4.1 Vantagens
}

As principais vantagens apontadas pelos entrevistados sobre o modelo de avaliação utilizado pela EC foram: gestão dos programas, parceria com áreas internas, simplicidade e contribuição da EC para a organização.

Gestão dos programas. Apontado como vantagem por três entrevistados, o modelo empregado permite que sejam realizadas melhorias nos programas, contribuindo para melhor qualidade das ações educacionais. A seguir trechos que demonstram essa vantagem:

\begin{abstract}
A principal vantagem é você avaliar se, é, o programa que você tá aplicando, né?, se ele exige correções de rota, né? Se você perceber que não está dando resultado, você pode mudar o programa ou deixar de fazer esse treinamento, né? Tem treinamento que é desnecessário, então por que que tá fazendo? (D04)
\end{abstract}

O segundo é que eu retroalimento os meus processos, porque, uma vez que eu estou mensurando, é mais um input do meu processo de melhoria contínua para identificar aonde pode ser diferente, será que a metodologia tem que ser diferente, o parceiro não é este, o treinamento não é este, não é treinamento, eventualmente eu errei no diagnóstico, então, assim, ele vai retroalimentar o meu processo. (G07)

Vantagens é que a gente consegue ter minimamente um, uma, informações para gente tomar decisão de mudança de rota, ajustes de programa. (G06)

Parceria com áreas internas. A realização de parcerias com áreas especializadas em avaliar projetos, tal como a área de riscos e marketing, é uma vantagem apontada por duas fontes. Isso é facilitado pelo segmento de atuação da organização estudada, o setor financeiro.

Toda essa metodologia quem apoia para gente é uma pessoa da CRF, tá? São econometristas que sabem fazer aferições de modelos estatísticos, sabem como analisar grupos de controle, para, para perceber a, a variação de um grupo que foi treinado e de um grupo que não foi treinado, que seja possível de fazer comparação para tentar desprezar o, os ambientes externos e aí vai. (G02)

É o que eu posso te dizer assim que a gente acaba sabendo e construindo até juntos, é que tem áreas de negócio nos auxiliando nessa construção, né?, áreas reconhecidas até nacionalmente, né?, com executivos super-renomados, e eles têm nos ajudado a construir o nosso modelo de avaliação de resultados, de como é que eu chego a esse ROI de treinamento.

[...] eu acho que isso é uma questão muito legal de tá construindo com uma área que faz, por exemplo, os modelos de risco do banco, mensurar treinamento, que tem profissionais 
superconceituados no mercado, então isso para mim dá uma credibilidade muito grande no instrumento, sabe? (G05)

Simplicidade. O modelo utilizado foi apontado como de fácil assimilação, entendimento e realização. A área está conseguindo desenvolver e implementar o modelo:

\begin{abstract}
Eu acho que é uma metodologia, no meu ponto de vista, quando eu falo principalmente nas avaliações de aplicabilidade, é uma metodologia simples, sem custo, porque a gente usa uma ferramenta de pesquisa aí que é free, que é o Survey Monkey e é rápida, tá? (G03)

É, eu acho que uma vantagem dessa metodologia é que é uma metodologia interna, ela é algo que a gente consegue fazer (risos). Eu acho que a primeira vantagem é essa (risos), porque não adianta a gente ter um modelo robusto que não consegue ser aplicado. Então de fato, quem tá no projeto, fala: a gente consegue, né? E é um know how que a gente tá apren..., a gente tá absorvendo e é de dentro de casa, né? Isso eu acho que é uma primeira vantagem. Outra vantagem, deixa eu pensar, eu acho que é algo que as pessoas tão compreendendo, ela é fácil de entender, né? (S01)
\end{abstract}

Contribuição da EC para a organização. Conseguir identificar a contribuição da EC para o alcance dos objetivos do negócio é uma das vantagens apontadas por G07. Em sua visão, a EC, inclusive, deixa de sentir-se culpada por demonstrar os resultados de suas ações:

Eu acho primeiro, assim, a gente vai se livrar um pouco do sentimento de culpa para falar que eu não consigo responder para organização, em muitos momentos, o quanto o meu produto responde à necessidade da organização, então acho que essa é uma grande vantagem que a gente tem. (G07)

\title{
4.2.4.2 Limitações
}

A investigação procurou identificar as principais limitações do modelo de avaliação de EC utilizado no caso estudado, entretanto, os entrevistados acabaram trazendo, além das limitações do modelo, as dificuldades que eles têm enfrentado em sua implementação.

Cultura de avaliação. A principal dificuldade apontada foi a criação de uma cultura de avaliação, citada por cinco entrevistados. A criação de uma cultura de avaliação é enfatizada por Phillips (1991) na proposição de seu modelo de avaliação orientada por resultados, que passa pela mudança de atitude da organização em relação à avaliação de resultados em treinamento. A área de treinamento deve ser orientada por resultados e essa postura é parte 
importante da estratégia de avaliação. Assim, percebe-se que essa constatação de Phillips (1991) se confirma na realidade do caso estudado, tornando-se aspecto fundamental para a perenidade do modelo de avaliação. As ações empreendidas pela organização estudada para lidar com essa barreira, conforme aponta G07, são a condução de programas para a formação da equipe e a cobrança de resultados, através de metas de desempenho.

Eu acho que a gente ganha esse jogo de mensuração em duas óticas. Uma eu já te falei, que é disciplina, mas eu acho que assim, você discutir com o cliente indicadores, possibilidades de coisas que precisam ser coletadas para medir resultado depois que o projeto já foi pro ar é muito mais difícil do que você discutir na partida. Então, se você olhar toda a bibliografia, ela diz isso: o quão importante é você falar de, de mensuração de resultados na partida do projeto, defina quais são os indicadores que você quer mensurar, quais são os objetivos que você quer mensurar, e quais são os indicadores possíveis para você fazer essa investigação. Hoje a gente ainda faz isso depois, eu tenho certeza que, se a gente conseguir amadurecer esse processo e conseguir fazer isso na partida, isso vai ser mais tranquilo. (G02)

Então eu acho que a gente tem que evoluir para isso, né?, como área de educação, a gente tem que ter esses números na cabeça, sabe? Tem que pensar em educação, mas também um pouco matemático, economista, tudo isso. (G03)

E eu acho que isso, assim, vou extrapolar bastante, eu acho que isso demanda até modelos de mindset dentro das organizações, porque as pessoas na sua grande maioria nas organizações, elas não são acostumadas a olhar muito o todo, elas olham mais a parte, né? Então isso eu acho que provoca uma mudança até de atuação da organização como um todo, mas principalmente das áreas de educação.

[...] Então eu talvez te sugerisse completar com cultura de mensuração nas organizações, se isso existe? Qual é o modelo mental dominante, né? As pessoas estão acostumadas a isso? (G05)

Então ainda não tá no sangue do analista, na pele assim, a questão da prontidão pro processo de mensuração, então, às vezes, ele perde o melhor momento para fazer isso que é no diagnóstico. Se no diagnóstico eu não tiver esse modelo mental já inputado, depois, quando eu já tiver na aplicação do treinamento, eu não vou ter mais condições de mensurar por que eu deixei de identificar os indicadores lá na partida [...] a gente tem indicadores, e no contrato de metas dos analistas de treinamento tem o processo de mensuração. Então a gente tá usando assim, capacitação e processos formais para garantir o aculturamento das pessoas pro processo de mensuração. (G07)

Eu acho que um outro limitante, eu acho que são dificultadores, mas eu não acho que eles me limitam. Assim, uma área de 86 pessoas, eu preciso garantir que essa cultura de mensuração de 
resultado esteja em 100\% desse público. Então eu preciso garantir isso, então tem todo um processo de disseminação da importância disso para dentro da escola, né? [...] Eu preciso criar essa cultura dentro do banco, eu preciso fazer isso ser um ato contínuo, né? (S01)

Ausência de relação de causa e efeito. Essa foi a segunda limitação mais apontada, foram três entrevistados que a relataram. É difícil especificar a contribuição concreta do programa, pois, juntamente com ele, ocorreram outras variáveis que também podem ter influenciado o resultado alcançado pelo negócio. Portanto, isolar variáveis e estabelecer relação de causa e efeito aparecem como um dos principais limitadores do modelo de avaliação de EC.

É a, estabelecer a relação de causa e efeito concreta, né? É difícil você dizer este resultado foi graças a este treinamento, né? Essa relação de causa e efeito ela é mais, mais difícil, é um desafio. (D04)

Então isso com certeza é um investimento que tem retorno, né?, é claro que pode ter uma série de variáveis quando você tá usando uma pesquisa de clima para acompanhar essa evolução. Então eu te diria, assim, que a nossa ambição é colocar lupa naquilo que é específico, nosso mesmo e esse é o nosso desafio. (G05)

Tá. Eu não sei se é aqui do banco ou de qualquer empresa, porque todo mundo que eu converso sobre mensuração de resultado em treinamento fala um pouco disso. Acho que, quando a gente tá avaliando, fazendo mensuração de resultado de treinamento é, às vezes a gente não consegue isolar é, dizendo que aquela, aquele resultado foi 100\% por conta de uma ação de treinamento. [...] Então a gente considera, tem até um executivo aqui dentro do banco que fala: eu sei que tem outras variáveis, mas, se eu alcancei os resultados, vocês são sócios meus, né? Vocês são meus sócios nisso. (S01)

Tecnologia. A ausência de sistemas que suportem todo o processo de avaliação é apontado por três entrevistados como um limitador. O tamanho da organização estudada gera volumes elevados para se realizar a tabulação de dados de forma manual e a ausência de um sistema dificulta o monitoramento de todas as fases da avaliação de forma integrada.

Para fazer outros tipos de avaliação, a gente precisa eu acho que melhorar tecnologia e ter metodologia para se chegar num resultado melhor. Então, quando eu falo em avaliação de aplicabilidade, eu preciso ter ferramenta para conseguir fazer isso, hoje eu tenho algumas limitações tecnológicas. (G06)

[...]E faz uma, pelo SABA lá nosso LMS, você faz uma avaliação de múltipla escolha, ele é fácil de tabular, mas quando, e assim dá para abranger um público enorme que a gente consegue fazer 
uma tabulação fácil. Mas, se você passa a avaliação de aplicabilidade que são perguntas em que, é são perguntas às vezes abertas em que você precisa responder a, o, a nossa tecnologia não consegue é consolidar essas, essas informações de um modo simples. (G06)

Sistemas, a gente tem limitações sistêmicas para fazer isso, então a gente faz de uma forma que ainda é meio incipiente, né? A gente usa, por exemplo, um provedor externo, tô falando da avaliação de aplicabilidade, tá? A gente usa ainda um provedor externo que nos ajuda, que é sem custo, então a gente ainda tá amadurecendo para poder eventualmente desenvolver uma plataforma sistêmica melhor, né? (G07)

Eu acho que um outro limitador é uma ferramenta sim. Assim, hoje a gente tem um grupo de trabalho, a gente tem um grupo de pessoas, mas eu não tenho algo que sistematiza a minha avaliação. Eu acho que, se eu tivesse algo que sistematizasse essa avaliação, seria ótimo. (S01)

Falta amadurecimento. A falta de amadurecimento do modelo é um limitador, pois, como ele ainda está em construção, as informações fornecidas como resultados ainda não são utilizadas como medidas de monitoramento.

O modelo ainda não tá consolidado, né?, Carol. A gente começou a, a, a fa..., não é nem consolidar, a gente começou a trabalhar mais com isso o ano passado, por meio das avaliações de aplicabilidade [...] eu acho que a gente ainda tá num processo de construção, tá? Igual eu comentei anteriormente, no passado, a gente fez realmente ROI, isolando variáveis, pegando públicos-alvo, vendo questões de sexo e de idade, enfim, né?, todas as variáveis possíveis, mas é um processo muito longo, que demora aí nove meses. E as áreas não têm aí esse tempo para estar esperando [...]. (G03)

Eu só vejo um limitante, assim, que eu devia ter comentado no outro. Quanto eu vejo as avaliações, elas são todas muito altas, então, assim, quando tá tudo bom, como que eu consigo de fato ter essa sacada do que que eu preciso fazer de diferente. (S01)

Disciplina. A disciplina em realizar a avaliação dos programas também foi apontada como limitação. Esforçar-se para a disseminação do modelo de avaliação internamente poderá garantir perenidade e constância na geração de resultados.

Então a gente tem insumos para mostrar muito mais do que a gente mostra hoje. Mas a gente precisa dedicar tempo, a gente precisa garantir que todo mundo esteja na mesma página em termos conceitual, a gente precisa ter uma área de educação que se aproprie desse nosso resultado e que 
ela enxergue o quanto nós somos responsáveis por esse resultado, sim, o quanto nós não fomos responsáveis ou o quanto que nós fomos responsáveis pelo insucesso de uma ação.

[...] eu acho que falta disciplina. Se eu fosse dizer para você o que falta é, a gente acreditar que a gente precisa investir tempo e ter disciplina para fazer esse tipo de medição. (G02)

Mas as demais ações quando eu meço se o cara aprendeu, se o cara aplicou e tal, ele tá tirando uma foto, é algo muito pontual, eu queria algo que pudesse me dar uma visão mais contínua. (S01)

Conscientização da área cliente. Para a condução da avaliação, conforme relata a fonte G07, é necessário o envolvimento da área cliente. Isso ocorre, pois, como são utilizados indicadores do negócio, este tem de ter regularidade na apuração desses indicadores e atuar como parceiro, visto que ele fornece os dados para a apuração dos resultados. Outro ponto destacado por S01 é que os participantes dos programas precisam conscientizar-se da importância de responderem às avaliações.

Quando a gente chega no nível de resultado, de ROI por exemplo, eu acho que aí as dificuldades são outras. A dificuldade, assim, é primeiro trabalhar com exe..., apesar do executivo cobrar a gente para ter esse número, o esforço compartilhado dele conosco é muito grande, porque assim eu vou ter que entrar na operação dele e identificar quais são os indicadores, né?, ter uma disciplina de identificação de indicadores, de, de separar grupos de controle, então, assim, o esforço que ele vai precisar imprimir no processo é tão grande quando o nosso. Então às vezes a limitação que a gente tem ainda é um pouco da conscientização desses executivos da importância de se fazer essa mensuração e da necessidade é, de investir um tempo para isso.

$[\ldots]$

À medida que eu identifico qual o problema que eu quero mensurar, eu tenho um trabalho todo de abordagem desse executivo, eu entro, então a gente tem feito esse, esse trabalho constantemente. (G07)

Eu acho que uma outra questão, uma outra limitação é, assim, muitas das nossas pesquisas, a gente usa através de questionários e a gente precisa que as pessoas respondam, né? Eu acho que você vivencia isso (risos), se eu não tenho insumo de resposta, eu não tenho como fazer uma avaliação mais elaborada e... Então, assim, eu preciso sensibilizar a organização em relação a isso e muita gente quer fazer pesquisa sobre muita coisa, todo mundo tá querendo fazer avaliação de seus resultados, então eu acho que uma limitação, eu ainda não me, me deparei com ela, isso não foi um limitador para gente não seguir em frente. Mas o ano passado nós tivemos um bom número de respondentes, mas não foi excelente, sobre um conjunto de ações que a gente tava avaliando de aprendizado e aplicabilidade. (S01) 
Apenas um entrevistado apontou ainda outros dois fatores como limitantes do modelo de avaliação: a demora na apuração dos resultados e a complexidade do modelo. É interessante destacar que uma das principais vantagens do modelo foi justamente sua simplicidade, havendo, portanto, divergência de opiniões em relação ao modelo de avaliação de resultados empregado no caso estudado.

\title{
4.2.4.3 Tendências
}

Neste tópico o levantamento de dados gerou pouca conciliação entre as percepções dos entrevistados. Sendo assim, apenas dois fatores foram comentados por dois entrevistados: demonstração da efetividade da EC e parceria com áreas clientes. É válido destacar que algumas das limitações apontadas no tópico anterior reaparecem aqui na forma de tendência: estabelecimento de relação de causa e efeito; simplicidade do modelo; e parceria com áreas clientes. Por isso, serão descritos apenas os fatores ainda não expostos.

Demonstração de efetividade da EC. Mostrar para a organização a real contribuição da EC para o alcance dos objetivos estratégicos é apontada como uma tendência. Desse modo, um avanço em relação à utilização dos demais níveis de avaliação, que não só reação e aprendizagem, é uma tendência exposta pelos entrevistados.

\footnotetext{
Quais são as tendências? Eu acho que hoje as organizações ainda estão muito ligadas aos primeiros níveis, que é a avaliação de aprendizagem, a avaliação de reação, eu acho que cada vez mais, quando eu estou pensando em tendência, é, cada vez mais a área de educação tem que estar caminhando para mostrar realmente a efetividade do treinamento, ou seja, por meio de uma avaliação de aplicabilidade, ou seja por meio de uma avaliação do impacto do treinamento nas vendas, né? Eu acho que esse caminho que tem que ser seguido. A gente tem que mostrar que a gente é uma área de resultado e não só de custo. (G03)
}

\begin{abstract}
Mas uma tendência que eu sinto também é que cada vez mais a gente pergunta pras pessoas o quanto aquilo é aplicável, o quanto que aquele conhecimento ele realmente agregou valor e até na estrutura para que você tenha momentos de prática nesses treinamentos, que você possa voltar e aplicar realmente, o que que aquilo agregou, né? (G05)
\end{abstract}

Diversos métodos de avaliação. Utilizar diferentes formas de avaliação que captem o comportamento do indivíduo é uma tendência. O modelo de avaliação baseada na observação 
colhe outros insumos para o processo de avaliação, trazendo uma percepção diferente a respeito dos resultados gerados.

Então eu acho que uma tendência que tem é a gente passar a observar o comportamento das pessoas e a mudança desse comportamento de uma forma diferente do que a gente faz hoje. Que nem eu mencionei, né?, a aplicabilidade a gente faz por pesquisa, apesar de fazer por pesquisa, então tá bom, quais são as outras formas que eu tenho de olhar essa questão do dia a dia? Então a gente vai precisar desenhar uma forma de trabalhar. Eu acho que uma coisa que a gente tem é de sair um pouquinho desse modelo mais é... acadêmico, comumente chamado assim, para um modelo um pouco mais de observação, um pouco mais de percepções que a gente hoje não consegue colher. Então esse é um esforço que a gente vai ter que fazer. (G07)

Consistência e segurança do modelo. Em termos de consistência, é esperado que as avaliações gerem números mais consistentes, garantindo segurança para quem utiliza seus resultados:

Então é um pouco de veracidade do modelo, assim, o quanto que, veracidade não, consistência do modelo. Eu acho que isso para mim é... O modelo do futuro que me dá essa consistência, que me permita medir em vários momentos [...]. Então o modelo do futuro ele me, me direciona isso. Ele me dá mais essa segurança e ele me dá notas mais realistas. Eu acho que as notas são muito altas, principalmente, pelo nível mais inicial o reação, as notas são sempre muito altas. (S01)

Houve ainda quem apontasse que não conseguia visualizar nenhuma tendência.

Por fim cabe ressaltar que são enviados mensalmente os resultados das ações de educação para as áreas de negócio. Essa comunicação dos resultados tem por objetivo informar a área cliente sobre as ações realizadas, as faltas no período etc. Servindo como meio de divulgação da Escola Itaú Unibanco de Negócios.

\subsubsection{Síntese do estudo de caso Itaú Unibanco}

O Itaú Unibanco é uma organização do segmento financeiro, direcionada para o alcance de resultados, como se visualiza em sua visão "Ser o banco líder em performance sustentável e em satisfação dos clientes” (ITAÚ UNIBANCO, 2012a). 
Esse direcionamento se traduz pela busca sistemática de resultados pela Escola Itaú Unibanco de Negócios, a área de educação corporativa da organização. Por isso, esta área desenvolveu um modelo de avaliação de resultados de EC com o objetivo de verificar de forma objetiva e tangível os resultados gerados pelas ações educacionais. O modelo de avaliação utilizado pela organização baseia-se nos modelos propostos por Kirkpatrick e Jack Phillips e apresenta muita similaridade ao modelo de Allen e McGee (2004), pois avalia aspectos relacionados à qualidade do programa e ao processo para sua realização.

É interessante observar que o modelo empregado no caso estudado não contempla a verificação dos impactos gerados pelo programa na organização, pois, no nível de aplicação, é avaliado se a ação gerou mudanças de comportamento no trabalho, ou seja, se o aprendizado está sendo aplicado ao contexto do trabalho. Depois deste nível, parte-se direto para a apuração do ROI. A seguir é exposta uma síntese do caso, com os principais pontos de destaque observados (Quadro 9).

Quadro 9 - Síntese do caso Itaú Unibanco

\begin{tabular}{|c|c|}
\hline Fatores Analisados & Itaú Unibanco \\
\hline Fatores Relevantes & $\begin{array}{l}\text { Fusão entre Itaú e Unibanco. } \\
\text { Cultura organizacional. } \\
\text { Fortalecimento da atuação da consultoria pessoas e educação } \\
\text { corporativa. }\end{array}$ \\
\hline \multicolumn{2}{|l|}{ Educação Corporativa } \\
\hline Objetivos da EC & $\begin{array}{l}\text { Não formalmente estabelecidos, mas relatados pelos entrevistados } \\
\text { como desenvolver as pessoas de forma a atender aos objetivos do } \\
\text { negócio. }\end{array}$ \\
\hline $\begin{array}{l}\text { Alinhamento da EC aos objetivos } \\
\text { organizacionais }\end{array}$ & $\begin{array}{l}\text { Os objetivos organizacionais são capturados por meio de duas } \\
\text { entradas: comitê executivo e unidades de negócio. O currículo de } \\
\text { conhecimento captura as necessidades das unidades de negócio e a } \\
\text { visão do comitê executivo é trazida pelo vice-presidente de GP. }\end{array}$ \\
\hline Alinhamento da EC à GP & $\begin{array}{l}\text { Ocorre verticalmente, por meio de comitês da Área Pessoas e seu } \\
\text { planejamento estratégico, e horizontalmente por meio do alinhamento } \\
\text { realizado junto às consultorias internas de RH. }\end{array}$ \\
\hline Público atendido & $\begin{array}{l}\text { Interno e externo, este último com ações voltadas aos fornecedores e } \\
\text { pontualmente para terceiros e clientes. }\end{array}$ \\
\hline Aprendizagem contínua & $\begin{array}{l}\text { Realização de práticas formais pela EC, tais como construção do } \\
\text { currículo e realização dos programas. A postura de } \\
\text { autodesenvolvimento foi apontada como crucial para fomentar a } \\
\text { aprendizagem contínua na organização. }\end{array}$ \\
\hline \multicolumn{2}{|c|}{ Avaliação de Resultados em Educação Corporativa } \\
\hline Critérios para avaliar & $\begin{array}{l}\text { Não há critérios definidos. Porém foram relatados os seguintes } \\
\text { aspectos: custos dos programas; quantidade de participantes; apoio de } \\
\text { áreas de negócio; recorrência dos programas; mudança estratégica } \\
\text { relevante; variedade em termos de tipos de programas. }\end{array}$ \\
\hline
\end{tabular}

Continua... 
Continuação do Quadro 9

\begin{tabular}{|c|c|}
\hline Fatores Analisados & Itaú Unibanco \\
\hline \multicolumn{2}{|l|}{ Medidas de Efetividade } \\
\hline Reação & $\begin{array}{l}\text { Formulário padrão realizado para todos os programas em que é } \\
\text { avaliada a relevância do programa. } \\
\text { Aspectos avaliados: instrutor, conteúdo, metodologia, infraestrutura } \\
\text { (ambiente, equipamentos e materiais). }\end{array}$ \\
\hline Aprendizagem & $\begin{array}{l}\text { Não há padronização sobre os critérios para realização deste nível de } \\
\text { avaliação, entretanto, busca-se realizar pré e pós-teste. }\end{array}$ \\
\hline Aplicação & $\begin{array}{l}\text { Realizado por meio de questionário para colher as percepções do } \\
\text { participante e do gestor sobre a aplicação do aprendizado ao trabalho. }\end{array}$ \\
\hline Processos & Não realizado. \\
\hline Cultura & Não realizado. \\
\hline Objetivos & $\begin{array}{l}\text { Apurações pontuais de ROI de programas foram realizadas no } \\
\text { passado e está em desenvolvimento a avaliação do retorno de alguns } \\
\text { projetos. } \\
\text { A satisfação do cliente interno avalia a atuação da EC sobre o alcance } \\
\text { dos objetivos das áreas de negócio. } \\
\text { Indicadores do BSC da Área Pessoas. }\end{array}$ \\
\hline \multicolumn{2}{|l|}{ Medidas de Eficiência } \\
\hline Custos & $\begin{array}{l}\text { Custos diretos apurados e controlados de forma centralizada. } \\
\text { Custos indiretos não apurados. }\end{array}$ \\
\hline Eficiência na utilização de recursos & $\begin{array}{l}\text { Indicadores como índice de eficiência, taxa de adesão, taxa de } \\
\text { ocupação do programa e de logística. }\end{array}$ \\
\hline $\begin{array}{l}\text { Avaliação de procedimentos } \\
\text { instrucionais }\end{array}$ & $\begin{array}{l}\text { Validação da turma piloto e verificação dos resultados das medidas } \\
\text { de efetividade do programa. }\end{array}$ \\
\hline
\end{tabular}

Uma ferramenta utilizada na integração entre avaliação em EC, avaliação em GP e estratégia da organização tem sido a avaliação de desempenho. No Itaú Unibanco, os objetivos da organização são desdobrados em ações nos contratos de metas das pessoas, utilizando o conceito de BSC até o nível de gerência, e atrelando indicadores a essas ações. Os resultados fornecidos pela avaliação de desempenho podem também ser utilizados como indicadores de efetividade da ação educacional, verificando se houve progressão no desempenho do participante.

Este caso trouxe também informações relevantes sobre as limitações, vantagens e tendências sobre avaliação de resultados em educação corporativa. As principais vantagens apontadas pelos entrevistados, em relação à metodologia empregada no caso estudado, foram: fornecimento de subsídios para gestão dos programas, estabelecimento de parceria com áreas internas, simplicidade do modelo e identificação da contribuição da EC para a organização. Por outro lado, foram apontadas como limitações do modelo a necessidade de tecnologia para seu funcionamento; a falta de amadurecimento, pois o modelo ainda está em construção; a demora na apuração dos resultados; e a complexidade do modelo. Foram mencionados, ainda, os desafios enfrentados pela área para implantação da avaliação, são elas a criação de cultura de avaliação, pois as pessoas ainda não têm o hábito de pensar em avaliação durante a 
elaboração de programas e realização de diagnóstico; ausência de relação de causa e efeito; necessidade de criar disciplina na realização da avaliação, pois deve-se investir tempo para sua condução; e conscientização da área cliente, visto que ela também é parte no processo de avaliação, fornecendo os indicadores e dados necessários. Por fim, quando questionados sobre tendências em avaliação de resultados em EC, os entrevistados relataram que a EC será cada vez mais cobrada a demonstrar sua efetividade; a utilização de outros métodos de avaliação também foi apontada como tendência; e por fim, o modelo do futuro fornecerá consistência e segurança sobre seus resultados. 


\subsection{Análise comparativa entre MEPT e Itaú Unibanco}

O estudo de caso Itaú Unibanco forneceu informações valiosas para a generalização teórica dos achados, pois proporcionou o aprofundamento necessário para averiguar os aspectos da avaliação de resultados em educação corporativa. Algumas teorias foram corroboradas e lacunas identificadas. Já o estudo conduzido junto aos dados dos Cadernos de Evidências das MEPT possibilitou traçar um panorama da avaliação de resultados nas organizações que se destacam em gestão de pessoas no Brasil.

Os objetivos da educação corporativa, em ambos os estudos, são estabelecidos buscando a promoção da aprendizagem e o desenvolvimento das pessoas, atrelados aos objetivos organizacionais. O estabelecimento de objetivos nestes termos está em consonância com os objetivos da educação corporativa propostos por Meister (1999) e Eboli (2004; 2010): desenvolver as competências organizacionais auxiliando a organização a alcançar seus objetivos.

O alinhamento da EC à gestão de pessoas foi apontado como ocorrendo de formas diferentes nos dois casos. O Itaú Unibanco promove o alinhamento por meio de comitês e insumos trazidos pela consultoria de recursos humanos; enquanto as MEPT procuram fazer o alinhamento utilizando práticas de gestão de pessoas na etapa de diagnósticos das ações educacionais. As práticas identificadas foram: avaliação de desempenho, gestão da carreira, gestão por competências e pesquisa de clima organizacional. É válido destacar que o alinhamento entre EC e GP ocorre, em geral, por meio da avaliação de desempenho. Esse foi um aspecto citado como peça-chave no caso Itaú Unibanco e pela maioria das MEPT, sendo citada por $54 \%$ das fontes categorizadas.

As organizações estudadas atendem seu público interno e estão buscando ampliar sua atuação, por meio da ampliação de suas ações aos seguintes públicos externos: fornecedores, clientes, terceiros, comunidade, concorrentes, distribuidores, familiares, parceiros e universidades. A ampliação do público atendido, buscando-se a formação dos stakeholders atrelados à estratégia da organização, é uma das características mais apontadas na literatura (MEISTER, 1999; VERGARA, 2000; ALPERSTEDT, 2001; EBOLI, 2004; PILATI, 2006). 
A promoção da aprendizagem contínua é um aspecto que caracteriza a atuação da educação corporativa (MEISTER, 1999; VERGARA, 2000; EBOLI, 2004). Foi destacada no Itaú Unibanco a importância da postura proativa do funcionário na busca por seu desenvolvimento: o autodesenvolvimento foi apontado como fundamental para que haja aprendizagem contínua na organização. Como práticas de promoção da aprendizagem contínua foram mencionados a realização de eventos, o desenvolvimento de ferramentas colaborativas, a promoção da leitura, a atuação de funcionários como docente, o fornecimento de recursos financeiros e a realização de reuniões e visitas técnicas.

Quadro 10 - Análise comparativa entre MEPT e Itaú Unibanco: educação corporativa

\begin{tabular}{|c|c|c|}
\hline Fatores Analisados & Itaú Unibanco & MEPT \\
\hline \multicolumn{3}{|l|}{ Educação Corporativa } \\
\hline Objetivos da EC & $\begin{array}{l}\text { Não formalmente estabelecidos, mas } \\
\text { relatados pelos entrevistados como } \\
\text { desenvolver as pessoas de forma a atender } \\
\text { aos objetivos do negócio. }\end{array}$ & $\begin{array}{l}\text { Promoção da aprendizagem voltada } \\
\text { aos objetivos do negócio. }\end{array}$ \\
\hline $\begin{array}{l}\text { Alinhamento da EC aos } \\
\text { objetivos } \\
\text { organizacionais }\end{array}$ & $\begin{array}{l}\text { Os objetivos organizacionais são } \\
\text { capturados por meio de duas entradas: } \\
\text { comitê executivo e unidades de negócio. } \\
\text { O currículo de conhecimento captura as } \\
\text { necessidades das unidades de negócio e a } \\
\text { visão do comitê executivo é trazida pelo } \\
\text { vice-presidente de GP. }\end{array}$ & $\begin{array}{l}\text { Os objetivos organizacionais } \\
\text { permeiam os relatos das organizações, } \\
\text { verifica-se alinhamento, principal- } \\
\text { mente, a estratégia da organização. }\end{array}$ \\
\hline $\begin{array}{l}\text { Alinhamento da EC à } \\
\text { GP }\end{array}$ & $\begin{array}{l}\text { Ocorre verticalmente por meio de comitês } \\
\text { da Área Pessoas e seu planejamento } \\
\text { estratégico e horizontalmente por meio do } \\
\text { alinhamento realizado junto às } \\
\text { consultorias internas de RH. }\end{array}$ & $\begin{array}{l}\text { Promovida, em geral, por meio da } \\
\text { utilização de práticas de GP no } \\
\text { diagnóstico das ações. As práticas } \\
\text { mencionadas são avaliação de } \\
\text { desempenho, gestão da carreira, gestão } \\
\text { por competências e pesquisa de clima } \\
\text { organizacional. }\end{array}$ \\
\hline Público atendido & $\begin{array}{l}\text { Interno e externo, este último com ações } \\
\text { voltadas aos fornecedores e pontualmente } \\
\text { para terceiros e clientes. }\end{array}$ & $\begin{array}{l}\text { Internos e os externos compreendem } \\
\text { clientes, comunidade, concorrentes, } \\
\text { distribuidores, familiares, } \\
\text { fornecedores, parceiros, terceiros e } \\
\text { universidades. }\end{array}$ \\
\hline Aprendizagem contínua & $\begin{array}{l}\text { Realização de práticas formais pela EC, } \\
\text { tais como construção do currículo e } \\
\text { realização dos programas. A postura de } \\
\text { autodesenvolvimento foi apontada como } \\
\text { crucial para fomentar a aprendizagem } \\
\text { contínua na organização. }\end{array}$ & $\begin{array}{l}\text { Práticas identificadas: promoção de } \\
\text { eventos, ferramentas colaborativas, } \\
\text { leitura, atuação docente, recursos } \\
\text { financeiros, reuniões e visitas técnicas }\end{array}$ \\
\hline
\end{tabular}

A avaliação de resultados em educação corporativa, conforme modelo de avaliação proposto por Allen e McGee (2004), apresenta duas esferas de avaliação: a efetividade e a eficiência da educação corporativa. Como identificado no estudo com as MEPT, a realização de avaliação de resultados das ações educacionais ainda é incipiente; mesmo sendo organizações que se 
destacam em gestão de pessoas, poucas realizam avaliação de EC. Entretanto, foi possível identificar, dentre as que a fazem, certo padrão na condução deste tema.

A reação é o nível mais aplicado pelas organizações estudadas, como visto no Itaú Unibanco, é aplicada uma avaliação padronizada para todos os programas e são avaliados os seguintes aspectos: instrutor, conteúdo, metodologia e infraestrutura.

A aprendizagem, em ambos os estudos, é realizado por meio de métodos tradicionais como a aplicação de provas. Foram encontrados indícios, nos dois estudos, de realização de testes antes e após a realização do programa para verificar a mudança que seja oriunda do curso realizado. O Itaú Unibanco não apresenta critérios definidos para a realização desse nível, enquanto algumas organizações pertencentes às MEPT apontam os programas técnicos e que buscam certificação como sendo alvos da avaliação neste nível.

A avaliação da aplicação da aprendizagem ao trabalho ocorre, de forma geral, três meses após o término do programa e é conduzida por meio de pesquisa de percepção junto, principalmente, ao gestor. O Itaú Unibanco e uma organização pertencente às MEPT também colhem a percepção do participante. Indicadores atrelados ao desempenho do indivíduo foram apontados como fontes de dados para este nível de avaliação.

Verificar o impacto da educação corporativa no funcionamento da empresa envolve, em geral, o monitoramento de indicadores de negócio. Foram identificadas nas MEPT medições neste nível. São monitorados indicadores operacionais, de qualidade e de gestão de pessoas.

A disseminação da cultura é uma das características da educação corporativa que assegura sua perpetuidade (MEISTER, 1999; EBOLI, 2004; PANCZUK, 2001 apud MORIN e RENAUD, 2004). Como verificado nos estudos as organizações ainda não possuem avaliação neste nível. É importante destacar que não são todos os programas que precisam ser avaliados neste nível, apenas as ações que envolvam o desenvolvimento de atitudes alinhadas à cultura organizacional.

Enfim, a avaliação da contribuição da EC para o alcance dos objetivos do negócio se dá nas organizações estudadas por meio da apuração do retorno sobre os investimentos realizados em educação corporativa; apuração da satisfação das áreas de negócio (clientes internos) em 
relação à EC; e alcance dos objetivos traçados no planejamento estratégico, quer seja pela identificação das competências organizacionais e humanas que a suportem, quer seja pela percepção dos gestores sobre a contribuição da EC no desempenho do negócio. Cabe destacar que o Itaú Unibanco apresenta indicadores em EC atrelados ao BSC da Área Pessoas, buscando demonstrar de forma objetiva o impacto das ações educacionais para o alcance das estratégias do negócio.

Quadro 11 - Análise comparativa entre MEPT e Itaú Unibanco: medidas de efetividade

\begin{tabular}{|c|c|c|}
\hline Fatores Analisados & Itaú Unibanco & MEPT \\
\hline \multicolumn{3}{|c|}{ Avaliação de Resultados em Educação Corporativa } \\
\hline \multicolumn{3}{|c|}{ Medidas de Efetividade } \\
\hline Reação & $\begin{array}{l}\text { Formulário padrão realizado para todos } \\
\text { os programas em que é avaliada a } \\
\text { relevância do programa. } \\
\text { Aspectos avaliados: instrutor, conteúdo, } \\
\text { metodologia e infraestrutura (ambiente, } \\
\text { equipamentos e materiais). }\end{array}$ & $\begin{array}{l}\text { Nível de avaliação mais realizado } \\
\text { pelas MEPT. } \\
\text { Aspectos avaliados: instrutor, } \\
\text { conteúdo, metodologia e infraestrutura }\end{array}$ \\
\hline Aprendizagem & $\begin{array}{l}\text { Não há padronização sobre os critérios } \\
\text { para realização deste nível de avaliação, } \\
\text { entretanto, busca-se realizar pré e pós- } \\
\text { teste. }\end{array}$ & $\begin{array}{l}\text { Aplicadas quando há necessidade de } \\
\text { certificação e em cursos técnicos. } \\
\text { Pode ser realizada três meses após o } \\
\text { término do programa e uma fonte } \\
\text { relata realizar pré e pós-teste. }\end{array}$ \\
\hline Aplicação & $\begin{array}{l}\text { Realizado por meio de questionário para } \\
\text { colher as percepções do participante e do } \\
\text { gestor sobre a aplicação do aprendizado } \\
\text { ao trabalho. } \\
\text { Aplicada três meses após a realização do } \\
\text { programa. }\end{array}$ & $\begin{array}{l}\text { Colhe-se mais a percepção do gestor e } \\
\text { poucas consideram a percepção do } \\
\text { participante. } \\
\text { Aplicada, em média, três meses após o } \\
\text { término do programa. } \\
\text { São utilizados indicadores tais como } \\
\text { resultados da avaliação de } \\
\text { desempenho e indicadores de } \\
\text { produtividade. }\end{array}$ \\
\hline Processos & Não realizado. & $\begin{array}{l}\text { Utilização de três categorias de } \\
\text { indicadores: operacionais, qualidade e } \\
\text { gestão de pessoas. }\end{array}$ \\
\hline Cultura & Não realizado. & Não identificado. \\
\hline Objetivos & $\begin{array}{l}\text { Apurações pontuais de ROI de programas } \\
\text { foram realizadas no passado e está em } \\
\text { desenvolvimento a avaliação do retorno } \\
\text { de alguns projetos. } \\
\text { A satisfação do cliente interno avalia a } \\
\text { atuação da EC sobre o alcance dos } \\
\text { objetivos das áreas de negócio. } \\
\text { Indicadores do BSC da Área Pessoas. }\end{array}$ & $\begin{array}{l}\text { Alcance dos objetivos traçados no } \\
\text { planejamento estratégico, por meio de: } \\
\text { - definição de metas e identificação } \\
\text { das competências organizacionais e } \\
\text { humanas necessárias para alcançá-las; } \\
\text { - percepção dos gestores sobre o } \\
\text { impacto da EC nos indicadores do } \\
\text { planejamento estratégico. }\end{array}$ \\
\hline
\end{tabular}

A avaliação de eficiência da EC perpassa a escolha dos meios mais eficientes pelos quais o currículo possa ser ensinado (ALLEN e MCGEE, 2004). Assim, a apuração dos custos diretos e indiretos relaciona-se diretamente a este quesito. Os custos diretos são monitorados nos dois casos, entretanto, os custos indiretos não são controlados de forma sistemática. Apenas a 
remuneração da equipe de EC e investimentos em estrutura foram apontados como custos indiretos apurados por algumas organizações pertencentes às MEPT.

A eficiência na utilização dos recursos é medida no Itaú Unibanco por meio do índice de eficiência em custos, da taxa de adesão, da taxa de ocupação do programa e da taxa de ocupação de logística. O retorno financeiro gerado pela ação também foi apontado como medida de eficiência. O indicador de eficiência, custo por participante/hora, mencionado por Fitz-Enz (1995) como medida de comparação entre os programas, não foi identificado em nenhuma das organizações estudadas.

Por fim, a avaliação dos procedimentos instrucionais acontece por meio da validação da turma piloto, apuração das medidas de efetividade do programa e condução de reuniões multidisciplinares.

Quadro 12 - Análise comparativa entre MEPT e Itaú Unibanco: medidas de eficiência

\begin{tabular}{|l|l|l|}
\hline \multicolumn{1}{|c|}{ Fatores Analisados } & \multicolumn{1}{|c|}{ Itaú Unibanco } & \multicolumn{2}{|c|}{ MEPT } \\
\hline Avaliação de Resultados em Educação Corporativa & \multicolumn{2}{|c|}{} \\
\hline Medidas de Eficiência & $\begin{array}{l}\text { Custos diretos apurados e controlados de } \\
\text { forma centralizada. } \\
\text { Custos indiretos não apurados. }\end{array}$ & $\begin{array}{l}\text { São apurados os custos diretos e os } \\
\text { indiretos relativos à remuneração da } \\
\text { equipe da EC e estrutura. }\end{array}$ \\
\hline Custos & $\begin{array}{l}\text { Indicadores como índice de eficiência, } \\
\text { taxa de adesão, taxa de ocupação do } \\
\text { programa e de logística. }\end{array}$ & $\begin{array}{l}\text { O retorno financeiro gerado pelas } \\
\text { ações de educação corporativa. }\end{array}$ \\
\hline $\begin{array}{l}\text { Avaliação de } \\
\text { procedimentos na utilizaçãos } \\
\text { instrucionais }\end{array}$ & $\begin{array}{l}\text { Validação da turma piloto e verificação } \\
\text { dos resultados das medidas de efetividade } \\
\text { do programa. }\end{array}$ & $\begin{array}{l}\text { Reuniões multidisciplinares para } \\
\text { avaliação do sistema gerencial, } \\
\text { incluindo as ações de educação. }\end{array}$ \\
\hline
\end{tabular}




\subsection{Proposição de modelo teórico: avaliação de resultados em educação corporativa}

A partir da análise empreendida nesta dissertação, depreende-se um modelo de avaliação de resultados de educação corporativa. Ao descrevê-lo, não se tem como objetivo transformá-lo em uma modelo normativo, aplicável a qualquer organização, pois este modelo sofre influência de fatores que permeiam seu funcionamento e que serão descritos na sequência. Entretanto, como ressalta Martins e Theophilo (2009), as avaliações qualitativas são mais aplicáveis quando se deseja construir teorias, por isso, a proposição do modelo.

As variáveis levantadas na revisão de literatura foram confirmadas por meio das evidências encontradas nos estudos realizados, com exceção da categoria cultura. Esse fato reflete o descompasso entre teoria e prática. Apesar de a disseminação da cultura ser uma das principais características das EC, não há avaliação nesse sentido. Por sua relevância, esse aspecto será inserido no modelo para que seja investigado em estudos futuros. A avaliação de resultados de educação corporativa caracteriza-se pela análise de duas perspectivas: efetividade e eficiência (Ilustração 13).

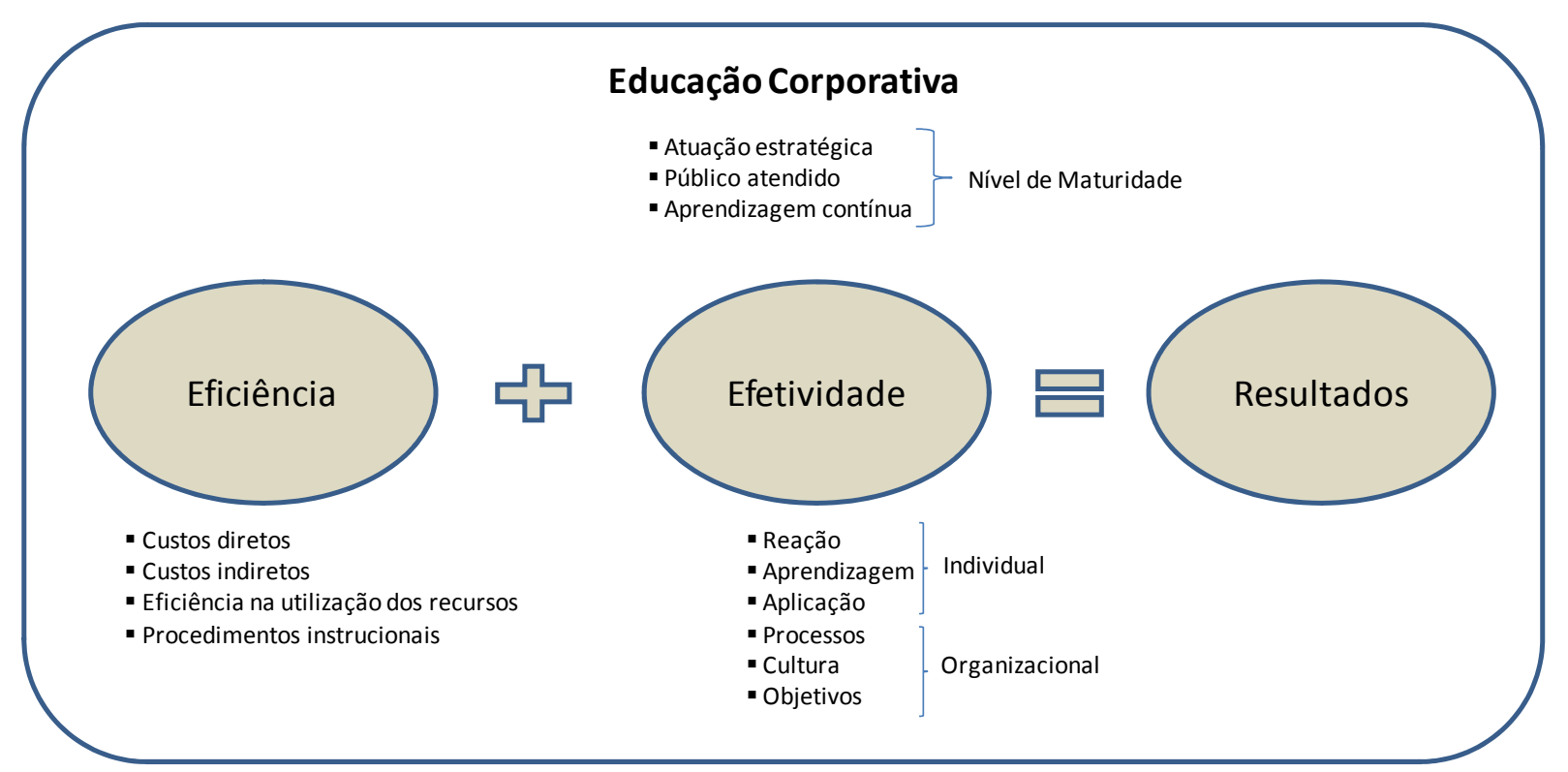

Ilustração 13 - Proposta de modelo teórico: avaliação de resultados em educação corporativa Fonte: Adaptado de Allen e McGee (2004).

A perspectiva eficiência avalia aspectos relacionados aos recursos empregados na realização das ações educacionais, desse modo, são monitorados os custos diretos, os custos indiretos, a eficiência na utilização dos recursos e os procedimentos instrucionais. Esse critério envolve a 
escolha dos meios mais eficientes pelos quais o currículo possa ser ensinado (ALLEN e MCGEE, 2004).

Por conseguinte, a perspectiva efetividade avalia a qualidade dos programas de educação corporativa, medida em termos do quão bem os participantes conseguem alcançar os resultados esperados (ALLEN e MCGEE, 2004). Essa perspectiva envolve avaliar os efeitos da ação educacional no indivíduo e na organização. Os efeitos no indivíduo são identificados por meio das avaliações de reação, aprendizagem e aplicação. Já os efeitos gerados na organização são avaliados por meio dos impactos gerados em seus processos, em sua cultura e da contribuição da ação para o alcance dos objetivos do negócio.

Ambas as perspectivas, quando tomadas em conjunto, geram os resultados da EC na organização. Entretanto, é válido destacar que o nível de maturidade da educação corporativa pode afetar o modelo de avaliação de resultados, pois sua adoção será facilitada quanto mais maduro for o sistema de educação corporativa da organização. O nível de maturidade pode ser identificado por meio das seguintes características: atuação estratégica, público atendido e promoção da aprendizagem contínua.

Esse modelo proposto, tomando suas limitações, traz contribuições para a prática das organizações e para o avanço da teoria sobre o tema. Ele não pretende ser exaustivo, mas trazer características que se confirmaram nos estudos realizados nesta dissertação. Cabe, a partir dessa proposição inicial, a condução de estudos posteriores que busquem testar as teorias aqui propostas. 


\section{CONSIDERAÇÕES FINAIS}

As organizações vêm passando por constantes transformações em um curto período de tempo e, para auxiliá-las a lidar com essas constantes mudanças, a gestão de pessoas está se reinventado. O Treinamento \& Desenvolvimento não está fornecendo o suporte necessário ao desenvolvimento das organizações e a Educação Corporativa surge, então, para suprir essa lacuna.

A Educação Corporativa tem o intuito de alinhar a aprendizagem organizacional aos objetivos do negócio, por meio do desenvolvimento das competências organizacionais necessárias para o alcance das estratégias. Assim, avaliar a contribuição da Educação Corporativa para os resultados do negócio torna-se uma demanda da organização e do próprio Sistema de Educação Corporativa. Desse modo, a avaliação de resultados em educação corporativa tornase um tema constante e esforços têm sido empreendidos pelas organizações nesse sentido.

Apesar de sua relevância, a avaliação de resultados em educação corporativa é um tema pouco desenvolvido em termos teóricos e pouco aplicado pelas organizações. Isso se deve, em grande parte, às barreiras a sua implementação. Como visto no estudo de caso Itaú Unibanco, o principal desafio é criar uma cultura de avaliação dentro da área. A mudança de atitude passa pela disciplina em avaliar as ações de EC, realizando-a desde as etapas iniciais de desenvolvimento de um programa, como o diagnóstico. Esse é o principal ponto destacado por Phillips (1991), autor reconhecido mundialmente pelo cálculo do retorno sobre o investimento em treinamento, o qual destaca que é simples medir, a dificuldade reside justamente nos mitos criados em torno da avaliação.

A partir desse contexto é que se insere este estudo que buscou investigar como as organizações que se destacam em gestão de pessoas avaliam os resultados em educação corporativa. Já que são poucas as organizações que a realizam, buscou-se identificar o que vem sendo feito, em termos de avaliação de resultados em educação corporativa, pelas organizações reconhecidas como avançadas em gestão de pessoas e tentou-se identificar os fatores contextuais que interferem nesse processo. 
Este estudo conseguiu responder à pergunta de pesquisa, pois descreveu as práticas e políticas de avaliação de resultados em educação corporativa realizadas pelas organizações estudadas e identificou alguns fatores que podem interferir nesse processo.

O referencial teórico forneceu as variáveis que foram investigadas neste estudo. A Educação Corporativa caracteriza-se por ter sua atuação norteada pelos objetivos organizacionais, assim, sua atuação deve ser estratégica, suas ações passam a contemplar os stakeholders que também impactam os resultados do negócio e a aprendizagem deve ser contínua. Para avaliar se as ações de Educação Corporativa estão, de fato, auxiliando a organização a atingir seus objetivos, um sistema de avaliação se faz necessário. Essa avaliação, conforme a literatura, contempla duas perspectivas: a efetividade e a eficiência da EC. A efetividade trata da qualidade das ações, ou seja, avalia o quão os participantes atingiram os objetivos a que o programa se propôs. Já a efetividade avalia os meios empreendidos para a promoção da aprendizagem. Assim, as práticas e políticas investigadas basearam-se nessas duas perspectivas.

Para responder à pergunta de pesquisa, foram estabelecidos quatro objetivos específicos. O primeiro foi descrever o sistema de educação corporativa empregado pelas MEPT e suas práticas de avaliação de resultados. Observou-se que poucas organizações realizam avaliação em EC (apenas 45, das 144 analisadas apresentam algum nível de avaliação de efetividade). A partir da análise das 45 organizações, foi possível identificar dados empíricos sobre as práticas levantadas na revisão de literatura, exceto a prática de avaliação da contribuição da EC para a disseminação da cultura organizacional. É interessante notar que, dessas 45 organizações, apenas uma apresenta cinco níveis de avaliação das medidas de efetividade e, além disso, também é uma das três organizações que mais apresentam os aspectos que caracterizam a Educação Corporativa. Esse achado fornece indícios de que pode haver relação entre a maturidade de um Sistema de Educação Corporativa e a adoção da avaliação de resultados em EC.

Para maior aprofundamento, foi conduzido um estudo de caso sobre o tema desta dissertação. Desse modo, os próximos três objetivos específicos referem-se a aspectos investigados no estudo de caso único. 
O segundo objetivo específico contemplou descrever a organização alvo do estudo de caso e seu sistema de educação corporativa. Esse objetivo foi alcançado, pois a organização foi caracterizada, neste estudo, por meio do levantamento de seu histórico com o apontamento de fatos relevantes; identificação de sua visão, missão e planejamento estratégico; e levantamento de número de funcionários, estrutura organizacional e locais de atuação. É importante destacar que um fato importante foi descrito em maior profundidade, a fusão, dada a sua relevância para entender a organização estudada. O sistema de educação corporativa, chamado de Escola Itaú Unibanco de Negócios, também foi descrito nesta dissertação e observou-se a adoção de práticas nos seguintes aspectos: alinhamento da EC aos objetivos organizacionais; alinhamento da EC à GP; público atendido; e aprendizagem contínua. Apenas na variável “objetivos da EC” não foram observados indícios formais no caso estudado, entretanto, capturando as percepções dos entrevistados sobre qual é o objetivo da Escola Itaú Unibanco de Negócios, a maioria afirmou que é desenvolver pessoas de forma a atender aos objetivos do negócio. É importante destacar que essa organização é direcionada para o alcance de resultados, possivelmente devido a seu setor de atuação, por isso, verifica-se que há uma demanda muito forte da organização e da própria área por demonstrar sua contribuição para o alcance dos resultados do negócio.

O terceiro objetivo foi levantar as práticas e os procedimentos de avaliação de resultados em EC no caso estudado. Foi observado que a organização apresenta práticas em todos os aspectos relacionados às medidas de eficiência, assim, realiza a apuração dos custos (somente diretos), monitora indicadores de eficiência na utilização de recursos e apresenta processos para avaliar os procedimentos instrucionais. Já em relação às medidas de efetividade da EC, foram observadas evidências de práticas nos seguintes níveis de avaliação: reação, aprendizagem, aplicação e objetivos. Para os níveis de avaliação de "processos” e "cultura”, não foram identificadas evidências. Entretanto, nas MEPT foram detectadas evidências de apuração de indicadores para avaliar o nível "processos”, esses indicadores foram classificados como: operacionais, qualidade e gestão de pessoas. Desse modo, verifica-se que, em ambos os casos - Itaú Unibanco e MEPT -, não foram identificadas práticas para avaliar o impacto da EC na disseminação da cultura da organização. Esperava-se que houvesse alguma avaliação neste nível - cultura - no Itaú Unibanco, visto que a cultura organizacional foi apontada como um dos fatos de relevante impacto na organização e na gestão de pessoas. Esse é um aspecto a ser investigado em futuras pesquisas, pois é um dos principais papéis da Educação Corporativa. 
Por fim, o quarto e último objetivo específico contemplou analisar as limitações, vantagens e tendências de avaliação de resultados em EC na organização investigada. Este objetivo também foi alcançado, pois os entrevistados apontaram diversos aspectos que influenciam a adoção de um modelo de avaliação de resultados em educação corporativa. Como vantagens do modelo adotado, foram citados o fornecimento de subsídios para gestão dos programas, o estabelecimento de parceria com áreas internas, a simplicidade do modelo e a identificação da contribuição da EC para a organização. Por outro lado, foram apontadas como limitações do modelo a necessidade de tecnologia para seu funcionamento; a falta de amadurecimento; a demora na apuração dos resultados; e a complexidade do modelo. Verifica-se que entre os entrevistados há divergência de percepção sobre o modelo no que tange a sua complexidade/simplicidade. Foram mencionados, ainda, os desafios enfrentados pela área para implantação da avaliação, são eles: a criação de cultura de avaliação; a ausência de relação de causa e efeito; a necessidade de criar disciplina na realização da avaliação; e a conscientização da área cliente. Por fim, como tendências, os entrevistados relataram que a EC será cada vez mais cobrada a demonstrar sua efetividade; haverá diversidade de métodos de avaliação; e o modelo do futuro fornecerá consistência e segurança sobre seus resultados.

Além do alcance dos objetivos deste estudo, cabe destacar algumas observações realizadas a partir das análises.

A avaliação de aprendizagem, como visto no estudo das MEPT, tem sido realizada nos moldes tradicionais, ou seja, para aferir conhecimentos e prover certificados. É importante uma mudança de visão em relação a este nível de avaliação, estudando formas que contemplem também os programas comportamentais e que, antes de tudo, seja uma oportunidade de aprendizado complementar ao programa, que proporcione experiência para o participante, e não um mero instrumento para gerar um indicador. O uso de simuladores, casos de ensino e outras ferramentas que proporcionem vivências, impactaria inclusive os próprios resultados deste nível de avaliação.

A avaliação de aplicação realizada por algumas organizações constantes no ranking das MEPT considera indicadores de produtividade da área do participante como resultados para este nível. Este é um aspecto conflituoso, pois, como se trata de um nível de transferência do aprendizado do indivíduo para a organização, caberia a utilização desses indicadores; 
entretanto, eles se confundem com os indicadores muitas vezes monitorados no próximo nível, que avalia os efeitos do programa na organização. É preciso retomar os conceitos de Kirkpatrick (1994), Kirkpatrick e Kirkpatrick (2010) e de Hamblin (1978), ambos os autores mencionam que a avaliação a este nível procura identificar se a mudança de comportamento gerou transferência da aprendizagem ao contexto de trabalho do participante. Tomando este conceito, parece ser mais adequado avaliar ainda no âmbito individual, ou seja, colhendo as percepções do próprio participante e de seu gestor. Indicadores da área já estariam mais relacionados aos impactos do evento na organização e, desse modo, seriam alocados no próximo nível de avaliação - processos. Já indicadores de desempenho e produtividade do indivíduo, colhidos antes e depois da ação, poderiam ser utilizados na avaliação de aplicação.

Outro ponto importante a destacar é que a avaliação de aplicação deve colher a percepção não só do gestor, mas também do participante, como relatado no caso Itaú Unibanco. Isso porque, segundo Kirkpatrick (1994) e Kirkpatrick e Kirkpatrick (2010), neste nível o ambiente exerce forte influência na transferência do aprendizado ao trabalho, pois o participante deve encontrar condições para aplicar o que aprendeu em seu trabalho, incluindo o apoio fornecido pelo gestor. Ao tomar-se apenas a visão do gestor, os impedimentos decorrentes do ambiente podem não ser relatados em sua totalidade.

A avaliação do impacto gerado pelos eventos na disseminação da cultura ainda não é foco das organizações. Nenhuma organização pertencente ao ranking MEPT mencionou empreender avaliação neste nível, assim como, o Itaú Unibanco. Desse modo, como a cultura é um aspecto que foi intensamente relatado pelos entrevistados, que enfatizaram a importância deste tema para a organização, foi uma surpresa constatar que não há avaliação neste nível.

A avaliação do impacto das ações educacionais no alcance dos objetivos do negócio deve ser realizada para programas que tenham relação com esses objetivos, pois foi constatado, no caso Itaú Unibanco, que há dificuldades em encontrar-se relação entre os resultados de programas do dia a dia para o alcance dos objetivos do negócio. O sistema de avaliação não necessita avaliar todos os programas em todos os níveis, a avaliação deve ser empreendida quando for relevante e factível (FITZ-ENZ, 1995). Assim, o planejamento do sistema de avaliação, estabelecendo parâmetros para avaliação de programas, tais como os critérios de elegibilidade dos programas, torna-se tão relevante. 
Um aspecto importante a considerar no desenvolvimento de um sistema de avaliação de resultados em educação corporativa é contar com a parceria de áreas internas que têm conhecimentos específicos em determinado aspecto ou nível de avaliação. No caso Itaú Unibanco, a EC realiza parceria com as áreas de marketing e riscos. A área de marketing colaborou na realização da avaliação de aplicação, pois auxiliou a Escola a estipular os critérios para dimensionamento da amostra e apresentou ferramentas para condução da pesquisa. A área de riscos auxiliará a Escola no cálculo do ROI, pois é uma área que já realiza a avaliação de viabilidade econômica de projetos sociais na organização. Assim, contar com a experiência e conhecimentos de áreas especialistas traz mais credibilidade ao modelo e ainda colabora para a comunicação das ações de avaliação empreendidas pela área.

Finalmente, este estudo confirma as variáveis teóricas encontradas na revisão de literatura, com exceção da avaliação do impacto da Educação Corporativa na disseminação da cultura. Portanto, o modelo de avaliação proposto nesta pesquisa contempla as perspectivas eficiência e efetividade, apresentando, inclusive, o nível de avaliação “cultura” como ponto de atenção para pesquisas futuras. A perspectiva eficiência trata de avaliar os custos diretos, os custos indiretos, a eficiência na utilização dos recursos e os procedimentos instrucionais. Por outro lado, a perspectiva efetividade avalia a reação, a aprendizagem e a aplicação promovida pelo programa na esfera individual e os processos e objetivos na esfera organizacional.

As limitações desta pesquisa referem-se à interferência da subjetividade da pesquisadora e aos métodos empregados. O estudo de caso realizado nesta dissertação não poderá ter seus resultados extrapolados para outras organizações, entretanto, o aprofundamento proporcionado pela metodologia fornece uma visão ampla e profunda sobre as variáveis estudadas, fornecendo insumos para a generalização teórica. Já a análise de conteúdo tem como principais limitações a possível falta de neutralidade da investigadora e a falta ou fraca análise contextual. A interferência da subjetividade da investigadora foi minimizada pela revisão bibliográfica empreendida neste estudo, que fundamentou as variáveis aqui descritas, e pela descrição detalhada da operacionalização da pesquisa. A falta de análise contextual também foi mitigada, pois investigou-se o sistema de educação corporativa, no qual se insere a avaliação de resultados.

Como recomendações para estudos futuros, será muito relevante a replicação desta pesquisa em outros casos para que se possam confrontar esses resultados aos encontrados em outras 
organizações. Isto é o que daria maior legitimidade aos achados e à generalização da teoria comentada por Martins e Theophilo (2009). Para realizar a replicação, outra recomendação é estudar algumas das organizações pertencentes às MEPT, edição 2011, que apresentam quatro ou cinco níveis de avaliação implantados, pois há indícios de riqueza de dados nessas organizações. Por fim, a condução de estudos quantitativos que busquem testar as variáveis expostas no modelo teórico é outra recomendação. 


\section{REFERÊNCIAS}

ABTD - Associação Brasileira de Treinamento e Desenvolvimento. O retrato do treinamento no Brasil. Pesquisa Anual ABTD/MOT, 2010.

ABTD - Associação Brasileira de Treinamento e Desenvolvimento. O retrato do treinamento no Brasil 2008/2009. Pesquisa Anual ABTD/MOT, 2008.

ALLEN, M. What is a corporate university, and why should an organization have one? In.: ALLEN, M. (Org.) The corporate university handbook. New York: AMACOM, 2002 apud VARGAS, M. R. M.; ABBAD, G. S. Bases conceituais em treinamento, desenvolvimento e educação - TD\&E. In.: BORGES-ANDRADE, J. E.; ABBAD, G. S.; MOURÃO, L. et. al. Treinamento, desenvolvimento e educação em organizações e trabalho: fundamentos para a gestão de pessoas. Porto Alegre: Artmed, 2006.

ALLEN, M.; MCGEE, P. Measurement and evaluation in corporate universities. New Directions for Institutional Research, no. 124, p. 81-92, Winter 2004.

ALPERSTEDT, C. Universidades corporativas: discussão e proposta de uma definição. Revista de Administração Contemporânea (RAC), v. 5, n. 3, p. 149-166, Set./Dez. 2001.

ALVES, Gilmar Luiz Frotté. Universidade corporativa, alinhamento estratégico de administração de recursos humanos e desenvolvimento profissional dos trabalhadores. Rio de Janeiro, 2007. Dissertação (Mestrado em Administração e Desenvolvimento Empresarial) - Universidade Estácio de Sá.

ANDRADE, Ronnie Joshé Figueiredo de. O processo de análise do retorno sobre investimento em treinamento: um estudo de caso. [Niterói], 2008. Resumo da Dissertação (Mestrado) - Universidade Federal Fluminense. Banco de Teses CAPES 18-09-2011.

BARDIN, Laurence. Análise de conteúdo. Tradução Luís Antero Reto e Augusto Pinheiro. Lisboa: Edições 70, 2009. (Obra original publicada em 1977). 
BARDIN, Laurence. Análise de conteúdo. Tradução Luís Antero Reto e Augusto Pinheiro. São Paulo: Edições 70, 2011.

BARTLETT, Christopher A.; MCLEAN, Andrew N. GE's talent machine: the making of a CEO. Harvard Business School Case 304-049, November 2006. (Revised from original October 2003 version.)

BARRETO, Leilianne Michelle Trindade da Silva. Gestão de pessoas: projetando desafios e tendências para 2015. In: Encontro de Estudos Organizacionais da ANPAD, 6, 2010, Florianópolis, Anais... Florianópolis: ANPAD, 2010, CD-ROM.

BASTOS, A. V. B. O suporte oferecido pela pesquisa na área de treinamento. Revista de Administração (RAUSP), São Paulo, v. 26, n. 4, p. 87-102, out./dez. 1991 apud PILATI, R. História e importância de TD\&E. In.: BORGES-ANDRADE, J. E.; ABBAD, G. S.; MOURÃO, L. et. al. Treinamento, desenvolvimento e educação em organizações e trabalho: fundamentos para a gestão de pessoas. Porto Alegre: Artmed, 2006.

BECKER, B.; HUSELID, M. High performance work systems and firm performance: a synthesis of research and managerial implications. In: FERRIS, G. (Ed.). Research in personnel and human resources management. New York: Jai Press, v.16, 1998.

BECKER, Brian. E.; HUSELID, Mark A.; ULRICH, Dave. The HR scorecard: linking people, strategy, and performance. Boston: Harvard Business School Press, 2001.

BECKER, G. Investment in human capital: a theoretical analysis. Journal of Political Economy. 70, 9-49, 1962 apud MORIN, Lucie; RENAUD, Stéphane. Participation in corporate university training: its effect on individual job performance. Canadian Journal of Administrative Sciences. 21(4), p. 295-306, 2004.

BEZERRA, Marlene Jesus Soares. Educação corporativa: uma metodologia para avaliar a aderência entre o profissional desejado e o obtido. O caso da engenharia em uma empresa de mineração. [Niterói], 2009. Resumo da Tese (Doutorado) - Universidade Federal Fluminense. Banco de Teses CAPES 18-09-2011. 
BOGDAN, Robert C.; BIRTEN, S. K. Qualitative research for education: an introduction for to theory and methods. Boston: Allyn and Bacon, 1982 apud TRIVIÑOS, Augusto N. S. Introdução à pesquisa em ciências sociais: a pesquisa qualitativa em educação. $1^{\mathrm{a}}$ ed. São Paulo: Atlas, 2008.

BORGES-ANDRADE, J. E. Avaliação somativa de sistemas instrucionais: integração de três propostas. Tecnologia Educacional, Rio de Janeiro, v. 11, n. 46, p. 29-39, 1982.

BORGES-ANDRADE, J. E. Avaliação integrada e somativa em TD\&E. In.: BORGESANDRADE, J. E.; ABBAD, G. S.; MOURÃO, L. et. al. Treinamento, desenvolvimento e educação em organizações e trabalho: fundamentos para a gestão de pessoas. Porto Alegre: Artmed, 2006.

BORSATTO, Paulo César. Avaliação da aprendizagem em educação online na universidade corporativa. Rio de Janeiro, 2007. Dissertação (Mestrado em Educação) - Faculdade de Educação da Universidade Estácio de Sá.

BRANDÃO, H. P.; GUIMARÃES, T. A. Gestão de competências e gestão de desempenho: tecnologias distintas ou instrumentos de um mesmo constructo? Revista de Administração de Empresas (RAE), v. 41, n. 1, p. 8-15, jan./mar. 2001 apud HIPÓLITO, J. A. M.; REIS, G. G. A avaliação como instrumento de gestão. In.: FLEURY, M. T. L. As pessoas na organização. São Paulo: Editora Gente, 2002.

CARVALHO, Luciana. Parceria com universidades é solução do ‘apagão de talentos'. Disponível em: <http://exame.abril.com.br> Acessado em: 01/08/2011

EBOLI, M. P. Um novo olhar sobre a educação corporativa - desenvolvimento de talentos no século XXI. In: DUTRA, J. S. (Org.). Gestão por Competências: um modelo avançado para o gerenciamento de pessoas. São Paulo: Gente, 2001.

. O desenvolvimento das pessoas e a educação corporativa. In.: FLEURY, M. T. L. (Coord.). As pessoas na organização. 8a ed. São Paulo: Gente, 2002. 
. Educação corporativa no Brasil: mitos e verdades. São Paulo: Gente, 2004.

. Fundamentos e evolução da educação corporativa. In.: Marisa EBOLI; FISCHER, A. L.; MORAES, F. C. C.; AMORIM, W. A. C. (Org.). Educação corporativa: fundamentos, evolução e implantação de projetos. São Paulo: Atlas, 2010.

FISCHER, André Luiz; ALBUQUERQUE, Lindolfo Galvão. Trends of the human resources management model in Brazilian companies: a forecast according to opinion leaders from the area. The Internacional Journal of Human Resource Management, 16:7, 1222-1227, July 2005.

FISCHER, André Luiz; ALBUQUERQUE, Lindolfo Galvão. Delphi RH 2010: edição confirmatória - tendências em gestão de pessoas nas empresas brasileiras. São Paulo: Fundação Instituto de Administração, Programa de Estudos em Gestão de Pessoas (PROGEP) 2011.

FITZ-ENZ, J. How to measure human resources managment. $2^{\text {nd }}$ ed. [New York]: McGrawHill, 1995.

FREITAS, H. M. R.; CUNHA, M. V. M. Jr.; e MOSCAROLA, J. Aplicação de sistemas de software para auxílio na análise de conteúdo. Revista de Administração da USP, 32(3), 97109, 1997 apud MOZZATO, Anelise Rebelato; GRZYBOVSKI, Denise. Análise de conteúdo como técnica de análise de dados qualitativos no campo da administração: potencial e desafios. Revista de Administração Contemporânea (RAC). v. 15, n. 4, pp. 731-747, Jul./Ago. 2011.

GALLAGHER, M. Corporate universities, higher education and the future: emerging policy issues. Corporate University Week. Sydney, 2000 apud MORIN, Lucie; RENAUD, Stéphane. Participation in corporate university training: its effect on individual job performance. Canadian Journal of Administrative Sciences. 21(4), p. 295-306, 2004.

GIARDINO, A. Ainda é difícil para o RH mudar seu perfil nas empresas. Disponível em: $<$ http://www.valoronline.com.br> Acesso em: 31 jan. 2007. 
GRIX, Jonathan. Introducing students to the generic terminology of social research, Politics, Washington, v.23, n.3, p.175-186, July/ Sept. 2002 apud MAFFEZZOLLI, Eliane Cristine F.; BOEHS, Carlos Gabriel Eggerts. Uma reflexão sobre o estudo de caso como método de pesquisa. Revista da FAE, Curitiba, v.11, n.1, p.95-110, jan./jun. 2008.

HAMBLIN, A. C. Avaliação e controle de treinamento. Tradução de Gert Meyer. São Paulo: McGraw-Hill do Brasil, 1978.

HASHIMOTO, Marcos; ANDREASSI, Tales; ARTES, Rinaldo; NAKATA, Lina Eiko. Relações entre intraempreendedorismo, clima organizacional e desempenho financeiro - um estudo sobre as melhores empresas para se trabalhar no Brasil. In: ENCONTRO DA ANPAD - ENANPAD, 34., 2010, Rio de Janeiro. Anais... Rio de Janeiro: ANPAD, 2010.

HOURNEAUX JÚNIOR, F. Avaliação dos resultados. In.: Marisa EBOLI; FISCHER, A. L.; MORAES, F. C. C.; AMORIM, W. A. C. (Org.). Educação corporativa: fundamentos, evolução e implantação de projetos. São Paulo: Atlas, 2010.

HUSELID, M. The impact of human resource management practices on turnover, productivity and corporate financial performance. The Academy of Management Journal, New York, v.38, n.3, p.635-672, June 1995.

ITAÚ UNIBANCO. Relatório anual de sustentabilidade 2011. São Paulo, 2011a. Disponível em: $\quad<$ http://www.itauunibanco.com.br/relatoriodesustentabilidade/pt-br/index.html>. Acessado em: 02/07/2012.

Análise gerencial da operação, desempenho das ações e dos ADRs e demonstrações contábeis 2011. São Paulo, 2011b. Disponível em: $<$ http://ww13.itau.com.br/PortalRI/HTML/port/download/demon/dfs_itauunibanco2011.pdf> . Acessado em: 02/07/2012.

Escola Itaú Unibanco de Negócios. São Paulo, out. 2011c.

Conheça o Itaú. Disponível em: <http://www.itau.com.br/bem_vindo/index.htm>. Acessado em: 27/07/2012 (a). 
Pirâmide de conhecimentos (documento). São Paulo, 2012b.

. Trilhas de conhecimento específico (documento). São Paulo, 2012c.

Avaliação de reação presencial: modelo de avaliação de reação múltipla

(documento). São Paulo, 2012d.

Avaliação de Reação: NOVA_EAD (documento). São Paulo, 2012e.

KERBER, Nalú Pereira da Costa. A atenção domiciliária e direito à saúde: análise de uma experiência na rede pública de saúde no Brasil, Florianópolis (SC), 2007. Tese (Doutorado) Programa de Pós-Graduação em Enfermagem da Universidade Federal de Santa Catarina,

KIRKPATRICK, D. L. Evaluating training programs: the four levels. San Francisco: BerrettKoehler Publichsers, 1994.

KIRKPATRICK, D. L.; KIRKPATRICK, J. D. Como avaliar programas de treinamento de equipes: os quatro níveis. Tradução José Henrique Lamensdorf; revisão técnica Klalter Fontana. Rio de Janeiro: Senac Rio, 2010.

LACOMBE, B. M. B.; ALBUQUERQUE, L. G. de. Avaliação e mensuração de resultados em gestão de pessoas: um estudo com as maiores empresas instaladas no Brasil. Revista de Administração da USP (RAUSP). São Paulo, v.43, n.1, p.5-16, jan./fev./mar. 2008.

LEE, Jieun. Design of blended training for transfer into the workplace. British Journal of Educational Technology. v. 11, n. 2, p. 181-198, 2010.

LEITE, N. P. et al. Treinamento, desenvolvimento e educação de pessoas: um desafio na estratégia organizacional. In.: ALBUQUERQUE, Lindolfo Galvão de; LEITE, Nildes Pitombo (Org.). Gestão de Pessoas: perspectivas estratégicas. São Paulo: Atlas, 2009. 
MAFFEZZOLLI, Eliane Cristine F.; BOEHS, Carlos Gabriel Eggerts. Uma reflexão sobre o estudo de caso como método de pesquisa. Revista FAE, Curitiba, v.11, n.1, p.95-110, jan./jun. 2008.

MALVEZZI, S. Do taylorismo ao comportamentalismo: 90 anos de desenvolvimento de recursos humanos. In.: BOOG, G. Manual de treinamento e desenvolvimento. São Paulo: Maddron Books, 1994 apud PILATI, R. História e importância de TD\&E. In.: BORGESANDRADE, J. E.; ABBAD, G. S.; MOURÃO, L. (Org.). Treinamento, desenvolvimento e educação em organizações e trabalho: fundamentos para a gestão de pessoas. Porto Alegre: Artmed, 2006.

MARINO, C. Treinar e aprender a contar. Revista Melhor Gestão de Pessoas. Disponível em: http://revistamelhor.uol.com.br/textos.asp?codigo=12351 Acessado em: 29 set. 2009.

MARTINS, G. A.; THEÓPHILO, C. R. Metodologia da investigação científica para ciências sociais aplicadas. São Paulo: Atlas, 2009.

MATHIAS, José Ricardo Loretti. Melhoria de processos-chaves a partir da medição de indicadores de desempenho através da capacitação em educação corporativa à distância: Um estudo de caso. [Niterói], 2009. Resumo da Dissertação (Mestrado Profissionalizante) Universidade Federal Fluminense. Banco de Teses CAPES 18-09-2011.

MAZZON, José A. Análise do programa de alimentação do trabalhador sob o conceito de marketing social. São Paulo, 1981. Tese (Doutorado) Faculdade de Economia, Administração e Contabilidade da Universidade de São Paulo, São Paulo apud TELLES, Renato. A efetividade da "matriz de amarração” de Mazzon nas pesquisas em administração. Revista de Administração. São Paulo, v.36, n.4, p.64-72, outubro/dezembro 2001.

MEISTER, Jeanne C. Educação Corporativa. Tradução Maria Cláudia Santos Ribeiro Ratto. São Paulo: Pearson Makron Books, 1999.

MORIN, Lucie; RENAUD, Stéphane. Participation in corporate university training: its effect on individual job performance. Canadian Journal of Administrative Sciences. 21(4), p. 295306, 2004. 
MOZZATO, Anelise Rebelato; GRZYBOVSKI, Denise. Análise de conteúdo como técnica de análise de dados qualitativos no campo da administração: potencial e desafios. Revista de Administração Contemporânea (RAC). v. 15, n. 4, pp. 731-747, Jul./Ago. 2011.

NADLER, Leonard. The handbook of human resource development. New York: Wiley, 1984 apud VARGAS, M. R. M.; ABBAD, G. S. Bases conceituais em treinamento, desenvolvimento e educação - TD\&E. In.: BORGES-ANDRADE, J. E.; ABBAD, G. S.; MOURÃO, L. (Org.). Treinamento, desenvolvimento e educação em organizações e trabalho: fundamentos para a gestão de pessoas. Porto Alegre: Artmed, 2006.

- Using critical events to develop training programmes. Industrial Training International, 6 (4), 1971 apud HAMBLIN, A. C. Avaliação e controle de treinamento. Tradução de Gert Meyer. São Paulo: McGraw-Hill do Brasil, 1978.

- Implications of the HRD concept: broadening the scope of traning and development. Training and Development Journal. v. 28 Issue 5, p. 3-13, May, 1974.

NAKATA, Lina Eiko. As expectativas de aprendizagem nas organizações que buscam se destacar pelo clima organizacional. São Paulo, 2009. Dissertação (Mestrado) - Programa de Pós-Graduação em Administração - Universidade de São Paulo.

NAKATA, Lina Eiko; VELOSO, Elza Fátima Rosa; FISCHER, André Luiz; DUTRA, Joel Souza. Uso de pesquisas de clima organizacional no Brasil. Gestão Contemporânea, Porto Alegre, ano 6, n. 6, p. 45-68, jan./dez. 2009.

NORTON, D.P.; KAPLAN, R.S. A estratégia em ação. 8.ed. Rio de Janeiro: Campus, 1997.

POLÍTICA DE USO DO BANCO DADOS DA PESQUISA AS MELHORES EMPRESAS PARA VOCÊ TRABALHAR - DADOS EDIÇÃO 2010. Programa de Estudos em Gestão de Pessoas (PROGEP) da Fundação Instituto de Administração (FIA), 2011.

OLIVEIRA, Agostina Mafalda Barra de; OLIVEIRA, Alexandre José de. Gestão de recursos humanos: uma metanálise de seus efeitos sobre desempenho organizacional. Revista de 
Administração Contemporânea (RAC), Curitiba, v. 15, n. 4, art. 5, pp. 650-669, Jul./Ago. 2011.

OLIVEIRA, Antonella Carvalho de. Impacto da educação corporativa no desempenho dos colaboradores da empresa Perdigão S/A - Unidade de Carambeí. Ponta Grossa, Paraná, 2007. Mestrado (Engenharia de Produção) - Programa de Pós-Graduação em Engenharia de Produção do Departamento de Pesquisa e Pós-Graduação, Campus Ponta Grossa da Universidade Tecnológica Federal do Paraná.

OLIVEIRA, M. A. Evolução do T\&D nas organizações do Brasil: lições do passado e tendências para o futuro. In.: Gustavo G. Boog; Magdalena T. Boog (Coord.). Manual de treinamento e desenvolvimento: gestão e estratégias. São Paulo: Pearson Prentice Hall, 2006.

PANCZUK, S. Les universities d'entreprise: outil stratégique pour les dirigeants? Actualité de la formacion permanent. 172, 65-70, 2001 apud MORIN, Lucie; RENAUD, Stéphane. Participation in corporate university training: its effect on individual job performance. Canadian Journal of Administrative Sciences. 21(4), p. 295-306, 2004.

PHILLIPS, J. J. Handbook of training evaluation and measurement methods. $2^{\text {nd }}$ ed. London: Kogan Page, 1991.

PILATI, R. História e importância de TD\&E. In.: BORGES-ANDRADE, J. E.; ABBAD, G. S.; MOURÃO, L. (Org.). Treinamento, desenvolvimento e educação em organizações e trabalho: fundamentos para a gestão de pessoas. Porto Alegre: Artmed, 2006.

RAMOS, Hellen Costa. Indicadores de desempenho em Universidades Corporativas. [Niterói], 2008. Resumo da Dissertação (Mestrado) - Universidade Federal Fluminense. Banco de Teses CAPES 18-09-2011.

RENAUD-COULON, A. Corporate Universities in Europe. In.: ALLEN, M. (Ed.). The corporate university handbook. New York: AMACOM, 2002 apud ALLEN, M.; MCGEE, P. Measurement and evaluation in corporate universities. New Directions for Institutional Research, no. 124, Winter 2004. 
RUGGIERO, Sérgio. Sistema de medição de desempenho para avaliação da gestão de universidades corporativas. [Piracicaba], 2007. Resumo da Tese (Doutorado) - Universidade Metodista de Piracicaba. Banco de Teses CAPES 18-09-2011.

SCHRÖEDER, Christine da Silva. Critérios e indicadores de desempenho para sistemas de treinamento corporativo virtual: um modelo para medir resultados. Porto Alegre, 2005. Dissertação (Mestrado em Administração) - Programa de Pós-graduação em Administração, Escola de Administração da Universidade Federal do Rio Grande do Sul.

SELLTIZ, Claire et al. Métodos de pesquisa nas relações sociais. $2^{\mathrm{a}}$ ed. São Paulo: EPU, 1987.

SEVERINO, Antônio Joaquim. Metodologia do trabalho científico. 23 ed. São Paulo: Cortez, 2007.

SILVA, Ricardo Castro Jesuíno da. Construção e validação de escala de medida de mudança organizacional causada pela implantação de uma universidade corporativa. Brasília, 2006. Dissertação (Mestrado em Gestão Social e Trabalho) - Programa de Pós-Graduação, Faculdade de Economia, Administração, Contabilidade e Ciência da Informação e Documentação da Universidade de Brasília.

TELLES, Renato. A efetividade da "matriz de amarração" de Mazzon nas pesquisas em administração. Revista de Administração. São Paulo, v.36, n.4, p.64-72, outubro/dezembro 2001.

TRIVIÑOS, Augusto N. S. Introdução à pesquisa em ciências sociais: a pesquisa qualitativa em educação. $1^{\text {a }}$ ed. São Paulo: Atlas, 2008.

TUMELERO, Cleonir; VELOSO, Elza Fátima Rosa; AMORIM, Wilson Aparecido Costa de; LUCAS, Angela Christina. Relação entre práticas de educação corporativa e resultados financeiros de empresas que atuam no mercado brasileiro. In: ENCONTRO DA ANPAD ENANPAD, 35., 2011, Rio de Janeiro. Anais... Rio de Janeiro: ANPAD, 2011. 
VARGAS, M. R. M.; ABBAD, G. S. Bases conceituais em treinamento, desenvolvimento e educação - TD\&E. In.: BORGES-ANDRADE, J. E.; ABBAD, G. S.; MOURÃO, L. (Org.). Treinamento, desenvolvimento e educação em organizações e trabalho: fundamentos para a gestão de pessoas. Porto Alegre: Artmed, 2006.

VARGAS, M. R. M. Educação à distância no contexto da mudança organizacional. In.: LIMA, S. M. V. (Org.). Mudança organizacional: teoria e gestão. Rio de Janeiro: FGV, 2003.

VERGARA, Sylvia Constant. Universidade corporativa: a parceria possível entre empresa e universidade tradicional. Revista de Administração Pública (RAP). Rio de Janeiro, v. 34, n. 5, 181-188, set./out. 2000.

— Sylvia Constant. Métodos de pesquisa em administração. $3^{\mathrm{a}}$ ed. São Paulo: Atlas, 2008.

YIN, Robert K. Estudo de caso: planejamento e métodos. Tradução Ana Thorell; revisão técnica Cláudio Damacena. 4 ed. Porto Alegre: Bookman, 2010.

ZERBINI, Thaís; ABBAD, Gardênia. Impacto de treinamento no trabalho via internet. Revista de Administração Eletrônica (RAE-eletrônica), São Paulo, v. 4, n. 2, Art. 16, jul./dez. 2005. 


\section{APÊNDICES}

APÊNDICE A: CONVITE PARA PARTICIPAÇÃO NA PESQUISA

APÊNDICE B: AUTORIZAÇÃO DE PESQUISA

APÊNDICE C: TERMO DE ESCLARECIMENTO E CONSENTIMENTO

APÊNDICE D: ROTEIRO DE ENTREVISTA COM GESTOR DA ÁREA GESTÃO DE PESSOAS

APÊNDICE E: ROTEIRO DE ENTREVISTA COM GESTOR DA ÁREA EDUCAÇÃO CORPORATIVA

APÊNDICE F: ROTEIRO DE ENTREVISTA COM GESTORES DE EDUCAÇÃO CORPORATIVA

APÊNDICE G: ROTEIRO DE ENTREVISTA COM GESTOR DO BALANCED SCORECARD

APÊNDICE H: ROTEIRO DE ENTREVISTA COM GESTOR DO SISTEMA DE INFORMAÇÕES GERENCIAIS 


\title{
APÊNDICE A - CONVITE PARA PARTICIPAÇÃO NA PESQUISA
}

\author{
UNIVERSIDADE DE SÃO PAULO \\ FACULDADE DE ECONOMIA, ADMINISTRAÇÃO E CONTABILIDADE \\ PROGRAMA DE PÓS-GRADUAÇÃO EM ADMINISTRAÇÃO
}

CONVITE PARA PARTICIPAÇÃO NA PESQUISA

Bom-dia,

Após quatro anos retomo o contato agora como pesquisadora! Não sei se lembrará de mim, mas trabalhei sob sua gestão na área Gestão de Riscos, ainda no Unibanco, e sai para atuar em Gestão de Pessoas. Ainda lembro a conversa que tivemos e de sua orientação me fazendo pensar se era a melhor escolha, eu tinha um plano B que agora está se realizando.

Hoje sou aluna de Mestrado do Programa de Pós-Graduação em Administração da Faculdade de Economia, Administração e Contabilidade da Universidade de São Paulo e o motivo do meu contato é o interesse em realizar minha pesquisa acadêmica no Itaú Unibanco, como requisito para o desenvolvimento de minha dissertação na linha de pesquisa Gestão de Pessoas, com o tema Gestão Estratégica de Pessoas, sob orientação do Professor Doutor Lindolfo Galvão de Albuquerque.

A pesquisa intitulada “Avaliação de Resultados em Educação Corporativa” tem por objetivo identificar, descrever e analisar as formas como as organizações avaliam os resultados em educação corporativa.

O Itaú Unibanco é uma das poucas organizações que desenvolve avaliações dessa natureza e será de extrema relevância para a minha pesquisa. Por isso, gostaria de pedir sua autorização para conduzir a pesquisa na empresa.

Estou à disposição para esclarecer dúvidas e apresentar o projeto de pesquisa em detalhes, com suas etapas e informações a serem coletadas.

Desde já agradeço sua atenção e aguardo um retorno!

Abraço e muito obrigada,

Carolina Aparecida de Freitas Dias

Mestranda em Administração

Programa de Pós-Graduação em Administração

Universidade de São Paulo 


\title{
APÊNDICE B - AUTORIZAÇÃO DE PESQUISA
}

\author{
UNIVERSIDADE DE SÃO PAULO \\ FACULDADE DE ECONOMIA, ADMINISTRAÇÃO E CONTABILIDADE \\ PROGRAMA DE PÓS-GRADUAÇÃO EM ADMINISTRAÇÃO
}

\section{AUTORIZAÇÃO PARA DESENVOLVIMENTO DE PESQUISA}

Prezados Senhores,

Sou Carolina Aparecida de Freitas Dias, aluna de Mestrado do Programa de Pós-Graduação em Administração da Faculdade de Economia, Administração e Contabilidade da Universidade de São Paulo. Tenho interesse em realizar minha pesquisa acadêmica nessa empresa, como requisito para o desenvolvimento de minha dissertação na linha de pesquisa Gestão de Pessoas, com o tema Gestão Estratégica de Pessoas, sob orientação do Professor Doutor Lindolfo Galvão de Albuquerque.

A pesquisa intitulada “Avaliação de Resultados em Educação Corporativa” tem por objetivo identificar, analisar e descrever as metodologias de avaliação de resultados em educação corporativa utilizadas pelas organizações que se destacam em desenvolvimento de pessoas.

Conforme estabelecido no Código de Ética da Pesquisa da FEA/USP, para que possamos realizar a pesquisa faz-se necessário que um responsável legal pela organização autorize formalmente, assinando o termo anexo, e autorizando os seguintes procedimentos:

a) utilização das informações sobre sua organização na pesquisa em questão; e

b) divulgação dos resultados dessa pesquisa.

Comprometo-me a enviar uma cópia da dissertação, bem como das publicações científicas oriundas da pesquisa.

Atenciosamente,

Carolina Aparecida de Freitas Dias

Mestranda em Administração

Programa de Pós-Graduação em Administração

Universidade de São Paulo 


\section{(Papel com o timbre da empresa)}

São Paulo, dia de mês de 2012.

À

Universidade de São Paulo

Faculdade de Economia, Administração e Contabilidade

Departamento de Administração

Programa de Pós-Graduação em Administração

\section{DECLARAÇÃO}

Declaro que autorizamos o uso das informações obtidas por Carolina Aparecida de Freitas Dias, aluna do Mestrado em Administração, junto a esta organização na pesquisa intitulada “Avaliação de Resultados em Educação Corporativa”, realizada sob a responsabilidade do Professor Dr. Lindolfo Galvão de Albuquerque da Faculdade de Economia, Administração e Contabilidade da Universidade de São Paulo, bem como a divulgação dos resultados da referida pesquisa em artigos, monografias, teses, dissertações, livros etc.

Atenciosamente,

\section{Responsável legal pela organização}

$\operatorname{Sr}(\mathrm{a})$

Cargo

Carimbo 


\title{
APÊNDICE C - TERMO DE ESCLARECIMENTO E CONSENTIMENTO
}

\author{
UNIVERSIDADE DE SÃO PAULO \\ FACULDADE DE ECONOMIA, ADMINISTRAÇÃO E CONTABILIDADE \\ PROGRAMA DE PÓS-GRADUAÇÃO EM ADMINISTRAÇÃO
}

\section{TERMO DE ESCLARECIMENTO E CONSENTIMENTO}

\begin{abstract}
A aluna Carolina Aparecida de Freitas Dias, do curso de Mestrado em Administração, do Programa de Pós-Graduação em Administração da Faculdade de Economia, Administração e Contabilidade da Universidade de São Paulo - FEA/USP, estará desenvolvendo a pesquisa “AVALIAÇÃO DE RESULTADOS EM EDUCAÇÃO CORPORATIVA”. O objetivo deste estudo é analisar como as organizações avaliam os resultados em educação corporativa.
\end{abstract}

Você está sendo convidado (a) a participar desta pesquisa que será desenvolvida no período de 23 de março de 2012 à 30 de junho de 2012. Embora não haja benefícios diretos para a sua participação nesta pesquisa, ela oferecerá a você a oportunidade de refletir sobre a forma como vem sendo realizada a avaliação de resultados em educação corporativa em sua organização. Dada a carência de estudo nesta área, a sua participação é fundamental para nos auxiliar a melhor compreender o processo de avaliação de resultados em educação corporativa realizado pelas organizações.

Sua participação nesta pesquisa consiste na concessão de entrevista à pesquisadora que terá duração de aproximadamente uma hora e será gravada com o seu consentimento. Esta entrevista poderá ocorrer em uma sala no seu local de trabalho ou outro lugar de sua escolha. Durante a entrevista lhe serão feitas perguntas relacionadas à organização, ao sistema de educação corporativa utilizado e às formas de avaliação em educação corporativa empregados.

A entrevista será anotada pela pesquisadora e o relatório de pesquisa será enviado posteriormente para validação dos dados. O resultado final desta pesquisa será disponibilizado a todos os participantes.

Todas as informações obtidas permanecerão confidenciais, sendo utilizado um nome código para manter o seu anonimato nas informações e no relatório da pesquisa e serão usadas somente para este estudo. Durante o estudo e após o seu término, todas as informações serão guardadas com a pesquisadora, com o acesso somente pela pesquisadora e seu orientador. Sua participação nesta pesquisa é completamente voluntária. Sua decisão de não participar ou se retirar em qualquer momento não terá qualquer implicação para você. Caso você tiver ainda alguma outra dúvida em relação à pesquisa poderá comunicar-se pelos telefones abaixo: 
Pesquisadora: CAROLINA APARECIDA DE FREITAS DIAS. Fone: (11) 82597005.

Orientador: Dr. LINDOLFO GALVÃO DE ALBUQUERQUE. Fone: (11) 30915834.

Assinatura:

$\mathrm{Eu}$, esclarecido(a) sobre a pesquisa: "AVALIAÇÃO DE RESULTADOS EM EDUCAÇÃO CORPORATIVA”, concordo em participar dela e autorizo que meus dados sejam utilizados em sua realização.

São Paulo, de de 2012.

Assinatura:

RG:

Nota: O presente Termo terá duas vias, uma ficará à guarda da pesquisadora e a outra via é da posse do(a) próprio(a) participante da pesquisa. 


\title{
APÊNDICE D - ROTEIRO DE ENTREVISTA COM GESTOR DA ÁREA GESTÃO DE PESSOAS
}

\author{
UNIVERSIDADE DE SÃO PAULO \\ FACULDADE DE ECONOMIA, ADMINISTRAÇÃO E CONTABILIDADE \\ PROGRAMA DE PÓS-GRADUAÇÃO EM ADMINISTRAÇÃO
}

ROTEIRO DE ENTREVISTA - GESTOR(A) DA ÁREA GESTÃO DE PESSOAS

Data:

Identificação do entrevistado:

Cargo:

LEMBRETE: Pedir as seguintes informações ao entrevistado: objetivos e missão (empresa.

GP e EC), estrutura organizacional (empresa e GP); número de funcionários (empresa e GP).

1. Conte um pouco da evolução da organização, destacando acontecimentos relevantes e seus impactos em GP e em EC.

2. Sobre a EC como ela surgiu na organização, como evoluiu e quais foram os fatos relevantes.

3. Como ocorre o alinhamento entre a EC e a GP na organização? É utilizada alguma ferramenta para apoiar esse processo?

4. Como ocorre o alinhamento entre as ações educacionais e os objetivos organizacionais?

5. Por que vocês realizam a avaliação de resultados em EC?

6. Como ocorre o processo de avaliação de resultados em EC?

7. Diante do exposto sobre a forma como vocês avaliam EC explique quais são as vantagens da avaliação de resultados em EC utilizada pela organização?

8. Quais são as dificuldades no processo de avaliação em EC? E quais são as limitações da metodologia de avaliação em EC empregada?

9. Em sua opinião quais são as tendências em avaliação de EC? (pedir ao entrevistado para pensar em termos gerais e não apenas na organização em que trabalha). 


\title{
APÊNDICE E - ROTEIRO DE ENTREVISTA COM GESTOR DA ÁREA EDUCAÇÃO CORPORATIVA
}

\author{
UNIVERSIDADE DE SÃO PAULO \\ FACULDADE DE ECONOMIA, ADMINISTRAÇÃO E CONTABILIDADE \\ PROGRAMA DE PÓS-GRADUAÇÃO EM ADMINISTRAÇÃO
}

ROTEIRO DE ENTREVISTA - GESTOR(A) DA ÁREA EDUCAÇÃO CORPORATIVA

Data:

Identificação do entrevistado:

Cargo:

LEMBRETE: Pedir as seguintes informações ao entrevistado: objetivos e missão (empresa) estrutura organizacional (empresa e EC); número de funcionários (empresa e EC).

1. Conte um pouco da evolução da organização, destacando acontecimentos relevantes e seus impactos em GP e em EC.

2. Sobre a EC como ela surgiu na organização, como evoluiu e quais foram os fatos relevantes?

3. Há diferença entre T\&DE, Educação Corporativa e Universidade Corporativa? Por quê?

4. Quais são os objetivos da EC e da organização?

5. De que forma está estruturado o sistema de EC de sua organização (organograma da área; parceria com fornecedores/consultorias externas; parcerias com insituições de ensino; utiliza-se currículos de aprendizagem; utiliza-se ferramentas tecnológicas)?

6. Quais são os macros processos do sistema de EC de sua organização? Descreva-os.

7. Como ocorre o alinhamento entre a EC e a GP na organização? É utilizada alguma ferramenta para apoiar esse processo?

8. Como ocorre o alinhamento entre as ações educacionais e os objetivos organizacionais?

9. Quais são os públicos atendidos pelos programas de EC?

10. Há uma cultura de aprendizagem contínua na organização? Quais são as práticas empregadas pela EC para a promoção dessa cultura?

11. Por que vocês realizam a avaliação de resultados em EC?

12. Quais são as limitações da metodologia de avaliação em EC empregada? O que é feito para superar essas limitações? 
13. Explique as vantagens da metodologia de avaliação em EC empregada em sua organização?

14. Em sua opinião quais são as tendências em avaliação de EC? (pedir ao entrevistado para pensar em termos gerais e não apenas na organização em que trabalha). 


\title{
APÊNDICE F - ROTEIRO DE ENTREVISTA COM GESTORES DE EDUCAÇÃO CORPORATIVA
}

\author{
UNIVERSIDADE DE SÃO PAULO \\ FACULDADE DE ECONOMIA, ADMINISTRAÇÃO E CONTABILIDADE \\ PROGRAMA DE PÓS-GRADUAÇÃO EM ADMINISTRAÇÃO \\ ROTEIRO DE ENTREVISTA - GESTOR(A) DE EDUCAÇÃO CORPORATIVA E \\ RESPONSÁVEL PELA AVALIAÇÃO EM EDUCAÇÃ̃O CORPORATIVA
}

Data:

Identificação do entrevistado:

Cargo:

1. Conte um pouco da evolução da organização, destacando acontecimentos relevantes e seus impactos em GP e em EC.

2. Sobre a EC como ela surgiu na organização, como evoluiu e quais foram os fatos relevantes?

3. Há diferença entre T\&DE, Educação Corporativa e Universidade Corporativa? Por quê?

4. Quais são os objetivos da EC e da organização?

5. De que forma está estruturado o sistema de EC de sua organização (organograma da área; parceria com fornecedores/consultorias externas; parcerias com insituições de ensino; utiliza-se currículos de aprendizagem; utiliza-se ferramentas tecnológicas)?

6. Quais são os macros processos do sistema de EC de sua organização? Descreva-os.

7. Como ocorre o alinhamento entre a EC e a GP na organização? É utilizada alguma ferramenta para apoiar esse processo?

8. Como ocorre o alinhamento entre as ações educacionais e os objetivos organizacionais?

9. Quais são os públicos atendidos pelos programas de EC?

10. Há uma cultura de aprendizagem contínua na organização? Quais são as práticas empregadas pela EC para a promoção dessa cultura?

11. Por que vocês realizam a avaliação de resultados em EC?

12. De que forma são avaliadas as reações dos participantes? Quais fatores são avaliados?

13. A aferição da aprendizagem é realizada de que forma?

14. Como é avaliado se os programas promoveram as mudança de comportamentos (atitudes e habilidades) a que se propuseram? 
15. Como é avaliado se o que foi aprendido no programa está sendo aplicado ao trabalho?

16. De que forma é avaliado se a mudança de comportamento no trabalho está provocando mudanças no funcionamento da empresa?

17. Como é avaliado se a EC está auxiliando a organização a atingir seus objetivos? Quais ferramentas ou sistemas são utilizados para isso?

18. Como ocorre a avaliação em GP em sua organização? De que forma a avaliação em GP e avaliação em educação corporativa se relacionam?

19. De que maneira é avaliado se a disseminação da cultura da organização está sendo promovida pela educação corporativa?

20. É realizado o controle dos custos envolvidos diretamente com os programas, tais como remuneração dos consultores, o aluguel de sala, os recursos, a alimentação, o transporte e a hospedagem? Como é realizado o controle?

21. É realizado controle dos custos indiretos relacionados aos programas, tais como salários e benefícios dos treinandos, salários e benefícios dos treinadores, custo fixo da área de treinamento? Como é realizado o controle?

22. Como é realizada a avaliação dos programas em relação ao uso eficiente do orçamento?

23. Como é avaliado se a estratégia instrucional adotada para os programas está auxiliando no ensino dos currículos?

24. Quais são as limitações da metodologia empregada? O que é feito para superar essas limitações?

25. Explique as vantagens da metodologia de avaliação em EC empregada em sua organização?

26. Em sua opinião quais são as tendências em avaliação de EC? (pedir ao entrevistado para pensar em termos gerais e não apenas na organização em que trabalha). 


\title{
APÊNDICE G - ROTEIRO DE ENTREVISTA COM GESTOR DO BALANCED SCORECARD
}

\author{
UNIVERSIDADE DE SÃO PAULO \\ FACULDADE DE ECONOMIA, ADMINISTRAÇÃO E CONTABILIDADE \\ PROGRAMA DE PÓS-GRADUAÇÃO EM ADMINISTRAÇÃO \\ ROTEIRO DE ENTREVISTA - GESTOR(A) DE BALANCED SCORECARD
}

Data:

Identificação do entrevistado:

Cargo:

1. Conte um pouco sobre sua área e seu papel no planejamento estratégico.

2. Como é realizado o planejamento estratégico na organização e como ele é traduzido no balanced scorecard - BSC?

3. O BSC é utilizado em quais níveis organizacionais?

4. O BSC da Área de Pessoas contempla quais áreas?

5. Quais são os objetivos da Educação Corporativa de sua organização?

6. Como é avaliado se a EC está auxiliando a organização a atingir seus objetivos? Quais ferramentas ou sistemas são utilizados para isso?

7. Como ocorre o alinhamento entre a EC e a GP na organização? É utilizada alguma ferramenta para apoiar esse processo?

8. Nas diferentes perspectivas do BSC há indicadores relativos à Educação Corporativa? Quais são?

9. Como ocorre o alinhamento entre as ações educacionais e os objetivos organizacionais?

10. Como se relacionam os indicadores do BSC da Área de Pessoas e a avaliação de resultados em educação corporativa?

11. Como ocorre a avaliação em GP em sua organização? De que forma a avaliação em GP e avaliação em educação corporativa se relacionam?

12. Explique as vantagens do sistema de planejamento estratégico empregada em sua organização?

13. Quais são as limitações do sistema de planejamento estratégico? O que é feito para superar essas limitações?

14. Em sua opinião quais são as tendências em sistema de planejamento estratégico? (pedir ao entrevistado para pensar em termos gerais e não apenas na organização em que trabalha). 


\section{APÊNDICE H - ROTEIRO DE ENTREVISTA COM GESTOR DO SISTEMA DE INFORMAÇÕES GERENCIAIS}

UNIVERSIDADE DE SÃO PAULO

FACULDADE DE ECONOMIA, ADMINISTRAÇÃO E CONTABILIDADE PROGRAMA DE PÓS-GRADUAÇÃO EM ADMINISTRAÇÃO

ROTEIRO DE ENTREVISTA - GESTOR(A) DE SISTEMAS DE INFORMAÇÕES GERENCIAIS

Data:

Identificação do entrevistado:

Cargo:

1. Quais informações que vocês monitoram/controlam?

2. Quais indicadores são monitorados pela escola?

3. Qual é o objetivo de monitorar essas informações e indicadores?

4. Quais informações são inseridas no Share Point e quais relatórios são criados?

5. Em conversa com a Superintendente do BSC da Área de Pessoas ela comentou que o banco tem a meta de atingir em 2013 o índice de eficiência de 41\% e que há indicadores monitorados na escola que estão diretamente ligados a essa estratégia. Quais são esses indicadores e como vocês monitoram?

6. Como é realizado o controle do orçamento? Quais indicadores vocês utilizam?

7. O que é o Projeto Fábrica de Gente? Quais indicadores são monitorados nesse projeto?

8. O que é o Projeto de Liderança? Quais indicadores são monitorados nesse projeto?

9. Há algum outro indicador que vocês monitoram e que esteja ligado à estratégia da Área de Pessoas? 
256

ANEXOS

ANEXO 1 - RELAÇÃO DAS 150 MELHORES EMPRESAS PARA VOCÊ TRABALHAR, EDIÇÃO 2011. 


\section{ANEXO 1 - RELAÇÃO DAS 150 MELHORES EMPRESAS PARA VOCÊ TRABALHAR, EDIÇÃO 2011}

\begin{tabular}{|c|c|c|c|c|c|}
\hline Nome Fantasia & Nota Desenv. & IQGP - Total & Nome Fantasia & Nota Desenv. & IQGP - Total \\
\hline Coelce & 95,63 & 90,47 & Aon & 80,84 & 80,35 \\
\hline Volvo do Brasil & 93,75 & 90,69 & COPACOL & 80,67 & 70,05 \\
\hline EUROFARMA & 91,67 & 89,64 & Gerdau & 80,63 & 75,15 \\
\hline SAMA & 91,25 & 84,16 & São Marco & 80,34 & 64,02 \\
\hline Banco Bradesco & 91,25 & 82,32 & Magazine Luiza & 80,25 & 77,50 \\
\hline Tenaris Confab & 91,25 & 78,05 & PERKINS MOTORES & 80,21 & 68,94 \\
\hline Vivo Participações S/A & 89,67 & 89,58 & Central Nacional Unimed & 80,17 & 78,40 \\
\hline Randon & 89,17 & 89,13 & Colgate-Palmolive & 79,59 & 81,91 \\
\hline Hospital Unimed & 88,38 & 79,62 & Cultura Inglesa & 79,59 & 61,08 \\
\hline Universidade Católica de Brasília & 86,88 & 76,19 & Cielo & 79,50 & 77,39 \\
\hline BV Financeira & 86,79 & 88,85 & Grupo Boticário & 79,00 & 79,40 \\
\hline Fras-le & 86,50 & 86,20 & ALBRAS-Alumínio Brasileiro S/A & 78,75 & 80,78 \\
\hline Promon & 86,46 & 83,93 & TORTUGA CIA. ZOOTENICA AGRARI & 78,67 & 69,62 \\
\hline YAZAKI & 86,46 & 68,27 & LOSANGO & 78,13 & 75,35 \\
\hline SUPERINTENDÊNCIA DE PRODUÇÃO HIDRÁC & 86,25 & 80,65 & ITAÚ UNIBANCO & 77,92 & 83,55 \\
\hline BASF & 86,04 & 82,30 & Weber Saint-Gobain & 77,50 & 75,27 \\
\hline Whirlpool Latin America & 85,84 & 82,00 & AMIB & 77,29 & 73,75 \\
\hline HOSPITAL ALBERT EINSTEIN & 85,84 & 74,91 & Filtros Tecfil & 77,09 & 73,54 \\
\hline TECHINT & 85,63 & 74,07 & SAS Institute Brasil & 77,09 & 60,87 \\
\hline Votorantim Cimentos & 85,42 & 82,94 & NIVEA & 77,09 & 67,54 \\
\hline Ambev & 85,21 & 66,73 & Electrolux & 77,09 & 73,76 \\
\hline CATERPILLAR & 85,17 & 84,83 & International Paper & 76,88 & 76,96 \\
\hline DuPont & 85,04 & 81,46 & PELLEGRINO & 76,67 & 55,41 \\
\hline UNISC & 85,04 & 74,39 & P\&G & 76,46 & 79,12 \\
\hline $3 \mathrm{M}$ & 84,79 & 79,87 & ThyssenKrupp Bilstein Brasil & 76,46 & 74,07 \\
\hline HSBC Seguros & 84,38 & 78,44 & AMANCO & 76,46 & 66,99 \\
\hline Prudential do Brasil & 84,38 & 78,73 & U\&M Mineração e Construção S/A & 76,38 & 68,07 \\
\hline Zambon & 83,96 & 68,07 & MTP & 76,04 & 64,34 \\
\hline Marelli Ambientes Racionais & 83,96 & 71,42 & LOJAS RENNER & 75,63 & 73,26 \\
\hline Laboratório Sabin de Análises Clínicas Ltda. & 83,82 & 81,36 & Sorocaba Refrescos & 75,50 & 63,28 \\
\hline Elektro & 83,34 & 73,81 & Fundação Pró-Rim & 75,42 & 71,54 \\
\hline CPFL ENERGIA S.A. & 83,34 & 82,19 & Endesa Geração & 75,42 & 73,28 \\
\hline CBSS - Administradora dos Cartões Visa Vale & 82,92 & 76,58 & redecard & 75,25 & 67,24 \\
\hline GVT & 82,71 & 76,41 & SAP Brasil & 75,21 & 75,78 \\
\hline Affinia & 82,71 & 72,63 & PepsiCo do Brasil Ltda & 75,21 & 74,05 \\
\hline TIGRE SA & 82,29 & 77,18 & Zen & 75,00 & 65,35 \\
\hline Cisco & 81,88 & 80,06 & TRANSOCEAN & 74,79 & 74,27 \\
\hline PAINCO S/A & 81,75 & 78,46 & IESA ÓLEO \& \& GÁS & 74,63 & 60,66 \\
\hline MAN Latin America & 81,46 & 74,91 & UNIMED-RIO & 74,59 & 64,90 \\
\hline Ecorodovias & 81,46 & 73,82 & Ci\&T & 74,38 & 70,28 \\
\hline Unimed Sul Capixaba & 81,25 & 79,24 & MONSANTO DO BRASIL & 74,17 & 74,51 \\
\hline amil resgate saude & 81,04 & 58,20 & ATA INDÚSTRIA MECÂNICA & 74,00 & 55,57 \\
\hline Case New Holland & 80,84 & 75,38 & Brasilata & 73,96 & 76,39 \\
\hline Masisa & 73,96 & 76,45 & BICBANCO & 68,54 & 61,57 \\
\hline Certel & 73,71 & 64,53 & REDE AMIGÃO SARAIVA & 68,44 & 72,00 \\
\hline Rhede Reciclar & 73,13 & 66,50 & EMBALAGENS JAGUARE & 67,54 & 56,21 \\
\hline Unimed Vales do Taquari e Rio Pardo & 72,92 & 70,33 & Embraer & 67,50 & 80,58 \\
\hline GlaxoSmithKline & 72,92 & 72,87 & MRS LOGÍSTICA & 67,21 & 61,57 \\
\hline TRACTEBEL ENERGIA & 72,50 & 80,54 & Apart Hospital & 67,09 & 70,73 \\
\hline Intelbras S/A & 72,50 & 75,05 & CACIQUE PNEUS & 66,46 & 62,96 \\
\hline MATERA Systems & 72,44 & 59,37 & Atlas Schindler & 66,25 & 73,96 \\
\hline Moinho Globo Alimentos S.A. & 72,29 & 61,87 & PORMADE PORTAS & 66,21 & 57,92 \\
\hline SANOFI-A VENTIS & 72,21 & 69,57 & Algar & 66,04 & 63,68 \\
\hline TICKET & 72,09 & 68,90 & Schneider Electric Brasil & 65,82 & 57,68 \\
\hline Metal Ar Engenharia Ltda & 72,09 & 59,00 & Sicredi & 65,63 & 52,78 \\
\hline
\end{tabular}




\section{Continuação Anexo 1}

\begin{tabular}{|c|c|c|c|c|c|}
\hline Nome Fantasia & Nota Desenv. & IQGP - Total & Nome Fantasia & Nota Desenv. & IQGP - Total \\
\hline Kraft & 72,04 & 70,57 & Agro Amazônia & 65,54 & 48,02 \\
\hline Google Brasil & 71,67 & 69,70 & Latapack-Ball & 65,54 & 63,06 \\
\hline TETRA PAK & 71,25 & 72,02 & Phito Fórmulas Farmacias de Manip. & 65,34 & 59,71 \\
\hline Netsolutions & 71,04 & 72,23 & Instituto Nordeste Cidadania & 65,21 & 56,51 \\
\hline SKF & 70,84 & 61,08 & Kinross Brasil & 65,00 & 57,38 \\
\hline Unimed de Volta Redonda & 70,84 & 63,54 & Unimed Circuito das Águas & 64,88 & 61,18 \\
\hline Rio Quente Resorts & 70,84 & 72,47 & Unimed São José do Rio Preto & 64,88 & 56,91 \\
\hline SOL INFORMÁTICA & 70,63 & 57,80 & Meritor & 64,67 & 60,78 \\
\hline Dow Brasil S.A. & 70,42 & 83,42 & FACULDADE DO VALE DO IPOJUCA & 64,59 & 53,20 \\
\hline T.W. ESPUMAS & 70,42 & 63,40 & BANCO MERCANTIL DO BRASIL S.A. & 64,46 & 52,52 \\
\hline Fundação Antonio Prudente & 70,38 & 69,97 & LOJAS MM & 64,42 & 62,67 \\
\hline Ourofino Agronegócio & 70,34 & 62,95 & ARROZ PRATO FINO & 64,25 & 59,37 \\
\hline Nextel & 70,13 & 69,15 & SAP Labs Latin America & 64,17 & 62,64 \\
\hline Hospital Santa Paula & 69,59 & 56,95 & CP Promotora & 64,09 & 67,37 \\
\hline DIGISYSTEM & 69,38 & 65,52 & GAZIN & 64,00 & 65,83 \\
\hline Instituto de Pesquisas Eldorado & 69,17 & 64,94 & São Bernardo Saude & 63,67 & 63,71 \\
\hline SICOOB CREDICITRUS & 69,17 & 56,44 & Irizar Brasil & 63,63 & 55,51 \\
\hline Lojas Colombo & 69,00 & 63,13 & Nycomed Pharma Ltda & 63,17 & 63,97 \\
\hline SAGA & 68,92 & 64,64 & Teleperformance & 62,92 & 54,46 \\
\hline KSPG & 68,71 & 64,08 & Prezunic Supermercados & 62,71 & 43,79 \\
\hline
\end{tabular}

